\title{
The Synthesis of Modified Trehalose Glycolipids: Towards Understanding Mincle and MCL Binding
}

\author{
By
}

Jessica Helen Bird

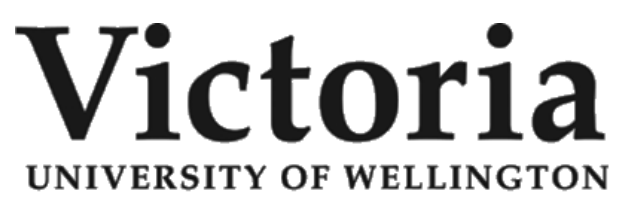

Te Whare Wānanga

o te Ūpoko o te Ika a Māui

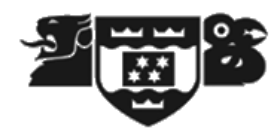

\begin{abstract}
A thesis
Submitted to the Victoria University of Wellington in fulfilment of the requirements for the degree of Master of Biomedical Science
\end{abstract}





\begin{abstract}
Trehalose glycolipids are a diverse family of long-chain fatty acid diesters isolated from the cell walls of bacteria, in particular Mycobacterium species including M. tuberculosis. These molecules possess an array of biological activities which contribute to the survival and virulence of the organism, however, it is their activity as potent stimulators of innate and early adaptive immunity for which they are of interest. In particular, trehalose glycolipids have an application as adjuvants in vaccines and immunotherapies, for diseases such as tuberculosis (TB) and cancer. Recently, the macrophage-inducible Ctype lectin, Mincle, and the macrophage C-type lectin, MCL, were identified as receptors for trehalose glycolipids, however, the exact mechanisms by which these receptors recognise and bind glycolipids is, as yet, unknown.
\end{abstract}

This thesis presents the synthesis of a variety of structurally diverse trehalose glycolipid analogues. As such, three mycolic acids bearing a C22 $\alpha$-chain and diversified meromycolate branches were prepared from an epoxide intermediate, itself prepared in eight steps from commercially available starting materials. The mycolic acids were then coupled to TMS-trehalose and subsequently deprotected to give the mono- and diester derivatives, 1a-c and 2c, which will be assessed for their immunostimulatory activity through the activation of wild type and Mincle $^{-/}$murine macrophages. This work provides a first step towards determining how the structures of trehalose glycolipids influence Mincle and MCL binding and activity, and allow for the development of improved trehalose glycolipids for use in adjuvant therapies.

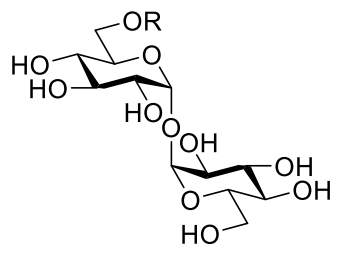

1

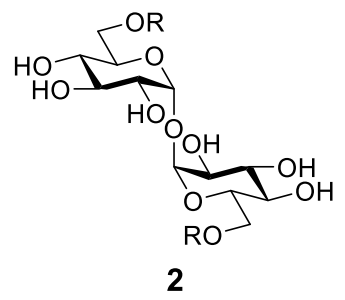

2
$\mathbf{R}=$

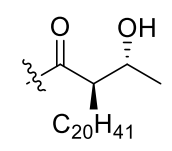

a

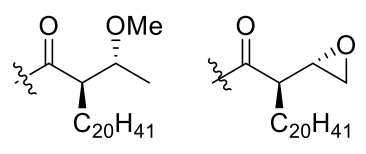

b c 


\section{Acknowledgements}

Though I started Masters two and a half years ago, my experience really began when I was recruited into the Immunoglycomics lab as an undergrad student, and without the unfailing support, guidance, and encouragement of my supervisors, Dr Bridget Stocker and Dr Mattie Timmer, I wouldn't be where I am today. Throughout all the elations and frustrations you have believed in me and my ability as a chemist; thank you.

I would like to thank Emma and Janice who took me under their wings and taught me, and later Ashna, whose work provided the basis of this research. To Amy - my friend and lab buddy throughout our Masters. Your friendship and support, the jokes and silly antics, late night music, junk food runs... what can I say? You have helped to make the last three years a fun and fulfilling experience. Thank you to Hilary, Cij, Rhia, your friendship and support I will value long after we part chemistry ways; and to Stefan, Kris, Jaimé, Kristel, Steph, Janelle, Julien, Selma and other past and present members of the Immunoglycomics group who have helped make the lab a great place to be.

I would like to thank VUW, Curtis-Gordon Research Scholarship, Kathleen Stewart Postgraduate Scholarship, and the NZ Federation of Graduate Woman Masters Scholarship for Funding throughout my Masters. Thank you to the SCPS staff, in particular Ian, for all your assistance.

Finally, I want to thank my family - Mum, Dad, Sarah, Rowan, Rosie - I'm not sure you fully understand what we chemists get up to all day in the lab, but you have been there for me throughout it all. Rosie - your support has been incredible, especially during the final few months - I am truly indebted to you! And Kieran, over the last six months you have provided support, encouragement, and wisdom to keep me focused on what's most important, thank you. 


\section{Contents}

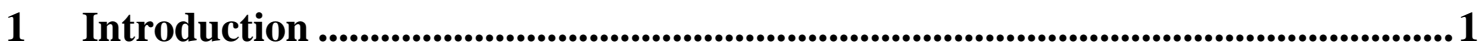

1.1 Trehalose glycolipids: A diverse family of bioactive molecules ...................... 1

1.2 Trehalose Glycolipids are Integral Components of the Mycobacterium Cell

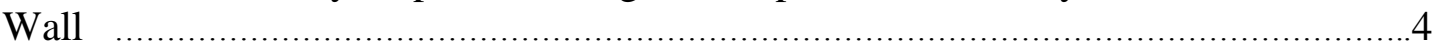

1.3 The Role of TDMs in Tuberculosis …........................................................

1.4 The Use of Bacteria in Cancer Immunotherapy ...........................................

1.5 Bacterial Cell wall Components as Vaccine Adjuvants.....................................

1.6 Immunomodulatory Properties of Trehalose Glycolipids ................................

1.7 The TDM Receptors - Macrophage Inducible C-type Lectin (Mincle) \& Macrophage C-type Lectin (MCL) ….................................................................. 9

1.7.1 Macrophage Inducible C-type Lectin Mincle ......................................... 9

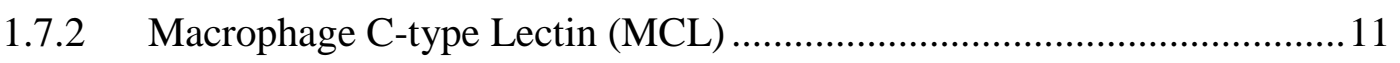

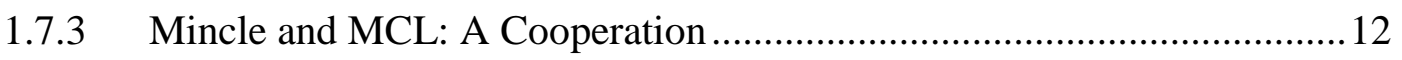

1.7.4 Receptor - Ligand Binding Interactions.............................................. 13

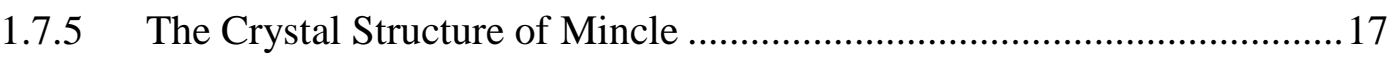

1.7.6 The Crystal Structure of MCL: A Comparison to Mincle ........................2 21

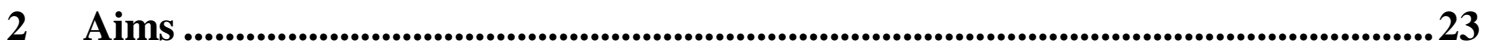

2.1 Understanding Mincle \& MCL: Modified Trehalose Glycolipids...................23

2.2 Biological Evaluation of Trehalose Glycolipids ............................................25

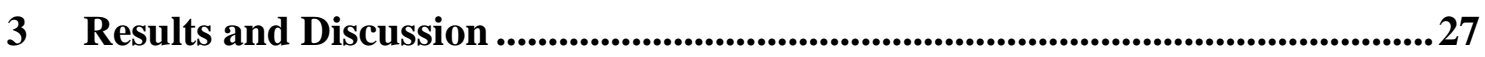

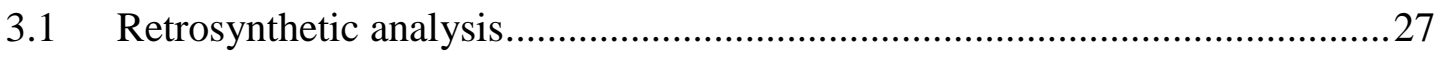

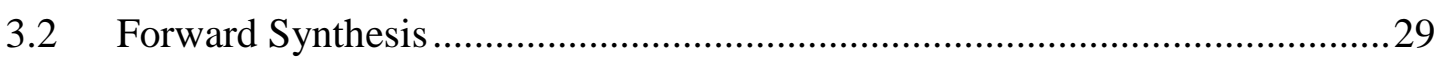

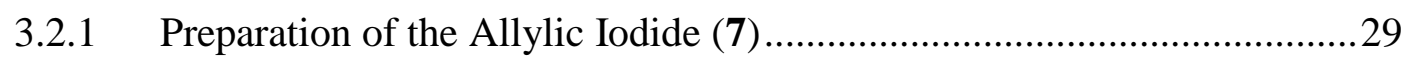

3.2.2 Preparation of the Intermediate Epoxide (5).......................................... 30

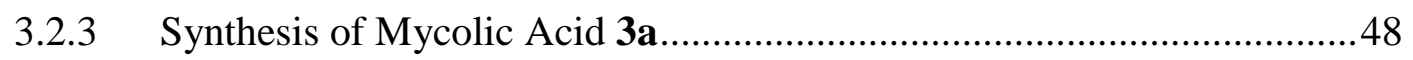

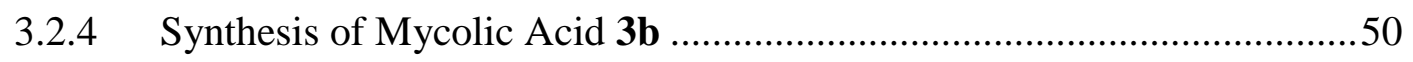

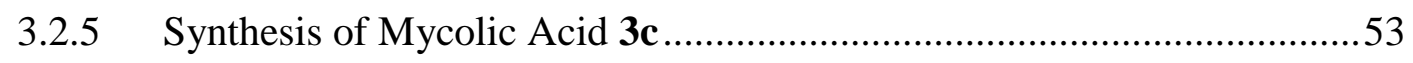

3.2.6 Synthesis of Target TMEs 1a-c and TDEs 2a-c...................................5

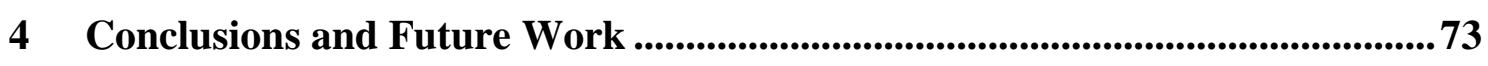

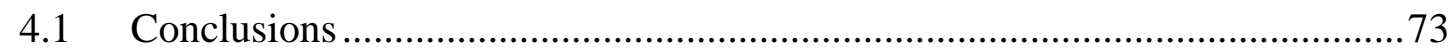

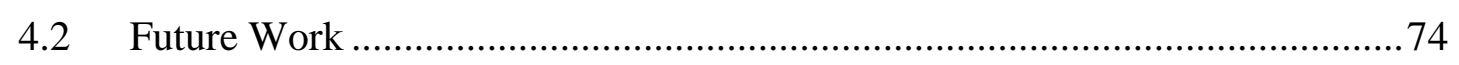

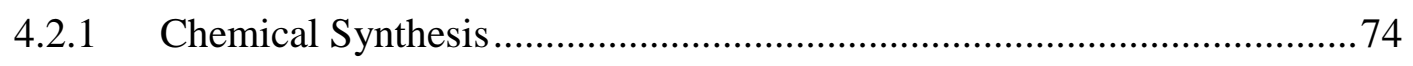

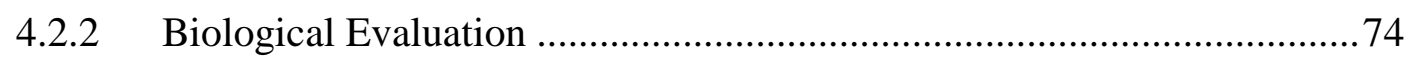

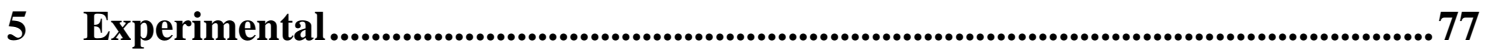

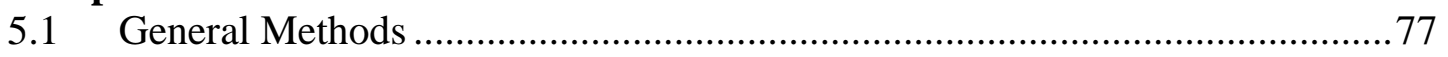

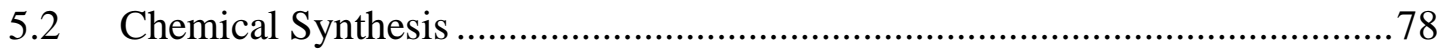

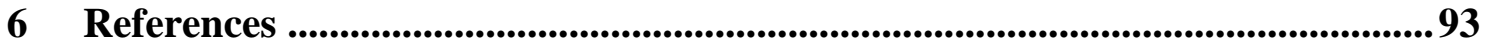

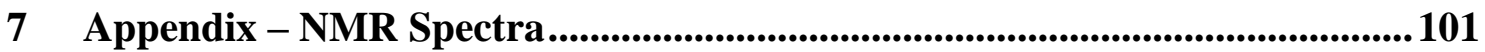




\section{List of Abbreviations}

\begin{tabular}{|c|c|}
\hline $\mathrm{AcOH}$ & Acetic acid \\
\hline aq. & Aqueous \\
\hline BCG & Bacillus Calmette-Guerin \\
\hline BMS & Borane dimethyl sulfide \\
\hline BSA & $\mathrm{N}, \mathrm{O}$-bis-trimethylsilylacetamide \\
\hline calcd. & Calculated \\
\hline CFA & Complete Freund's adjuvant \\
\hline COSY & Correlation spectroscopy \\
\hline d & Doublet \\
\hline $\mathrm{DC}$ & Dendritic cell \\
\hline DCC & $N, N^{\prime}$-dicyclohexylcarbodiimide \\
\hline DCM & Dichloromethane \\
\hline dd & Doublet of doublets \\
\hline DDA & Dioctadecylammonium bromide \\
\hline DMAP & 4-(Dimethyl)-aminopyridine \\
\hline $\mathrm{DMF}$ & Dimethylformamide \\
\hline EA & Ethyl acetate \\
\hline EAE & Experimental autoimmune encephalomyelitis \\
\hline EDCI & 1-ethyl-3-(3-dimethylaminopropyl)carbodiimide \\
\hline ELISA & Enzyme-linked immunosorbent assay \\
\hline EPD & Glutamic acid-proline-aspartic acid \\
\hline EPN & Glutamic acid-proline-asparagine \\
\hline equiv. & Equivalents \\
\hline ESI & Electro spray ionisation \\
\hline $\mathrm{Et}$ & Ethyl \\
\hline GFP & Green fluorescent protein \\
\hline HMBC & Heteronuclear multiple bond correlation \\
\hline HRMS & high resolution mass spectrometry \\
\hline HSQC & Heteronuclear single quantum correlation \\
\hline IFN & Interferon \\
\hline $\mathrm{IL}$ & Interleukin \\
\hline IR & Infrared \\
\hline$J$ & Coupling constant \\
\hline LAM & Lipoarabinomannan \\
\hline LDA & Lithium diisopropylamide \\
\hline LPS & Lipopolysaccharide \\
\hline $\mathrm{m}$ & Multiplet \\
\hline M & Molar \\
\hline MCL & Macrophage C-type lectin \\
\hline $\mathrm{Me}$ & Methyl \\
\hline
\end{tabular}




\begin{tabular}{ll} 
MHz & Megahertz \\
Mincle & Macrophage inducible C-type lectin \\
MMG & Monomycoloyl glycerol \\
mRNA & messenger Ribonucleic acid \\
BuLi & Butyllithium \\
NK & Natural killer \\
NMR & Nuclear magnetic resonance \\
OAc & Acetate \\
obsd. & Observed \\
PAMP & Pathogen associated molecular patterns \\
PCC & Pyridinium chlorochromate \\
PE & Petroleum ether \\
Ph & Phenyl \\
PRR & Pattern recognition receptor \\
q & Quartet \\
quin. & Quintet \\
r.t. & Room temperature \\
$R_{\mathrm{f}}$ & Retention factor \\
TB & Tuberculosis \\
TBAF & tetra-Butylammonium fluoride \\
TBS & tert-Butyldimethylsilyl \\
TBSOTf & tert-Butyldimethylsilyl trifluromethanesulfonate \\
TDB & Trehalose dibehenate \\
TDCM & Trehalose dicorynomycolate \\
TDE & Trehalose diester \\
TDM & Trehalose dimycolate \\
THF & Tetrahydrofuran \\
TLC & Thin layer chromatography \\
TLR & Toll-like receptor \\
TMCM & Trehalose monocorynomycolate \\
TME & Trehalose monoester \\
TMS & Trimethylsilyl \\
TNF & Tumour necrosis factor \\
Ts & Tosyl \\
\hline
\end{tabular}




\section{Introduction}

\subsection{Trehalose glycolipids: A diverse family of bioactive molecules}

Trehalose glycolipids are a diverse family of long-chain fatty acid esters of trehalose, a symmetrical 1,1'- $\alpha$-linked glucose disaccharide, isolated from bacterial species Mycobacteria, Corynebacteria, and from the dauer larvae Caenorhabditis elegans. ${ }^{1-4}$ These glycolipids can be classified into two main categories: the 6,6'-trehalose diesters, and the 2,3-trehalose diesters (Figure 1). ${ }^{5}$ The 6,6'-diesters include the branched trehalose dimycolates (TDM, 1), trehalose dicorynomycolates (TDCM, 2), and the linear chain trehalose diesters (TDE, 3). The 2,3-diesters include diacyl trehalose sulfates (4) and sulfolipid-1 (SL-1, 5). 


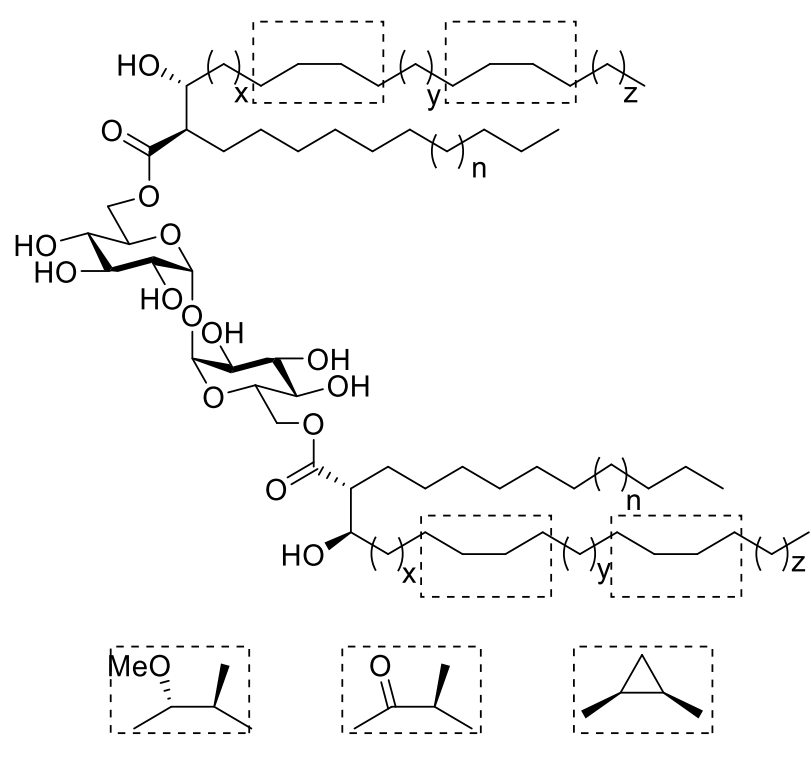

TDM (1) e.g. $n=13, x=16, y=12, z=17$

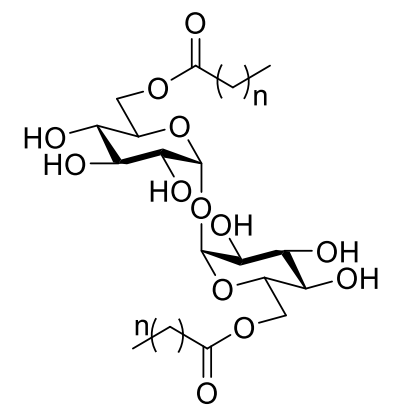

TDE (3) e.g. $n=20$

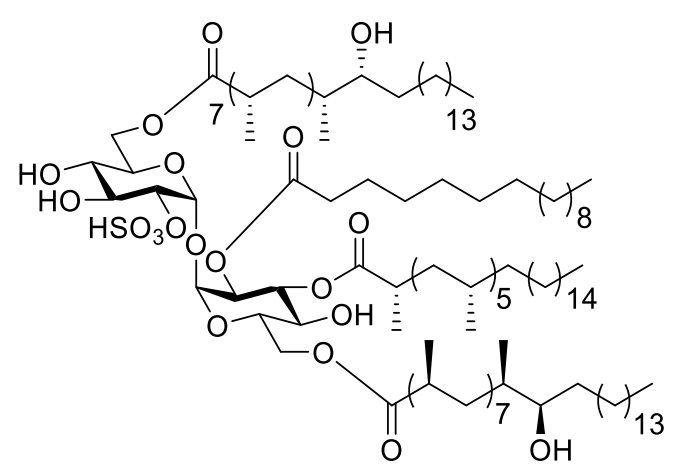

SL-1 (5)

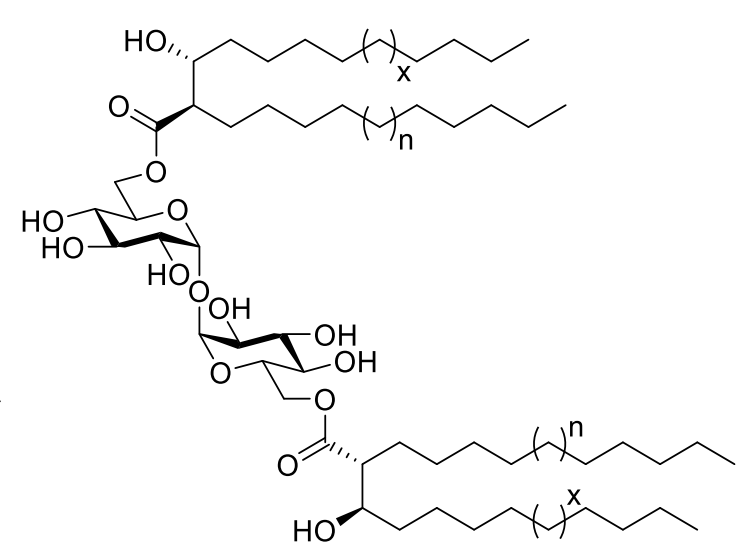

$\operatorname{TDCM}(2)$ e.g. $n=7, x=7$

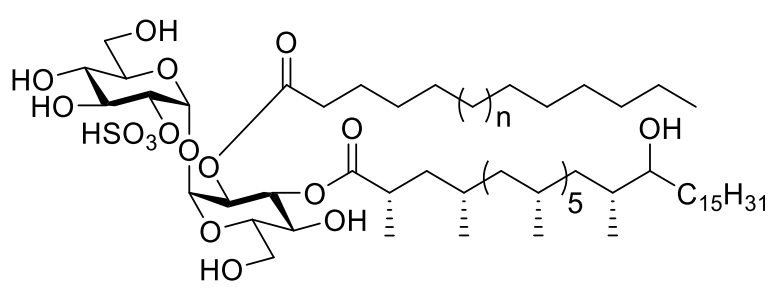

Diacyl trehalose sulfate (4) $n=5,7$

Figure 1: Trehalose glycolipids 
The mycobacterial fatty acid (mycolic acid) esters of TDMs are composed of a functionalised meromycolate branch (ca. C60) with a linear side chain at the alpha position (C20-C25) ${ }^{6}$ (Figure 2) giving a total chain length varying between C60-C90. 5, 7 There are three main classes of these molecules; the $\alpha$-mycolic acids containing two cis cyclopropanes are the most common, ${ }^{8}$ while the oxygenated mycolates include the methoxy- and keto-mycolic acids, as well as the less prevalent epoxy- and unsaturated derivatives (Figure 1). ${ }^{5,11}$ Conversely, the TDCMs isolated from Corynebacteria lack the complex functionalities of the TDMs and vary only in lipid length (total C22-C36), with C32 being the most abundant. ${ }^{5,11-13}$ The sulfolipids differ in both the acyl chain length, functionality, and position on the trehalose headgroup. ${ }^{14}$
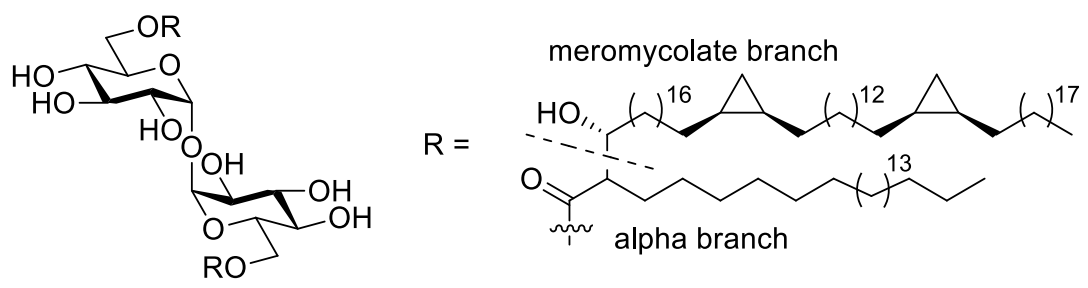

Figure 2: TDM meromycolate and alpha branches

Trehalose glycolipids are of interest because of their diverse biological properties. Even the most simple trehalose glycolipids, the TDEs, have shown promising immunological properties. ${ }^{15}$ In particular, the C22 TDE analogue, trehalose dibehenate (TDB), has been shown to activate macrophages in a manner similar to its more complex counterpart, TDM. ${ }^{16}$ This gives TDEs and TDMs a range of important immunostimulatory qualities including potential use as adjuvants for tuberculosis (TB) and cancer vaccines. ${ }^{2,17-21}$ Of particular note is the use of CAF01, a cationic liposome formulation of TDB in combination with dioctadecylammonium bromide (DDA), which is an effective vaccine adjuvant currently in phase I clinical trials as part of a new TB vaccine. ${ }^{18,20,22}$ TDCMs from Corynebacterium cell wall extracts also exhibit macrophage activation properties and have been shown to be as effective as TDM at providing host resistance to various bacterial and viral infections in murine models. ${ }^{23-24}$ These cell wall extracts are also effective in experimental vaccines for $\mathrm{TB}^{25}$ and Leishmania ${ }^{3}$ as part of the Ribi Adjuvant system. 


\subsection{Trehalose Glycolipids are Integral Components of the Mycobacterium Cell Wall}

Mycobacteria have lipid rich cell walls incorporating both membrane-bound and sugarlinked mycolic acids, which are critical for the survival of the organism within a host immune cell (e.g. macrophage), and in the environment. TDMs are the most abundant of all the surface glycolipids isolated from the cell wall of Mycobacteria ${ }^{26}$ and are known to confer resistance to environmental pressures such as desiccation, freezing, and bactericidal drugs. ${ }^{6,}$ 27-28 In addition, TDMs impart protection against enzymatic and chemical stresses encountered within the phagosomes of macrophages, including hydrolase and reactive oxygen species. ${ }^{29,30}$ Similarly, TDCMs and trehalose monocorynomycolates (TMCMs) are the most abundant cell wall lipids isolated from the closely related Corynebacterium species such as $C$. diphtheria, the causative agent of diphtheria. $^{12,31}$

Although the cell wall architecture of Corynebacteria has not been studied as extensively as that of Mycobacteria, their overall composition is similar. ${ }^{24}$ Both Corynebacteria and Mycobacteria cell walls consist of a layer of peptidoglycan adjacent to the cell membrane, then a layer of arabinogalactan interspersed with lipoarabinomannan (LAM) (Figure 3). ${ }^{6,24,31}$ Covalently linked to the arabinogalactan are the mycolic acids, which together with esterified trehalose glycolipids (e.g. TDMs and TDCMs), form a thick outer coating. The interaction of the short and long mycolate lipid tails of the TDMs allows the glycolipids to interlock, forming a virtually impenetrable barrier, ${ }^{32}$ and the hydrophilic trehalose head group is, in turn, positioned to prevent exposure of the hydrophobic lipids to the aqueous surroundings. ${ }^{17}$ This construction of the cell wall gives mycobacteria a unique advantage over other bacterial species as it enables them to avoid immune recognition and survival within the host as a latent infection for many decades before causing disease. ${ }^{26}$ The waxy glycolipid coating also hinders the access of small polar molecules into the mycobacterium, thus contributing to the resistance of $M$. tuberculosis to many common antibiotics. ${ }^{28,6}$ 

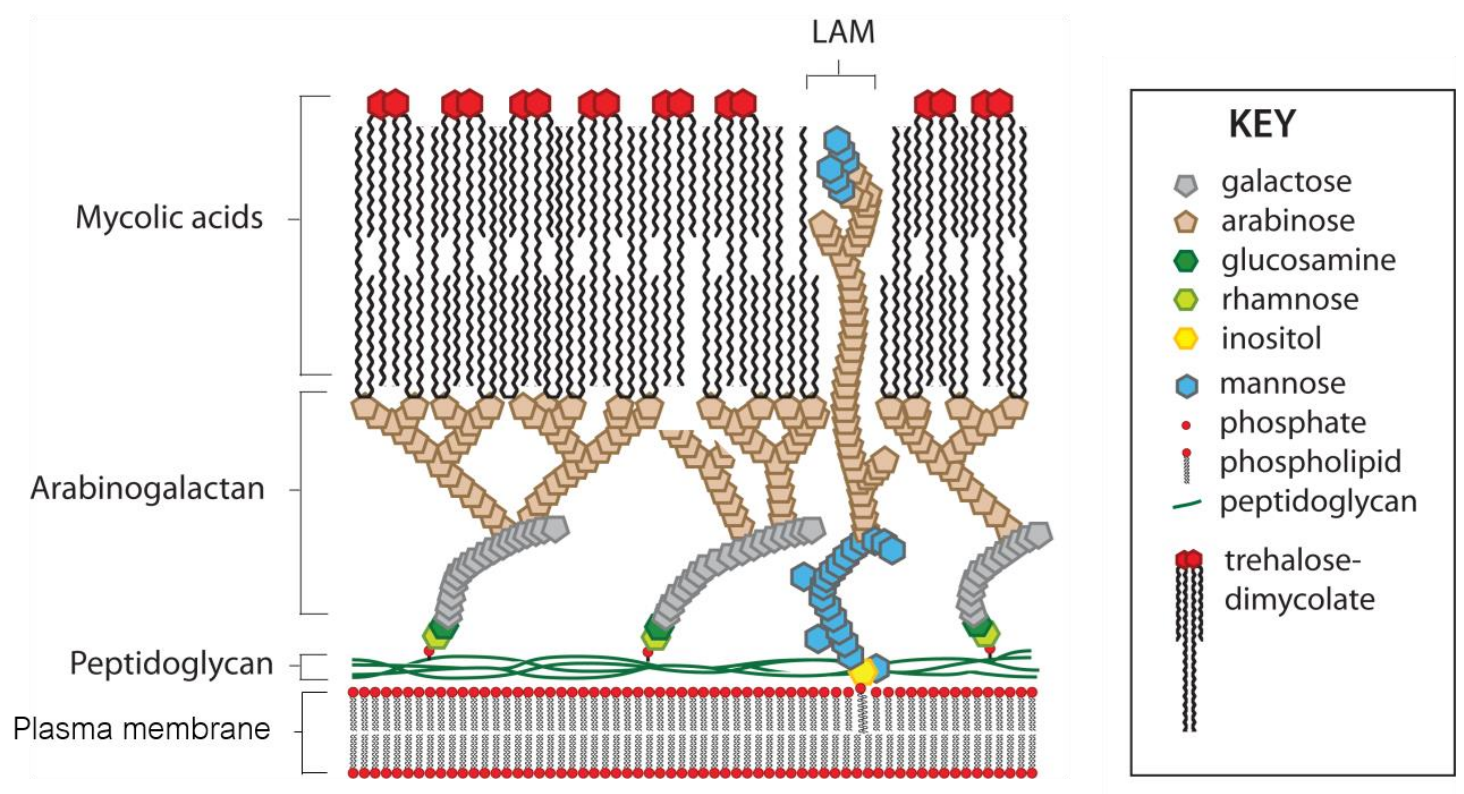

Figure 3: Cartoon of the mycobacterial cell wall

\subsection{The Role of TDMs in Tuberculosis}

Of all bacterial diseases, tuberculosis has the greatest global infection rate and highest mortality, with over a third of the world's population infected to date. ${ }^{33}$ Unusually, $M$. tuberculosis rarely causes disease immediately on infection, but remains dormant within the host cells for many years before the onset of secondary tuberculosis, which is accountable for $80 \%$ of disease and almost all infection. ${ }^{26,34}$ While the immunological processes involved in the pathogenesis of the disease are relatively unknown, it is thought that $M$. tuberculosis is able to survive within host macrophages by preventing phagosome-lysosome fusion. ${ }^{7,}{ }^{35}$ After a pathogen is engulfed by a phagocytic cell such as a macrophage, the resultant phagosome normally undergoes maturation through fusion with lysosomes containing oxidative, acidifying and hydrolytic enzymes, resulting in pathogen death and degradation. ${ }^{30,36}$ Fundamental studies by Spargo et al. ${ }^{35}$ demonstrate that TDM is able to inhibit $\mathrm{Ca}^{2+}$ induced fusion of phospholipid vesicles in vitro. Moreover, experimentation by Indrigo et al. (2002) established the importance of TDMs for the survival of mycobacteria in vivo, ${ }^{37}$ with removal of TDMs from M. tuberculosis cell surfaces preventing the survival of mycobacteria within host macrophages, while restoration of purified TDM reinstated survival ability. ${ }^{38}$ These results suggest that TDM is the main component responsible for preventing phagosome-lysosome fusion and promoting survival of the mycobacteria within host cells. 
The ability of $M$. tuberculosis to cause a sudden change in the host immune response resulting in the characteristic caseating granulomas associated with secondary tuberculosis is poorly understood. Studies by Hunter et al. (2006), however, determined that the type of immune response elicited by TDM is very different depending on the physical medium in which it exists. ${ }^{26}$ Within the cell membrane of M. tuberculosis, or in a micelle structure, TDM has no toxicity whatsoever, but rather acts to prevent host immune recognition. ${ }^{34}$ However, as a component of a monolayer or when injected as an oil emulsion, TDM becomes highly toxic and immunostimulatory. Hunter et al. also found that secondary tuberculosis begins as lipid pneumonia, ${ }^{39}$ a form of lung inflammation caused by the presence of lipids in bronchiolar tissue ${ }^{40}$ and it is the buildup of lipid which allows the transformation of TDM to its 'toxic state'. This is an abrupt change that causes sudden necrosis of pneumatic tissue, forming cavities in which the mycobacteria are able to multiply and finally escape to infect new hosts. ${ }^{26}$ In particular, the main stimulatory agent responsible for the formation of these lung granulomas in secondary $\mathrm{TB}$ is $\mathrm{TDM}^{17}$ and TDM alone has been shown to induce typical granuloma morphology. ${ }^{26}$

\subsection{The Use of Bacteria in Cancer Immunotherapy}

Trehalose glycolipids possess a range of immunomodulatory activities in addition to their virulence factors involved in disease processes. ${ }^{26,33}$ As such, there is increasing interest for their use in immunotherapy, that is, the use of immunostimulatory compounds (adjuvants) to induce the appropriate immune response required to cure a given disease. In particular, there is much interest in the use of adjuvants for the treatment of cancer and the development of more effective vaccines, and bacteria provide a valuable source of these molecules.

The first experiments on the use of immunostimulatory agents to treat cancer were performed by William Coley in the early 1890's, when he successfully treated a number of patients with advanced sarcoma by infecting them with Streptococcus bacterial species. ${ }^{41-42}$ Although this caused an infectious skin disease, remission of the cancer was observed. Later, Coley used preparations of bacterial toxins with comparable effects, however the exact bacterial components responsible for these phenomena were unknown. 
Although a considerable number of cases in which cancers were successfully treated with Coley's toxins were reported early on, the use of this therapy did not become widespread as his experiments were often irreproducible, due, in part, to variations in the administration technique and potency of the toxin preparations. ${ }^{42}$

While the use of Coley's toxins is not mainstream, the use of other bacterial agents in the treatment of cancer has been explored, with the most significant development being the use of the Mycobacterium bovis Bacillus Calmette-Guerin (BCG) vaccine to prevent the progression and recurrence of non-muscular invasive bladder cancer. ${ }^{43-44}$ Clinical trials in the late 1970's were so successful that this is now a standard treatment wherein the BCG vaccine is injected into the bladder inducing a vigorous local immune response which results in tumour regression. ${ }^{45}$ These examples are indicative of the increasing importance of bacterial components as a source of vaccine adjuvants.

\subsection{Bacterial Cell wall Components as Vaccine Adjuvants}

An effective vaccine must contain both antigens specific for a given disease, and an adjuvant which activates and directs the acquired immune response towards these antigens. This antigen/adjuvant combination results in long term protection against infection (prophylactic vaccine), or activation of an immune response towards cancerous tissue (therapeutic vaccine). Vaccines composed of whole killed bacteria or viruses, or attenuated live pathogens, are usually able to induce a strong immune response without including additional adjuvants, however peptide subunit vaccines are not sufficiently immunogenic on their own. ${ }^{46}$ Many bacterial cell wall components such as phospholipids, glycolipids and lipoproteins have shown promise as adjuvants. For example, monophosphoryl lipid A (MPL), a non-toxic derivative of the lipopolysaccharide (LPS) from Salmonella minnesota, is used in current vaccines for human papilloma virus and Hepatitis B, and has been used in clinical trials as part of vaccine formulations for malaria, tuberculosis, HIV, and cancer. ${ }^{47,3}$

In the same way, trehalose glycolipids show promise as adjuvants. Indeed, the BCG vaccine is itself a live attenuated strain of $M$. bovis ${ }^{48}$ the causative agent of bovine tuberculosis, and as a mycobacterial species, M. bovis has many similarities with $M$. tuberculosis including a similar cell wall makeup incorporating trehalose glycolipids. ${ }^{43}$, 
${ }^{49}$ Likewise, Complete Freund's adjuvant (CFA), an oil emulsion of dried M. tuberculosis bacteria, ${ }^{47,}$ 50-51 is an extremely potent adjuvant and although these systems use whole bacteria, it is likely that trehalose glycolipids have a role in the elicited adjuvant effects. It has been noted that patients with tuberculosis seldom develop malignant tumours and this has been attributed to the immunomodulatory properties of the TDMs. ${ }^{43}$ Moreover, Ribi et al. (1978) demonstrated that very low doses of TDM as part of an adjuvant system with a glycolipid immunogen were able to cause the complete regression of $95 \%$ of line10 tumours in guinea pigs ${ }^{52}$ and, as previously mentioned, the synthetic trehalose diester TDB shows promise in clinical trials as part of an adjuvant formulation for a new tuberculosis vaccine. ${ }^{18,20,22}$ Given that trehalose glycolipids hold such potential as immunomodulatory agents, much research has been conducted to extract these molecules from a variety of Mycobacteria and related species and to elucidate their structures. ${ }^{1,53}$ With over 500 different TDMs found in the extracts of Mycobacteria, emphasis is now being placed on the synthesis of single components which can then be tested for their individual biological properties. ${ }^{2}$

\subsection{Immunomodulatory Properties of Trehalose Glycolipids}

Trehalose glycolipids are recognised by pattern recognition receptors located on macrophages and other myeloid cells, ${ }^{15-16,54}$ and this recognition can induce the release of pro-inflammatory cytokines and chemokines, and cytotoxic mediators. The release of a powerful interferon- $\gamma($ IFN- $\gamma$ ) signal can induce expansion of natural killer (NK) cell populations and the activation of macrophages primed for antigen presentation to $\mathrm{T}$ cells, thereby inducing adaptive cellular immunity. ${ }^{2,33,52}$ TDMs are among the most potent inducers of the pro-inflammatory cytokines IL-1 $\beta$, IL-6, and tumour necrosis factor (TNF) amongst the mycolic acid diesters, ${ }^{45,53}$ and they also stimulate the release of nitric oxide (NO) and the recruitment of neutrophils. ${ }^{53}$ Studies have established that TDMs possess anti-viral activities in mice inoculated with encephalomyocarditis virus, ${ }^{2}$ although they are of limited use as adjuvants due to their high toxicity. However, the shorter chain TDCMs have the same antitumor ${ }^{55}$ and adjuvant ${ }^{56}$ activities as the more complex TDMs, but without the associated toxicity and therefore show much promise as adjuvants for vaccines and cancer immunotherapy. ${ }^{17,23}$ 


\subsection{The TDM Receptors - Macrophage Inducible C-type Lectin (Mincle) \& Macrophage C-type Lectin (MCL)}

The first step in developing improved trehalose glycolipids as adjuvants is identifying the molecular target of the glycolipids and understanding how the immunomodulatory properties of the molecules are regulated. The cells of the innate immune system recognise pathogen associated molecular patterns (PAMPs) such as LPS and trehalose glycolipids, through their binding to pattern recognition receptors (PRRs). These PRRs include Toll-like receptors (TLR), NOD-like receptors, and C-type lectins. ${ }^{17}$ In 2009 , Ishikawa et al. identified the macrophage inducible C-type lectin, Mincle (also called Clec4e or Clecsf9) as a TDM receptor, ${ }^{17,} 45$ and a later study by Schoenen et al. (2010) confirmed that Mincle is essential for recognition of TDM and related glycolipids. ${ }^{16}$ Furthermore, very recently (2013) the structurally similar macrophage C-type lectin MCL (also called Clec4d or Clecsf8) was identified as a second receptor for TDM. ${ }^{57-58}$

The C-type lectins are a large family of carbohydrate-binding proteins (lectins) which share a common structural motif known as a C-type lectin domain. ${ }^{59}$ These proteins have a diverse range of functions including roles in cell adhesion, natural killer cell regulation, complement and platelet activation, endocytosis, and innate immunity. ${ }^{60}$ Many of the transmembrane C-type lectins are expressed on myeloid cells and have roles in microbe phagocytosis, pathogen binding, and inducing gene expression in the innate immune response..$^{59}$

\subsubsection{Macrophage Inducible C-type Lectin Mincle}

In order to identify the TDM receptor, Werninghaus et al. used murine bone marrowderived macrophage (BMM) knockout models to determine that C-type lectins, rather than TLRs, recognise TDMs. ${ }^{15}$ TLRs signal via MyD88, whereas C-type lectins use the kinase Syk. Accordingly, MyD88 ${ }^{-/-}$and $\mathrm{Syk}^{-/-}$BMMs were tested for their ability to respond to TDM, with activation of BMMs being measured by nitric oxide (NO) and cytokine production. Although MyD88 ${ }^{-/-}$BMMs retained their normal response, $\mathrm{Syk}^{-/-}$ BMMs elicited no response to TDM. ${ }^{15}$ In a similar manner, the myeloid cell-specific adaptor protein, Card9, and the downstream proteins Bcl10 and Malt1, were required for the TDM stimulated BMM response. The $\beta$-glucan receptor Dectin-1, which was 
previously linked to antigen presenting cell responses to whole mycobacteria, ${ }^{61}$ was also excluded as the TDM receptor after studying Dectin- $1^{-/-}$BMMs. ${ }^{15}$ As a large number of myeloid cell receptors which activate Syk are associated with adaptor proteins Dap12 or $\mathrm{FcR} \gamma$, the requirement for these proteins was tested. FcR $\gamma$ was found to be integral in linking TDM recognition to macrophage activation via the Syk-Card9 signalling pathway, while Dap12 was not required. ${ }^{15}$ A later study by Schoenen et al. found that a recombinant Mincle-Fc fusion protein specifically binds TDM, with Mincle $^{-/-}$mice being used to establish that this FcR $\gamma$-associated receptor is crucial for TDM induced macrophage activation and the generation of protective Th-1 and Th-17 immunity. ${ }^{16}$

Mincle is located on cells of the myeloid lineage such as macrophages, monocytes and neutrophils ${ }^{15-16,54}$ and is up-regulated in response to cytokines and PAMPs including polysaccharides and trehalose glycolipids. ${ }^{60,62-63}$ Upon exposure to TDM, Mincle signals via the FcR $\gamma$-Syk-Card9-Bcl10-Malt1 pathway to induce secretion of pro-inflammatory cytokines (e.g. IL-1 $\beta$, IL-6, TNF- $\alpha$, and IFN $\gamma$ ), cytotoxic mediator (e.g. NO) release, and recruitment of neutrophils ${ }^{15,53}$ (Figure 4) These phenomena induce further expression of Mincle on macrophages, ${ }^{62}$ and act on surrounding cells to cause apoptosis and immune cell recruitment through the stimulation of the early adaptive immune response, which directs protective $\mathrm{T}$ cell immunity. 


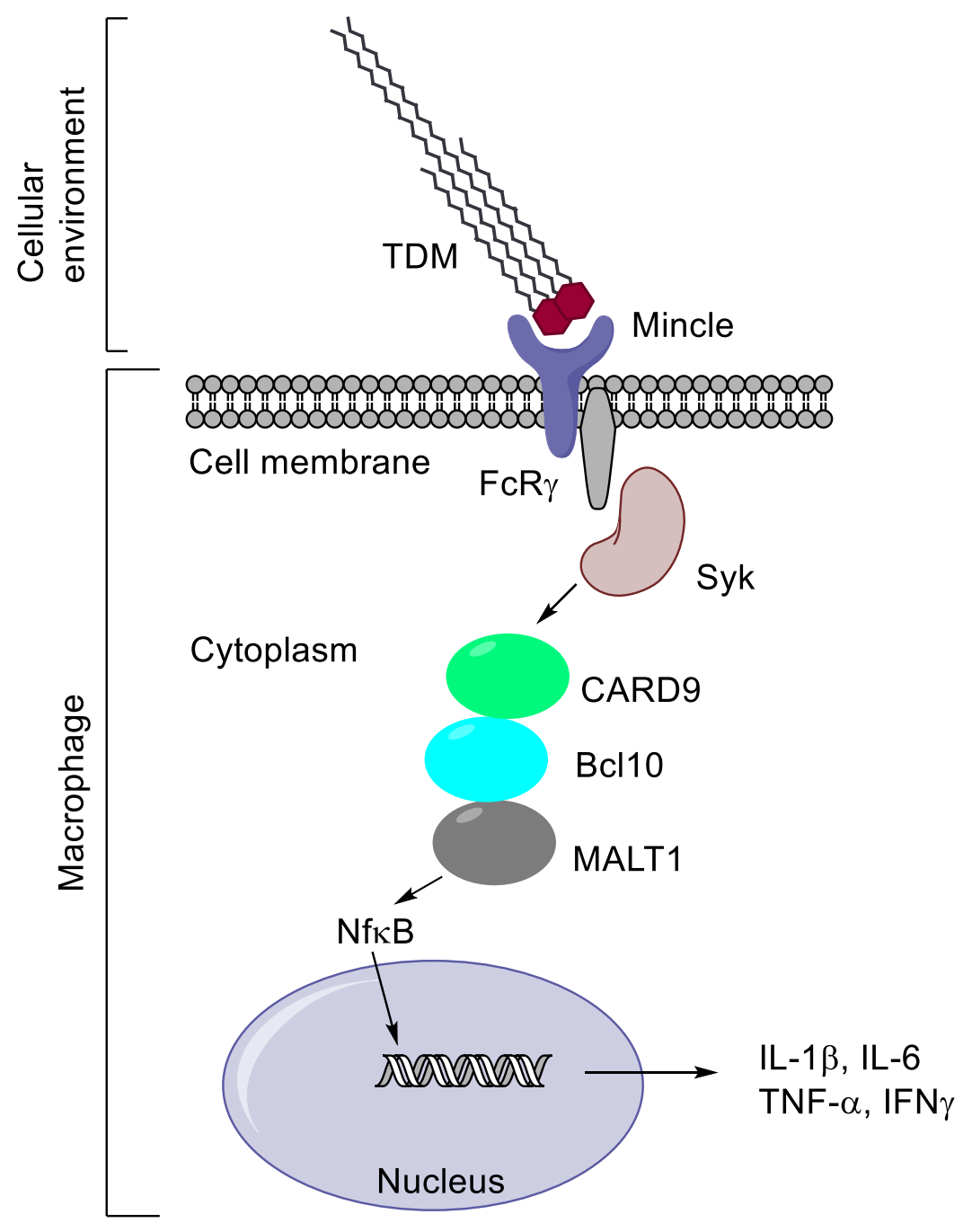

Figure 4: TDM binding to Mincle activates macrophage downstream signalling

\subsubsection{Macrophage C-type Lectin (MCL)}

Like Mincle, MCL is an FcR $\gamma$-coupled activating receptor which recognises TDM. ${ }^{57}$ Murine MCL was originally isolated in 1998 by Balch et al. who named it 'macrophagerestricted C-type lectin, ${ }^{64}$ however, since then human protein expression data has revealed that it is also expressed on peripheral blood neutrophils, monocytes, and some dendritic cell subsets. ${ }^{65-66} \mathrm{MCL}$ was characterised by Arce et al. (2004) via screening the Expressed Sequence Tag database from GenBank for carbohydrate recognition domain sequences. ${ }^{67}$ Analysis of the amino acid sequence ascertained that MCL is a type II transmembrane protein with an extracellular carbohydrate recognition domain with high homology to Mincle. The authors used internalisation assays and microscopy to determine that MCL is an endocytic receptor, ${ }^{67}$ and although it did not appear to associate 
with any known signalling molecules such as DAP10, DAP12, and FcR $\gamma,{ }^{66}$ a recent study using FcR $\gamma$ knockout mice indicates that MCL does in fact couple with FcR $\gamma$ to trigger Syk kinase mediated intracellular signalling, ${ }^{57}$ inducing phagocytosis, the respiratory burst, and pro-inflammatory cytokine production. ${ }^{65-66}$ Although MCL is known to act as an activation receptor on myeloid cells, ${ }^{66}$ binding assays with plate-coated TDM and TDB have only recently identified trehalose glycolipids as the MCL ligands responsible for this effect. ${ }^{57}$

\subsubsection{Mincle and MCL: A Cooperation}

Mincle and MCL are both FcR $\gamma$-coupled C-type lectin receptors required for TDMmediated innate and adaptive immunity. These receptors share $60 \%$ homology of their carbohydrate recognition domain, and their genes are located adjacent to each other on human chromosome 12, with MCL possibly arising from gene duplication of Mincle. ${ }^{57,}$ 67 Although studies have shown that Mincle is essential for the recognition and adjuvanticity of TDM, new evidence suggests that MCL also plays a vital part in driving the initial immune response. ${ }^{57,66}$

In resting myeloid cells, Mincle is present in barely detectable amounts, ${ }^{57-58}$ however, its expression is readily induced upon exposure to cytokines and PAMPs such as lipopolysaccharides and trehalose glycolipids, and Mincle expression is up-regulated by ligand interactions with Mincle itself. ${ }^{60,62}$ On the other hand, MCL is constitutively expressed in myeloid cells, with exposure to pro-inflammatory cytokines including TNF$\alpha$, IFN- $\gamma$, IL-6, and IL-10 causing only a small increase in MCL expression. ${ }^{57-58,67}$

To identify the roles of MCL and Mincle in the TDM mediated immune response, Miyake et al. (2013) used murine knockout models deficient in either MCL or Mincle. ${ }^{57}$ The authors found that both Mincle and MCL were required for TDM mediated induction of innate immunity, as well as the maturation of DCs involved in generating acquired T cell immunity. Further investigations into the requirement of MCL and Mincle in establishing acquired immunity to TDM revealed that both receptors were necessary for a delayed type hypersensitivity response to secondary challenge with TDM, while the experimental autoimmune encephalomyelitis (EAE) model of Th17-cell-mediated autoimmunity indicated that MCL is critical for acquired immunity and that this effect is independent 
of Mincle ${ }^{57}$ Finally, immune responses to the mycobacteria M. tuberculosis and M. bovis were examined in vitro and in vivo, respectively. In vitro production of pro-inflammatory cytokine TNF and MIP-2 mRNA was significantly reduced in both cell lines, while Mincle induction was compromised substantially in the MCL knockout cells, indicating that MCL is indeed necessary for the initial up-regulation of Mincle. This evidence complements prior experimentation by Miyaki et al. that confirmed the existence of an activating receptor which drives the initial up-regulation of Mincle. ${ }^{57}$ Here, reporter mice which express green fluorescent protein (GFP) instead of Mincle showed an increase in GFP expression upon stimulation with TDM even in the absence of Mincle. FcR $\gamma$ knockout mice were then used to confirm the necessity of the FcR $\gamma$ signalling molecule in this response, and the aforementioned MCL knockout models corroborate the hypothesis that MCL is an FcR $\gamma$-coupled activating receptor that drives Mincle induction in response to TDM stimulation. In the in vivo $M$. bovis model, pro-inflammatory cytokine IFN- $\gamma$ production was partially impaired in both knockout strains. Taken together, these results suggest that both Mincle and MCL are required to generate an innate immune response to TDM, while MCL is capable of inducing an acquired immune response, as seen in EAE, independently of Mincle. Furthermore, recent evidence suggests that the activity of MCL and Mincle are even more closely linked, with these lectins forming a heterodimer on the cell surface that associates with FcR $\gamma$ to enhance phagocytosis and increase Mincle expression. ${ }^{63,68-69}$ The authors suggest that the Mincle/MCL complex binds to TDM in a co-ordinated manner, with Mincle recognising the sugar moiety and MCL binding the lipid. ${ }^{68}$ However, it is unusual for C-type lectins to bind lipids, ${ }^{68}$ and affinity binding studies of trehalose glycolipids with Mincle have illustrated the necessity of the lipid portion for effective ligand binding to Mincle, as discussed in Section 1.7.5 (page 17). ${ }^{58,70}$

\subsubsection{Receptor - Ligand Binding Interactions}

Understanding the structure of the TDM receptor binding sites and the properties needed for ligand binding will provide insight into the features required to synthesise modified trehalose esters with improved adjuvant activity. MCL is not as well characterised as Mincle, however both are transmembrane proteins with an extracellular $\mathrm{Ca}^{2+}$-dependent carbohydrate recognition domain containing a mannose/glucose binding motif. ${ }^{60}, 62$ Mincle is known to recognise TDM, ${ }^{17,45}$ the yeast Candida albicans,${ }^{54}$ and the pathogenic 
fungi species Malassezia. ${ }^{60-61,71-72}$ C. albicans and Malassezia species are both opportunistic pathogens which are normally present in humans but can cause severe disease in immune compromised patients. While the Mincle carbohydrate recognition domain is thought to recognise and bind to mannose containing glycolipids from $C$. albicans and Malassezia species with specificity for $\alpha$-mannose geometry, ${ }^{54,61,71}$ it does not recognise $\alpha-1,2$ mannose containing glycolipids from Mycobacterium cell wall extracts, nor does it recognise any other mycobacterial cell wall components apart from TDM and associated analogues (e.g. TDB). ${ }^{16,45}$ The sugar head group of TDM is the disaccharide trehalose $\left(1,1^{\prime}\right.$ - $\alpha$-linked glucose) and studies by Ishikawa et al. (2009) established that this motif is essential for the recognition of mycobacteria by Mincle. ${ }^{17}$ It is thought that the carbohydrate recognition domain of Mincle also binds to the structurally related glucose, although this may not result in macrophage activation. ${ }^{45}$ Furthermore, TDB, a simplified synthetic analogue of TDM, and other trehalose diesters also activate cells by way of Mincle. ${ }^{16}$ In particular, research in our group has shown that simple linear chain monoesters and diesters of trehalose are able to activate macrophages, ${ }^{73-74}$ and incorporation of a probe bearing benzophenone and alkyne functionalities for affinity based proteome profiling did not prevent activation of macrophages. ${ }^{75}$ As such studies indicate, the carbohydrate recognition domain of Mincle is able to bind a variety of structurally related glycolipids.

To determine whether the individual sugar or the lipid portion of TDM is required for Mincle binding and activation, Ishikawa et al. tested both the mycolic acid and the trehalose sugar independently, and found that neither were able to activate Mincle expressing cells in isolation. ${ }^{17}$ This indicates that both the sugar and lipid components of TDMs are vital for ligand activity, perhaps with specific recognition of the sugar-lipid ester linkage. Other aspects of ligands thought to be important for Mincle binding are the organisation and functionality of the meromycolate branch and the length of the $\alpha$-branch of the lipid tails (Figure 2, page 3). Studies by Retzinger et al. (1981) proposed that the length of the shorter $\alpha$-branch of the mycolic acid determines the final glycolipid length at hydrophobic interfaces and that the longer meromycolate chain is kinked to fit into this smaller space. ${ }^{32}$ The flexing of the chain may contribute to the presentation of the disaccharide head to Mincle for optimum binding. On the other hand, TDEs that lack the branched nature and complex functionality of TDMs, such as the much studied TDB, are 
also active. ${ }^{16,52}$ The importance of the lipid chain length in TDEs was demonstrated by Khan et al. (2011), with lipids $>18$ carbons being required for macrophage activation. ${ }^{73}$ Retzinger et al. suggested that the effect of TDMs is due to their physical properties rather than chemical specificity ${ }^{32}$ and while this argument is supported by the differential activities of TDM when they are part of a lipid emulsion or the cell wall of Mycobacterium, ${ }^{26}$ both their physical presentation to Mincle and the specific components of each glycolipid appear to be important.

Work by Rao et al. $(2005,2006)^{76-77}$ demonstrates that cyclopropane modifications of the TDM mycolic acids alters the innate immune response to M. tuberculosis. While the ciscyclopropane containing glycolipids are proinflammatory, the trans-cyclopropane variants suppress the inflammatory response to $M$. tuberculosis and are five times less potent than commercially available TDM which lacks trans-cyclopropanes. ${ }^{77}$ In addition, Al Dulayymi et al. (2009) synthesised a variety of cyclopropane containing trehalose glycolipids and found that the cis-dicylopropanated TDM was three fold more potent at stimulating production of the pro-inflammatory cytokine TNF- $\alpha$ than purified TDM. ${ }^{2}$

Furthermore, a recent study by Vander Beken et al. (2011) investigated the structureactivity relationship of a variety of synthetic mycolic acids representative of those found in M. tuberculosis, and determined that the fine molecular structure and stereochemistry of the lipids does influence the activity of these molecules. ${ }^{78}$ The mycolic acids investigated here were the $\alpha$-mycolic acids containing two cis-cyclopropane rings and the oxygenated keto- and methoxy-mycolic acids with one cis- or trans-cyclopropane ring (Figure 5). ${ }^{6,8,78}$ These compounds were administered into the trachea of mice and pulmonary inflammation was determined by the level of innate immune cell recruitment (neutrophils, alveolar macrophages and dendritic cells) as measured using flow cytometry. The $\alpha$-mycolic acid was not immunogenic, however the cis-methoxy variant induced a strong inflammatory response which was partially attenuated in the transvariant. ${ }^{78}$ For the keto-mycolates, the $c i s$ variant induced a mild inflammatory response, however the trans derivative exhibited anti-inflammatory activity. These results clearly show that the activity of free mycolic acids is strongly dependent on the detailed lipid structure, and it is reasonable to expect that this activity extends to the trehalose-bound variants, as indicated in the studies by Rao et al. and Al Dulayymi et al. discussed previously. 


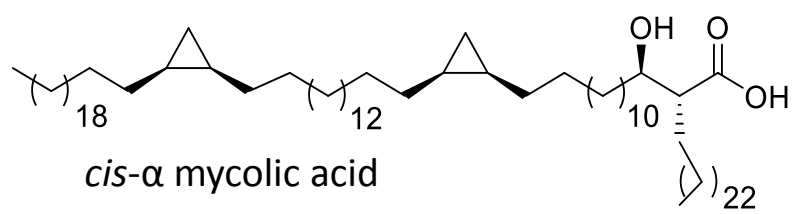

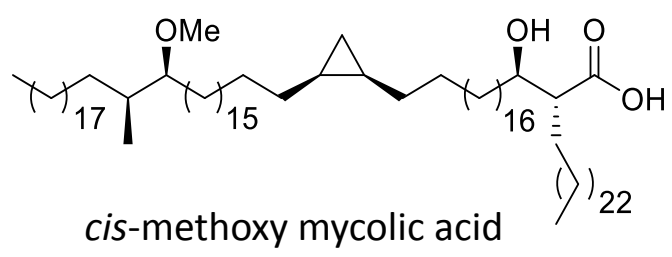

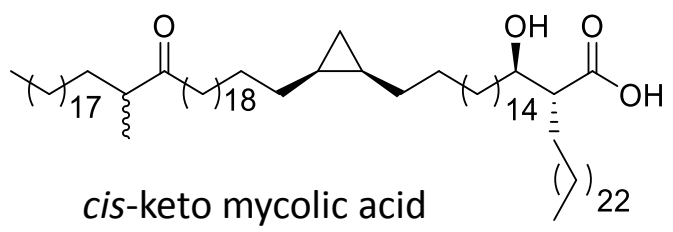

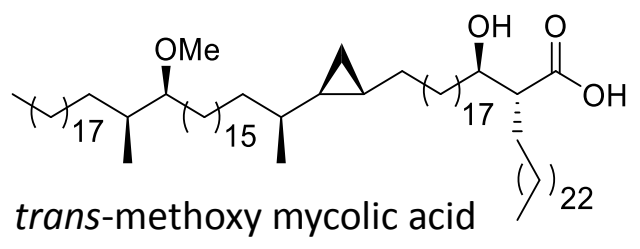

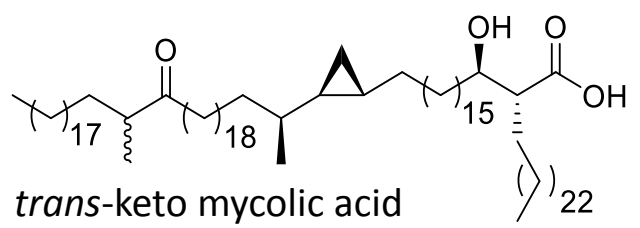

Figure 5: Synthetic mycolic acids

In related work, Martin-Bertelsen et al. $(2013)^{79}$ synthesised analogues of monomycoloyl glycerol (MMG), another mycobacterial cell wall lipid that stimulates dendritic cells (DCs). This study determined that the activation of DCs depended on both the stereochemistry of the sugar, and the length of the alkyl chain, but not on the stereochemistry of the lipid, and further analyses showed that the active and inactive compounds had distinct differences in their biophysical properties, and thus presentation to their receptor. Taken together, this information substantiates the hypothesis that the detailed chemical structure of the trehalose glycolipid mycolic acids also has an important role in the elicited immune response, resulting from both the chemical specificity and the physical properties of the molecules. 


\subsubsection{The Crystal Structure of Mincle}

Recently, the crystal structure of bovine Mincle was elucidated by Feinberg et al. $(2013),{ }^{70}$ and the crystal structures of both human Mincle and human MCL were elucidated by Furukawa et al. (2013). ${ }^{58}$ Both the Feinberg and Furukawa groups also analysed the crystal structure of Mincle when bound to either trehalose or citric acid, respectively. The structural analyses of Mincle determine that it behaves as a monomer and binds to sugars in a $\mathrm{Ca}^{2+}$-dependent manner common to C-type lectins. Here, the 3and 4-OH of one glucose molecule coordinate to $\mathrm{Ca}^{2+}$ in a primary binding site, as well as forming hydrogen bonds with four of the proximal amino acid side chains (Figure 6). ${ }^{70}$ This primary binding site includes a glucose/mannose binding motif (glutamic acidproline-asparagine) typical of C-type lectins, which is crucial for TDM recognition. ${ }^{58} \mathrm{An}$ additional secondary binding site lacking $\mathrm{Ca}^{2+}$ accommodates the second glucose moiety of the trehalose disaccharide and this extra recognition provides increased binding affinity for trehalose by 36 -fold compared to glucose. ${ }^{70}$ 

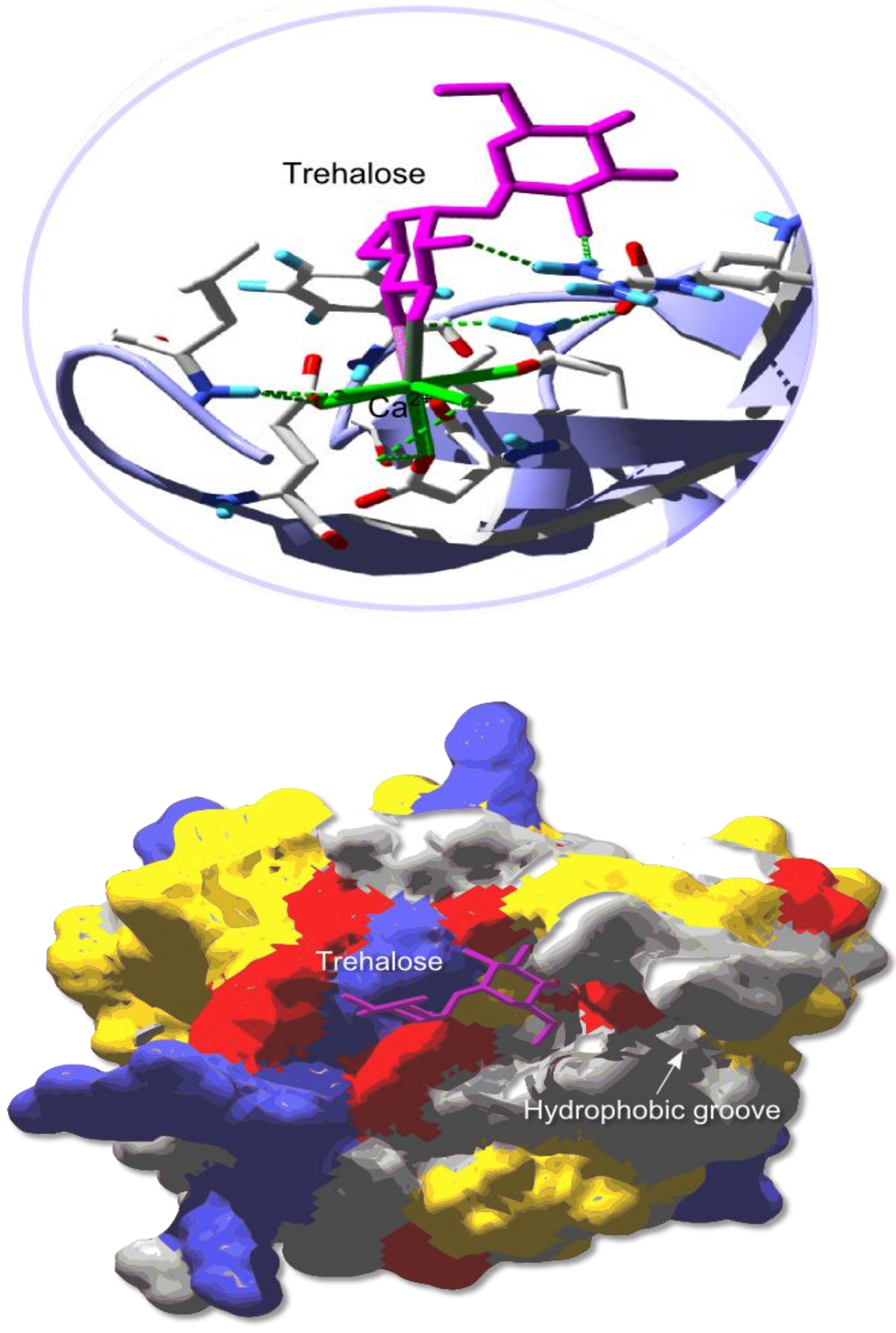

Figure 6: The Mincle binding site in complex with trehalose ${ }^{70}$ 
Both groups identified a single groove composed of hydrophobic amino acid side chains which lies adjacent to the primary binding site and is ideally positioned to accommodate the mycolic acid tail attached to the 6- $O$ residue of a bound trehalose glycolipid. ${ }^{58,70}$ While this suggests that only one lipid chain is bound to the receptor, the specified hydrophobic regions described by each group differ. Furukawa et al. analysed the crystal structure of human Mincle in complex with citric acid, identifying a shallow hydrophobic region to the right of the primary sugar binding site (Figure 7), ${ }^{58}$ whereas Feinberg et al. analysed the bovine Mincle-trehalose complex (Figure 8), identifying a narrower hydrophobic channel positioned to the left of the sugar binding site. ${ }^{70}$ The phenylalanine residues which form the right side of this channel correspond to the hydrophobic amino acids on the left of the region detected by Furukawa. Mutational studies were performed by Feinberg et al. on the amino acid residues of the hydrophobic groove and the resulting loss of affinity for a short chain (C8) trehalose monoester highlights the importance of those amino acids shared by both hydrophobic regions identified. ${ }^{70}$ Additionally, Furukawa et al. suggest that the shallow, open-sided structure of the hydrophobic groove in Mincle is able to accommodate the extra hydroxylation and branching of the more complex TDMs,${ }^{58}$ and it is therefore plausible that the two hydrophobic regions diverging from the sugar binding site may provide accommodation for both branches of the nonlinear trehalose glycolipids.

Although the Furukawa group examined the structure of human Mincle in complex with citric acid, the Feinberg group studied the bovine Mincle receptor when bound to trehalose, a substrate which more closely resembles the native Mincle ligands, the trehalose glycolipids. This has led to the recent suggestion by Jegouzo et al. ${ }^{80}$ that the active trehalose-binding conformation of human Mincle bears more resemblance to the crystal structure of the bovine Mincle-trehalose complex than that of the human Minclecitric acid complex, and certainly, the low $\mathrm{pH}$ at which the citric acid complex was crystallised is likely to have affected the binding conformation of the crystal structure. Therefore, in order to conclusively identify the exact binding interactions of the mycolic acid with the receptor, crystal structure analyses will need to be performed on human Mincle-bound trehalose glycolipids that have been crystallised at physiological $\mathrm{pH}$. 


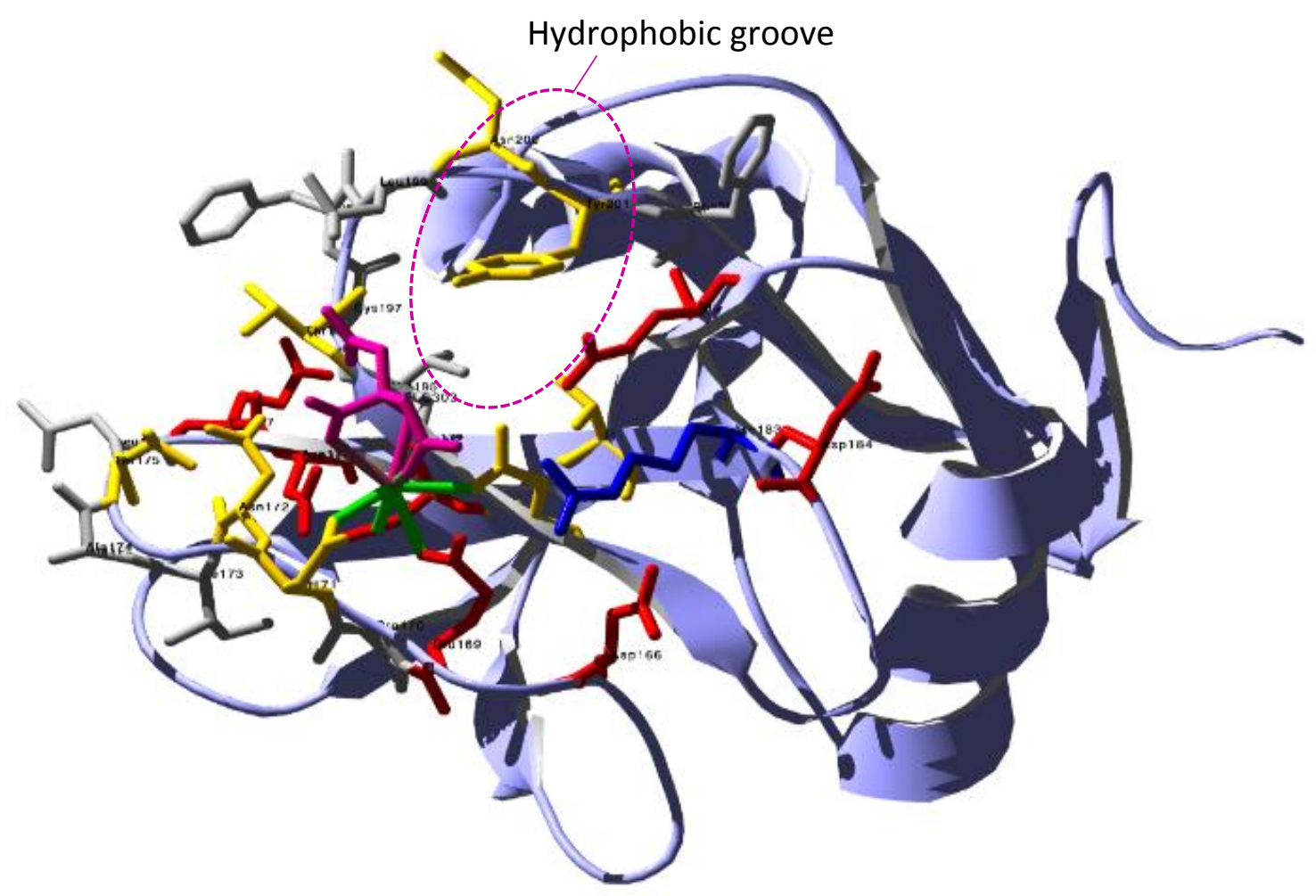

Figure 7: Human Mincle-citric acid complex illustrating identified hydrophobic groove

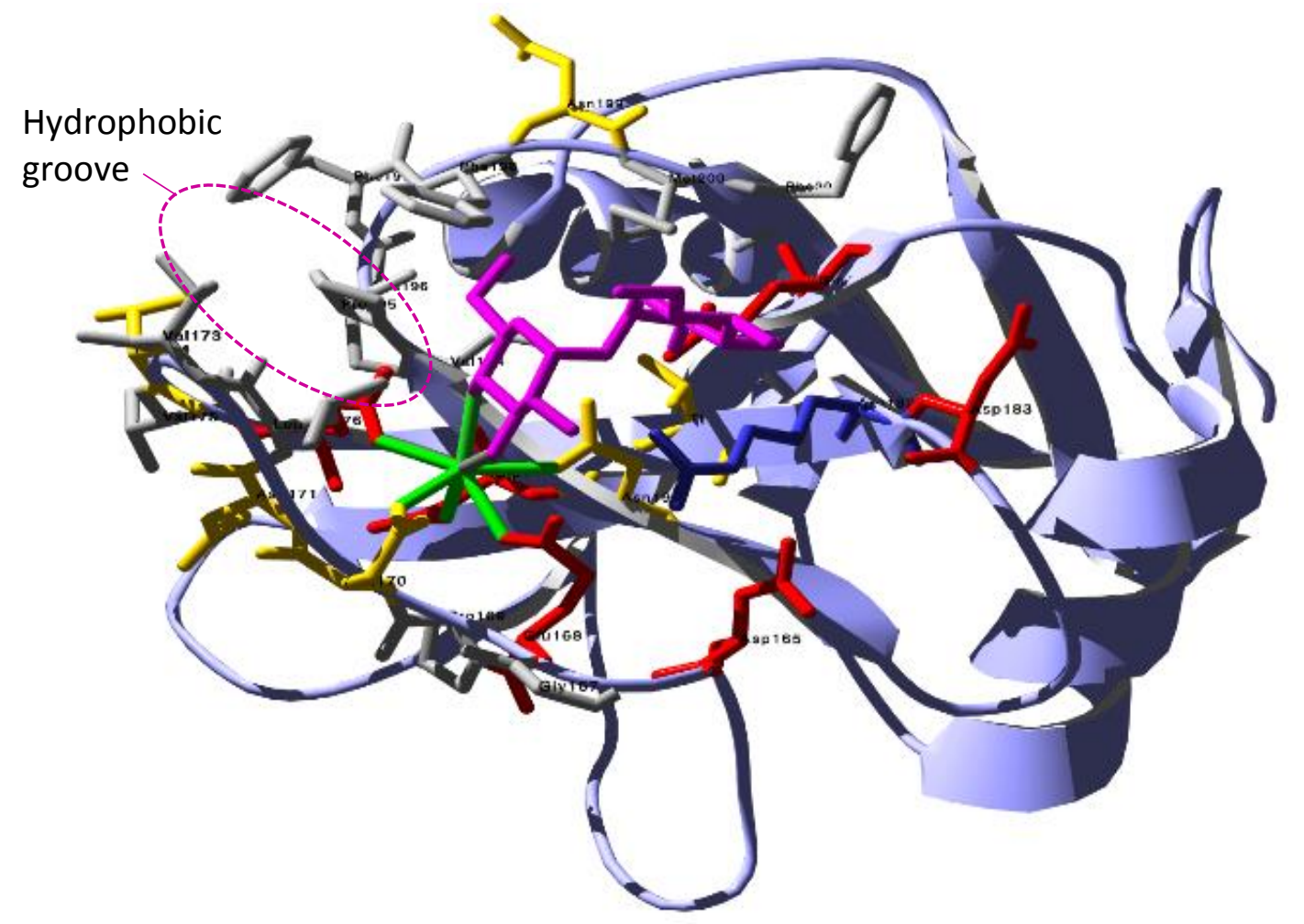

Figure 8: Bovine Mincle-trehalose complex illustrating identified hydrophobic groove 
While it is apparent that one lipid is accommodated in a binding site adjacent to the primary sugar, analysis of the crystal structure indicates that the 6-O of the second glucose residue is orientated away from the receptor surface, and along with the lack of a hydrophobic region adjacent to the secondary binding site, these features indicate that only one fatty acid chain is necessary for recognition, although diacylation is tolerated. ${ }^{70}$ Indeed, this observation was supported by work in our group whereby trehalose monoesters were found to be capable of activating macrophages in a manner similar to their diester counterparts. ${ }^{74}$ Modelling and binding assays suggest that longer chain lipids have increased affinity for Mincle ${ }^{80}$ with a minimum acyl chain length of 10 carbons required for binding. ${ }^{58}$ Research in our group has also shown that long chain lipids are required for the activation of macrophages, however, here it was determined that $>18$ carbons are required for activation, illustrating that binding to Mincle does not always lead to the induction of an immune response. ${ }^{73}$

\subsubsection{The Crystal Structure of MCL: A Comparison to Mincle}

Although MCL shares considerable homology with Mincle, it has some distinct structural and functional differences. In particular, MCL lacks the standard glucose/mannosebinding motif [glutamic acid-proline-asparagine, (EPN)] present in Mincle, instead having an unusual EPD motif (glutamic acid-proline-aspartic acid). ${ }^{58}$ Substitution of the EPN motif in Mincle with an EPD motif compromises the ability of Mincle to bind TDM, however substitution of the EPD motif for EPN in MCL does not improve the binding affinity, indicating that the binding site of each receptor may interact with trehalose diesters in a slightly different manner. Overall, the structure of the carbohydrate recognition domain of MCL is not dissimilar to that of Mincle, with the $\mathrm{Ca}^{2+}$ ion and other amino acids in comparable positions, however, the position of the Arg183 side chain in Mincle is in a more favourable position to interact with the hydroxyl groups of TDM, compared with the corresponding Val186 residue in MCL (Figure 9 and Figure $10)$.

The lipid binding regions of Mincle and MCL contain hydrophobic loops unique to these receptors, however Mincle has a larger hydrophobic area than MCL. These structural differences likely result in the considerably weaker binding affinity of TDM to MCL than to Mincle..$^{57-58}$ It has been hypothesised that less toxic trehalose glycolipids, such as 
TDCM, may preferentially bind to MCL, presenting this lower affinity receptor as an attractive target for adjuvant synthesis. ${ }^{57}$ Taken together, analyses of the crystal structures of MCL and Mincle suggest that these receptors recognise glycolipids in a manner similar to each other, but distinct to other glycolipid receptors.

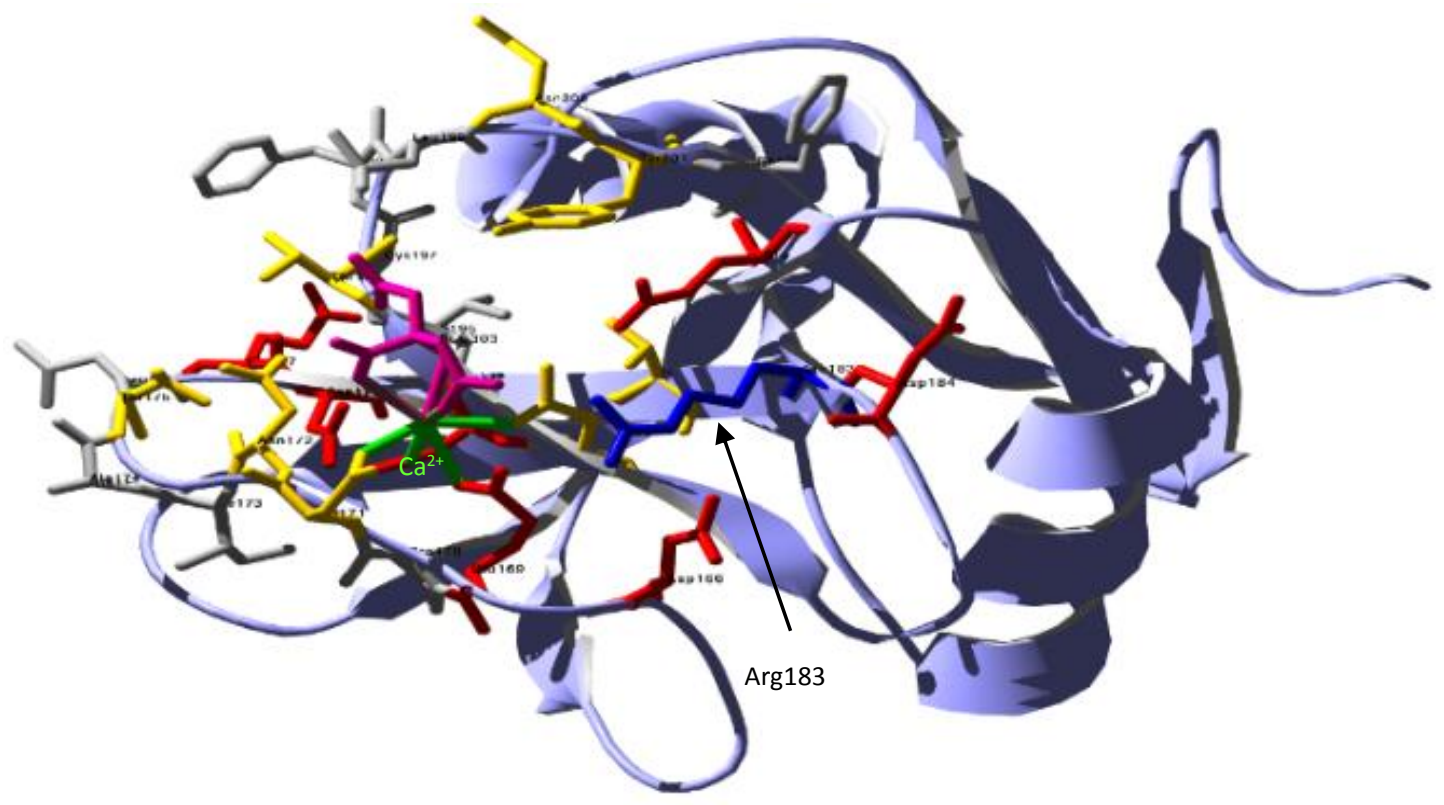

Figure 9: Mincle-citric acid complex

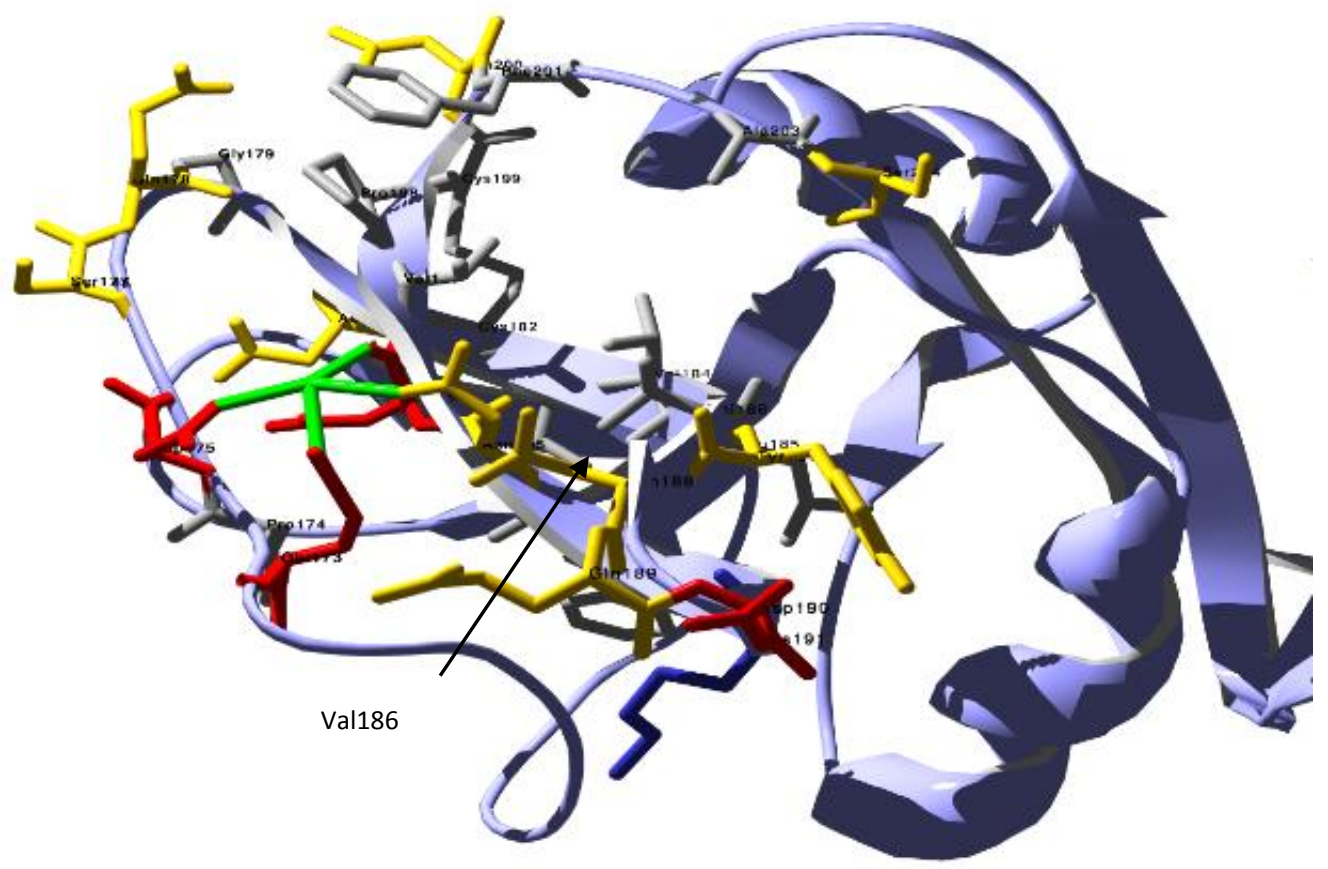

Figure 10: MCL 


\section{Aims}

\subsection{Understanding Mincle \& MCL: Modified Trehalose Glycolipids}

Recent crystal structure elucidation has provided important information on the binding sites of the trehalose glycolipid receptors Mincle and MCL, ${ }^{58,70}$ however, the effect of trehalose glycolipid structure on immunomodulatory properties, as mediated by binding interactions with these receptors, is poorly understood. Thus, it is of considerable interest to investigate the binding interactions of trehalose glycolipids with Mincle and MCL to allow for the development of improved vaccine adjuvants. To this end it was envisioned that several synthetic trehalose glycolipid analogues could be prepared, which consist of mono- and di-ester derivatives (TMEs 1a-c and TDEs 2a-c, respectively) with a C22 $\alpha-$ backbone and a short meromycolate branch bearing varied functional groups (Figure 11).

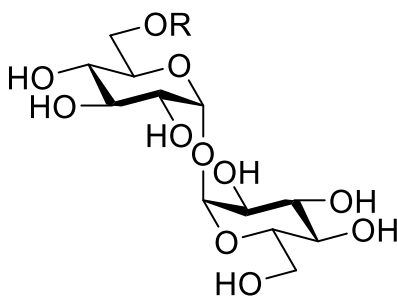

1

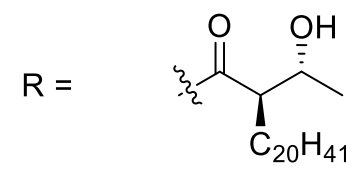

a

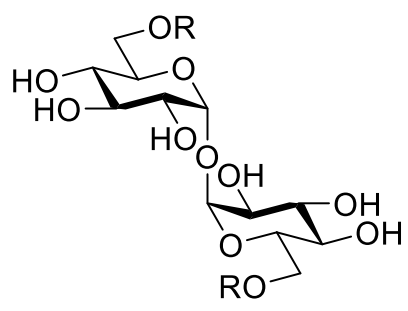

2<smiles>CCCC(C(C)=O)C(C)OC</smiles>

b<smiles>CCCC(CCC)C1CO1</smiles>

C

Figure 11: Synthetic Trehalose Glycolipid Targets

Research in our group has determined that long chain lipids are required for the binding and immune activation of macrophages by TDEs, with the C22 TDE, known as trehalose dibehenate (TDB), being the most potent immune stimulator. ${ }^{73}$ Furthermore, TDB has shown great promise as an adjuvant due to its ability to strongly activate the immune system with low toxicity, and is currently in phase I clinical trials as part of an adjuvant system for a tuberculosis vaccine. ${ }^{18,22,81}$ Hence, a C22 $\alpha$-chain length was selected for the synthetic trehalose glycolipids (1a-c and 2a-c). 
In addition, the functional groups present on the meromycolate chain of TDMs influence their immunomodulatory properties, as evidenced by the lower toxicity and enhanced immunogenicity of the TDCMs and TDEs compared to the highly functionalised TDMs. ${ }^{2}$, 23, 82 It has also been postulated that the portion of the lipid closest to the sugar has the greatest effect on ligand recognition ${ }^{58}$ and as TDMs and TDCMs are hydroxylated at the $\beta$-position of the meromycolate branch, the effect of alterations to this centre on the activity of the TDMs will be explored. Notably, crystal structure analysis indicates that $\beta$-positioned residues will sit at the entrance of the hydrophobic groove and are likely to interact with the surrounding amino acids to influence binding. ${ }^{58,70}$ With this in mind, derivatives with the native $\mathrm{OH}$ functionality (1a and 2a), were proposed. It is hypothesised that the hydroxyl group in these derivatives may H-bond with the amino acids in this vicinity (i.e. Thr175 and Thr196 in Mincle, and Ser177 and Cys199 in MCL), while an intramolecular $\mathrm{H}$-bond with the ester-group carbonyl locks the conformation of the mycolic acid. ${ }^{19}$ Further derivatives, $\mathbf{1 b}$ and $\mathbf{2 b}$, will be prepared, whereby any H-bond donation from the $\mathrm{OH}$ is prevented by masking the hydroxyl as a methyl ether. These derivatives should give information on the importance of both inter- and intra-molecular H-bonding at this position. Finally analogues $\mathbf{1 c}$ and $\mathbf{2 c}$, in which an epoxide functionality was installed at the $\beta$-position to act as an electrophilic trap, were envisioned. It is proposed that the epoxide will react with neighbouring nucleophilic amino acids, such as the threonine residues (Thr175 and Thr196) at the entrance of the hydrophobic groove in Mincle, or the serine and cysteine (Ser177, Cys199) residues in MCL, resulting in covalent bond formation. Indeed, if this occurs it is likely to induce long lasting activation or inhibition of the receptor.

Herein, it is also important to note that the exact binding interactions of the trehalose glycolipids with the receptors cannot be reliably modelled using crystal structure predictions, therefore the synthesis of trehalose glycolipid analogues is crucial to understanding these interactions. This is illustrated in the crystal structure analysis of the bovine Mincle-trehalose complex by Feinberg et al. and the human Mincle-citric acid complex by Furukawa et al., in which slight differences in the crystal structure has led to the identification of different hydrophobic regions which may accommodate the fatty acid. Finally, as highlighted previously, examination of the crystal structures of Mincle and MCL suggests that only one lipid binds to the receptor with the second lipid orientated away from the receptor surface ${ }^{58,70}$ and work from our group has established 
that monoesters and diesters alike can activate macrophages. ${ }^{74}$ Accordingly, both monoand di-acetylated trehalose glycolipids were proposed in order to further explore this phenomenon.

\subsection{Biological Evaluation of Trehalose Glycolipids}

Although beyond the scope of this project, biological testing will be carried out to determine the immunostimulatory activity of the prepared trehalose glycolipids. This will provide information on the properties required for binding to the receptors Mincle and MCL, which will allow for the development of improved trehalose glycolipids for use in adjuvant therapies. 


\section{Results and Discussion}

\subsection{Retrosynthetic analysis}

The retrosynthetic analysis for the target trehalose glycolipids is depicted in Scheme 1. TMEs 1a-c and TDEs 2a-c are envisioned to be accessible by coupling one or two of the mycolic acid derivatives 3a-c to the TMS-protected trehalose 4. ${ }^{73}, 83$ TMS-protected trehalose 4, is in turn available from $\alpha, \alpha^{\prime}$-D-trehalose (6) in two steps via persilylation followed by selective cleavage of the primary TMS ethers. ${ }^{4}{ }^{84}$ The mycolic acid derivatives 3a-b can be obtained via the regioselective ring opening of the common epoxide precursor 5 using $\mathrm{H}_{2}$ with $\mathrm{Pd}(\mathrm{OH})_{2} / \mathrm{C}$, followed by TBS protection or $O$ methylation and subsequent ester hydrolysis to give $\mathbf{3 a}\left[\mathrm{R}^{\prime}=\mathrm{CH}(\mathrm{OTBS}) \mathrm{CH}_{3}\right]$ and $\mathbf{3 b}\left[\mathrm{R}^{\prime}\right.$ $\left.=\mathrm{CH}(\mathrm{OMe}) \mathrm{CH}_{3}\right]$, respectively. In the case of $\mathbf{3 c}\left[\mathrm{R}^{\prime}=\mathrm{CH}(\mathrm{O}) \mathrm{CH}_{2}\right]$, only ester hydrolysis of epoxide $\mathbf{5}$ is required. Epoxide $\mathbf{5}$ can be prepared from allylic iodide $\mathbf{7}$ and diethyl Lmalate (8) via a Fráter-Seebach alkylation, ${ }^{85}$ subsequent reduction of the $\alpha$-alkyl- $\beta$ hydroxy diester, tosylation of the primary alcohol, and base-mediated cyclisation. Diethyl L-malate $(\mathbf{8})$ is available from L-malic acid (10), ${ }^{86}$ while allylic iodide $\mathbf{7}$ is readily prepared from octadecanol (9) in 3 steps. $^{85}$ 


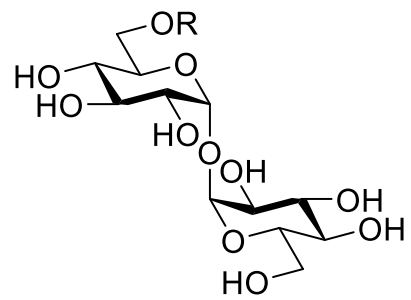

1

$\mathrm{R}$ :<smiles>[Y]C(=O)C(CCCCCCCCCCC)C(C)O</smiles>

a

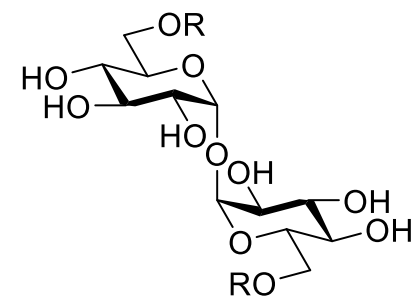

2<smiles>CCCCC(CCC)C(CCC)C1CO1</smiles>

C<smiles>CCCCCCC(C)C([18OH])C(=O)O</smiles>

$3 a$<smiles>CCCC(C(=O)O)C(C)OC</smiles>

$3 b$<smiles>C1=CC=C1</smiles><smiles>CCCC(C(=O)OCC)C1CO1</smiles>

5<smiles>C1=C[CH-]1</smiles>

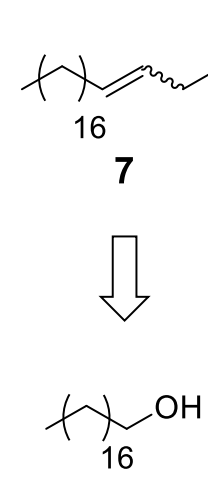

9<smiles>CCCC(C(=O)O)C1CO1</smiles>

$3 c$<smiles>CCCC(C(C)=O)C(C)OC</smiles>

b<smiles>c1ccccc1</smiles>

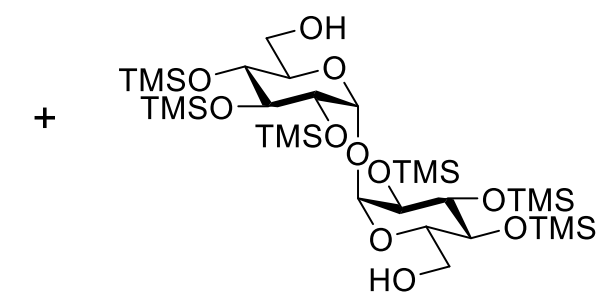

4<smiles>C1=CC=C1</smiles>

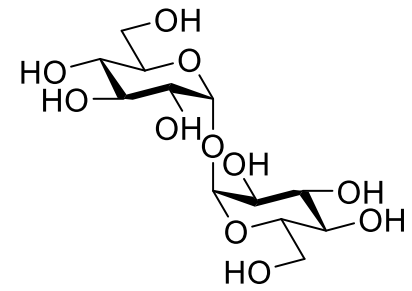

6

Scheme 1: Retrosynthesis of target TMEs 1a-c and TDEs 2a-c 


\subsection{Forward Synthesis}

\subsubsection{Preparation of the Allylic Iodide (7)}

The synthetic strategy begins with the synthesis of the C20 allylic iodide 7 (Scheme 2), which will be used to install the $\alpha$-alkyl chain of the TMEs and TDEs. ${ }^{73}$ To this end, octadecanol (9) was oxidised using pyridinium chlorochromate (PCC) under dry conditions to give octadecanal (11) in good (76\%) yield, with this reaction being performed on a multi-gram (12 g) scale. The aldehyde was purified by silica gel flash column chromatography to remove the chromium from the reaction mixture, however when performed on such a large scale (10-15 g), removal of the chromium proved difficult and repeated silica gel flash column chromatography was required. Unfortunately this resulted in some over oxidation of the aldehyde to the carboxylic acid (ca. 20-30\%), and while the acid was separable by chromatography, in future, the over oxidation could be prevented by quenching the reaction with methanol prior to purification. Octadecanal (11) was then subjected to a Grignard reaction with vinylmagnesium bromide to yield allylic alcohol 12. Due to the instability of this intermediate, which was prone to elimination of $\mathrm{H}_{2} \mathrm{O}, \mathbf{1 2}$ was used immediately and without further purification. Subjection of allylic alcohol 12 to a solution of iodine and triphenylphosphine in dichloromethane (DCM) then yielded allylic iodide 7 in $66 \%$ yield (two steps) after purification by silica gel flash column chromatography.
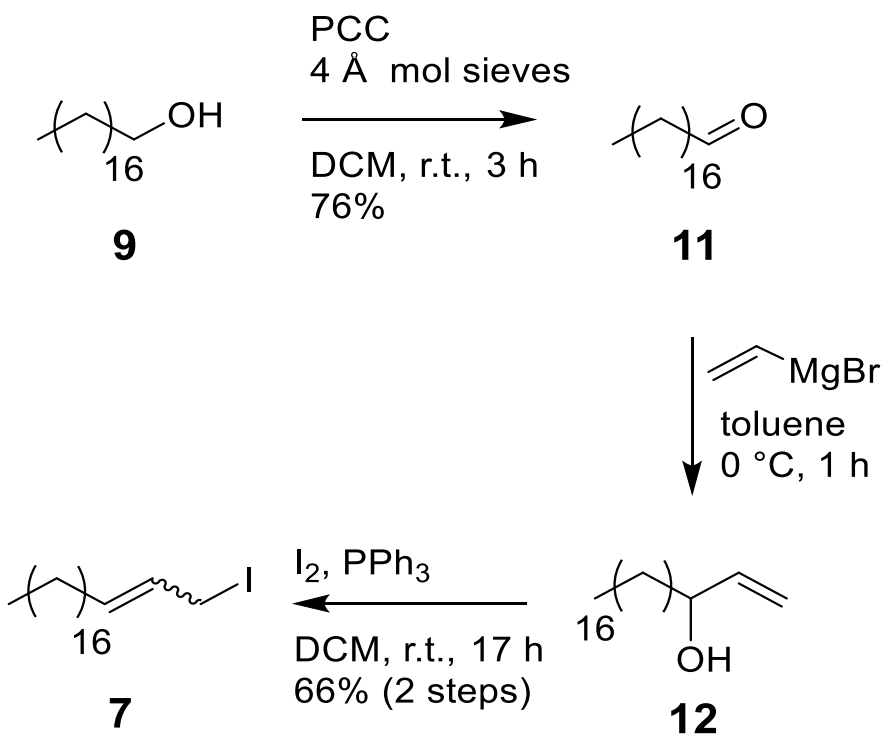

Scheme 2: Synthesis of C20 allylic iodide 7 
Iodide 7 was obtained as a 4:1 mixture of the $E$ - and $Z$ - isomers. Characteristic vinylic proton resonances were observed at 5.73-5.71 ppm in the ${ }^{1} \mathrm{H}$ NMR, while the allylic protons of the $\mathrm{CH}_{2} \mathrm{I}$ group could be identified by the presence of two doublets at 3.89 and $3.93 \mathrm{ppm}$ ( $E$ - and $Z$-isomers, respectively), with these resonances shifted downfield from the allylic protons of the alkyl chain due to the presence of the deshielding iodine. The $E$-isomer was determined to be the major product by comparison of these iodide-adjacent allylic proton resonances with literature data, ${ }^{85}$ as overlapping signals prevented the characteristic coupling constants of the vinylic protons to be determined ( $E$-isomer, $J \approx$ $16 \mathrm{~Hz}$; $Z$-isomer, $J \approx 8 \mathrm{~Hz}$ ). The mechanism for the iodination of allylic alcohol 12 can be explained by a $S_{N} 2^{\prime}$ reaction (Scheme 3). Here, reaction of iodine with triphenylphosphine leads to the in situ generation of the iodophosphonium iodide, which reacts with allylic alcohol 12 to form the alkoxytriphenylphosphonium intermediate. The $\mathrm{S}_{\mathrm{N}} 2^{\prime}$ reaction of iodide with this intermediate then leads to the formation of the allylic iodide 7 with the desired internal alkene, and triphenylphosphine oxide is produced as the by-product.

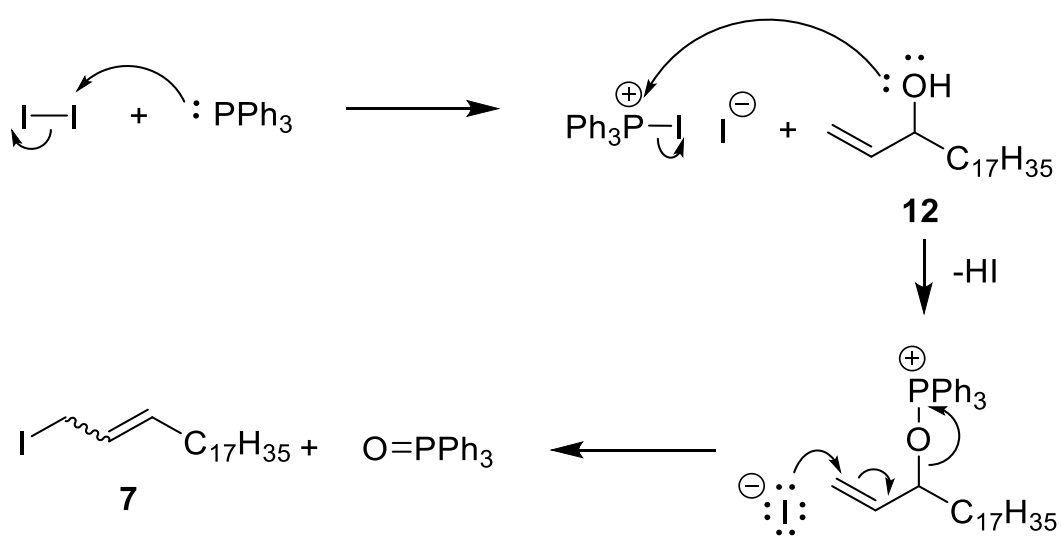

Scheme 3: $\mathrm{S}_{\mathrm{N}} 2^{\prime}$ Iodination mechanism

\subsubsection{Preparation of the Intermediate Epoxide (5)}

Having successfully prepared the required allylic iodide, preparation of the key epoxide 5 was then attempted. To this end, diethyl L-malate (8) was prepared by refluxing L-malic acid (10) with concentrated sulfuric acid in ethanol to provide 8 in excellent (95\%) yield (Scheme 4). ${ }^{73,86}$ Subsequent Fráter-Seebach alkylation with iodide 7 then gave the $\alpha$ alkyl- $\beta$-hydroxy diester 13 in yields exceeding those in the literature $(61 \%)^{85}$ and in a 5:1 
anti:syn ratio, as determined by ${ }^{1} \mathrm{H}$ NMR analysis of the reaction mixture. To achieve such a yield, it is essential that the reaction is performed under exceptionally dry conditions (i.e. flame drying all glassware before use), and that the $n \mathrm{BuLi}$ is of excellent quality. In particular, it is important to note that the use of substandard $n \mathrm{BuLi}$ results in a dramatic decrease in yield, with negligible amounts of product being formed $(<5 \%)$. This decreased yield does not appear to be the consequence of the concentration of $n \mathrm{BuLi}$ used (as determined by titration experiments), but rather, by the presence of an unknown impurity in the reagent which prevents the desired reaction from proceeding.<smiles>O=C(O)CC(O)C(=O)O</smiles>

10

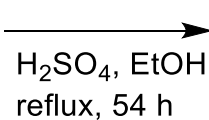

$95 \%$<smiles>CCOC(=O)CC(O)C(=O)OCC</smiles>

8

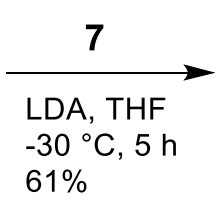

$-30{ }^{\circ} \mathrm{C}, 5 \mathrm{~h}$ $61 \%$<smiles>CCCCCCCCCCCCC=CCC(C(=O)OCC)C(O)C(=O)OCC</smiles>

Scheme 4: Preparation of the Fráter-Seebach $\alpha$-alkylation product

To confirm the stereochemistry of $\beta$-hydroxy diester 13, NMR spectral data was compared with that in the literature, ${ }^{85}$ with the ${ }^{1} \mathrm{H}$ NMR spectrum showing the characteristic vinylic protons at $5.58 \mathrm{ppm}$ and $5.40 \mathrm{ppm}$, while the five protons adjacent to oxygens (H-2 and the ethyl ester $\mathrm{CH}_{2}$ 's) appear as multiplets at $4.26 \mathrm{ppm}$ and 4.16 ppm (Figure 12). The shift of H-3 was used to determine the ratio of diasteriomers (6:1 anti:syn, $\delta 2.89$ and $\delta 2.82 \mathrm{ppm}$, respectively), while the $E / Z$ isomeric ratio remained 4:1, as determined by the resonances of the allylic H-7 protons (1.98 and 2.07 ppm, respectively). The optical rotation value $\left([\alpha]_{\mathrm{D}}^{22}=+7.5, c=1.0, \mathrm{CHCl}_{3}\right)$ also matched that of the literature and confirmed that the anti-diastereomer was indeed the major product. 
${ }^{1} \mathrm{H}$ NMR (500 MHz, $\left.\mathrm{CDCl}_{3}\right)$

13

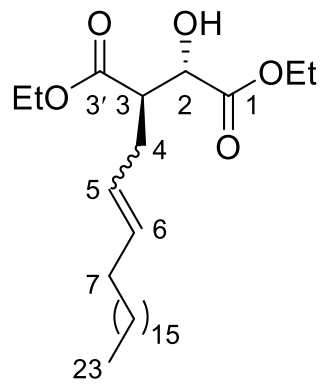

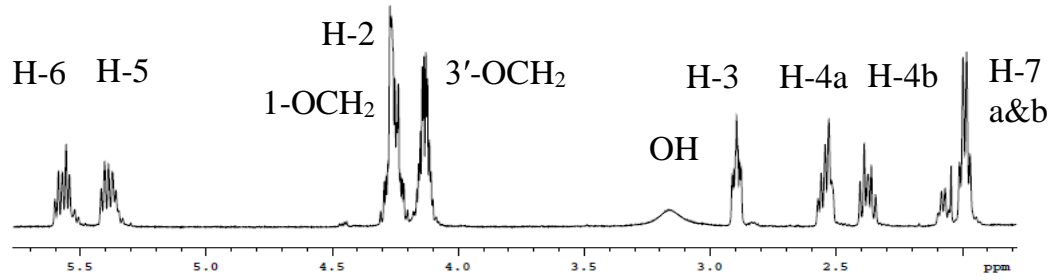

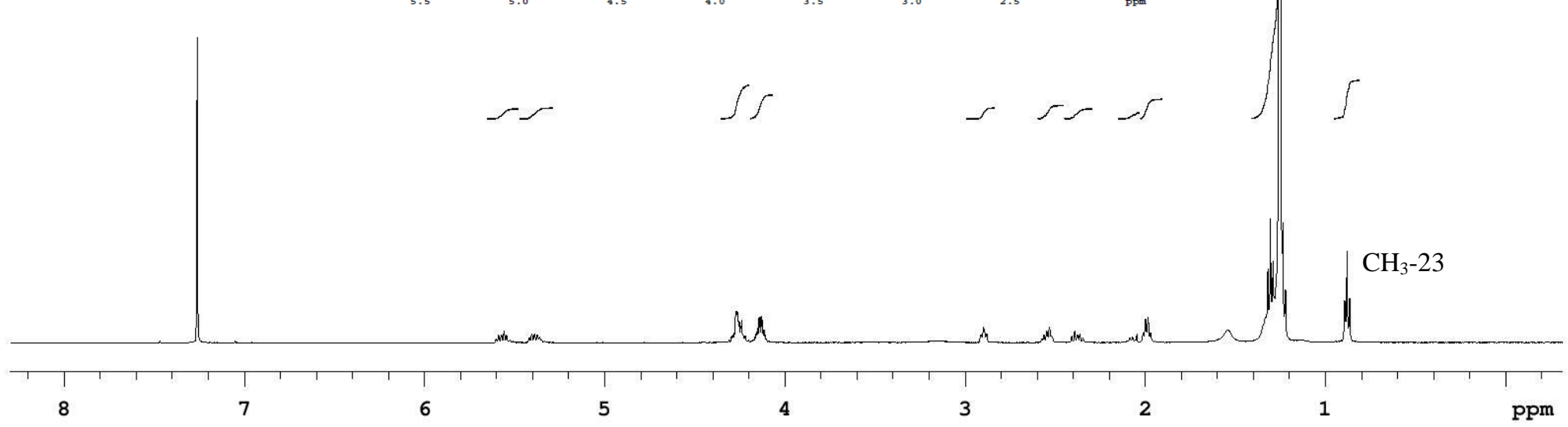

Figure 12: ${ }^{1} \mathrm{H}$ NMR spectrum of (2S,3R)-Ethyl 3-(ethoxycarbonyl)-2-hydroxytricos-5-enoate 13 
The formation of the $2 S, 3 R$ anti-isomer as the major product can be explained by considering the transition state of the Fráter-Seebach alkylation (Scheme 5). Here, the $\beta$ hydroxyl of malic acid diester $\mathbf{8}$ is deprotonated by one equiv. of lithium diisopropylamide (LDA) to form the alkoxide, while a second equiv. of LDA deprotonates the alkoxide intermediate at the $\alpha$-position to form an ester enolate. The lithium cation associates with these two negative charges, forming a six-membered ring, in which the adjacent ethyl ester sterically hinders attack of the enolate from the syn-face. Thus, regeneration of the carbonyl and attack of the alkyl halide by the enolate results predominantly in the formation of the anti-diasteriomer $\mathbf{1 3}$.

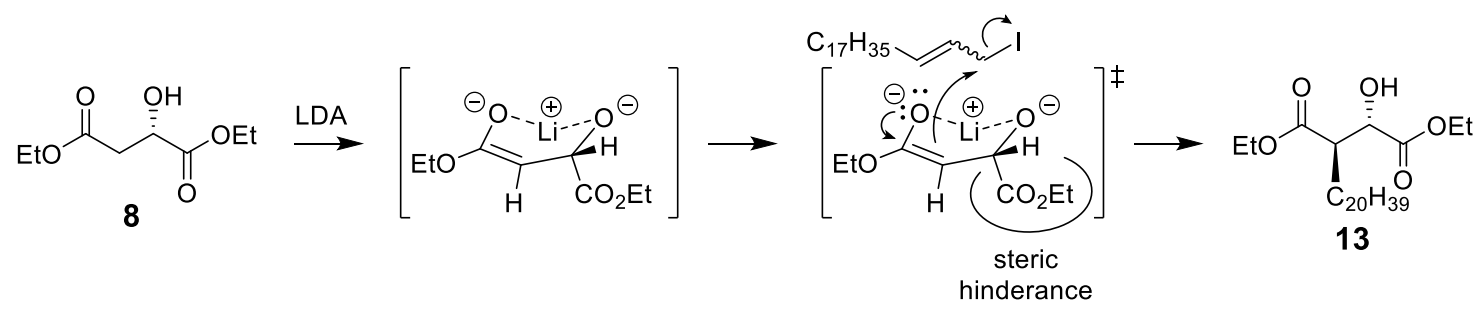

Scheme 5: Fráter-Seebach alkylation proceeds via a cyclic 6-membered transition state

With the $\alpha$-alkyl- $\beta$-hydroxy diester $\mathbf{1 3}$ in hand, this was then subjected to a palladiumcatalysed hydrogenation of the double bond to yield 14 in excellent (quant.) yield (Scheme 6). The regioselective reduction of 14 with borane dimethyl-sulfide (BMS) complex and sodium borohydride was then attempted. ${ }^{85,87}$<smiles>CCOC(=O)C(C)C(O)C(=O)OCC</smiles>

13

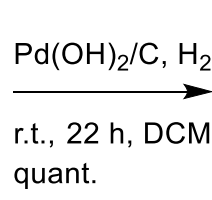

quant.<smiles>CCOC(=O)C(O)C(CC)C(=O)OCC</smiles>

14

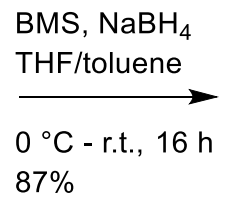
$87 \%$<smiles>CCCC(C(=O)OCC)C(O)CO</smiles>

15

Scheme 6: Synthesis of the 1,2-diol 15

This reaction proved challenging, and indeed, initial attempts to obtain the desired 1,2diol 15 were unsuccessful. It was anticipated that the $\mathrm{C}-1$ ethyl ester would be selectively reduced to the 1,2-diol on account of the five-membered boron-chelate being more thermodynamically stable and amenable to reduction with $\mathrm{NaBH}_{4}$ than the corresponding six-membered chelate, ${ }^{87}$ with the latter intermediate leading to the formation of the 
undesired 1,3-diol 16 (Scheme 7). Indeed, on similar, shorter chain substrates, Khan et $a l .{ }^{85}$ and Saito et al. ${ }^{87}$ saw selective reduction of the C-1 ethoxy ester.<smiles>CCOC(=O)C(O)[C@@H](O)C(=O)OCC</smiles>

14

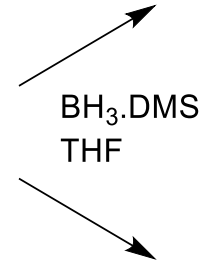

$\mathrm{BH}_{3}$.DMS<smiles>[BH3-]B([BH3-])O[C@@H](C(=O)OCC)[C@@H](C)C(=O)OCC</smiles><smiles>CCOC(=O)C1OB(O)OC(CC)C1[C@H](C)CC</smiles><smiles>CCCC(C)C(=O)OCC</smiles>

15<smiles>CCOC(=O)[C@H](O)[C@@H](CC)CO</smiles>

16

Scheme 7: Hydride reduction via 5- or 6-membered boron-chelates to give $\mathbf{1 5}$ or $\mathbf{1 6}$, respectively

In the initial attempt at the reduction of diester 14, borane dimethyl sulfide (BMS) was added and the reaction stirred at room temperature for $22 \mathrm{~h}$ to allow for formation of the boron chelate. $\mathrm{NaBH}_{4}$ was then added and the reaction stirred for a further $25 \mathrm{~h}$ until complete disappearance of the starting material was observed by thin layer chromatography (TLC). After silica gel flash column chromatography, a single diol was obtained in low (23\%) yield. Unexpectedly, rather than forming the desired diol $\mathbf{1 5}$ by the reduction of the $\mathrm{C}-1$ ester, the $\mathrm{C}-3^{\prime}$ ester was reduced to give $\mathbf{1 6}$ as the sole product.

To confirm that the 1,3-diol 16 had been formed in preference to the 1,2-diol 15, ${ }^{1} \mathrm{H}$ and ${ }^{13} \mathrm{C} 2 \mathrm{D}$ NMR spectroscopy proved invaluable. The presence of a single carbonyl peak at $171.9 \mathrm{ppm}$ in the ${ }^{13} \mathrm{C}$ NMR spectrum of $\mathbf{1 6}$ established the presence of only one ester functionality, confirming that one ester had been reduced. Further signals indicated the presence of both an oxymethine $[\delta 4.39(\mathrm{~d}, J=3.8 \mathrm{~Hz})]$ and an oxymethylene $[\delta 4.01(\mathrm{dd}$, $J=11.7 \mathrm{~Hz}, J=3.8 \mathrm{~Hz})$ and $\delta 3.78(\mathrm{dd}, J=11.7 \mathrm{~Hz}, J=3.8 \mathrm{~Hz})]$ (Figure 13), which both showed COSY correlations (Figure 14) with a methine at $\delta 2.00 \mathrm{ppm}(\mathrm{m})$. This methine in turn correlated to the alkyl chain protons $\mathrm{H}-4 \mathrm{a}(\mathrm{m}, \delta 1.56-1.50)$ and $\mathrm{H}-4 \mathrm{~b}(\mathrm{~m}, \delta 1.46-$ 1.42). From this, the oxymethine could be assigned as $\mathrm{H}-2$, the methine at $\delta 2.00 \mathrm{ppm}$ as H-3 and the oxymethylene signals as H-3'a and H-3'b, in accordance with the 1,3-diol structure 16. This was further corroborated by the observation of HMBCs between H-2 
and $\mathrm{C}-1, \mathrm{C}-3$, and $\mathrm{C}-4$ of the lipid chain, and a strong HMBC between $\mathrm{H}-3^{\prime} \mathrm{a} / \mathrm{H}-3^{\prime} \mathrm{b}$ and $\mathrm{C}-4$, indicative of a three bond coupling, while the distance between the oxymethylene and C-4 in 1,2-diol 15 is four bonds and thus unlikely to HMBC. Most importantly however, the oxymethine $\left(\mathrm{CH}_{2}-3^{\prime}\right)$ proton signals show COSY correlations with methine $\mathrm{CH}-3$, and not with oxymethine $\mathrm{CH}-2$, which confirms irrevocably that the product is indeed 1,3-diol 16. 


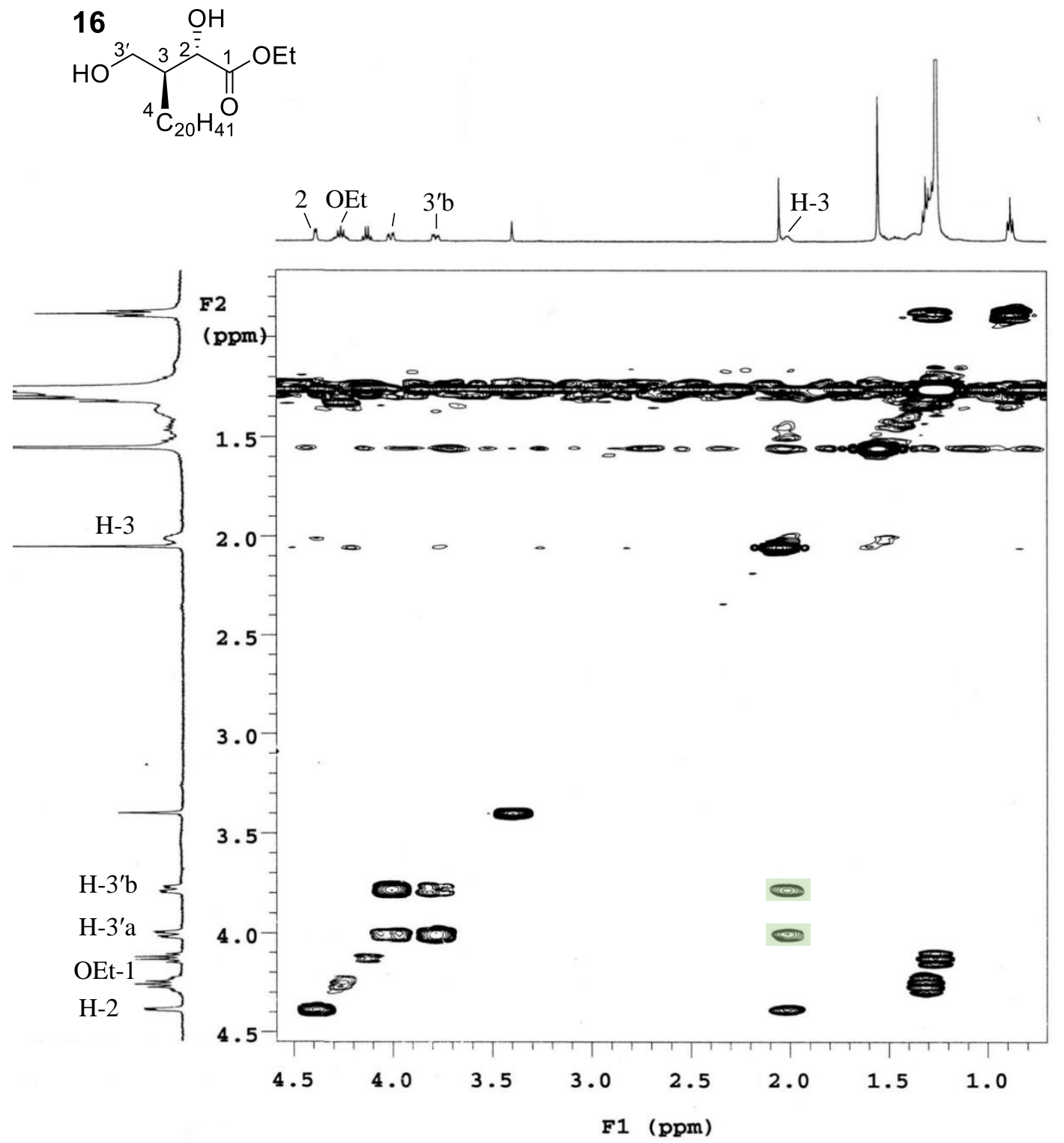

Figure 14: COSY of (2S,3S)-Ethyl 2-hydroxy-3-(hydroxymethyl)tricosanoate 16

It was proposed that the long reaction time combined with the high $\mathrm{pH}$ of the reaction mixture could have led to the formation of $\mathbf{1 6}$ in preference to $\mathbf{1 5}$. During the reaction, 0.25 equiv. of $\mathrm{NaBH}_{4}$ were added rather than the catalytic amount required (0.05 eq.), which would have significantly increased the basicity of the solution. The increased $\mathrm{pH}$ may have resulted in degradation of the starting material, or the desired product if it formed. The presence of several products as gauged by TLC analysis of the reaction mixture also supports this hypothesis, though characterisation of each compound would be necessary to determine the mechanisms by which such degradation occurred. One proposed mechanism is that under basic conditions the desired product breaks down via 
a retro-aldol reaction, in which base-mediated decomposition forms a fatty acid ester and an alkoxy enolate (Scheme 8). Accordingly, only diol 16 would remain under very basic conditions. Alternatively, it is also possible that the C20 lipid chain, which is thirteen carbon atoms longer than that used previously by Khan et al., ${ }^{85}$ may alter the relative stabilities of the 5- and 6-membered transition states, thereby reducing the energy difference between them, and thus allowing the formation of 16. Finally, it should be noted that this reduction was performed with $10 \mathrm{M} \mathrm{BMS}$, rather than the previously reported $2 \mathrm{M}$ solution, and consequently, the more concentrated reaction mixture may have played a role in the reduced selectivity of this reaction.

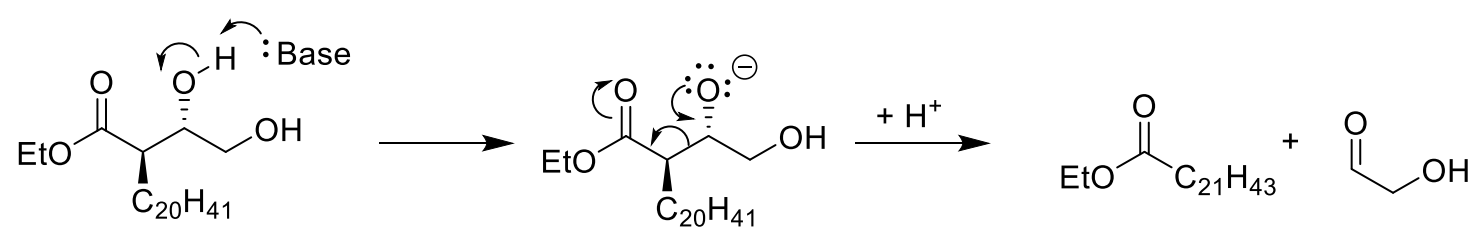
15

Scheme 8: Proposed retro-aldol decomposition to account for the absence of product $\mathbf{1 5}$ when the reaction was performed under basic conditions

As the initial attempt at the selective borane-mediated reduction of the diester to form the 1,2-diol 15 was unsuccessful, a thorough optimisation of the experimental procedure was undertaken in order to affect the desired transformation. As summarised (Table 1, page 42), additional $\mathrm{NaBH}_{4}(0.25$ equiv.) lead to the formation of the 1,3-diol 16 only (entry 1), and while this undesired product was not isolated in subsequent reactions, the cyclised product (17) of this 1,3-diol, along with unreacted starting material, were often observed. Accordingly, due to the complex mixture of products formed, in each experiment the crude product mixture was purified by silica gel flash chromatography so that structures could be assigned and yields attained.

The structure of the cyclisation product 17 was determined by ${ }^{1} \mathrm{H}$ NMR spectroscopy and COSY correlations, while ${ }^{13} \mathrm{C}$ NMR 2D data and HRMS confirmed these assignments (HRMS calcd. for $\left[\mathrm{C}_{24} \mathrm{H}_{46} \mathrm{O}_{3}+\mathrm{NH}_{4}\right]^{+}: 400.3785$, obsd.: 400.3767). In the ${ }^{1} \mathrm{H} \mathrm{NMR}$ spectra of 17 , the lack of the methylene signal of the ethyl ester at $4.20 \mathrm{ppm}$ indicated that the product no longer contained an ethyl ester (Figure 15), however, the H-2 proton signals appeared relatively down-field $(\delta 4.47)$ indicative of its location next to a carbonyl. 
Protons $\mathrm{H}-3^{\prime} \mathrm{a}$ and $\mathrm{H}-3^{\prime} \mathrm{b}$ show the characteristic splitting patterns of geminal protons adjacent to a chiral centre $\left(\delta 4.30, \mathrm{dd}, J_{3^{\prime} \mathrm{a}, 3^{\prime} \mathrm{b}}=9.4 \mathrm{~Hz}, J_{3^{\prime} \mathrm{a}, 3}=5.5 \mathrm{~Hz}\right.$, and $\delta 4.19$, dd, $J_{3^{\prime} \mathrm{a}, 3^{\prime} \mathrm{b}}$ $\left.=9.4 \mathrm{~Hz}, J_{3^{\prime} \mathrm{b}, 3}=2.5 \mathrm{~Hz}\right)$, and these protons have COSY correlations to H-3 $(\delta 2.57)$ but not H-2 ( $\delta$ 4.47) (Figure 16), confirming that this is a product of C-3'-ethoxy ester reduction, rather than the desired reduction of the $\mathrm{C}-1$ ethoxy ester. Indeed, the formation of the cyclic product $\mathbf{1 7}$ can be readily explained by deprotonation of the primary hydroxyl and subsequent attack of the alkoxide onto the electrophilic carbonyl centre (Scheme 9). Reformation of the carbonyl double bond then results in the elimination of the ethoxy group, forming the 5-membered lactone 17. As lactone 17 was typically isolated, and not diol 16, it is unusual that $\mathbf{1 6}$ was in fact isolated under the experimental conditions initially employed. This observation suggests that the high concentration of $\mathrm{NaBH}_{4}$ used in the initial reaction (entry 1, Table 1) may have stabilised the borane chelate transition state, thereby preventing it from breaking down after reduction to the diol 16, and consequently, preventing cyclisation to 17.

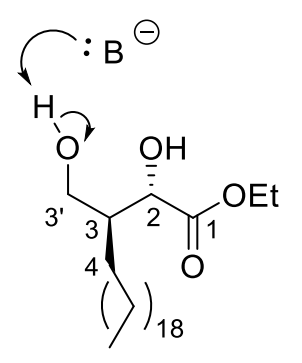

16
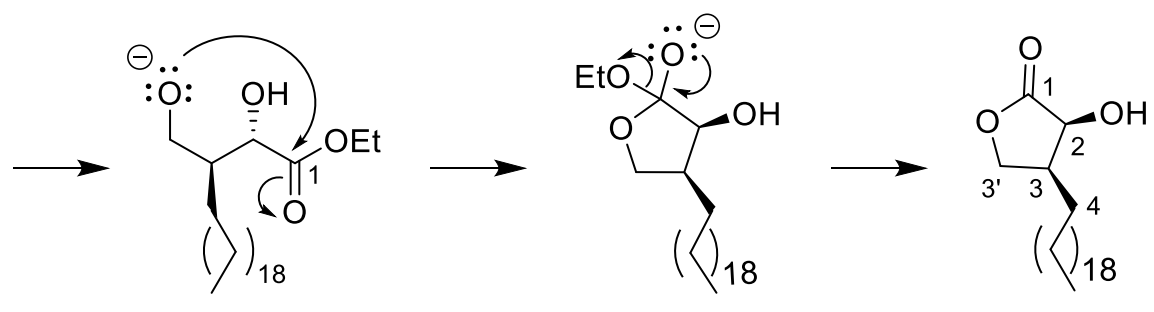

17

Scheme 9: Formation of lactone 17 
${ }^{1} \mathrm{H}$ NMR (500 MHz, $\left.\mathrm{CDCl}_{3}\right)$
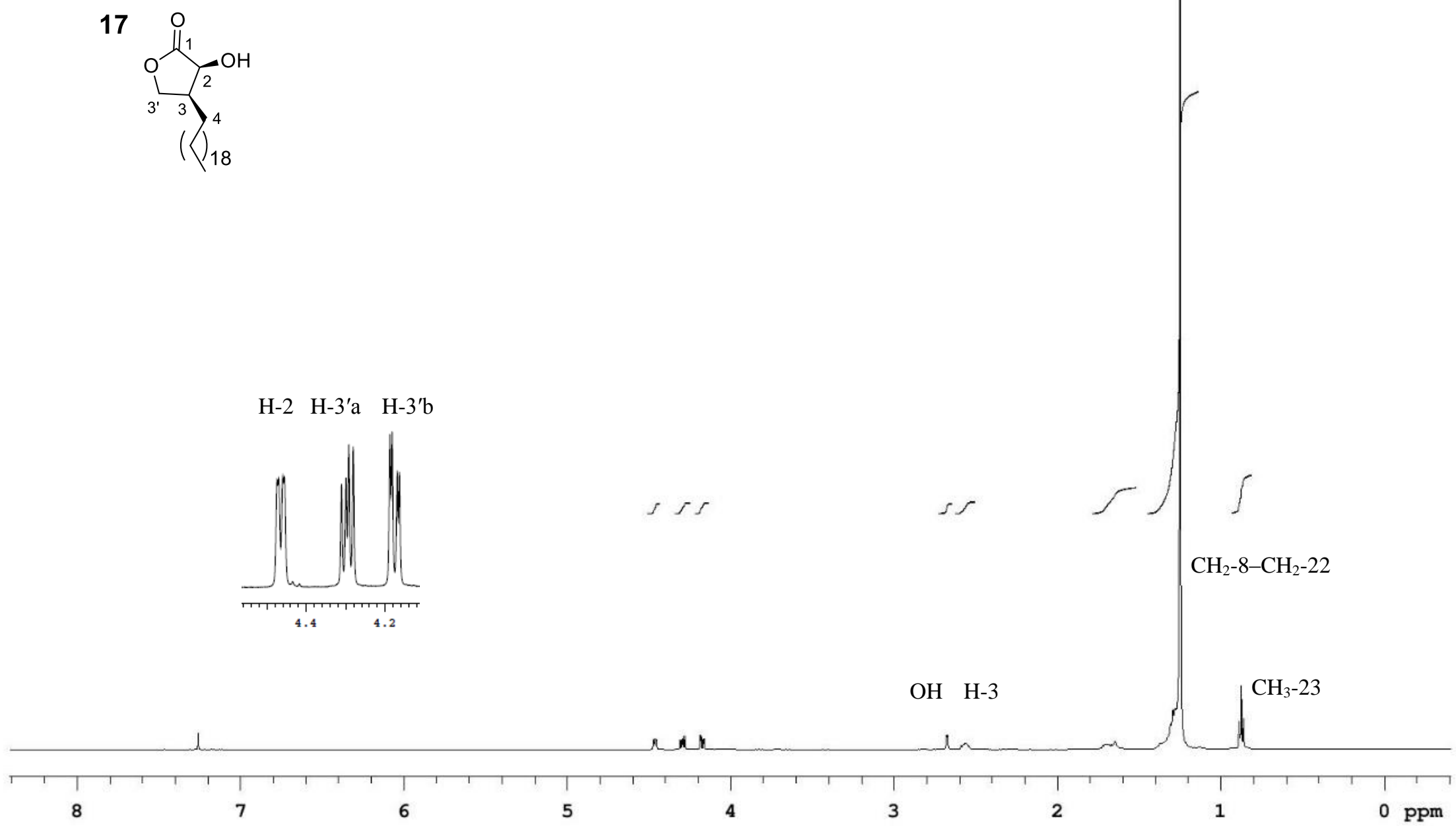

Figure 15: ${ }^{1} \mathrm{H}$ NMR spectrum of lactone 17 


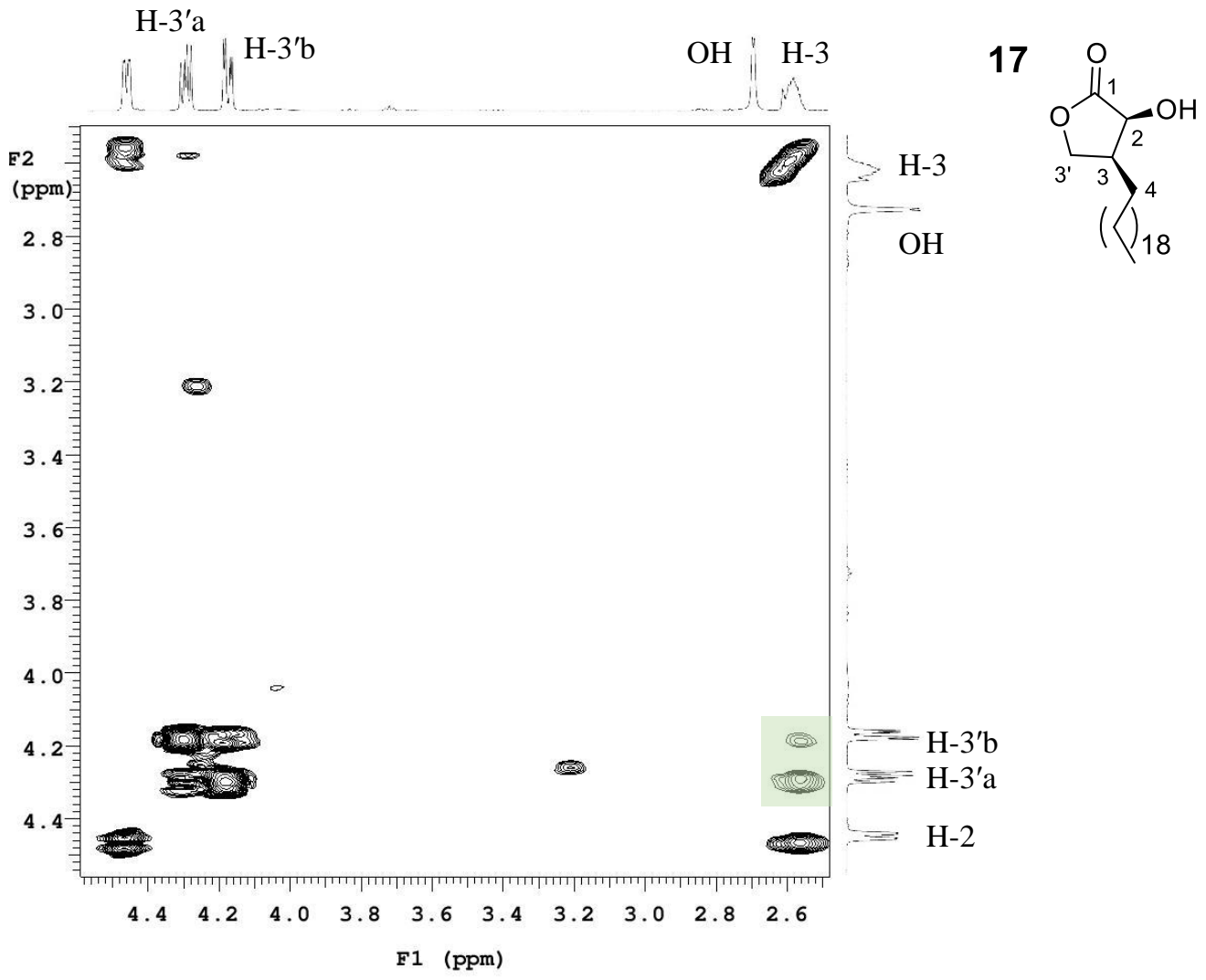

Figure 16: COSY of lactone 17 
Table 1: Borane-mediated reduction of diester 14

\begin{tabular}{|c|c|c|c|c|c|}
\hline O & 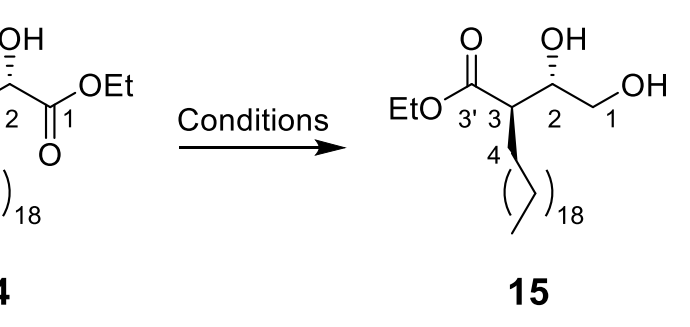 & + & $\prod_{18}$ & & \\
\hline \multirow[t]{2}{*}{ Entry } & \multirow[t]{2}{*}{ Conditions } & \multicolumn{4}{|c|}{ Yield (\%) } \\
\hline & & 14 & 15 & 16 & 17 \\
\hline 1 & $\begin{array}{l}\text { BMS (1.5 eq., } 10 \mathrm{M}), 0{ }^{\circ} \mathrm{C}-\text { r.t., } 22 \mathrm{~h} \\
\mathrm{NaBH}_{4}(0.25 \text { eq. }) \text {, r.t., } 25 \mathrm{~h} \\
\text { THF }\end{array}$ & - & - & 23 & - \\
\hline 2 & $\begin{array}{l}\text { BMS ( } 1.5 \text { eq., } 2 \mathrm{M}), 0{ }^{\circ} \mathrm{C}-\text { r.t., } 18 \mathrm{~h} \\
\mathrm{NaBH}_{4}(0.05 \text { eq. }) \text {, r.t., } 7 \mathrm{~h} \\
\text { THF }\end{array}$ & 73 & - & - & $<5$ \\
\hline 3 & $\begin{array}{l}\text { BMS }(1.5 \text { eq., } 2 \mathrm{M}), 0{ }^{\circ} \mathrm{C}-\text { r.t., } 4 \mathrm{~d} \\
\mathrm{NaBH}_{4}(0.05 \text { eq. }), 0{ }^{\circ} \mathrm{C}-\text { r.t., } 2 \mathrm{~d} \\
\mathrm{THF}\end{array}$ & 34 & 15 & - & 16 \\
\hline 4 & $\begin{array}{l}\text { BMS }(1.5 \text { eq., } 2 \mathrm{M}), 0{ }^{\circ} \mathrm{C}-\text { r.t., } 1.5 \mathrm{~h} \\
\mathrm{NaBH}_{4}(0.10 \text { eq. }), 0{ }^{\circ} \mathrm{C}-\text { r.t., } 4 \mathrm{~d} \\
\text { THF }\end{array}$ & 37 & 18 & - & 21 \\
\hline 5 & $\begin{array}{l}\text { BMS (3.0 eq., } 2 \mathrm{M}), 0{ }^{\circ} \mathrm{C}-35^{\circ} \mathrm{C}, 1.5 \mathrm{~h} \\
\mathrm{NaBH}_{4}\left(0.05 \text { eq.), } 0{ }^{\circ} \mathrm{C}-\text { r.t., } 2 \mathrm{~h}\right. \\
\text { THF/toluene ( } 1: 1)\end{array}$ & - & 37 & - & 30 \\
\hline 6 & $\begin{array}{l}\mathrm{BMS}^{\dagger}(3.0 \text { eq., } 2 \mathrm{M}), 0{ }^{\circ} \mathrm{C}-40{ }^{\circ} \mathrm{C}, 1.5 \mathrm{~h} \\
\mathrm{NaBH}_{4}(0.05 \text { eq. }), 0{ }^{\circ} \mathrm{C}-\text { r.t., } 4 \mathrm{~h} \\
\text { THF/toluene ( } 1: 1)\end{array}$ & - & 13 & - & - \\
\hline 7 & $\begin{array}{l}\mathrm{BMS}^{*}(1.2 \mathrm{eq}), 0{ }^{\circ} \mathrm{C}, 1 \mathrm{~h} \\
\mathrm{NaBH}_{4}(0.05 \text { eq. }), 0{ }^{\circ} \mathrm{C}-\text { r.t., } 5 \mathrm{~h} \\
\text { THF/toluene }(1: 1)\end{array}$ & - & 63 & - & - \\
\hline 8 & $\begin{array}{l}\mathrm{BMS}^{*}(1.2 \text { eq }), 0{ }^{\circ} \mathrm{C}, 1.5 \mathrm{~h} \\
\mathrm{NaBH}_{4}(0.05 \text { eq. }), 0{ }^{\circ} \mathrm{C}-\text { r.t., } 15 \mathrm{~h} \\
\text { THF/toluene }(1: 1)\end{array}$ & - & 87 & - & - \\
\hline 9 & $\begin{array}{l}\mathrm{BMS} \text { (1.2 eq.), } 0{ }^{\circ} \mathrm{C}, 1 \mathrm{~h} \\
\mathrm{NaBH}_{4}(0.05 \text { eq. }), 0^{\circ} \mathrm{C}-\text { r.t., } 22 \mathrm{~h} \\
\text { THF/toluene }(1: 1)\end{array}$ & 31 & 40 & - & - \\
\hline
\end{tabular}

${ }^{\ddagger}$ Distilled BMS

*New reagent, not in solution 
In light of the initial results, it was proposed that using fewer equiv. of $\mathrm{NaBH}_{4}$ would promote the formation of the thermodynamic 5-membered borane chelate, and thus the desired 1,2-diol 15. To this end, $\alpha$-alkyl ester 14 was stirred with BMS complex (2 M in THF, 1.5 equiv.) for 18 hours, followed by the addition of 0.05 equiv. of $\mathrm{NaBH}_{4}$ (entry 2, Table 1), however, under these conditions, predominantly starting material 14 was isolated (73\%). In an attempt to facilitate the reaction, the reaction time for both the formation of the boron chelate, and subsequent reduction with $\mathrm{NaBH}_{4}$, were then extended (entry 3). Here, diester 14 was stirred with BMS for four days before the addition of $\mathrm{NaBH}_{4}$ at $0{ }^{\circ} \mathrm{C}$, after which the reaction was warmed to room temperature, as per literature procedures, ${ }^{85}$ and stirred for an additional two days. These conditions lead to the formation of the desired 1,2-diol 15 in a low (15\%) yield, along with comparable amounts of lactone $17(16 \%)$ and a $34 \%$ recovery of the starting ester. This result suggested that while longer reaction times after the addition of the reducing agent increases reaction yields, the extended reaction time for the formation of the boronchelate does not appear to favour formation of the 5-membered chelate over the 6memberd chelate. Accordingly, the reaction was repeated with the addition of BMS (1.5 equiv., 2 M) 1.5 hours prior to the addition of $\mathrm{NaBH}_{4}(0.10$ equiv, entry 4$)$, and while these conditions led to a slight increase in reaction yield, overall the result was comparable with low yields of diol 15 (18\%) and lactone 17 (21\%), and considerable amounts of starting material $14(37 \%)$ being isolated.

At this stage, careful analysis of the reaction conditions revealed the presence of a white, gel-like suspension which formed prior to the addition of the reducing agent. This was thought to be some type of undesired borane-THF complex, which could have been limiting the reaction yield. Furthermore, the formation of both $\mathbf{1 5}$ and $\mathbf{1 7}$ was detected by TLC analysis before addition of $\mathrm{NaBH}_{4}$, indicating that the BMS reagent was not chelating to the diester starting material $\mathbf{1 4}$ in the desired way, but was instead causing reduction of the starting material in a non-selective manner. Thus, subsequent reactions were performed using a THF/toluene mixed solvent system, which reduced the formation of the gel-like suspension, the number of equivalents of BMS were increased to 3.0 equiv., and the reactions were warmed after the addition of BMS in an attempt to drive the reaction to completion (entries 5-6). Accordingly, diester 14 in THF/toluene was reacted with excess BMS for $1.5 \mathrm{~h}$, with warming of the initial solution from $0{ }^{\circ} \mathrm{C}$ to 35 ${ }^{\circ} \mathrm{C}$, followed by the addition of $\mathrm{NaBH}_{4}$ at $0{ }^{\circ} \mathrm{C}$ (entry 5). Indeed, these conditions led to 
the complete consumption of starting material, and while the yield of the desired diol $\mathbf{1 5}$ was improved (37\% yield), a 30\% yield of the lactone $\mathbf{1 7}$ was also obtained.

With the quality of the BMS in question, attempts were then made to purify this reagent via Kugelrohr distillation, and the reaction was repeated using similar conditions to those used in entry 5. Indeed, using the distilled BMS, only the desired diol 15 was obtained, however, this was in a very poor (13\%) yield (entry 6). As the quality of the BMS appeared to significantly influence the reaction yields and regioselectivity, new reagent was purchased and the reactions repeated (entries 7-8). Here, formation of the borane chelate was undertaken at $0{ }^{\circ} \mathrm{C}$ without warming to room temperature, and the amount of BMS was reduced to 1.2 equiv. due to the anticipated enhanced reactivity of the new, more concentrated reagent. Accordingly, diester 14 was treated with fresh BMS (1.2 equiv.) and the solution stirred at $0{ }^{\circ} \mathrm{C}$ for $1 \mathrm{~h}$ prior to the addition of $\mathrm{NaBH}_{4}$ (entry 7). Gratifyingly, this resulted in diol $\mathbf{1 5}$ being isolated in a 63\% yield as the sole product. Increasing the reaction times for both chelate formation (from $1 \mathrm{~h}$ to $1.5 \mathrm{~h}$ ) and reduction (from $5 \mathrm{~h}$ to $15 \mathrm{~h}$ ), allowed for the formation of diol $\mathbf{1 5}$ in a very satisfying $87 \%$ yield. However, we noticed that the success of the reaction decreased over time from when the bott; e of BMS reagent was first opened, with degradation of the reagent occurring very quickly even when stored at $4{ }^{\circ} \mathrm{C}$ under an atmosphere of argon, as evidenced by a drop in yield of ca. $40 \%$ for reactions performed 4 days later (entries 8 and 9). Taken as a whole, the above results thus outline the fickle nature of this selective reduction when using lipophilic diesters and highlight the importance of using boron reagents of the highest quality.

With the desired 1,2-diol 15 in hand, tosylation of the primary hydroxyl was then undertaken (Table 2). Initially, $\mathrm{Bu}_{2} \mathrm{SnO}$ and $\mathrm{Et}_{3} \mathrm{~N}$ were added to a solution of the 1,2-diol 15 in DCM, followed by the addition of tosyl chloride ( $\mathrm{TsCl}$ ). The Sn-catalyst was added in order to mediate the selective tosylation of the primary hydroxyl, through the formation of a Sn-ketal. ${ }^{88}$ Indeed, these conditions led to the formation of the desired primary tosylate 18, albeit in average (38\%) yield (entry 1). 
Table 2: Tosylation of diol 15

\begin{tabular}{c|lccccc}
\hline & & & \\
\end{tabular}

Due to the modest reaction yield and the difficulties in removing the $\mathrm{Bu}_{2} \mathrm{SnO}$ by-products from the reaction mixture, the need for the Sn catalyst was investigated. To this end, the reaction was performed in the absence of $\mathrm{Bu}_{2} \mathrm{SnO}$ and by increasing the reaction time to 17 hours (entry 2), this led to an improved (56\%) yield of the desired product with no over-tosylation to form 19 being observed. In light of this result, it was postulated that the presence of a long lipid at the $\alpha$-position introduces steric hindrance, which resulted in the primary $\gamma$-hydroxyl being much more accessible to tosylation than the secondary $\beta$-hydroxyl.

With the use of the Sn catalyst deemed unnecessary, a more standard tosylation method was then employed (entries 3-8). ${ }^{89}$ Here, pyridine was used as both the solvent and the base. Initially, 1.2 equiv. of $\mathrm{TsCl}$ and a relatively short reaction time ( $6 \mathrm{~h}$ ) were used (entry 3), however a significant amount of starting material 15 (23\%) was recovered. Increasing the reaction time to $38 \mathrm{~h}$ (entry 4) improved the yield of $\mathbf{1 8}(55 \%)$, however, increasing the amount of $\mathrm{TsCl}$ from 1.4 to 2.8 equiv. (entry 5) saw the formation of large amounts of the di-tosylated adduct 19 (29\%). In light of these results, the reaction time 
was decreased while excess $\mathrm{TsCl}$ was used. Accordingly, 3 equiv. of $\mathrm{TsCl}$ were added, and the reaction stirred for 3 hours before quenching (entry 6). These conditions resulted in a good yield of 18 (70\%) and only minor amounts of 19 (ca. 5\%), as well as the recovery of starting material (15\%). By extending the reaction time to 6 hours, the desired product 18 was obtained in good yield $(73 \%)$ with a small amount of starting material and minor amounts of the di-tosylated product isolated (entry 7). These results suggest that a large amount of $\mathrm{TsCl}$ is required to push the reaction to completion, while a short reaction time is key to preventing over-tosylation.

In the desired primary tosylate $\mathbf{1 8}$, protons $\mathrm{H}-1 \mathrm{a}$ and $\mathrm{H}-1 \mathrm{~b}$ appeared as a multiplet $(\delta 4.05)$ in the ${ }^{1} \mathrm{H}$ NMR spectrum and showed COSY correlations with $\mathrm{H}-2$ at $3.90 \mathrm{ppm}$. These protons were shifted down-field relative to $\mathrm{H}-1 \mathrm{a}$ and $\mathrm{H}-1 \mathrm{~b}$ in the diol starting material $(\delta$ 3.70 and 3.54 ) as anticipated. In the ${ }^{13} \mathrm{C}$ NMR spectrum of $\mathbf{1 8}$, aside from the carbonyl, C-1 was the most down-field of the non-aromatic carbons, appearing at $71.6 \mathrm{ppm}$, while the observed HRMS $\left[\mathrm{C}_{33} \mathrm{H}_{58} \mathrm{O}_{6} \mathrm{~S}+\mathrm{Na}\right]^{+}: 605.3848$ corresponded to that of the calculated mass (605.3846) for this product.

For the di-tosylated product 19, however, the $\mathrm{H}-2$ proton had a downfield chemical shift $(\delta 4.84)$ in the ${ }^{1} \mathrm{H}$ NMR spectrum, as expected when the oxymethine is substituted with a tosyl group, and H-2 also showed COSY correlations into $\mathrm{H}-1 \mathrm{a}, \mathrm{H}-1 \mathrm{~b}$ and $\mathrm{H}-3$. H-1a and $\mathrm{H}-1 \mathrm{~b}$ show typical $\mathrm{ABX}$ coupling patterns $\left(\delta 4.29\right.$, dd, $J_{1 \mathrm{a}, 1 \mathrm{~b}}=11.3 \mathrm{~Hz}, J_{1 \mathrm{a}, 3}=3.3 \mathrm{~Hz}$ and $\delta 4.13, \mathrm{dd}, J_{1 \mathrm{a}, 1 \mathrm{~b}}=11.3 \mathrm{~Hz}, J_{1 \mathrm{a}, 3}=4.8 \mathrm{~Hz}$ ), and the tosyl protons have the expected integrations of the di-tosylated product, while HRMS confirmed the presence of two tosyl groups (HRMS calcd. for $\left[\mathrm{C}_{33} \mathrm{H}_{58} \mathrm{O}_{6} \mathrm{~S}+\mathrm{NH}_{4}\right]^{+}:$754.4381, obsd.: 754.4381).

Having optimised the yield for the synthesis of tosylate 18, this was then subjected to base-mediated cyclisation with $\mathrm{K}_{2} \mathrm{CO}_{3}$ in methanol (Table 3). Initially, the reaction was performed at room temperature, and while the desired epoxide $\mathbf{5}$ was formed in reasonable (69\%) yield, elimination product 20 was also observed (entry 1, Table 3). 
Table 3: Formation of epoxide 5

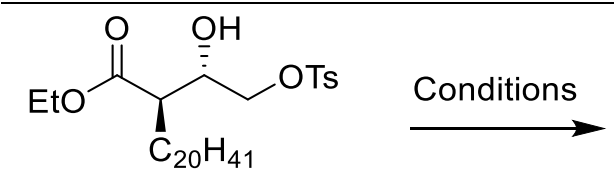

18<smiles>CCOC(=O)C(CC)C1CO1</smiles>

5<smiles>CCOC(=O)/C(=C/CO)CC</smiles>

20

\begin{tabular}{c|lcccc}
\hline Entry & Conditions & Temp. & Time & \multicolumn{2}{c}{ Yield (\%) } \\
& & $\left({ }^{\circ} \mathbf{C}\right)$ & $(\mathbf{h})$ & $\mathbf{5}$ & $\mathbf{2 0}$ \\
\hline $\mathbf{1}$ & $\mathrm{K}_{2} \mathrm{CO}_{3}(1.2$ eq. $), \mathrm{MeOH}$ & r.t. & 3.5 & 69 & ca. 15 \\
$\mathbf{2}$ & $\mathrm{KHCO}_{3}(1.2 \mathrm{eq}), \mathrm{EtOH}$ & $0-$ r.t. & 4 & & \\
& then $\mathrm{K}_{2} \mathrm{CO}_{3}(0.9$ eq. $), \mathrm{MeOH}$ & r.t. -35 & 3 & 54 & - \\
$\mathbf{4}$ & $\mathrm{K}_{2} \mathrm{CO}_{3} / \mathrm{MeOH}(10 \mathrm{mg} / \mathrm{mL}, 0.9$ eq. $)$ & 40 & 21 & - & ca. 90 \\
$\mathbf{5}$ & $\mathrm{K}_{2} \mathrm{CO}_{3} / \mathrm{MeOH}(10 \mathrm{mg} / \mathrm{mL}, 1.0$ eq. $)$ & 0 & 3 & 80 & - \\
& $\mathrm{K}_{2} \mathrm{CO}_{3} / \mathrm{MeOH}(10 \mathrm{mg} / \mathrm{mL}, 1.0$ eq. $)$ & $-10-0$ & 7 & 87 & -
\end{tabular}

It is thought that the elimination product is formed from epoxide $\mathbf{5}$ via an E1cB reaction as illustrated (Scheme 10). The formation of allylic alcohol $\mathbf{2 0}$ was confirmed by HRMS (calcd. for $\left[\mathrm{C}_{26} \mathrm{H}_{50} \mathrm{O}_{3}+\mathrm{H}\right]^{+}:$411.3833, obsd.: 411.3818), and ${ }^{1} \mathrm{H}$ NMR analysis, in which H-2 appeared as a triplet with a downfield shift to $6.80 \mathrm{ppm}\left(J_{2,1 \mathrm{ab}}=6.2 \mathrm{~Hz}\right)$, as expected for the vinyl proton, while $\mathrm{H}-1 \mathrm{a}$ and $\mathrm{H}-1 \mathrm{~b}$ appear as a doublet at $4.36 \mathrm{ppm}$.

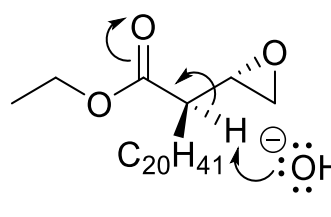

5

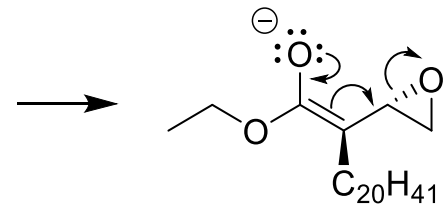<smiles>CCCC(=CCO)C(=O)OCC</smiles>

20

Scheme 10: Elimination of epoxide 5 to give allylic alcohol 20

In an attempt to limit the formation of allylic alcohol 20, less basic conditions were employed via the use of $\mathrm{KHCO}_{3}$ (1.2 equiv.) in ethanol, however no product was formed until additional $\mathrm{K}_{2} \mathrm{CO}_{3}$ (0.9 equiv.) and methanol were added. It was also necessary to warm the reaction mixture to $35{ }^{\circ} \mathrm{C}$ in order for the $\mathrm{K}_{2} \mathrm{CO}_{3}$ to dissolve, which gave a $54 \%$ yield of epoxide 5 (entry 2). Having noted the low solubility of $\mathrm{K}_{2} \mathrm{CO}_{3}$ in ethanol, a stock solution of $\mathrm{K}_{2} \mathrm{CO}_{3} / \mathrm{MeOH}(10 \mathrm{mg} / \mathrm{mL})$ was prepared and the reaction repeated at $40{ }^{\circ} \mathrm{C}$ 
(0.9 eq. $\mathrm{K}_{2} \mathrm{CO}_{3} / \mathrm{MeOH}, 21 \mathrm{~h}$ ) (entry 3). Unfortunately, the increased basicity of the reaction mixture, as well as the increased temperature, resulted in the exclusive formation of allylic alcohol 20. As it is well known that increased temperatures favour elimination reactions, the reaction was repeated at $0{ }^{\circ} \mathrm{C}\left(1.0\right.$ equiv. $\left.\mathrm{K}_{2} \mathrm{CO}_{3} / \mathrm{MeOH}, 3 \mathrm{~h}\right)$, which resulted in a respectable $80 \%$ yield of the desired epoxide (entry 4), and by further reducing the temperature $\left(-10-0{ }^{\circ} \mathrm{C}, 7 \mathrm{~h}\right)$, the yield of the epoxide 5 was improved to an excellent $87 \%$ (entry 5).

\subsubsection{Synthesis of Mycolic Acid 3a}

With the synthesis of the key epoxide 5 completed, this building block was then further modified to allow for the preparation of the required mycolic acid 3a. To this end, epoxide 5 was subjected to palladium catalysed hydrogenation, which gave the secondary alcohol 21 in quantitative yield (Scheme 11).

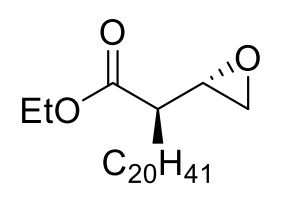

5

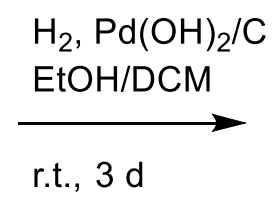

quant.<smiles>CCCCC(C(=O)OCC)C(C)O</smiles>

21

Scheme 11: Hydrogenation of epoxide 5 to give secondary alcohol 21

The excellent regioselectivity of the reduction of epoxide $\mathbf{5}$ can be explained by considering the steric availability of the epoxide for hydrogenation at the terminal position versus the secondary position. As illustrated in Figure 17, Pd coordinates to the oxygen and terminal carbon of the epoxide, with the hydrogen atoms associated with the $\mathrm{Pd}$ then being transferred to the epoxide generating the regioselectively hydrogenated product, $\beta$-hydroxy ester 21. 

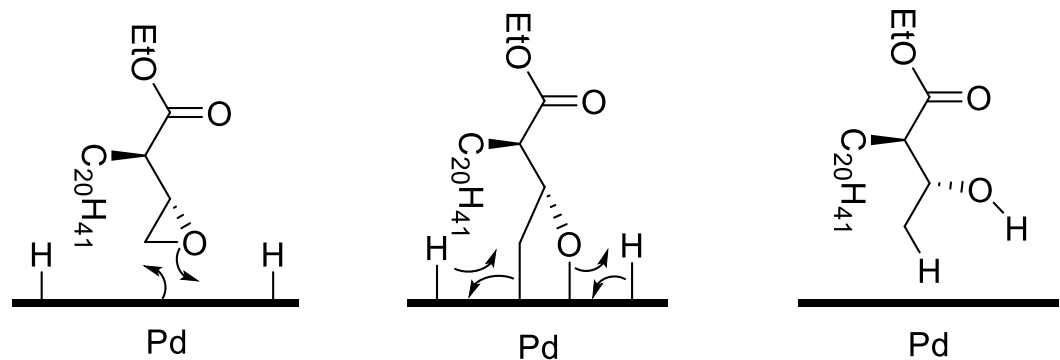

Figure 17: $\mathrm{Pd}(\mathrm{OH})_{2}$ catalysed hydrogenation of epoxide 5

After hydrogenation, hydrolysis of the ethyl ester using $\mathrm{LiOH}^{90}$ to give carboxylic acid 22 proceeded in excellent (92\%) yield (Scheme 12). Carboxylic acid 22 was then subjected to reaction with tert-butyldimethylsilyl trifluoromethanesulfonate (TBSOTf) and 2,6-lutidine, as per literature procedures, ${ }^{91}$ to give the bis-silylated product 23 . Subsequent treatment of $\mathbf{2 3}$ with $\mathrm{K}_{2} \mathrm{CO}_{3} / \mathrm{MeOH}$ gave the desired TBS protected mycolic acid 3a, in a $67 \%$ yield over two steps. Installation of the TBS protecting group on the secondary hydroxyl was carried out via this two-step procedure, as although the $\beta$ hydroxy ester $\mathbf{2 1}$ can be successfully protected with a TBS functionality, successive hydrolysis of the ethyl ester does not proceed in a chemo-selective manner, resulting in cleavage of the TBS group to give carboxylic acid 22.<smiles>CCOC(=O)C(CC)C(C)O</smiles>

21<smiles>CCCCCC(C)C(CCCC)C(=O)O</smiles>

$3 a$

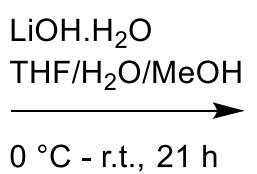
$92 \%$

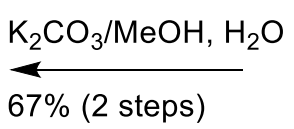
$67 \%$ (2 steps)<smiles>CCCC(C)C(O)C(=O)O</smiles>

22
TBSOTf, 2,6-lutidine DCM, r.t., $54 \mathrm{~h}$<smiles>CCCCC(C)C(OCCC)C(=O)O[Mg]</smiles>

23

Scheme 12: Preparation of target mycolic acid 3a

Here, the TBS ether was chosen to protect the $\mathrm{OH}$ functionality as it is both stable under coupling conditions with trehalose, and yet can be cleaved under global deprotection conditions with HF•pyridine without the risk of hydrolysing the mycolic acid ester. ${ }^{2}$ 
Alternatively, installation of a TMS group at this position is plausible, to give a fully TMS-protected final target which could be globally deprotected under relatively mild acidic conditions using Dowex $-\mathrm{H}^{+},{ }^{73}, 91$ However, the more labile TMS ether may not be stable under workup and coupling conditions, and in the interest of time this strategy was not investigated.

\subsubsection{Synthesis of Mycolic Acid $3 b$}

Mycolic acid target 3b was prepared from $\beta$-hydroxy ester 21. To this end, alcohol 21 was first subjected to Purdie methylation conditions, ${ }^{92-93}$ which utilise MeI and $\mathrm{Ag}_{2} \mathrm{O}$. The $\mathrm{Ag}_{2} \mathrm{O}$ was freshly prepared from $\mathrm{AgNO}_{3}$ and $\mathrm{NaOH},{ }^{94}$ and added to a solution of MeI and alcohol 21 in THF. The reaction mixture was then stirred at r.t. and when no reaction was observed by TLC analysis after 3.5 hours, further portions of MeI (total 16 equiv.) and $\mathrm{Ag}_{2} \mathrm{O}$ (total 4.5 equiv.) were added over the course of two days. However, as no product formation had occurred after this time, the reaction mixture was then quenched and resubmitted, this time using MeI as the solvent, and a total of 9 equiv. of $\mathrm{Ag}_{2} \mathrm{O}$ added over five days. These conditions resulted in an acceptable 58\% isolated yield of the desired product 24 (Scheme 13).

It was then postulated that the reaction yield could be improved further by employing the conditions developed by Barroso et al., which were used to methylate the hydroxyl group of a short lipid. ${ }^{95}$ Thus, a total of 12 equiv. of $\mathrm{NaH}$ were added gradually to a solution of alcohol 21 in $\mathrm{MeI}$ and the resulting mixture stirred at r.t. overnight. Following purification by silica gel column chromatography, this led to a $49 \%$ yield of the desired methyl ether as a 5:2 mixture of ethyl ester $\mathbf{2 4}$ and the corresponding methyl ester $\mathbf{2 5}$, which is formed through the conversion of the ethyl ester into a methyl ester and probably occurred upon quenching the reaction with methanol. The methyl ester was identified by a singlet at $3.69 \mathrm{ppm}$ in the ${ }^{1} \mathrm{H}$ NMR spectra and confirmed by HRMS (calcd. for $\left[\mathrm{C}_{26} \mathrm{H}_{52} \mathrm{O}_{3}+\mathrm{H}\right]^{+}:$413.3989; obsd.: 413.4061), and as the next synthetic step was hydrolysis of the ester functionality, conversion to the methyl ester was not an issue. Further optimisation of the methylation reaction was then undertaken, whereby 15 equiv. of $\mathrm{NaH}$ were added to a solution of $\mathbf{2 1}$ in $\mathrm{MeI}$ and the reaction stirred at room temperature for $24 \mathrm{~h}$. Gratifyingly, this resulted in an excellent $87 \%$ yield of the methyl ether, as a 5:1 mixture of $\mathbf{2 4}$ and $\mathbf{2 5}$ (Scheme 13). 
<smiles>CCOC(=O)C(CC)C(C)O</smiles>

21
Mel, $\mathrm{Ag}_{2} \mathrm{O}$, r.t., $5 \mathrm{~d}$
$58 \%(1: 0, \mathbf{2 4 / 2 5})$
$\stackrel{\text { or, }}{\longrightarrow}$
Mel, $\mathrm{NaH}$, r.t., $24 \mathrm{~h}$

$87 \%(5: 1,24 / 25)$<smiles>CCCC(C(=O)OCC)C(C)OC</smiles>

24<smiles>CCCC(C(=O)OC)[C@@H](C)OC</smiles>

25

Scheme 13: Methylation of $\beta$-hydroxy ester 21

With the methylated lipids $\mathbf{2 4}$ and $\mathbf{2 5}$ in hand, hydrolysis of the ester to render target mycolic acid 3b was attempted. Here, the methyl ether product mixture (24/25) was subjected to hydrolysis conditions with $\mathrm{LiOH}$ in the same manner as was used for the hydrolysis of $\beta$-hydroxy ester $\mathbf{2 1}$, en route to the formation of mycolic acid $\mathbf{3 a}$. For the synthesis of mycolic acid $\mathbf{3 b}$, however, such hydrolysis conditions proved unsuitable and even after the addition of 18 equiv. of $\mathrm{LiOH} / \mathrm{H}_{2} \mathrm{O}(1 \mathrm{M})$, no product formation was observed. The reaction was then repeated at $40{ }^{\circ} \mathrm{C}$, with a total of 60 equiv. of solid $\mathrm{LiOH}$ added over 3 days, yet only negligible amounts of acid $\mathbf{3 b}$ were formed.

Though it is unclear why the $\mathrm{LiOH}$-mediated hydrolysis of the $\beta$-hydroxy ester $\mathbf{2 1}$ was successful when the hydrolysis of the $\beta$-methoxy ester $\mathbf{2 4 / 2 5}$ was not, it is possible that the enhanced reactivity of the hydroxyl derivative $\mathbf{2 1}$ may be due to intramolecular hydrogen bonding of the carbonyl oxygen with the hydroxyl proton, thus increasing the electrophilicity of the carbonyl carbon for nucleophilic attack (Scheme 14).

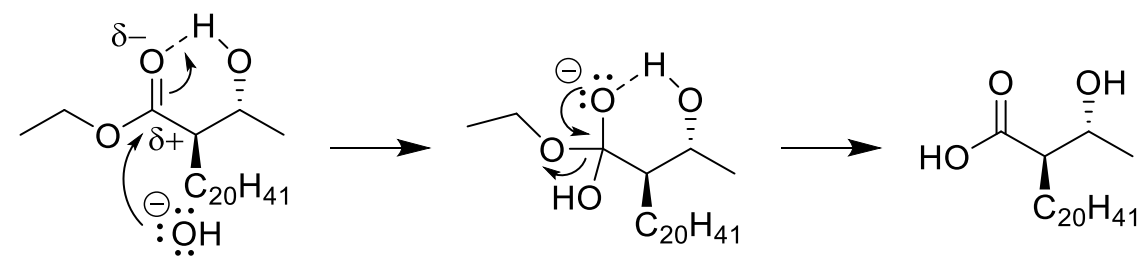

Scheme 14: Hydrolysis of $\beta$-hydroxy ester 21 may be enhanced by intramolecular hydrogen bonding, which makes the carbonyl centre more electrophilic.

Bearing this in mind, an alternative hydrolysis method utilising $\mathrm{LiCl}$ was then attempted. ${ }^{96-97}$ This reaction is carried out under dry conditions with the reaction proceeding via association of the $\mathrm{Li}^{+}$cation to the carbonyl oxygen, followed by attack of the $\mathrm{Cl}^{-}$anion at the ethyl ester (Scheme 15). Aqueous workup provides the carboxylic acid, while the ethyl chloride formed in this reaction is volatile. 


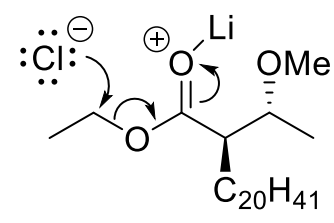

24<smiles>CCCC(C)[C@@H](CC)C(=O)O[AlH+]CCl</smiles><smiles>CCCC(C(=O)O)C(C)OC</smiles>

3b

Scheme 15: $\mathrm{LiCl}$ mediated hydrolysis to give mycolic acid derivative $\mathbf{3 b}$

Accordingly, the $\beta$-methoxy ester mixture 24/25 (4:1) was refluxed in pyridine for two days with the gradual addition of $\mathrm{LiCl}$. A total of 112 equiv. of $\mathrm{LiCl}$ were added over the course of this reaction, however no product formation was visible by TLC analysis. At this point, 20 equiv. of $\mathrm{LiOH} / \mathrm{H}_{2} \mathrm{O}$ were added and after refluxing for a further 4 hours, full conversion of the starting material was observed with the desired mycolic acid $\mathbf{3 b}$ obtained in a satisfactory $74 \%$ yield. Further optimisation of the reaction was then undertaken whereby $\beta$-methoxy esters $\mathbf{2 4 / 2 5}$ were refluxed in pyridine with $\mathrm{LiCl}$ (20 equiv.) and $\mathrm{LiOH}$ (20 equiv.) for 27 hours (Scheme 16). This resulted in a pleasing $80 \%$ yield of the desired mycolic acid $\mathbf{3 b}$, along with an elimination product (ca. 20\%), which could be separated by silica gel flash column chromatography.<smiles>CCCC(C(=O)OCC)C(C)OC</smiles>

24<smiles>CCCC(C(=O)OC)C(C)OC</smiles>

25

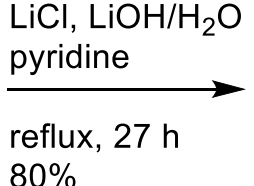

$80 \%$<smiles>CCCC(C(=O)O)C(C)OC</smiles>

3b

Scheme 16: Ester hydrolysis to render target mycolic acid $\mathbf{3 b}$

Although product formation was not observed under either the $\mathrm{LiCl}$ mediated reaction conditions or the $\mathrm{LiOH}$ conditions initially employed, the combination of these resulted in ester hydrolysis to give $\mathbf{3 b}$. It was postulated that the addition of $\mathrm{LiCl}$ could have enhanced the reaction rate, with the lithium cation associating with the two oxygen atoms to form an intermediate that increases the electrophilicity of the carbonyl centre, in much the same way as the hydrogen bond is thought to enhance the hydrolysis of $\beta$-hydroxy ester 21 (Scheme 14, page 51). However, to investigate whether the enhanced reactivity was due to temperature effects, the reaction was repeated without the addition of $\mathrm{LiCl}$. Accordingly, $\beta$-methoxy ester $\mathbf{2 4 / 2 5}$ was refluxed in pyridine with $\mathrm{LiOH}$ (10 equiv.) for 2 hours, after which time absence of starting material was observed by TLC analysis. ${ }^{1} \mathrm{H}$ 
NMR analysis of the crude reaction mixture revealed a mixture of acid $\mathbf{3 b}$ and an elimination product, in a 2:1 ratio. This result indicates that while increased temperature is necessary for ester hydrolysis of this substrate, $\mathrm{LiCl}$ is not. However, formation of the elimination product via $\mathrm{E} 1 \mathrm{cB}$ becomes significant at higher temperatures, and more so when $\mathrm{LiCl}$ is not used. Thus, further experimentation must be carried out to identify optimum reaction conditions for hydrolysis without elimination occurring.

\subsubsection{Synthesis of Mycolic Acid 3c}

Mycolic acid target 3c was envisioned to be prepared via the base mediated hydrolysis of epoxide 5 (Scheme 17). Accordingly, epoxide 5 was subjected to the $\mathrm{LiOH}$ mediated hydrolysis conditions used for the synthesis of $22[1 \mathrm{M} \mathrm{LiOH}, 5.0$ equiv. in $\mathrm{THF} / \mathrm{H}_{2} \mathrm{O} / \mathrm{MeOH}$ (12:2:1)], to give the desired product 3c in $37 \%$ yield, along with a considerable amount (34\%) of elimination product 20. Apparently, the acidic $\alpha$-proton and $\beta-\gamma$-position of the epoxide make 5 highly susceptible to an $\mathrm{E} 1 \mathrm{cB}$ reaction to form 20. Although the hydrolysed epoxide $3 \mathbf{c}$ could be separated from the elimination product 20 by silica gel flash column chromatography, this became challenging if the reaction proceeded further to give a product mixture including the hydrolysed elimination product 26, which was inseparable from $\mathbf{3 c}$ under the purification conditions employed.

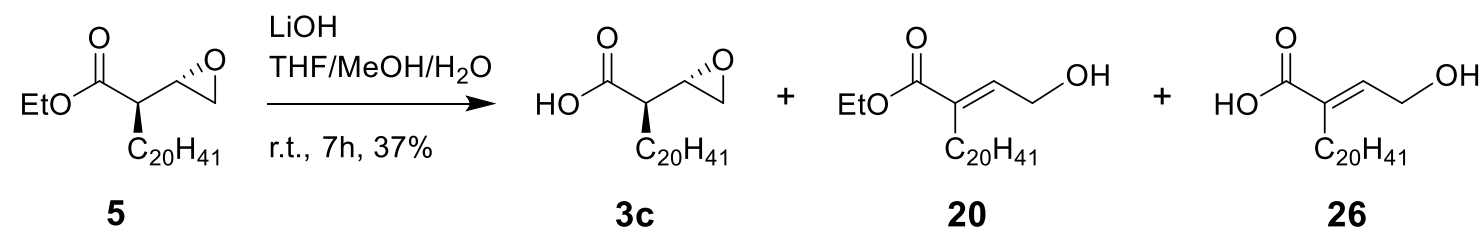

Scheme 17: Treatment of epoxide 5 with $\mathrm{LiOH}$ gives a mixture of products

Attempts were then made to limit the formation of the elimination products by reducing the amount of $\mathrm{LiOH}$ used (e.g. 3.0 equiv.) and performing the reaction at lower temperatures $\left(-20{ }^{\circ} \mathrm{C}\right)$, but to no avail. An alternative hydrolysis procedure was then explored using bis(tributyltin)oxide $\left[\left(n \mathrm{Bu}_{3} \mathrm{Sn}\right)_{2} \mathrm{O}\right] \cdot{ }^{98-99}$ Here, hydrolysis of the ethyl ester occurs via an organotin ester intermediate as illustrated (Scheme 18), with carboxylic acid $\mathbf{3 c}$ being released during aqueous workup. ${ }^{98,100}$ 


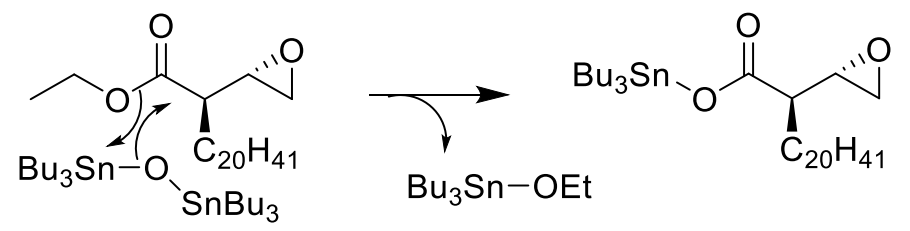

5

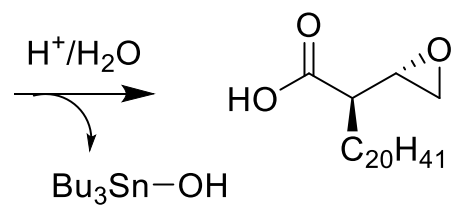

$3 c$

Scheme 18: $\left(n \mathrm{Bu}_{3} \mathrm{Sn}\right)_{2} \mathrm{O}$ mediated cleavage of the ethyl ester to give carboxylic acid 3c

While this method appeared to result in the selective formation of $\mathbf{3 c}$ by TLC and NMR analyses, separation of the acid 3c from the alkylated Sn by-products proved difficult. Multiple different purification strategies were employed, including washing the reaction mixture with aq. potassium fluoride $(\mathrm{KF}, 10 \%),{ }^{98,} 101$ performing silica gel column chromatography with $10 \% \mathrm{KF},{ }^{102}$ filtering the solution over silica gel with petroleum ether, and stirring with activated carbon or $1 \mathrm{M} \mathrm{NaOH},{ }^{103}$ however, none of these purification strategies enabled carboxylic acid $\mathbf{3 c}$ to be isolated in a higher yield. Thus, in the interests of time, the synthesis was continued accepting a $37 \%$ yield of $\mathbf{3 c}$ from LiOH mediated ester hydrolysis.

\subsubsection{Synthesis of Target TMEs 1a-c and TDEs $2 a-c$}

With the three key mycolic acids 3a-c in hand, the selectively protected trehalose core $\mathbf{4}$ was then synthesised for subsequent coupling to acids 3a-c. Accordingly, $\alpha, \alpha^{\prime}$-D-trehalose (6) was first per-silylated, and then the more labile primary trimethylsilyl (TMS) groups were removed to yield 4 in a respectable $80 \%$ yield over two steps (Scheme 19). This two-step one-pot methology, initially developed by Toubiana and co-workers ${ }^{83}$ and later optimised by Johnson et al., ${ }^{84}$ involves the use of $N, O$-bis(trimethylsilyl)acetamide (BSA) and catalytic tetra-butylammonium fluoride (TBAF) to install the TMS groups, with subsequent treatment of the per-silylated adduct with $\mathrm{K}_{2} \mathrm{CO}_{3}$ in methanol to selectively cleave the primary TMS ethers. The mechanism of the reaction is illustrated (Scheme 20), whereby the fluoride anion of TBAF attacks the silyl atom of BSA (I) to generate intermediate II. Here, attack of the fluoride on the $O$-silyl rather than the $N$-silyl is preferred due to the stability of intermediate II, which is stabilised by resonance structures with the negative charge localised on either the oxygen (II) or the nitrogen (III) atom. The negatively charged nitrogen of intermediate III then acts as a base and abstracts a proton from a trehalose hydroxyl to generate the nucleophilic trehalose 
intermediate IV, which in turn attacks another molecule of BSA (I) to form a TMS ether (V) and regenerate the BSA intermediate (II).

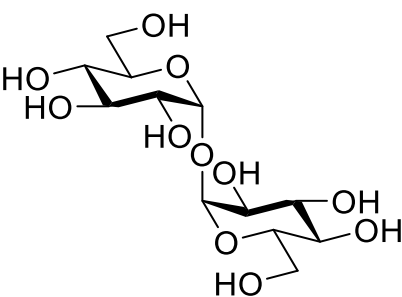

6

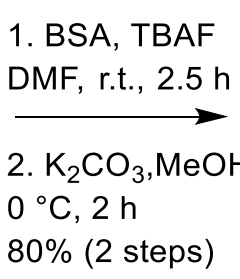

$80 \%$ (2 steps)

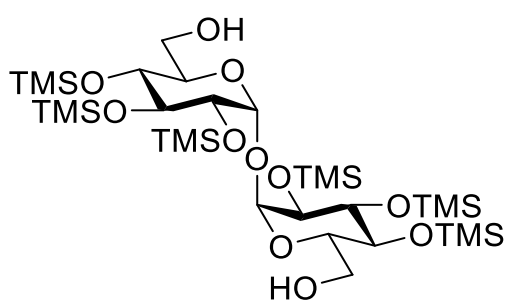

4

Scheme 19: TMS protection of trehalose<smiles>CCCC[N+](CCCC)(CCCC)CCC[Si](C)(C)O/C(I)=N/[Si](C)(C)C</smiles>

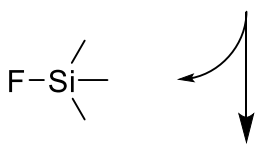

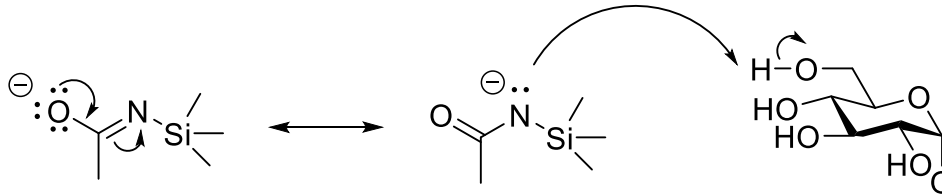

II

III
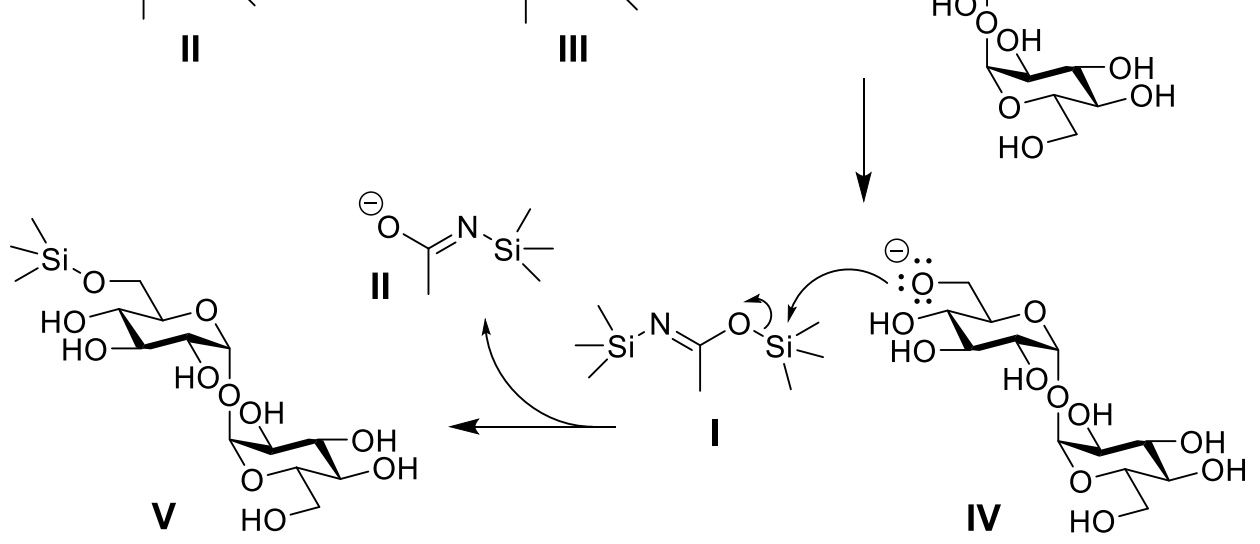

Scheme 20: Reaction mechanism for TMS protection of trehalose

TMS protected trehalose $\mathbf{4}$ was then subjected to esterification with mycolic acid $\mathbf{3 a}$ (Scheme 21), en route to the preparation of TME 1a and TDE 2a. Acid 3a (4.0 equiv.) and TMS trehalose 4 (1.0 equiv.) were thus stirred with 1-ethyl-3-(3- 
dimethylaminopropyl)carbodiimide (EDCI) (6.5 equiv.) and 4-(dimethylamino)pyridine (DMAP) (6.0 equiv. added over 2 days) at $55^{\circ} \mathrm{C}$ in toluene, according to the methodology of Khan et al. ${ }^{73-74}$ It was anticipated that these conditions would lead to a mixture of monoester 27 and diester 28, yet TLC analysis revealed three higher running spots $\left(R_{\mathrm{f}}=\right.$ $0.39,0.58$ and 0.69, PE/EA, 5:1, v/v) compared to mycolic acid 3a $\left(R_{\mathrm{f}}=0.14\right.$ PE/EA 5:1, $\mathrm{v} / \mathrm{v})$ and TMS trehalose $4\left(R_{\mathrm{f}}=0.12, \mathrm{PE} / \mathrm{EA}, 5: 1\right.$, v/v $)$. After stirring for five days, HRMS analysis of the reaction mixture revealed the presence of starting materials $\mathbf{3 a}$ and $\mathbf{4}$, as well as the monoester 27 (HRMS calcd. for $\left[\mathrm{C}_{60} \mathrm{H}_{130} \mathrm{O}_{13} \mathrm{Si}_{7}+\mathrm{NH}_{4}\right]^{+}$: 1272.8235; obsd.:1272.8094), however none of the desired diester 28 was detected. Accordingly, additional EDCI (total 8.5 equiv.) and DMAP (total 13 equiv.) were added in an attempt to push the reaction to completion, however, after stirring an additional two days, little change was observed by TLC analysis. The reaction mixture was then concentrated and the residue purified by silica gel flash column chromatography and size exclusion chromatography (lipophilic sephadex) to afford the desired TME $27\left(R_{\mathrm{f}}=0.69 \mathrm{PE} / \mathrm{EA}\right.$ $5: 1, \mathrm{v} / \mathrm{v}$ ), in $29 \%$ yield (Scheme 21 ). Minor quantities of the partially deprotected product $\left(R_{\mathrm{f}}=0.58\right)$, along with the EDCI coupled lipid $\left(R_{\mathrm{f}}=0.39\right)$, which is likely to be the unreactive $N$-acylurea by-product formed via Steglich rearrangement, were also observed. ${ }^{104}$ These products were tentatively assigned by ${ }^{1} \mathrm{H}$ NMR and HRMS analysis, respectively (HRMS calcd. for $\left[\mathrm{C}_{32} \mathrm{H}_{65} \mathrm{~N}_{3} \mathrm{O}_{3}+\mathrm{H}\right]^{+}$: 540.5099; obsd.:540.4900).
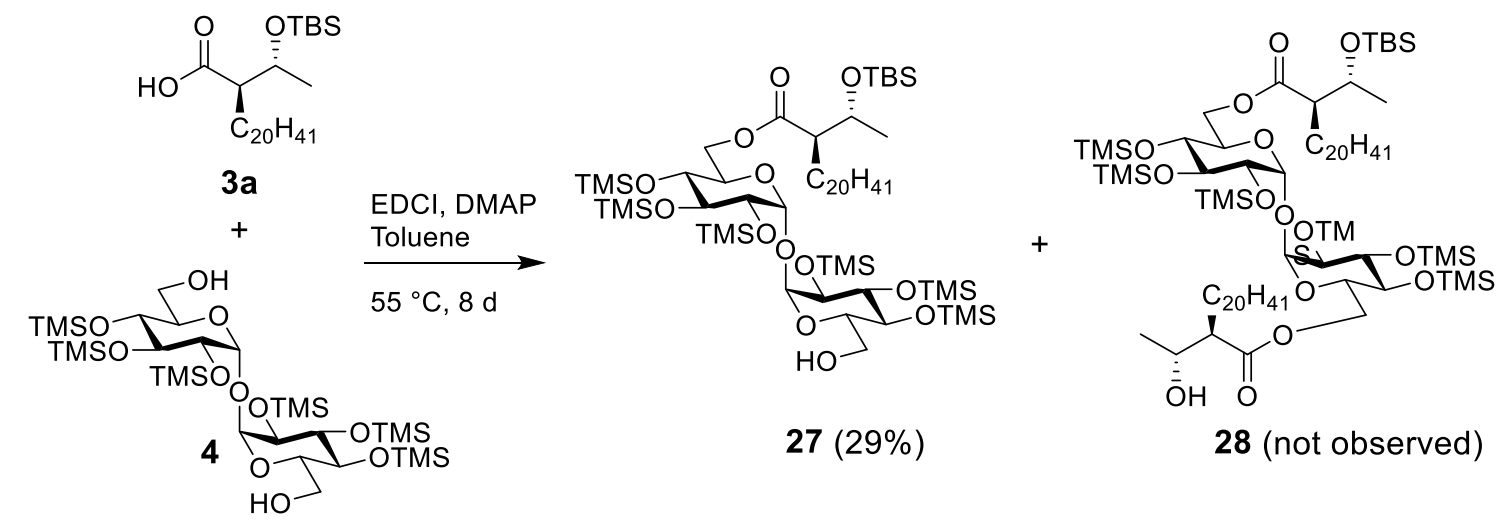

Scheme 21: Coupling of TMS-trehalose with mycolic acid 3a

The formation of TME 27 was confirmed by HRMS and NMR analyses. An HMBC between the carbonyl of the lipid and the protons at the 6-position of the coupled sugar confirmed that lipid coupling had occurred, while the presence of one carbonyl peak $(\delta$ 174.3) in the ${ }^{13} \mathrm{C}$ NMR spectra, and sixteen different proton environments between 4.91 
and $2.43 \mathrm{ppm}$ in the ${ }^{1} \mathrm{H}$ NMR spectrum indicated that only one lipid had been coupled, to give an asymmetric glycolipid. As anticipated, H-6a and H-6b of the coupled sugar had a downfield shift, appearing as two doublets of doublets ( $\delta 4.37$ and 4.08, respectively), compared to $\mathrm{H}-6 \mathrm{a}$ and $\mathrm{H}-6 \mathrm{~b}$ of the non-coupled glucose residue ( $\mathrm{m}, 3.71$ $3.64 \mathrm{ppm})$. Finally, an HMBC between the anomeric protons and carbons of the two sugar residues confirmed that the glycosidic linkage of the trehalose moiety was still intact.

The formation of the Steglich by-product can be explained by considering the mechanism of the coupling reaction and the poor reactivity of the mycolic acid (Scheme 22). Here, the deprotonated carboxylic acid attacks the electrophilic carbon centre of EDCI (II) to generate the $O$-acylisourea intermediate III. The activated carboxylic acid III can then be attacked by the 6-OH on trehalose (4) to form the TME 27. While this reaction occurs readily with amines to form amides, the coupling of an alcohol to give an ester is slower, allowing for the rearrangement of intermediate II to form the unreactive $N$-acylurea III. Accordingly, DMAP (I) is added as it reacts readily with the $O$-acylisourea intermediate II, generating the reactive intermediate $\mathbf{V}$ and urea $\mathbf{V I}$ and thereby avoiding the formation of by-product IV. Attack of the carbonyl centre of $\mathbf{V}$ by the alcohol then forms the desired ester 27 and regenerates DMAP (I). In the case of the sterically hindered mycolic acid 3a, however, formation of the ester is slow and hence the $N$-acylurea by-product was also observed, even when a large excess DMAP was used.

Unfortunately, this reaction did not result in the formation of any of the desired TDE $\mathbf{2 8}$. It is proposed that optimisation of reaction time, temperature and solvent (e.g. DCM or DMF) will lead to an improved yield of monoester 27 and the formation of diester 28. The use of $N, N^{\prime}$-dicyclohexylcarbodiimide (DCC) instead of EDCI may improve the overall reaction yield, as although this coupling reagent is more difficult to remove during the workup procedure, DCC is also more soluble in the preferred reaction solvent (toluene) and therefore likely to have enhanced reactivity. 


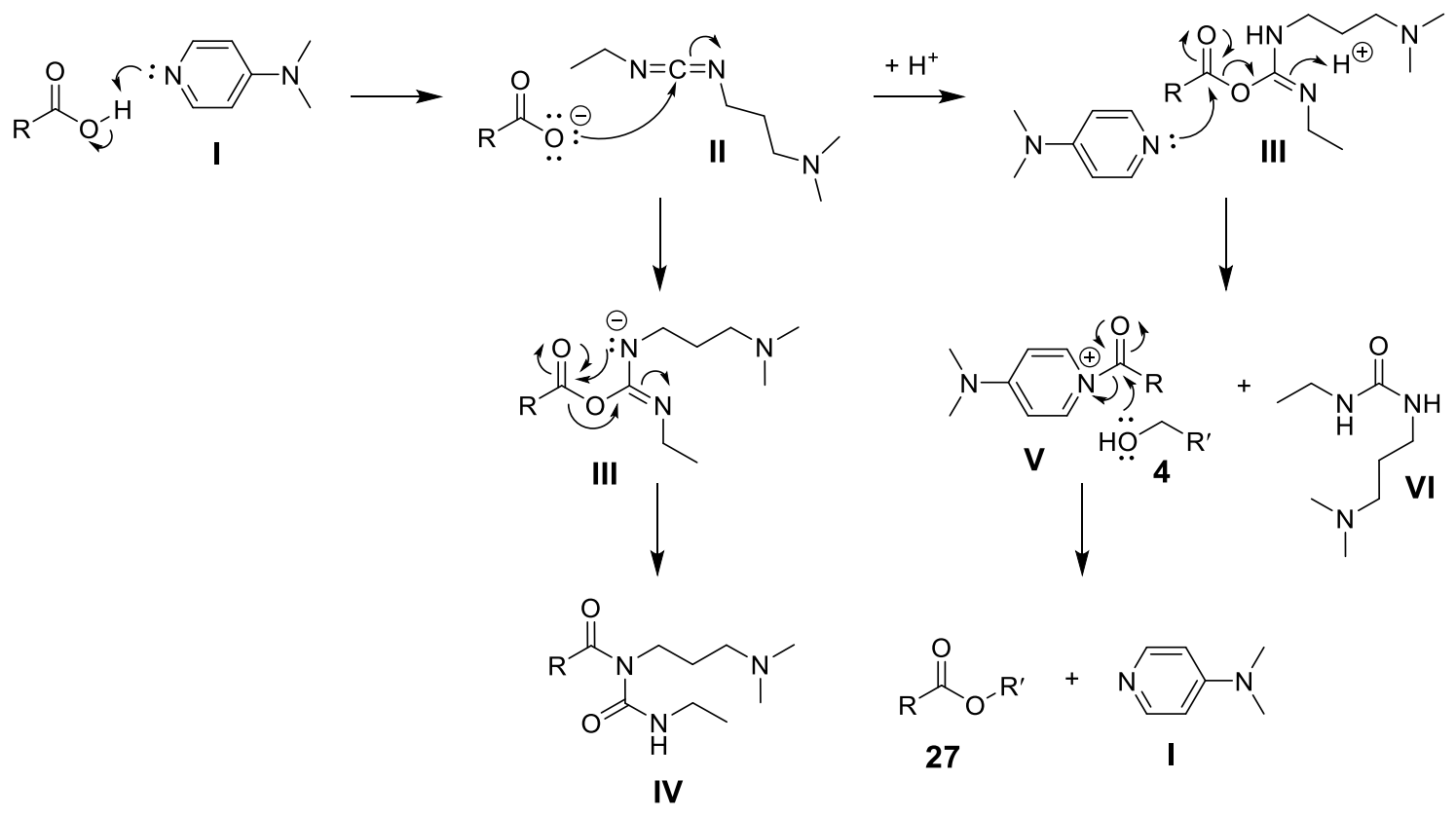

Scheme 22: Reaction mechanism for EDCI coupling and formation of the Steglich rearranged product

Although the coupling of mycolic acid 3a to TMS-trehalose $\mathbf{4}$ was achieved in low yield, a sufficient quantity of TME 27 was obtained to prepare final target 1a. Accordingly, TME 27 was treated with HF•pyridine (140 equiv., 17\% in pyridine), the reaction was neutralised with aq. $\mathrm{Ca}(\mathrm{OAc})_{2}(1.0 \mathrm{M})$ after 20 hours to precipitate $\mathrm{CaF}$, filtered, then purified by size exclusion column chromatography on lipophilic sephadex to yield the target 6-O-[(R)-2-((R)-1-hydroxyethyl)docosanoyl]-6'-hydroxy- $\alpha, \alpha^{\prime}$-D-trehalose (1a) in $88 \%$ yield (Scheme 23). Target 1a was obtained in very small quantities (1.0 mg) and was therefore not subject to additional column chromatography, and while the purity of the final compound was less than ideal, the formation of 1 a could be confirmed by HRMS and NMR analysis. In the ${ }^{1} \mathrm{H}$ NMR, the anomeric protons appear as two overlapping doublets (Figure 18), confirming that the asymmetric nature of the trehalose monoester has been conserved. As anticipated, H-6a and H-6b of the coupled sugar retained the downfield shift and geminal splitting pattern seen in the TMS-protected TME 27, appearing as two doublets of doublets ( $\delta 4.47$ and 4.17, respectively), while H-6ab of the non-coupled sugar appear as a multiplet at 3.68-3.64 ppm. Loss of the silyl protecting group signals $(\delta 0.91$ and $0.16-0.03)$ confirms that deprotection has occurred, and this is corroborated by HRMS (calcd. for $\left[\mathrm{C}_{36} \mathrm{H}_{68} \mathrm{O}_{13}+\mathrm{NH}_{4}\right]^{+}:$726.4998, obsd.: 726.4982). 
Due to the small quantities of material at hand, this reaction was performed once, and while overall yields for the preparation of $\mathbf{1 a}$ were modest, the successful synthesis of this derivative illustrates the validity of the synthetic route employed here. Moreover, additional material is available at earlier stages of the synthesis and will be used to prepare more of the target compounds.

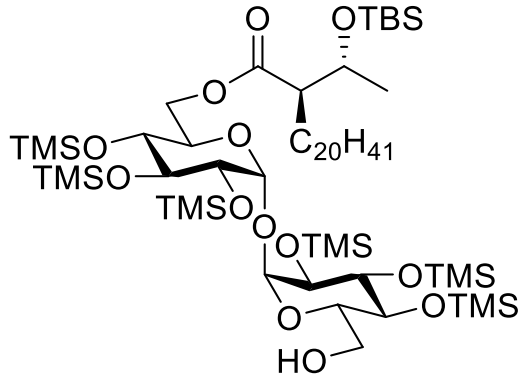

27
HF•pyridine

pyridine

r.t., $20 \mathrm{~h}$

$88 \%$

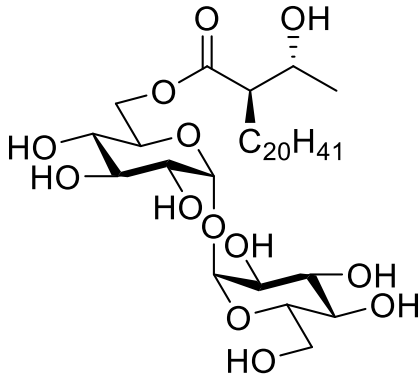

1a

Scheme 23: Deprotection of TME 27 to give target 1a 


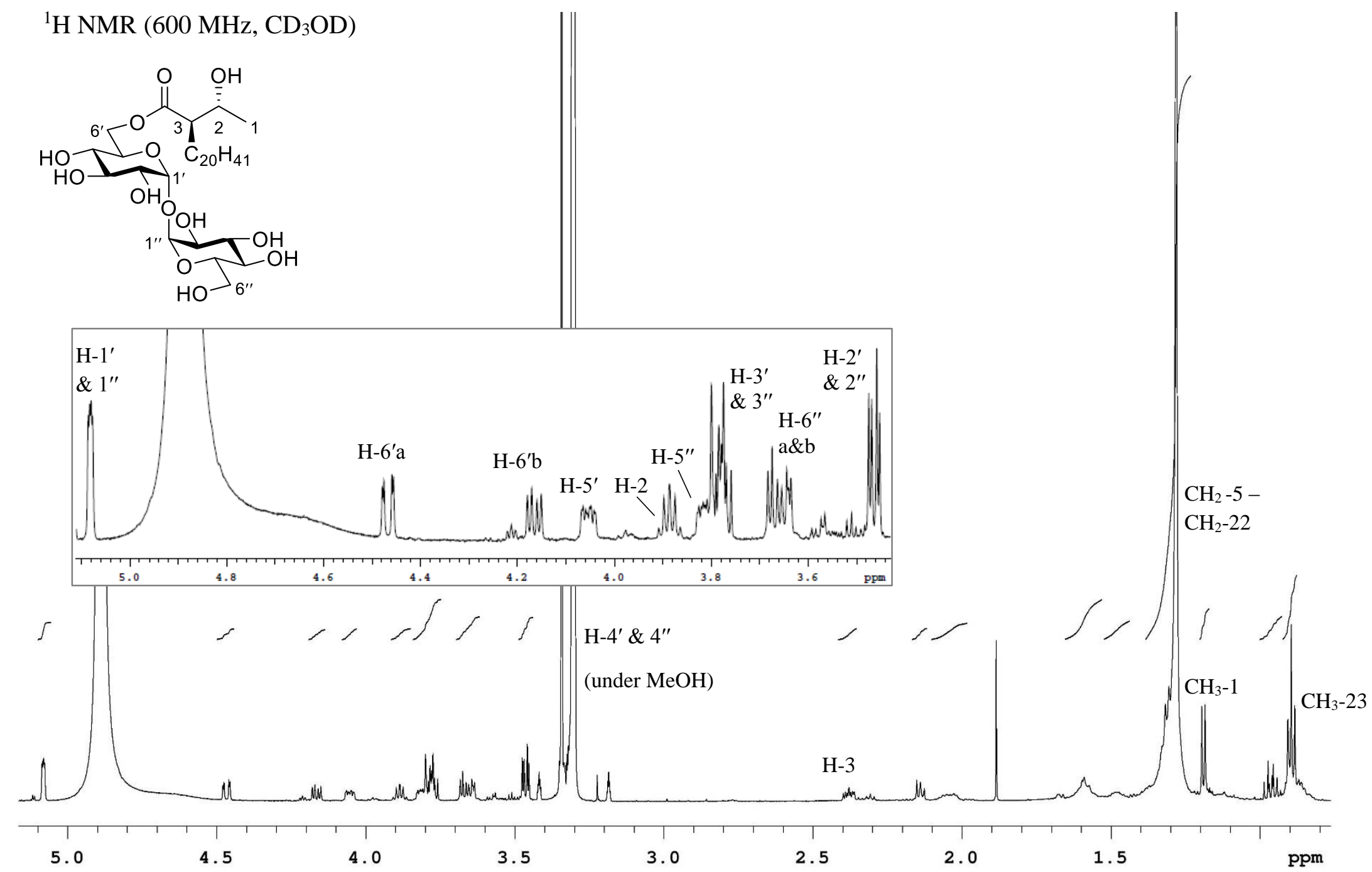

Figure 18: ${ }^{1} \mathrm{H}$ NMR of $6^{\prime}-O-[(R)-2-((R)-1-$ Hydroxyethyl $)$ docosanoyl $]-6^{\prime \prime}$-hydroxy- $\alpha^{\prime}, \alpha^{\prime \prime}$-D-trehalose 1a 
With the 2-hydroxy TME 1a in hand, this synthetic strategy was then repeated to prepare the target methoxy derivatives TME $\mathbf{1 b}$ and TDE $\mathbf{2 b}$. To this end, mycolic acid $\mathbf{3 b}$ (4.0 equiv.) was subjected to coupling with TMS-protected trehalose 4 (1.0 equiv.), in the presence of EDCI (6.5 equiv.) and DMAP (2.0 equiv.) (Scheme 25). After stirring at 55 ${ }^{\circ} \mathrm{C}$ in toluene for 24 hours, TLC analysis indicated the presence of three higher running products $\left(R_{\mathrm{f}}=0.74,0.58,0.47\right.$, PE/EA 5:1, v/v) compared to mycolic acid $\mathbf{3 b}\left(R_{\mathrm{f}}=0.14\right.$, PE/EA, 5:1, v/v) and TMS-trehalose $4\left(R_{\mathrm{f}}=0.12\right.$, PE/EA, 5:1, v/v), however, HRMS analysis showed that the major compounds present were the starting materials $\mathbf{3 b}$ and $\mathbf{4}$, and the anhydride 31, formed by dimerization of mycolic acid 3b (HRMS calcd. for $\left[\mathrm{C}_{50} \mathrm{H}_{98} \mathrm{O}_{5}+\mathrm{NH}_{4}\right]^{+}:$796.7753, obsd.: 796.7729). The formation of this anhydride can be explained by the attack of a deprotonated mycolic acid onto the electrophilic carbon centre of another molecule of the acid that has been activated by DMAP (Scheme 24). This, in turn, leads to the formation of anhydride $\mathbf{3 1}$ and regeneration of DMAP.<smiles></smiles>

3b<smiles>CCNC(=O)NCCCN(C)C</smiles>

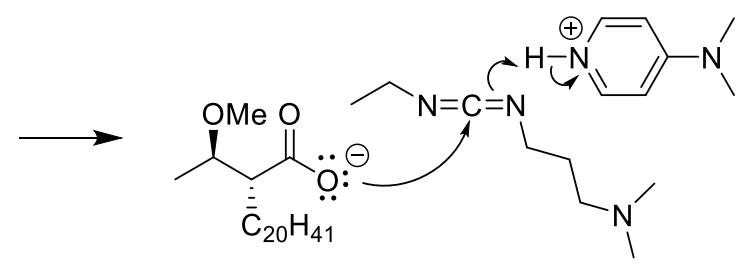<smiles>CCCC(C(=O)OC(=O)C(CC)C(C)OC)C(C)OC</smiles>

31

Scheme 24: Formation of anhydride 31 
It is known that in the presence of excess DMAP, and EDCI, anhydrides can react in coupling reactions, ${ }^{105}$ therefore additional equivalents of DMAP (total 4.0 equiv.) were added to the reaction mixture, however, after stirring for 8 days, ${ }^{1} \mathrm{H}$ NMR analysis of the crude material revealed only a small amount of product. The crude reaction mixture was therefore resubmitted to the same conditions, and stirred for a further six days, before being purified by silica gel flash column chromatography to yield TMS-protected TME 29 in $25 \%$ yield (Scheme 25), along with the recovery of unreacted TMS-trehalose 4. Due to the low mass of product obtained, TME 29 was not subject to further purification. Trace amounts of diester 30 and anhydride 31 were observed by HRMS analysis, however no significant quantity was isolated. The synthesis of $\mathbf{2 9}$ was confirmed by HRMS (calcd. for $\left[\mathrm{C}_{55} \mathrm{H}_{118} \mathrm{O}_{13} \mathrm{Si}_{6}+\mathrm{Na}\right]^{+}:$1177.7086, obsd.: 1177.7062) and validated by ${ }^{1} \mathrm{H}$ NMR, with the anomeric protons appearing at 4.92 and 4.85 ppm, and H-6a and H-6b of the coupled sugar shifted down field ( $\delta 4.52$ and 4.04, respectively) compared to the uncoupled sugar ( $\mathrm{m}, \delta 3.69-3.66$ ), as expected for the monoester. The characteristic lipid resonances occur at $\delta 3.54(\mathrm{H}-2), 3.29(\mathrm{OMe}), 2.54(\mathrm{H}-3)$ and $1.14\left(\mathrm{CH}_{3}-1\right)$ with integrations agreeing with the attachment of one lipid.

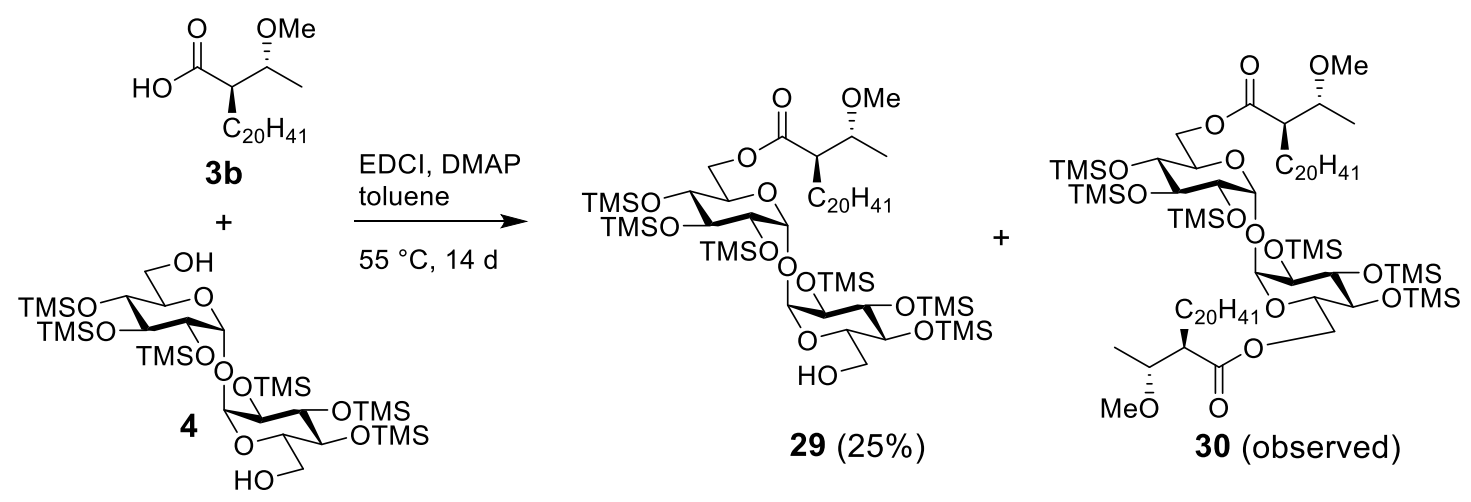

Scheme 25: Coupling of mycolic acid 3b to TMS-trehalose 4

In an attempt to optimise the formation of TME 29, the esterification reaction was repeated with more sugar relative to lipid (1 equiv. 4: 2 equiv. 3b, vs. 1:4 ratio previously used), and more equivalents of DMAP per acid (1.5 equiv. vs. 0.5 equiv. used initially). It was anticipated that increasing the ratio of DMAP to acid would reduce the formation of anhydride 31, while increasing the relative amount of sugar to acid would make more sugar available for reaction, thus promoting esterification. When little change in TLC 
was observed after stirring the reaction for 24 hours at $55^{\circ} \mathrm{C}$, the reaction was warmed to $72{ }^{\circ} \mathrm{C}$ and stirred for a further $24 \mathrm{~h}$. At this point TLC analysis showed a large product spot $\left(R_{\mathrm{f}}=0.28, \mathrm{PE} / \mathrm{EA}, 5: 1, \mathrm{v} / \mathrm{v}\right)$ and the absence of the TMS-trehalose starting material $\left(R_{\mathrm{f}}=0.12, \mathrm{PE} / \mathrm{EA}, 5: 1, \mathrm{v} / \mathrm{v}\right)$, as well as several smaller higher running products. However, after aqueous workup the product at $R_{\mathrm{f}}=0.28$ was no longer visible and NMR analysis showed mainly the uncoupled sugar 4, suggesting that this spot could in fact be attributed to 4 which may run at a higher $R_{\mathrm{f}}$ when toluene from the reaction mixture is present on the TLC plate. The crude reaction mixture was then resubmitted to the same conditions, with additional DMAP (6 equiv.) and EDCI (7 equiv.) added after 2 days of stirring at 75 ${ }^{\circ} \mathrm{C}$. Little change was observed by TLC analysis after stirring for an additional 10 days, therefore the reaction was worked up and the residue purified by silica gel flash column chromatography. This gave the desired TME 29 in 20\% yield, along with re-isolated TMS-trehalose and the Steglich rearrangement product [HRMS (calcd. for $\left[\mathrm{C}_{33} \mathrm{H}_{67} \mathrm{~N}_{3} \mathrm{O}_{3}+\mathrm{H}\right]^{+}:$554.5255, obsd.: 554.5262)], which may have formed in greater quantities than previously due to the large excess of EDCI used in this reaction. Although the uncoupled mycolic acid 3b was not isolated, methyl ester 25 was (Scheme 26). The formation of $\mathbf{2 5}$ in the conditions applied here was unexpected, however the proposed mechanism would account for its formation under basic conditions with excess DMAP. Here, the acidic $\alpha$-proton on anhydride $\mathbf{3 1}$ is removed by DMAP, generating enolate intermediate I. The methoxy group is then displaced via an E1cB reaction when the carbonyl reforms, generating elimination product II and methoxide. The methoxide can then attack an electrophilic carbonyl centre, such as that of the reactive acyl-DMAP intermediate III, generating mycolic acid ester 25 and releasing DMAP. Several other by-products were isolated from the crude reaction mixture, however full characterisation would be necessary to determine conclusively whether the mycolic acid ester $\mathbf{2 5}$ forms via this mechanism or not. 

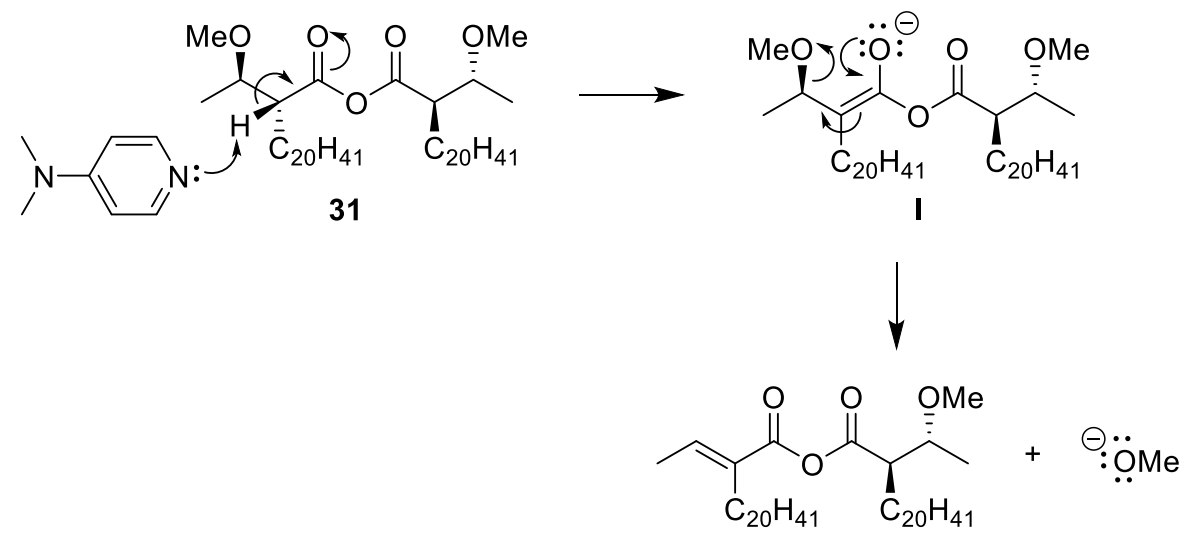

II

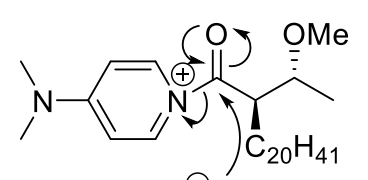

III $\Theta_{:}:$OMe

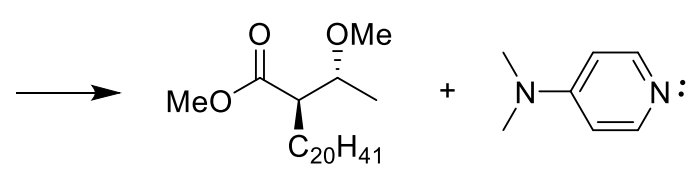

25

Scheme 26: Formation of methyl ester 25 under basic conditions

Although time constraints prevented optimisation of this esterification reaction, the results indicated that there will be an optimum quantity of DMAP and EDCI, with too little DMAP and too much EDCI resulting in formation of the unreactive Steglich rearrangement product, while too much DMAP may, in this case, lead to formation of an elimination product and the unreactive methyl ester 25. It is envisioned that optimisation of the reaction conditions will improve both the yield of monoester $\mathbf{2 9}$, and allow for the formation of diester $\mathbf{3 0}$.

With TME 29 in hand, this was subjected to global deprotection by treatment with HF.pyridine (10 equiv.) to yield the desired 2-methoxy TME $\mathbf{1 b}$ in quantitative yield after purification by size exclusion column chromatography (Scheme 27). Here, it was determined that fewer equivalents of HF•pyridine were necessary than used previously en route to the formation of $1 \mathrm{a}$ ( 1 vs. 10 per silyl group), providing the title compound in excellent yield. ${ }^{1} \mathrm{H}$ and ${ }^{13} \mathrm{C}$ NMR analysis indicated that deprotection of the TMS ethers was successful, with loss of the $\mathrm{Si}\left(\mathrm{CH}_{3}\right)$ resonances evident in both spectra. The anomeric carbons appear at $\delta 95.1$ and 95.0 in the ${ }^{13} \mathrm{C}$ NMR, while the protons occur as two overlapping doublets at $5.08 \mathrm{ppm}$ in the ${ }^{1} \mathrm{H}$ NMR. A total of sixteen resonances are visible between 95.1 and $53.5 \mathrm{ppm}$ in the ${ }^{13} \mathrm{C} \mathrm{NMR}$, corresponding to the expected fourteen 
sugar carbons, and $\mathrm{C}-2$ and $2-\mathrm{OCH}_{3}$ of the lipid (Figure 19). Although the 2-O-Methyl resonance is obscured by $\mathrm{CD}_{3} \mathrm{OH}$ in the ${ }^{1} \mathrm{H} \mathrm{NMR}$, it is visible at $\delta 56.8$ in the ${ }^{13} \mathrm{C}$ spectra (Figure 19), and along with HRMS (calcd. for $\left[\mathrm{C}_{37} \mathrm{H}_{70} \mathrm{O}_{3}+\mathrm{NH}_{4}\right]^{+}:$740.5155, obsd.: 740.5135) this confirms that the desired methoxy functionality of the lipid ester has been conserved.

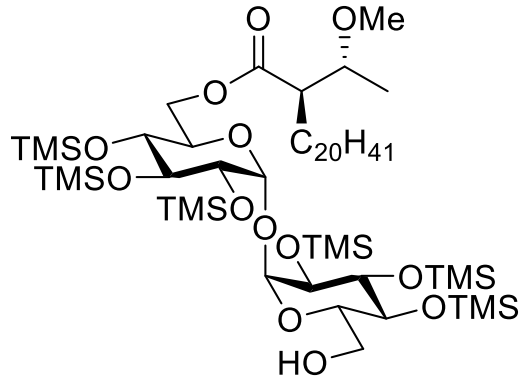

29
HF•pyridine pyridine r.t., $20 \mathrm{~h}$

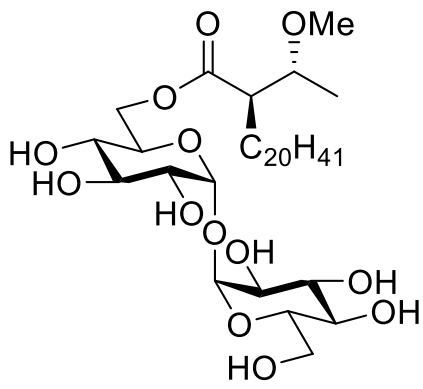

$1 b$

Scheme 27: Deprotection of TME 29 to give $6{ }^{\prime}-O-[(R)-2-((R)-1-$ Methoxyethyl)docosanoyl]-6"'-hydroxy- $\alpha^{\prime}, \alpha^{\prime \prime}$-D-trehalose 1b 
1b
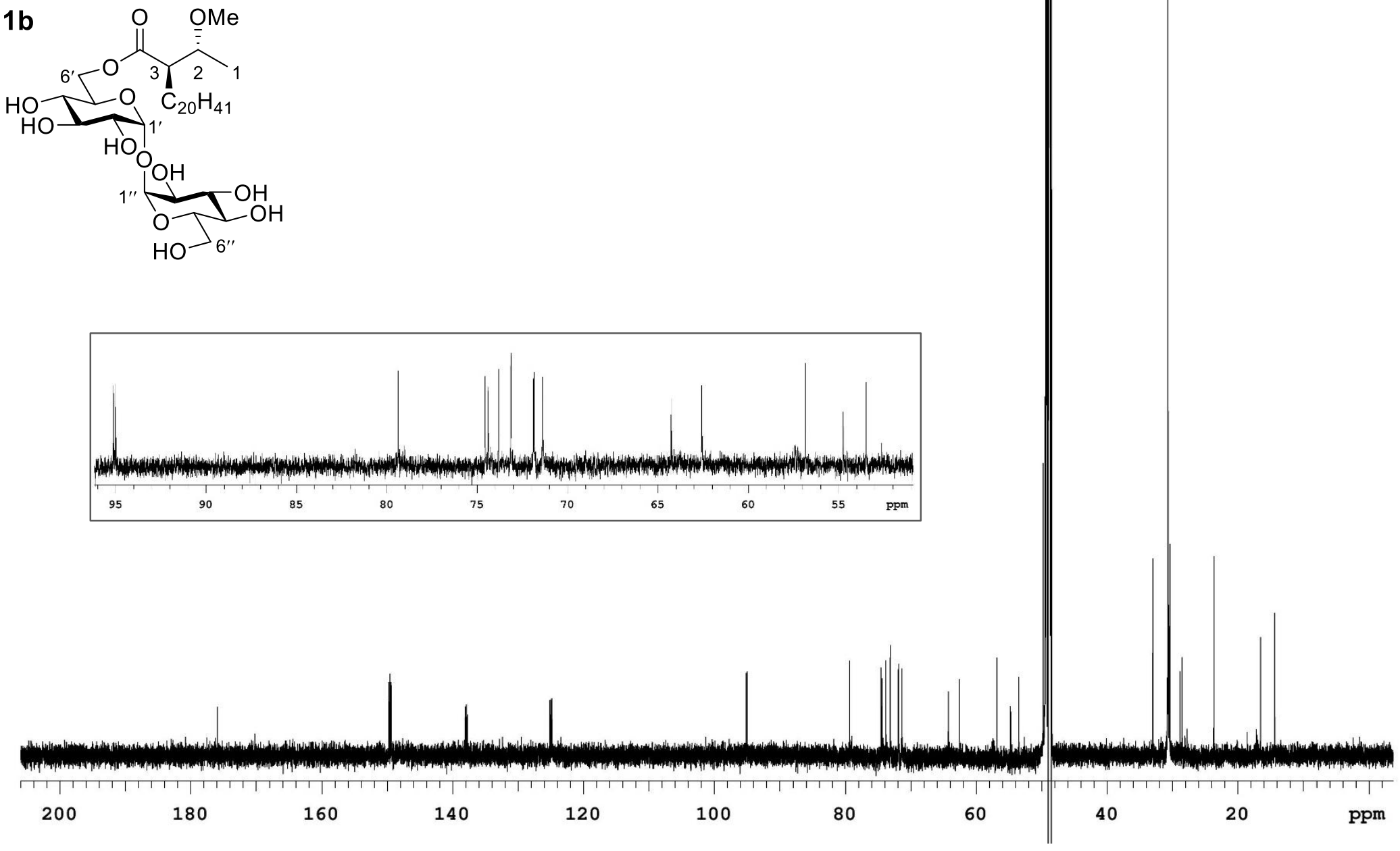

Figure 19: ${ }^{13} \mathrm{C}$ NMR spectrum of $6^{\prime}-O-\left[(R)-2-((R)-1-\right.$ Methoxyethyl $)$ docosanoyl] $-6^{\prime \prime}$-hydroxy- $\alpha^{\prime}, \alpha^{\prime \prime}-\mathrm{D}-$ trehalose $\mathbf{1 b}$ 
The last trehalose glycolipids in the series, TME 1c and TDE 2c, were prepared using the synthetic strategy employed for the synthesis of 1a and 1b. Accordingly, TMS-trehalose 4 (1.0 equiv.) was subjected to esterification with mycolic acid 3c (4.0 equiv.), in the presence of EDCI (6.5 equiv.) and DMAP (3.4 equiv.) (Scheme 28). The reaction mixture was stirred at $55{ }^{\circ} \mathrm{C}$ for $44 \mathrm{~h}$, then purified by silica gel flash column chromatography to give the desired monoester 32 in $45 \%$ yield. This reaction was repeated with a prolonged reaction time of five days, which resulted in the formation of TME 32 in $42 \%$ yield, and gratifyingly, TDE 33 in $15 \%$ yield. It is interesting to note the enhanced reactivity of mycolic acid 3c towards esterification with TMS-trehalose $\mathbf{4}$ when compared to acids $\mathbf{3 a}$ and 3b which gave TMEs 27 and 29 in $29 \%$ and 25\% yield, respectively, and only negligible amounts of the diesters $\mathbf{2 8}$ and 30. It is difficult to explain why esters $\mathbf{3 2}$ and $\mathbf{3 3}$ were more readily synthesised, though the more facile coupling of $\mathbf{3 c}$ may be due to the reduced steric interactions of the epoxy group when compared to the larger silyl ether and methoxy functionalities present at the $\beta$-position of acids $\mathbf{3 a}$ and $\mathbf{3 b}$. Reduced steric hindrance will facilitate acyl migration from the $O$-acylisourea intermediate to DMAP, thereby limiting formation of the Steglich rearrangement product.

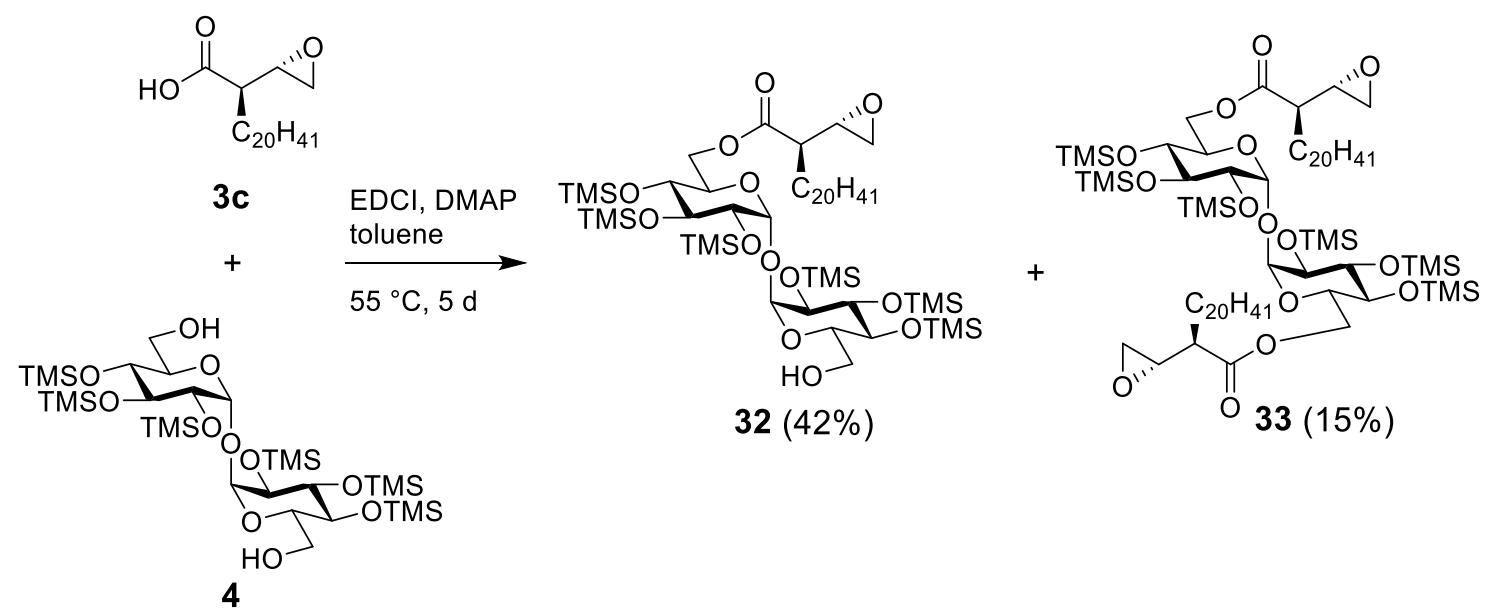

Scheme 28: Preparation of target TME 1c and TDE 2c

Formation of the mono- and diesters was established by NMR analysis, with the ${ }^{13} \mathrm{C}$ NMR of the monoester showing the twelve different chemical environments of the carbon atoms in the sugars, and the ${ }^{1} \mathrm{H}$ NMR revealing fourteen resonance signals for the sugar protons (Figure 20). All assignments were further corroborated by 2D NMR analysis 
(COSY, HSQC and HMBC). Integration of the mycolic acid protons correlated to the attachment of one lipid, and HRMS confirmed this (calcd. for $\left[\mathrm{C}_{54} \mathrm{H}_{118} \mathrm{O}_{13} \mathrm{Si}_{6}+\mathrm{NH}_{4}\right]^{+}$: 1156.7219, obsd.: 1156.7195). On the other hand, the ${ }^{1} \mathrm{H}$ NMR spectra of the diester revealed a symmetrical molecule with only seven proton environments in the sugar region, which integrate in a 1:1 ratio with the mycolic acid protons, thus providing evidence for diester formation. HRMS (calcd. for $\left[\mathrm{C}_{80} \mathrm{H}_{162} \mathrm{O}_{13} \mathrm{Si}_{6}+\mathrm{Na}\right]^{+}:$1522.0523, obsd.: 1522.0587) also confirmed that the desired TDE $\mathbf{3 3}$ had been synthesised, although the low yield of diester $\mathbf{3 3}$ meant that it was not purified further and spectral evidence shows that minor amounts of monoester $\mathbf{3 2}$ were also present. 

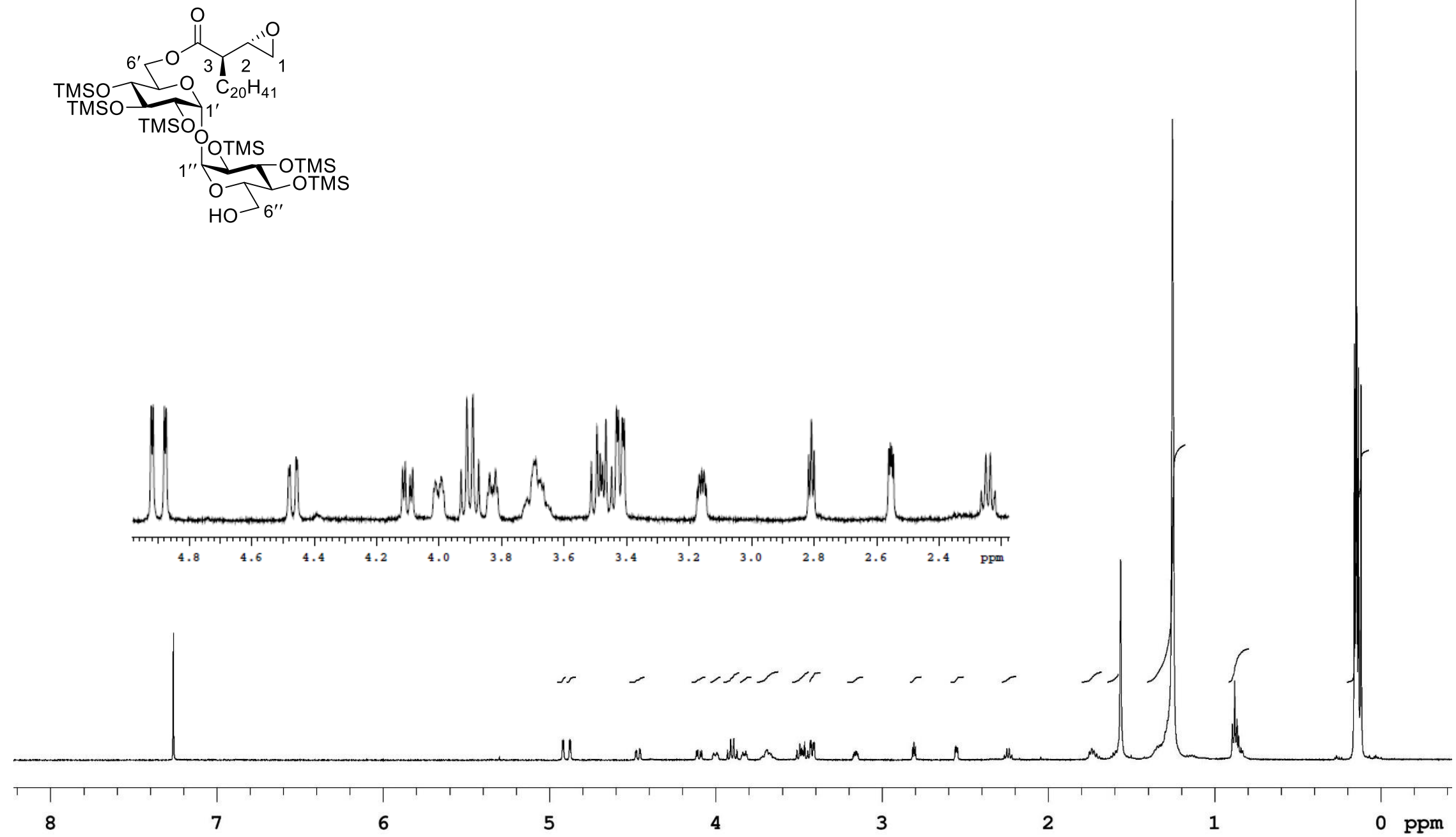

Figure 20: ${ }^{1} \mathrm{H}$ NMR of $2^{\prime}, 2^{\prime \prime}, 3^{\prime}, 3^{\prime \prime}, 4^{\prime}, 4^{\prime \prime}-$ Hexa- $O$-trimethylsilyl-6'-O-[(R)-2-((S)-oxiran-2-yl)docosanoyl]-6"'-hydroxy- $\alpha^{\prime}, \alpha^{\prime \prime}$-D-trehalose 32 
In order to prepare targets TME 1c and TDE 2c, TME 32 and TDE 33 were subjected to the deprotection conditions employed for the synthesis of TME 1b. Accordingly, TME 32 was treated with HF• pyridine (10 equiv., 11 h), neutralised with aq. $\mathrm{Ca}(\mathrm{OAc})_{2}$, filtered, and subjected to purification by size exclusion column chromatography on lipophilic sephadex. Although it was anticipated that the treatment of $\mathbf{3 2}$ with HF•pyridine would yield the desired target 1c, this reaction gave a complex mixture of products which, due to the small amount of material in hand, could not all be fully characterised. However, the formation of the desired epoxy-monoester 1c was apparent by NMR and HRMS analysis (calcd. for $\left[\mathrm{C}_{36} \mathrm{H}_{66} \mathrm{O}_{13}+\mathrm{NH}_{4}\right]^{+}$: 724.4842, obsd.: 724.4843). H-6a and H-6b of the coupled sugar maintain the downfield shift and geminal splitting patterns $[\delta 4.46(\mathrm{dd}$, $\left.J_{6^{\prime} \mathrm{a}, 6^{\prime} \mathrm{b}}=12.1 \mathrm{~Hz}, J_{6^{\prime} \mathrm{a}, 5^{\prime}}=2.1 \mathrm{~Hz}, 1 \mathrm{H}, \mathrm{H}-6^{\prime} \mathrm{a}\right)$ and $4.24\left(\mathrm{dd}, J_{6^{\prime} \mathrm{a}, 6^{\prime} \mathrm{b}}=12.1 \mathrm{~Hz}, J_{6^{\prime} \mathrm{b}, 5^{\prime}}=5.7 \mathrm{~Hz}\right.$, $\left.\left.1 \mathrm{H}, \mathrm{H}-6^{\prime} \mathrm{b}\right)\right]$ seen in the TMS-protected monoester 32, which confirms that the ester functionality remained intact, while loss of the TMS-ether signals ( $5 \mathrm{~s}, \delta 0.16-011 \mathrm{ppm})$ confirmed that deprotection had occurred. Furthermore, the protons of the meromycolate branch of the epoxy-functionalised lipid are apparent at $\delta 3.36-3.33(\mathrm{~m}, \mathrm{H}-2), 2.82(\mathrm{H}-$ 1a), $2.58(\mathrm{H}-1 \mathrm{~b})$ and 2.17-2.14 (m, H-3), verifying that the desired epoxide functionality has been retained.

Further analysis of the ${ }^{1} \mathrm{H}$ NMR spectra revealed the presence of a second trehalose monoester which, upon considering the reactivity of the epoxide functionality, was initially thought to be the fluorine substituted adduct 34 (Scheme 29). However, the lack of a fluorine signal in ${ }^{19} \mathrm{~F}$ NMR indicated that this product had not formed and indeed, the substantial downfield shift of protons H-6a and H-6b $[\delta$ 4.88-4.80 (m) and $\delta 4.61$ $4.57(\mathrm{~m})]$, compared to 1c, indicated that a larger, more electronegative group may have substituted. HRMS was used to rule out fluorine substitution and identify this by-product as the pyridinium substituted monoester 35 (calcd. for $\left[\mathrm{C}_{41} \mathrm{H}_{72} \mathrm{NO}_{13}\right]^{+}$: 786.4998, obsd.: $786.5012)$. This assignment was corroborated by the presence of three downfield signals $[\delta 8.96-8.95(\mathrm{~d}, J=6.8 \mathrm{~Hz}), 8.64-8.61(\mathrm{~m})$ and $8.14-8.11(\mathrm{dd}, J=14.4 \mathrm{~Hz}$ and $J=6.7$ $\mathrm{Hz})]$ in the ${ }^{1} \mathrm{H}$ NMR, which correspond to the pyridinium methine protons. Similarly, the treatment of diester $\mathbf{3 3}$ with HF-pyridine also gave a mixture of products which could be assigned by HRMS as the desired final target $2 \mathrm{c}$ (calcd. for $\left[\mathrm{C}_{60} \mathrm{H}_{110} \mathrm{O}_{15}+\mathrm{NH}_{4}\right]^{+}$: 1088.8183, obsd.: 1088.8087), the mono-substituted epoxy pyridinium diester $\mathbf{3 6}$ (calcd. for $\left[\mathrm{C}_{65} \mathrm{H}_{116} \mathrm{NO}_{15}\right]^{+}: 1150.8339$, obsd.: 1150.8312), and the di-substituted pyridinium diester 37 (calcd. for $\left[\mathrm{C}_{70} \mathrm{H}_{122} \mathrm{~N}_{2} \mathrm{O}_{15}+\mathrm{NH}_{4}\right]^{2+}$ : 1230.8834 obsd. $[\mathrm{M} / 2]^{+}$: 615.4411) 
(Scheme 30). It is anticipated that additional purification of the product mixtures obtained here will furnish the desired TME 1c and TDE $\mathbf{2 c}$, as well as the pyridinium adducts $\mathbf{3 5}$, 36 and 37.

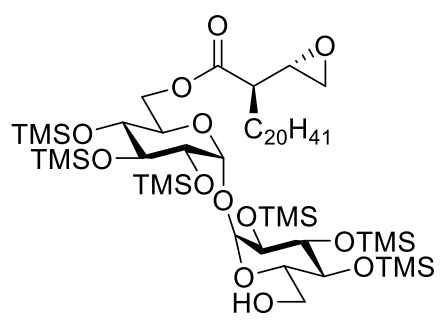

32

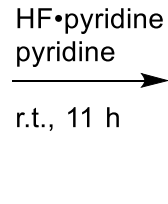

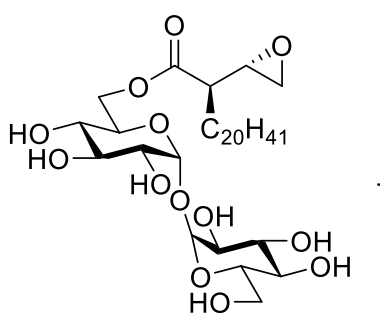

1c

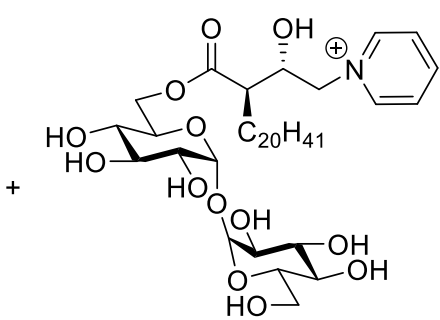

35

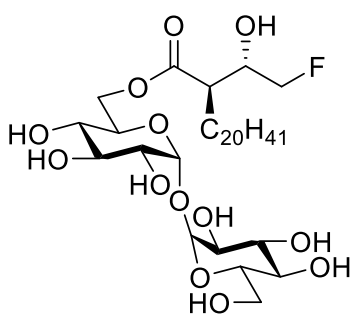

34 (not observed)

Scheme 29: HF• pyridine deprotection of TME 32 gave a mixture of products
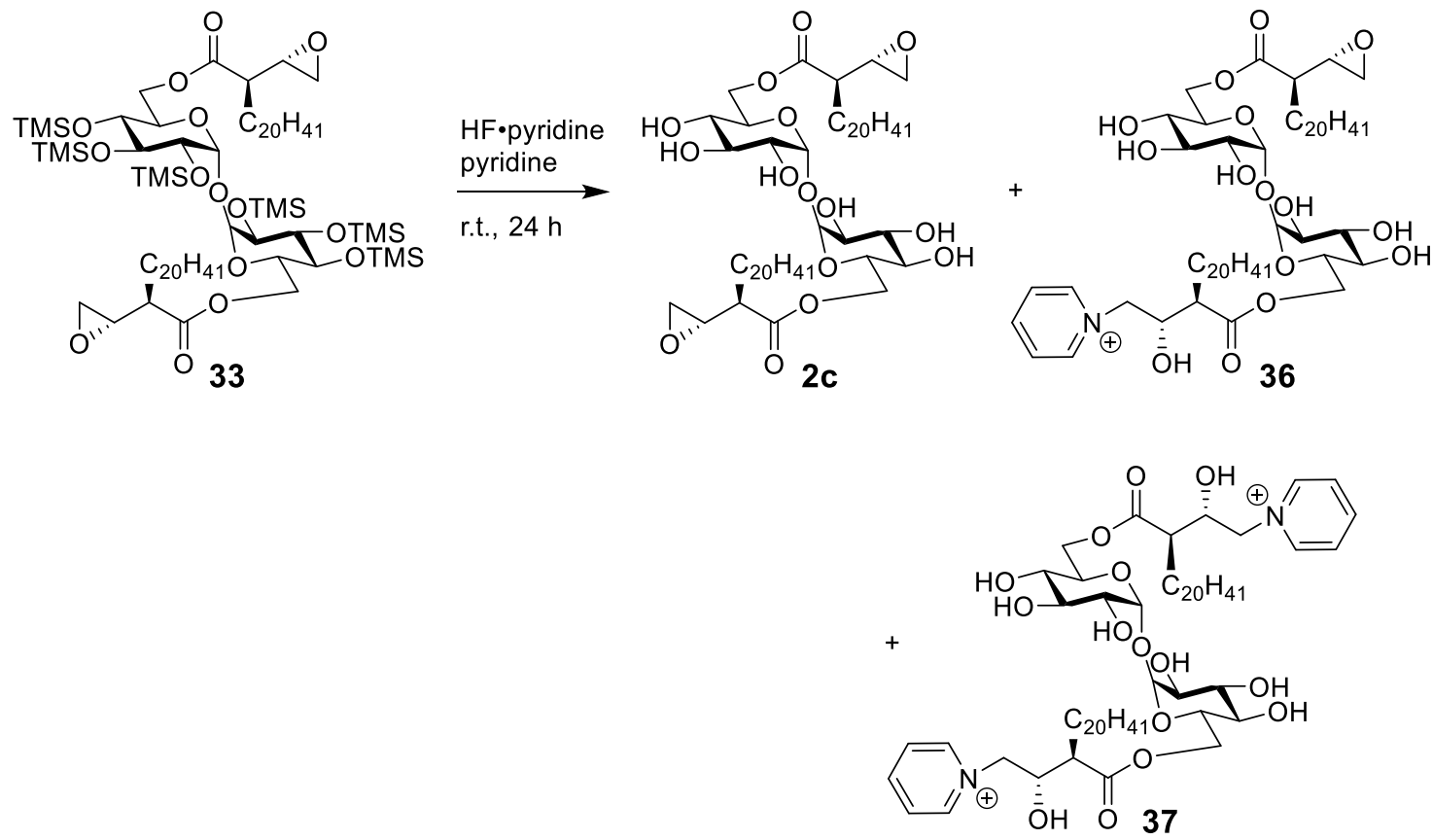

Scheme 30: HF•pyridine deprotection of TDE 33 gave a mixture of products 
While the formation of the pyridinium-substituted adducts was unexpected, this provides additional trehalose glycolipid derivatives which are likely to have interesting interactions with the Mincle and MCL receptor binding sites. In order to avoid the formation of the pyridinium by-products, the protected TME 32 and TDE 33 can be subjected to global deprotection with the milder conditions employed by Khan et al. ${ }^{73}$ using Dowex $-\mathrm{H}^{+}$and a non-nucleophilic solvent, which is expected to provide the desired target TME 1c and TDE $2 \mathbf{c}$ without the formation of undesired by-products. 


\section{Conclusions and Future Work}

\subsection{Conclusions}

The synthesis of three trehalose monoester derivatives 1a-c and one trehalose diester derivative $\mathbf{2 c}$ has been successfully accomplished. The mycolic acid analogues bear a C22 $\alpha$-chain and a short meromycolate branch functionalised with a hydroxy-, methoxy, or epoxy-group (3a-c, respectively). A key step in the synthesis of these compounds is the Fráter-Seebach alkylation, which was used to install the C20 $\alpha$-chain in the formation of the $\alpha$-alkylated $\beta$-hydroxy ester building block in good yield. Borane-mediated reduction of the diester proved challenging due to non-selective reduction and the formation of a cyclic by-product, however, optimisation of this reaction to provide the desired diol in respectable yield was successfully accomplished when careful attention was paid to the reaction conditions and quality of the reagents used. Preparation of the key intermediate, epoxide 5, proceeded smoothly, after which point the synthesis diverged for the preparation of mycolic acids 3a-c. Esterification of TMS-trehalose with the prepared acids provided the target TMS-protected TMEs 27, 29, and 32, as well as TDE 33. It is envisioned that through optimisation and scale up of the coupling reactions the yields of the glycolipids can be improved, and moreover, that diester derivatives $\mathbf{2 8}$ and 30 may also be synthesised. The synthetic trehalose esters were then subjected to global deprotection with HF-pyridine to afford target compounds 1a-c and 2c, which will be used in biological testing to determine their immunostimulatory activity and garner crystal structure data on the glycolipid-Mincle complexes. The synthesis and testing of these modified trehalose glycolipids will afford valuable information on the structureactivity relationship of trehalose glycolipids and the properties needed for ligand binding and immune cell activation via Mincle and MCL, thereby aiding in the development of improved vaccine adjuvants for diseases such as tuberculosis and cancer. 


\subsection{Future Work}

\subsubsection{Chemical Synthesis}

The validity of this synthetic strategy to provide modified trehalose glycolipid derivatives has been proven through the synthesis of target compounds 1a-c and $\mathbf{2 c}$, and although these syntheses were achieved in low yield, advanced intermediates are available and will be used to prepare more of the targets, and to optimise the coupling conditions for the preparation of TDEs 2a-b. Moreover, additional TME and TDE derivatives can be synthesised in order to further probe the properties of ligand binding to the receptors Mincle and MCL, and to investigate the immunostimulatory effects of these compounds. Here, a second alkyl chain can be introduced via selective opening of the epoxide ring, using alkylated copper-lithium ${ }^{106}$ or organoaluminium reagents, ${ }^{107}$ or copper-mediated Grignard reactions. ${ }^{108}$ A variety of alcohol, thiol and nitrogen containing compounds can also be used to open the epoxide by nucleophilic attack, to render alkoxyether, thioether, and nitrogen containing analogues, and it is expected that this should proceed in a straightforward manner as evidenced by the ready substitution of the epoxide with pyridine. ${ }^{109,110}$

\subsubsection{Biological Evaluation}

Biological testing will be carried out to determine the immunostimulatory activity of the prepared trehalose glycolipids. The ability of $\mathbf{1 a - c}$ and $\mathbf{2 c}$ to activate the innate immune response will be assessed via the in vitro activation of macrophages. Here, bone-marrowderived macrophages (BMMs) from wild type (C57BL/6) mice will be used to assess whether the synthetic trehalose glycolipids are able to activate macrophages, as determined by nitric oxide production using the Griess assay, and levels of proinflammatory cytokines (e.g. IL-1 $\beta$ and IL-6) using sandwich ELISA. The levels of such cytokines and toxic mediators in the cellular supernatant after exposure to the different trehalose glycolipids will give quantifiable data to compare between the analogues, thereby providing information on the properties of ligands that can activate macrophages. For compounds exhibiting activity, the assays will be repeated using macrophages from Mincle $^{-/-}$mice to ascertain if active derivatives are acting via the Mincle receptor. To determine if the activity is occuring via MCL, the immunostimulatory analogues will be sent to collaborators in Japan who can assess binding to MCL using expressed MCL 
protein in surface plasmon binding assays, and who can repeat the macrophage activation experiments in $\mathrm{MCL}^{-/-}$mice. Our collaborators, Prof. Sho Yamasaki (Kyushu University, Fukuoka, Japan and Japan Science and Technology Agency, Saitama, Japan) and Prof. Katsumi Maenaka (Hokkaido University, Sapporo, Japan) will also attempt to obtain crystal structures of the active trehalose glycolipids when bound to both Mincle and MCL. 


\section{Experimental}

\subsection{General Methods}

Unless otherwise stated, all reactions were carried out under an atmosphere of argon. Before use, THF was distilled from $\mathrm{Na}$ wire and benzophenone, $\mathrm{CH}_{2} \mathrm{Cl}_{2}$ was distilled from $\mathrm{P}_{2} \mathrm{O}_{5}$, toluene was dried and stored over $\mathrm{Na}$ wire, diisopropyl amine was dried with $\mathrm{NaOH}$, distilled and stored under argon, methanol was distilled, and methyl iodide was distilled prior to use. Octadecanol (BDH), PCC (Aldrich), vinyl magnesium bromide (Aldrich), $\mathrm{PPh}_{3}$ (Merck), I 2 (Unilab), L-(-)-Malic acid (Sigma), $n$-BuLi (Aldrich, 2M in hexanes), $\mathrm{Pd}(\mathrm{OH})_{2} / \mathrm{C}$ (Acros, $20 \mathrm{wt} \%$ ), $\mathrm{BH}_{3} \cdot \mathrm{Me}_{2} \mathrm{~S}$ (BMS, Aldrich, $10 \mathrm{M}$ in THF, $2 \mathrm{M}$ in THF and neat), $\mathrm{NaBH}_{4}$ (Aldrich), Dowex-H $\mathrm{H}^{+}$(Supleco), tosyl chloride (Aldrich), citric acid (BDH), $\mathrm{K}_{2} \mathrm{CO}_{3}$ (Panreac), $\mathrm{LiOH} \cdot \mathrm{H}_{2} \mathrm{O}$ (Reidel-deHaen), $\mathrm{HCl}$ (Panreac), TBSOTf (Apollo Scientific), 2,6-lutidine (Fluka), methyl iodide (Unilab), NaH (Aldrich), LiCl (Pure Science), D-(+)-trehalose dehydrate (Sigma), anhydrous DMF (Acros), $N, O$ bis(trimethylsilyl)acetamide (Fluka), TBAF (Aldrich), acetic acid (UniVar), $\mathrm{Et}_{2} \mathrm{O}$ (BioLab) isopropanol (Pure Science), EDCI (Aldrich), DMAP (Merck), HF.pyridine (Acros), $\mathrm{Ca}(\mathrm{OAc})_{2}$ (Sigma), EtOAc (Fisher Scientific), petroleum ether (Fisher Scientific), ethanol (Fisher Scientific), methanol (Fisher Scientific), pyridine (Panreac), $\mathrm{NaHCO}_{3}$ (Pure Science), NaOH (Pure Science), $\mathrm{KOH}$ (Panreac), $\mathrm{NH}_{4} \mathrm{Cl}$ (SciChem), $\mathrm{Na}_{2} \mathrm{~S}_{2} \mathrm{O}_{3}$ (Roth), $\mathrm{MgSO}_{4}$ (Pure Science) and $\mathrm{NaCl}$ (Panreac) were used as received. Solvents were removed by evaporation at reduced pressure. Reactions were monitored by TLC with Macherey-Nagel silica gel-coated plastic sheets $(0.20 \mathrm{~mm}$, Polygram SIL G/UV254) by coating with a solution of $5 \% \mathrm{~K}_{2} \mathrm{CO}_{3}, 1 \% \mathrm{KMnO}_{4}$ and $1 \% \mathrm{NaIO}_{4}$ in $\mathrm{H}_{2} \mathrm{O}$ followed by heating. Column chromatography was performed using silica gel (40 - 63 $\mu \mathrm{m}$, Pure Science), and size exclusion chromatography was performed using lipophilic sephadex (25-100 $\mu$, Sigma), HRMS were recorded with a Waters Q-TOF Premier Tandem Mass Spectrometer using electrospray ionisation in the positive or negative mode. Optical rotations were recorded with a Autopol II instrument (Rudolph Research Analytical) at $589 \mathrm{~nm}$ (sodium D-line). Infrared spectra were recorded as thin films with a Bruker Tensor 27 FTIR spectrometer equipped with an attenuated total reflectance (ATR) sampling accessory. NMR spectra were recorded at $20{ }^{\circ} \mathrm{C}$ in $\mathrm{CDCl}_{3}$ or $\mathrm{CD}_{3} \mathrm{OD}$ with Varian INOVA spectrometers operating at 300, 500 or $600 \mathrm{MHz}$. Chemical shifts 
are given in ppm $(\delta)$ relative to $\mathrm{CDCl}_{3}$ or $\mathrm{CD}_{3} \mathrm{OD}$. NMR peak assignments were made using COSY, HSQC and HMBC 2D experiments.

\subsection{Chemical Synthesis}<smiles>CC(C)(C)[13C](=O)C(=O)O</smiles>

1-Octadecanal (11). 1-Octadecanol (15.00 g, $55.5 \mathrm{mmol}, 1.0$ equiv.) was added to a solution of PCC (23.91 g, $111 \mathrm{mmol}, 2.0$ equiv.) with $4 \AA$ molecular sieves $(16.5 \mathrm{~g})$ in dry DCM $(270 \mathrm{~mL})$, and the reaction mixture stirred at r.t. for $3 \mathrm{~h}$. The mixture was then concentrated in vacuo and the resulting oil subjected to silica gel flash column chromatography (PE/EA, 20:1, v/v) to obtain 1-octadecanal as a white solid (12.04 g, $44.9 \mathrm{mmol}, 76 \%) . R_{\mathrm{f}}=0.66(\mathrm{PE} / \mathrm{EA}, 2 / 1, \mathrm{v} / \mathrm{v})$; IR (film) 2914, 2848, 1712, 1471, $1299 \mathrm{~cm}^{-1} ;{ }^{1} \mathrm{H}$ NMR $\left(500 \mathrm{MHz}, \mathrm{CDCl}_{3}\right) \delta 9.77$ (s, 1H, H-1), $2.43(\mathrm{t}$, $\left.J_{2,3}=6.7 \mathrm{~Hz}, 2 \mathrm{H}, \mathrm{H}-2\right), 1.63$ (t, $\left.J_{2,3}=7.0 \mathrm{~Hz}, 2 \mathrm{H}, \mathrm{H}-3\right), 1.30-1.26$ (m, 28H, H-4-H-17), $0.89(\mathrm{t}, J=6.9 \mathrm{~Hz}, 3 \mathrm{H}, \mathrm{H}-18) ;{ }^{13} \mathrm{C} \mathrm{NMR}\left(125 \mathrm{MHz}^{\mathrm{CDCl}} 3\right) \delta 203.1$ (C-1), 43.9 (C-2), 31.9 (C-3), 29.70, 29.67, 29.65, 29.59, 29.44, 29.37, 29.2, 22.7, 22.1, (C-4-C-17), 14.1 (C-18). HRMS (ESI): calcd. for $\left[\mathrm{C}_{18} \mathrm{H}_{36} \mathrm{O}+\mathrm{Na}\right]^{+}$: 291.2664; obsd.: 291.2652. Spectral data matched those reported in literature. ${ }^{85}$

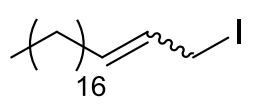

1-Iodoeicos-2-ene (7). Vinylmagnesium bromide (1 M in THF, 22.5 mmol, 1.2 equiv.) was added to a solution of 1-octadecanal $11(5.03 \mathrm{~g}$, $18.8 \mathrm{mmol})$ in toluene $(100 \mathrm{~mL})$ at $0{ }^{\circ} \mathrm{C}$. The reaction mixture was allowed to warm to r.t. while stirring for $1 \mathrm{~h}$, after which time the reaction was quenched by the addition of $\mathrm{NH}_{4} \mathrm{Cl}$ and the product extracted with EtOAc $(2 \times 80 \mathrm{~mL})$. The combined organic layers were washed with saturated $\mathrm{NH}_{4} \mathrm{Cl}$ solution $(200 \mathrm{~mL})$, water $(200 \mathrm{~mL})$, and brine $(200$ $\mathrm{mL}$ ), dried over $\mathrm{MgSO}_{4}$, filtered, and concentrated in vacuo to give the allylic alcohol as a bright yellow solid, which was used without further purification. In a separate flask, iodine (6.75 g, $26.7 \mathrm{mmol}, 1.5$ equiv.) was added to a solution of $\mathrm{PPh}_{3}(6.96 \mathrm{~g}, 26.7 \mathrm{mmol}$, 1.5 equiv.) in dry DCM (20 mL), and the resulting mixture was stirred at r.t. for $10 \mathrm{~min}$. A solution of the crude allylic alcohol (4.79 g, $17.8 \mathrm{mmol}, 1$ equiv.) in DCM (15 mL) was then added, and the mixture stirred at r.t. for $17 \mathrm{~h}$. The reaction mixture was diluted with DCM and washed with saturated $\mathrm{Na}_{2} \mathrm{~S}_{2} \mathrm{O}_{3}$ solution $(5 \times 75 \mathrm{~mL})$ to remove iodine, water $(75 \mathrm{~mL})$, and brine $(75 \mathrm{~mL})$. The organic layer was dried with $\mathrm{MgSO}_{4}$, filtered, concentrated in vacuo, and purified by silica gel flash column chromatography (PE), to 
give the allylic iodide 7 as an orange solid (5.05 g, $12.4 \mathrm{mmol}, 66 \%$ over two steps). $R_{\mathrm{f}}$ $=0.76(\mathrm{PE} / \mathrm{EA}, 2: 1, \mathrm{v} / \mathrm{v})$; IR (film) 2921, 2852, 1464, 1149, $962 \mathrm{~cm}^{-1} ;{ }^{1} \mathrm{H}$ NMR (500 $\left.\mathrm{MHz} \mathrm{CDCl}_{3}\right) \delta 5.73-5.71\left(\mathrm{~m}, 2 \mathrm{H}, \mathrm{H}-2\right.$ and H-3), $3.89\left(\mathrm{~d}, J_{2,3}=5.9 \mathrm{~Hz}, 2 \mathrm{H}, \mathrm{H}-1 \mathrm{a}\right.$ and H-1b, E-isomer), 2.03 (m, 2 H, H-4a and H-4b), 1.38-1.26 (m, 30 H, H-5-H-19), 0.89 (t, $\left.\mathrm{J}_{6,7}=7.0 \mathrm{~Hz}, 3 \mathrm{H}, \mathrm{CH}_{3}-20\right)$ ppm. ${ }^{13} \mathrm{C} \mathrm{NMR}\left(125 \mathrm{MHz}, \mathrm{CDCl}_{3}\right) \delta 135.4(\mathrm{C}-2), 127.8(\mathrm{C}-$ 3), 32.0, 31.9, 29.7, 29.6, 29.5, 29.4, 29.0, 28.8, 22.7 (C-4-C-19), 14.1 (C-20), 7.1 (C-1). HRMS (ESI) calcd. for $\left[\mathrm{C}_{20} \mathrm{H}_{39} \mathrm{I}\right]$ : 406.2096; obsd. 406.2632. Spectral data matched that reported in literature. ${ }^{85}$<smiles>CCOC(=O)CC(O)C(=O)OCC</smiles>

Diethyl L-malate (8). L-Malic acid (10.0 g, $75 \mathrm{mmol})$ was dissolved in ethanol and concentrated $\mathrm{H}_{2} \mathrm{SO}_{4}(5.0 \mathrm{~mL}, 93 \mathrm{mmol})$ was added. The reaction mixture was refluxed for $54 \mathrm{~h}$, then concentrated in vасио. The product was purified by silica gel flash column chromatography (PE/EA, 2:1) to give diethyl malate $\mathbf{8}$ as a colourless oil (13.5 g, 71 mmol, 95\%). $R_{\mathrm{f}}=0.22(\mathrm{PE} / \mathrm{EA}, 2: 1, \mathrm{v} / \mathrm{v})$; IR (film) 3494, 2984, 2940, 1729, 1467, 1264, $1163 \mathrm{~cm}^{-1}$; ${ }^{1} \mathrm{H}$ NMR $\left(500 \mathrm{MHz}, \mathrm{CDCl}_{3}\right) \delta 4.49-4.47$ (m, $\left.1 \mathrm{H}, \mathrm{H}-2\right), 4.28-4.26$ (m, $2 \mathrm{H}, 1-$ $\left.\mathrm{OCH}_{2} \mathrm{CH}_{3}\right), 4.17\left(\mathrm{q}, J=7.1 \mathrm{~Hz}, 2 \mathrm{H}, 4-\mathrm{OCH}_{2} \mathrm{CH}_{3}\right), 2.85\left(\mathrm{dd}, J_{3 \mathrm{a}, 3 \mathrm{~b}}=16.4 \mathrm{~Hz}, J_{2,3 \mathrm{a}}=4.4\right.$ $\mathrm{Hz}, 1 \mathrm{H}, \mathrm{H}-3 \mathrm{a}), 2.78\left(\mathrm{dd}, J_{3 \mathrm{a}, 3 \mathrm{~b}}=16.4 \mathrm{~Hz}, J_{2,3 \mathrm{~b}}=5.9 \mathrm{~Hz}, 1 \mathrm{H}, \mathrm{H}-3 \mathrm{~b}\right), 1.30$ (t, $J=7.5 \mathrm{~Hz}$, $\left.3 \mathrm{H}, 1-\mathrm{OCH}_{2} \mathrm{CH}_{3}\right), 1.26\left(\mathrm{t}, J=7.0 \mathrm{~Hz}, 3 \mathrm{H}, 4-\mathrm{OCH}_{2} \mathrm{CH}_{3}\right) ;{ }^{13} \mathrm{C} \mathrm{NMR}\left(125 \mathrm{MHz}, \mathrm{CDCl}_{3}\right)$ $\delta 173.4(\mathrm{C}-1), 170.5(\mathrm{C}-4), 67.3(\mathrm{C}-2), 62.0\left(1-\mathrm{OCH}_{2} \mathrm{CH}_{3}\right), 61.0\left(4-\mathrm{OCH}_{2} \mathrm{CH}_{3}\right), 38.7(\mathrm{C}-$ 3), $14.1\left(1-\mathrm{OCH}_{2} \mathrm{CH}_{3}\right.$ and $\left.4-\mathrm{OCH}_{2} \mathrm{CH}_{3}\right)$; HRMS (ESI) calcd. for $\left[\mathrm{C}_{8} \mathrm{H}_{14} \mathrm{O}_{5}+\mathrm{Na}\right]^{+}$: 213.0739; obsd. 213.0734.

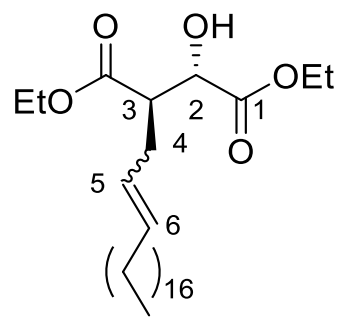

(2S,3R)-Ethyl 3-(ethoxycarbonyl)-2-hydroxytricos-5-enoate (13). $n \mathrm{BuLi}(2.0 \mathrm{M}$ in hexanes, $0.69 \mathrm{~mL}, 1.38 \mathrm{mmol}$ ) was added to a solution of diisopropylamine $(0.21 \mathrm{~mL}, 1.48 \mathrm{mmol})$ in THF $(2.0$ $\mathrm{mL}$ ) at $-78^{\circ} \mathrm{C}$. After stirring for $15 \mathrm{~min}$, the solution was warmed to $-30{ }^{\circ} \mathrm{C}$ and diethyl (S)-malate 8 (94 $\left.\mathrm{mg}, 0.49 \mathrm{mmol}\right)$ in THF (2.0

$\mathrm{mL}$ ) was added drop wise. The resulting mixture was stirred at $-30{ }^{\circ} \mathrm{C}$ for $10 \mathrm{~min}$, then cooled to $-45^{\circ} \mathrm{C}$ and the alkyl iodide $7(0.30 \mathrm{~g}, 0.74 \mathrm{mmol})$ in THF $(2.0 \mathrm{~mL})$ was added drop wise. The reaction was stirred for $5 \mathrm{~h}$, during which time the temperature increased to $-30{ }^{\circ} \mathrm{C}$. The reaction was quenched with saturated $\mathrm{NH}_{4} \mathrm{Cl}$ solution and extracted with 
EtOAc $(3 \times 50 \mathrm{~mL})$. The combined organic layers were washed with water $(150 \mathrm{~mL})$ and brine $(150 \mathrm{~mL})$, dried over $\mathrm{MgSO}_{4}$, filtered, and concentrated in vacuo to yield a yellow oil. The residue was purified by gradient silica gel flash column chromatography (PE/EA, $20: 1 \rightarrow 15: 1, \mathrm{v} / \mathrm{v})$ to give 13 as a white solid $(0.14 \mathrm{~g}, 0.30 \mathrm{mmol}, 61 \%) . R_{\mathrm{f}}=0.60(\mathrm{PE} / \mathrm{EA}$, $2: 1, \mathrm{v} / \mathrm{v}) ;[\alpha]_{\mathrm{D}}^{22}=+7.5\left(c=1.0, \mathrm{CHCl}_{3}\right) ; \mathrm{IR}($ film) $3505,2919,2851,1735,1466,1372$, 1212, 1110, 1032, 970, $861 \mathrm{~cm}^{-1} ;{ }^{1} \mathrm{H}$ NMR $\left(500 \mathrm{MHz}, \mathrm{CDCl}_{3}\right) \delta 5.61-5.55(\mathrm{~m}, 1 \mathrm{H}, \mathrm{H}-$ 6), 5.42-5.37 (m, $1 \mathrm{H}, \mathrm{H}-5), 4.30-4.22$ (m, $3 \mathrm{H}, 1-\mathrm{OCH}_{2} \mathrm{CH}_{3}$ and $\left.\mathrm{H}-2\right), 4.18-4.12$ (m, 2 $\mathrm{H}, 3^{\prime}-\mathrm{OCH}_{2} \mathrm{CH}_{3}$ ), 3.18 (broad s, $\left.1 \mathrm{H}, \mathrm{OH}\right), 2.92-2.89$ (m, $\left.1 \mathrm{H}, \mathrm{H}-3\right), 2.58-2.54(\mathrm{~m}, 1 \mathrm{H}$, H-4a), 2.41-2.35 (m, 1 H, H-4b), 1.98 (q, $J_{6,7}=J_{7,8}=7.1$ Hz, $\left.2 \mathrm{H}, \mathrm{H}-7 \mathrm{a}, \mathrm{b}\right), 1.33-1.23$ (m, $36 \mathrm{H}, \mathrm{H}-8-\mathrm{H}-22$ and $\left.2 \mathrm{x} \mathrm{OCH}_{2} \mathrm{CH}_{3}\right), 0.89$ (t, $\left.J=6.7 \mathrm{~Hz}, 3 \mathrm{H}, \mathrm{CH}_{3}-23\right) ;{ }^{13} \mathrm{C} \mathrm{NMR}(125$ $\mathrm{MHz}, \mathrm{CDCl}_{3}$ ) $\delta 173.7$ (C-1), 172.3 (C-3'), 134.5 (C-6), 125.8 (C-5), 70.2 (C-2), 61.8 (1$\mathrm{OCH}_{2} \mathrm{CH}_{3}$ ), 60.9 (3- $\left.\mathrm{OCH}_{2} \mathrm{CH}_{3}\right), 48.6$ (C-3), 32.6 (C-7), 31.9 (C-8), 31.1 (C-4), 31.0, 29.7, 29.67, 29.5, 29.4, 29.2, 22.7 (C-9-C-22), $14.1\left(\mathrm{C}-23,1-\mathrm{OCH}_{2} \mathrm{CH}_{3}\right.$ and $\left.3-\mathrm{OCH}_{2} \mathrm{CH}_{3}\right)$. HRMS (ESI): calcd. for $\left[\mathrm{C}_{28} \mathrm{H}_{52} \mathrm{O}_{5}+\mathrm{Na}\right]^{+}$491.3712; obsd. 491.3715. Spectral data matched those reported in literature. ${ }^{85}$

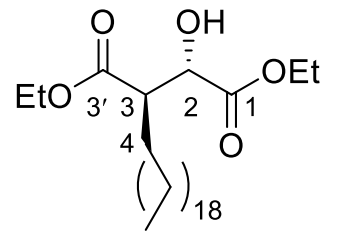

(2S,3R)-Ethyl 3-(ethoxycarbonyl)-2-hydroxy-tricosanoate (14). $\mathrm{Pd}(\mathrm{OH})_{2} / \mathrm{C}(6 \mathrm{wt} .-\%)$ was added to a solution of $\mathbf{1 3}(0.358 \mathrm{~g}, 0.76$ mmol) in a mixture of $\mathrm{CH}_{2} \mathrm{Cl}_{2} / \mathrm{EtOH}(15 \mathrm{~mL}, 1: 1$, v/v) and stirred at r.t. overnight under an atmosphere of $\mathrm{H}_{2}$. The reaction mixture was filtered through Celite, and the Celite washed with $\mathrm{CH}_{2} \mathrm{Cl}_{2} / \mathrm{EtOH}(50 \mathrm{~mL}, 1: 1$, v/v). After concentration of the filtrate in vacuo the residue was purified by silica gel flash column chromatography (PE/EA, 10:1, v/v) to give 17 as a white solid (0.359 g, 0.76 mmol, quant.). $R_{\mathrm{f}}=0.60(\mathrm{PE} / \mathrm{EA}, 2: 1, \mathrm{v} / \mathrm{v}) ;[\alpha]_{\mathrm{D}}^{22}=+2.8\left(c=1.0, \mathrm{CHCl}_{3}\right)$; IR (film) 3512 , 2915, 2851, 1737, 1467, 1372, 1189, 1030, $734 \mathrm{~cm}^{-1} ;{ }^{1} \mathrm{H}$ NMR (500 MHz, $\left.\mathrm{CDCl}_{3}\right) \delta 4.29$ $4.25\left(\mathrm{~m}, 3 \mathrm{H}, 1-\mathrm{OCH}_{2} \mathrm{CH}_{3}\right.$ and $\left.\mathrm{H}-2\right)$, 4.18-4.13 (m, $\left.2 \mathrm{H}, 3^{\prime}-\mathrm{OCH}_{2} \mathrm{CH}_{3}\right), 3.19$ (d, $J_{2, \mathrm{OH}}=$ 7.6 Hz, $1 \mathrm{H}, \mathrm{OH}), 2.85-2.84$ (m, $1 \mathrm{H}, \mathrm{H}-3), 1.85-1.82$ (m, $1 \mathrm{H}, \mathrm{H}-4 \mathrm{a}), 1.68-1.64$ (1 H, H4b), 1.43-1.24 (m, $42 \mathrm{H}, \mathrm{H}-5-\mathrm{H}-22,1-\mathrm{OCH}_{2} \mathrm{CH}_{3}$ and 3'- $\left.\mathrm{OCH}_{2} \mathrm{CH}_{3}\right), 0.90-0.85$ (m, $3 \mathrm{H}$, $\left.\mathrm{CH}_{3}-23\right) ;{ }^{13} \mathrm{C} \mathrm{NMR}\left(125 \mathrm{MHz}, \mathrm{CDCl}_{3}\right) \delta 173.5$ (C-1), 172.9 (C-3'), 71.0 ( C-2), 61.8 (1$\mathrm{OCH}_{2} \mathrm{CH}_{3}$ ), 60.8 (3- $\left.\mathrm{OCH}_{2} \mathrm{CH}_{3}\right), 48.6$ (C-3), 31.9 (C-4), 29.71, 29.68, 29.67, 29.65, 29.6, 29.5, 29.4, 28.1, 27.4, 22.7 (C-5-C-22), $14.1\left(\mathrm{C}-23,1-\mathrm{OCH}_{2} \mathrm{CH}_{3}\right.$ and $\left.3-\mathrm{OCH}_{2} \mathrm{CH}_{3}\right)$. HRMS (ESI): calcd. for $\left[\mathrm{C}_{28} \mathrm{H}_{54} \mathrm{O}_{5}+\mathrm{Na}\right]^{+}$493.3863; obsd. 493.3857. Spectral data matched those reported in literature. ${ }^{85}$ 


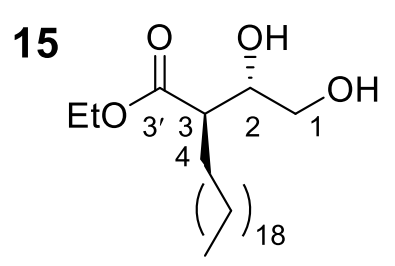

(R)-Ethyl 2-((S)-1,2-dihydroxyethyl)docosanoate

(15).

Borane dimethyl sulfide complex ( $35 \mu \mathrm{L}, 0.373 \mathrm{mmol})$ was added to a solution of $14(0.146 \mathrm{~g}, 0.311 \mathrm{mmol})$ in $\mathrm{THF} /$ toluene $(2 \mathrm{~mL}, 1: 1, \mathrm{v} / \mathrm{v})$ at $0{ }^{\circ} \mathrm{C}$. The reaction mixture was stirred for 1.5 $\mathrm{h}$ before the addition of $\mathrm{NaBH}_{4}$ (cat.), and was then allowed to warm to r.t. while stirring for $15 \mathrm{~h}$. The reaction was quenched with $\mathrm{EtOH}$ and Dowex- $\mathrm{H}^{+}$, and concentrated in vacuo. The residue was dissolved in toluene/EtOH $(10 \mathrm{~mL}, 1: 1, \mathrm{v} / \mathrm{v})$ and concentrated $(3 \mathrm{x})$ in order to remove ethanol and boron as $\mathrm{B}(\mathrm{OEt})_{3}$. The residue was purified by gradient silica gel flash column chromatography (PE/EA, 10:1 $\rightarrow$ 4:1, v/v) to give 15 as a white solid $(0.115 \mathrm{~g}, 0.269 \mathrm{mmol}, 87 \%) . R_{\mathrm{f}}=0.44(\mathrm{PE} / \mathrm{EA}, 1: 1, \mathrm{v} / \mathrm{v}) ;[\alpha]_{\mathrm{D}}^{22}=+6.0(c=$ 1, $\mathrm{CHCl}_{3}$ ); IR (film) 3397, 2917, 2850, 1717, 1467, $758 \mathrm{~cm}^{-1} ;{ }^{1} \mathrm{H}$ NMR (500 MHz, $\left.\mathrm{CDCl}_{3}\right) \delta$ 4.20-4.17 (m, $\left.2 \mathrm{H}, 3^{\prime}-\mathrm{OCH}_{2} \mathrm{CH}_{3}\right), 3.82-3.81(\mathrm{~m}, 1 \mathrm{H}, \mathrm{H}-2), 3.69-3.63(\mathrm{~m}, 1 \mathrm{H}$, H-1a), $3.54\left(\mathrm{dd}, J_{1 \mathrm{a}, 1 \mathrm{~b}}=11.2 \mathrm{~Hz}, J_{1 \mathrm{~b}, 2}=6.8 \mathrm{~Hz}, 1 \mathrm{H}, \mathrm{H}-1 \mathrm{~b}\right), 3.04$ (s, 1H, 2-OH), 2.54-2.51 (m, 1H, H-3), 1.03 (s, 1H, 1-OH), 1.71-1.67 (m, 2H, H-4a and H-4b), 1.30-1.25 (m, 39H, $\mathrm{CH}_{2}-5-22$ and $\left.3^{\prime}-\mathrm{OCH}_{2} \mathrm{CH}_{3}\right), 0.88\left(\mathrm{t}, J=6.7 \mathrm{~Hz}, 3 \mathrm{H}, \mathrm{CH}_{3}-23\right) ;{ }^{13} \mathrm{C} \mathrm{NMR}(125 \mathrm{MHz}$, $\left.\mathrm{CDCl}_{3}\right) \delta 175.3\left(\mathrm{C}-3\right.$ ') $, 72.6(\mathrm{C}-2), 65.1(\mathrm{C}-1), 60.8\left(1-\mathrm{OCH}_{2} \mathrm{CH}_{3}\right), 47.5(\mathrm{C}-3), 31.9,29.7$, 29.6, 29.5, 29.4, 29.4, 29.3, 27.1, 22.7 (C-4-C-22), 14.2, 14.1 (C-23 and 3'- $\left.\mathrm{OCH}_{2} \mathrm{CH}_{3}\right)$; HRMS (ESI): calcd. for $\left[\mathrm{C}_{26} \mathrm{H}_{52} \mathrm{O}_{4}+\mathrm{H}\right]^{+} 429.3938$; obsd.429.3877.

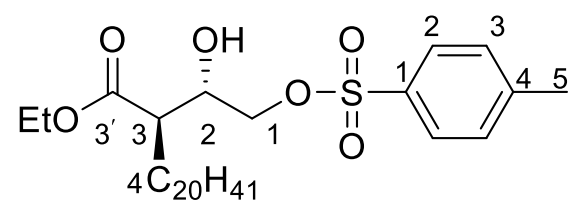

(R)-Ethyl 2-((S)-1-hydroxy-2-(tosyloxy)ethyl)docosanoate (18). $\mathrm{TsCl}(89 \mathrm{mg}, 0.47 \mathrm{mmol})$ was added to a solution of $\mathbf{1 5}(100 \mathrm{mg}, 0.23 \mathrm{mmol})$ in pyridine $(3 \mathrm{~mL})$. The reaction mixture was stirred at r.t. for $6 \mathrm{~h}$, then quenched with citric acid $(3 \mathrm{~mL}, 10 \%)$ and extracted with hot EtOAc $(3 \times 6 \mathrm{~mL})$. The combined organic layers were washed with water $(20 \mathrm{~mL})$ and brine $(20 \mathrm{~mL})$, dried over $\mathrm{MgSO}_{4}$, filtered, and concentrated in vacuo. The residue was purified by gradient silica gel flash column chromatography (PE/EA, 15:1 $\rightarrow$ 5:1, v/v) to give 18 as a white solid (99 mg, $0.17 \mathrm{mmol}$, $73 \%) . R_{\mathrm{f}}=0.80(\mathrm{PE} / \mathrm{EA}, 1: 1, \mathrm{v} / \mathrm{v}) ;$ IR (film) 2919, 2850, 1725, 1465, 1176, 1096, 755, $666 \mathrm{~cm}^{-1} ;{ }^{1} \mathrm{H}$ NMR $\left(300 \mathrm{MHz}, \mathrm{CDCl}_{3}\right) \delta 7.82(\mathrm{~d}, J=8.2 \mathrm{~Hz}, 2 \mathrm{H}, \mathrm{Ts} \mathrm{CH}-2), 7.38(\mathrm{~d}, J=$ $8.2 \mathrm{~Hz}, 2 \mathrm{H}$, Ts CH-3), 4.18 (m, $\left.2 \mathrm{H}, 3^{\prime}-\mathrm{OCH}_{2}\right), 4.07$ (d, $J_{1 \mathrm{ab}, 2}=5.0 \mathrm{~Hz}, 2 \mathrm{H}, \mathrm{H}-1 \mathrm{a}$ and H-1b), 3.93 (q, $J=5.0 \mathrm{~Hz}, 1 \mathrm{H}, \mathrm{H}-2), 2.57$ (dt, $J_{3,4}=9.1 \mathrm{~Hz}, J_{3,2}=5.6 \mathrm{~Hz}, 1 \mathrm{H}, \mathrm{H}-3$ ), 2.48 (s, 3 H, Ts $\mathrm{CH}_{3}-5$ ), 1.74-1.67 (m, 1H, H-4a), 1.55-1.47 (m, 1H, H-4b), 1.31-1.24 (m, 39H, 
$\mathrm{CH}_{2}-5-22$ and $\left.3^{\prime}-\mathrm{OCH}_{2} \mathrm{CH}_{3}\right), 0.90\left(\mathrm{t}, J=6.4 \mathrm{~Hz}, 3 \mathrm{H}, \mathrm{CH}_{3}-23\right) ;{ }^{13} \mathrm{C} \mathrm{NMR}(125 \mathrm{MHz}$, $\left.\mathrm{CDCl}_{3}\right) \delta 174.8$ (C-3'), 145.1 (Ts C-1), 132.6 (Ts C-4), 129.9 (Ts C-3), 128.0 (Ts C-2), 71.6 (C-1), 70.0 (C-2), 60.9 (3'-OCH 2$), 47.0$ (C-3), 29.7, 29.6, 29.6, 29.5, 29.4, 29.3, 27.1, 27.0, 22.7 (C-4-C-22), 21.7 (Ts C-5), 14.1 (C-23); HRMS (ESI): calcd. for $\left[\mathrm{C}_{33} \mathrm{H}_{58} \mathrm{O}_{6} \mathrm{~S}+\mathrm{Na}\right]^{+}:$605.3846; obsd.: 605.3848 .

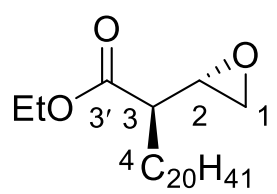

(R)-Ethyl 2-((S)-oxiran-2-yl)docosanoate (5). $\mathrm{K}_{2} \mathrm{CO}_{3}$ in $\mathrm{MeOH}(3.0$ $\mathrm{mL}, 10 \mathrm{M}, 0.22 \mathrm{mmol})$ was added to a solution of 18 (128 $\mathrm{mg}, 0.22$ $\mathrm{mmol})$ in $\mathrm{EtOH}(4.5 \mathrm{~mL})$ at $-10^{\circ} \mathrm{C}$. The reaction mixture was stirred at $-10-0{ }^{\circ} \mathrm{C}$ for $7 \mathrm{~h}$, then quenched with saturated $\mathrm{NH}_{4} \mathrm{Cl}$ solution and extracted with hot EtOAc $(3 \times 10 \mathrm{~mL})$. The combined organic layers were washed with water $(30 \mathrm{~mL})$, brine (30 mL), dried over $\mathrm{MgSO}_{4}$, filtered, and concentrated in vacuo. The residue was purified by gradient silica gel flash column chromatography (PE/EA, 50:1 $\rightarrow$ 40:1, v/v) to give 5 as a white solid $(78.5 \mathrm{mg}, 0.19 \mathrm{mmol}, 87 \%) . R_{\mathrm{f}}=0.87(\mathrm{PE} / \mathrm{EA}, 2: 1, \mathrm{v} / \mathrm{v}) ;[\alpha]_{\mathrm{D}}^{23}=+3.3$ $\left(c=0.1, \mathrm{CHCl}_{3}\right)$; IR (film) 2917, 2850, 1733, 1467, 1370, 1181, 755; ${ }^{1} \mathrm{H} \mathrm{NMR}(500 \mathrm{MHz}$, $\left.\mathrm{CDCl}_{3}\right) \delta 4.19\left(\mathrm{q}, J=7.0 \mathrm{~Hz}, 2 \mathrm{H}, 3^{\prime}-\mathrm{OCH}_{2} \mathrm{CH}_{3}\right), 3.16-3.13(\mathrm{~m}, 1 \mathrm{H}, \mathrm{H}-2), 2.82$ (t, $J=4.4$ $\mathrm{Hz}, 1-\mathrm{H}, \mathrm{H}-1 \mathrm{a}), 2.54$ (dd, $\left.J_{1 \mathrm{a}, 1 \mathrm{~b}}=4.6 \mathrm{~Hz}, J_{1 \mathrm{~b}, 2}=2.6 \mathrm{~Hz}, 1 \mathrm{H}, \mathrm{H}-1 \mathrm{~b}\right), 2.12$ (dd, $J_{3,2}=14.9$, $\left.J_{3,4}=7.9 \mathrm{~Hz}, 1 \mathrm{H}, \mathrm{H}-3\right), 1.72-1.69$ (m, $\left.1 \mathrm{H}, \mathrm{H}-4 \mathrm{a}\right), 1.60-1.58$ (m, $1 \mathrm{H}, \mathrm{H}-4 \mathrm{~b}$ ), 1.29-1.21 $\left(\mathrm{m}, 39 \mathrm{H}, \mathrm{CH}_{2}-5-\mathrm{CH}_{2}-22\right.$ and $\left.3^{\prime}-\mathrm{OCH}_{2} \mathrm{CH}_{3}\right), 0.87$ (t, $\left.J=6.9 \mathrm{~Hz}, 3 \mathrm{H}, \mathrm{CH}_{3}-23\right)$; ${ }^{13} \mathrm{C} \mathrm{NMR}$ $\left(125 \mathrm{MHz}, \mathrm{CDCl}_{3}\right) \delta 173.6\left(\mathrm{C}-3^{\prime}\right), 52.7\left(3^{\prime}-\mathrm{OCH}_{2} \mathrm{CH}_{3}\right), 49.0(\mathrm{C}-2), 46.5(\mathrm{C}-3), 31.9(\mathrm{C}-$ 1), 29.7, 29.6, 29.6, 29.5, 29.5, 29.4, 29.3, 27.2, 22.7 (C-5-C-22), 29.1 (C-4), 14.2 (3'$\mathrm{OCH}_{2} \mathrm{CH}_{3}$ ), 14.1 (C-23); HRMS (ESI): calcd. for $\left[\mathrm{C}_{26} \mathrm{H}_{50} \mathrm{O}_{3}+\mathrm{NH}_{4}\right]^{+} 428.4098$, obsd.; 428.4052 .

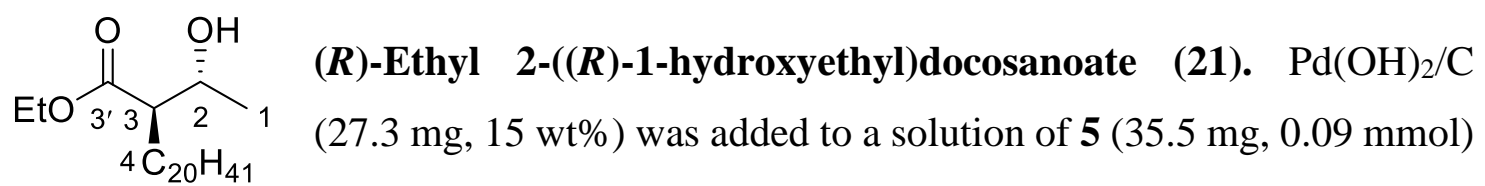
in $\mathrm{EtOH} / \mathrm{CH}_{2} \mathrm{Cl}_{2}(1 \mathrm{~mL}, 1: 1, \mathrm{v} / \mathrm{v})$ and the resulting mixture stirred at r.t. under $\mathrm{H}_{2}$ for 3 days. The reaction mixture was filtered over Celite, and the Celite washed with $\mathrm{CH}_{2} \mathrm{Cl}_{2} / \mathrm{EtOH}$ ( $5 \mathrm{~mL}, 1: 1$, v/v). After concentration in vacuo the residue was purified by gradient silica gel flash column chromatography (PE/EA, 50:1 $\rightarrow$ 10:1, v/v) to give (21) as a white solid (35.7 $\mathrm{mg}, 0.09 \mathrm{mmol}$, quant.). $R_{\mathrm{f}}=0.47$ (PE/EA, 3:1, v/v); $[\alpha]_{\mathrm{D}}^{24}=+4.0\left(c=0.5, \mathrm{CHCl}_{3}\right) ;[\alpha]_{\mathrm{D}}^{24}=+4.0\left(c=0.5, \mathrm{CHCl}_{3}\right) ;{ }^{1} \mathrm{H} \mathrm{NMR}\left(500 \mathrm{MHz}, \mathrm{CDCl}_{3}\right)$ $\delta 4.21$ (q, $J=7.1 \mathrm{~Hz}, 2 \mathrm{H}, 3^{\prime}-\mathrm{OCH}_{2} \mathrm{CH}_{3}$ ), 3.93-3.90 (m, $\left.1 \mathrm{H}, \mathrm{H}-2\right), 2.56$ (s, $\left.1 \mathrm{H}, 2-\mathrm{OH}\right)$, 
$2.37\left(\mathrm{dt}, J_{2,3}=9.1 \mathrm{~Hz}, J_{3,4 \mathrm{ab}}=5.6 \mathrm{~Hz}, 1 \mathrm{H}, \mathrm{H}-3\right), 1.71-1.56(\mathrm{~m}, 2 \mathrm{H}, \mathrm{H}-4 \mathrm{a}$ and H-4b), 1.33-1.20 (m, $42 \mathrm{H}, \mathrm{H}-5-\mathrm{H}-22$ and $3^{\prime}-\mathrm{OCH}_{2} \mathrm{CH}_{3}$ and $\left.\mathrm{CH}_{3}-1\right), 0.90(\mathrm{t}, J=6.5 \mathrm{~Hz}, 3 \mathrm{H}$, $\left.\mathrm{CH}_{3}-23\right) ;{ }^{13} \mathrm{C} \mathrm{NMR}\left(150 \mathrm{MHz}, \mathrm{CDCl}_{3}\right) \delta 175.6\left(\mathrm{C}-3\right.$ '), $68.4(\mathrm{C}-2), 60.4\left(3^{\prime}-\mathrm{OCH}_{2} \mathrm{CH}_{3}\right)$, 52.6 (C-3), 31.9, 29.7, 29.7, 29.6, 29.6, 29.5, 29.5, 29.4, 29.4, 27.2, 22.7, 21.6 (C-1, C4-C-22), $14.3\left(3^{\prime}-\mathrm{OCH}_{2} \mathrm{CH}_{3}\right), 14.1$ (C-23); HRMS (ESI): calcd. for $\left[\mathrm{C}_{26} \mathrm{H}_{52} \mathrm{O}_{3}+\mathrm{H}\right]^{+}$ 413.3989; found: 413.3988 .

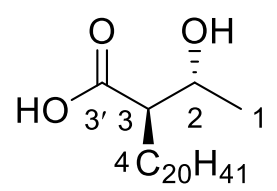

(R)-2-((R)-1-hydroxyethyl)docosanoic acid (22). $\mathrm{LiOH} \cdot \mathrm{H}_{2} \mathrm{O}$ in $\mathrm{H}_{2} \mathrm{O}$ ( $0.28 \mathrm{~mL}, 1 \mathrm{M}, 8$ equiv.) was added gradually to a solution of 21 (14.5 $\mathrm{mg}, 0.035 \mathrm{mmol})$ in $\mathrm{THF} / \mathrm{H}_{2} \mathrm{O} / \mathrm{MeOH}\left(1.1 \mathrm{~mL}, 5: 1: 1\right.$, v/v) at $0{ }^{\circ} \mathrm{C}$. The reaction mixture was allowed to warm to r.t. while stirring for $21 \mathrm{~h}$, after which time it was quenched with $\mathrm{HCl}(3 \mathrm{M})$ and extracted with hot EtOAc $(3 \times 3 \mathrm{~mL})$. The combined organic layers were washed with water $(10 \mathrm{~mL})$, brine $(10 \mathrm{~mL})$, dried over $\mathrm{MgSO}_{4}$, and concentrated in vacuo. The resulting residue was purified by gradient silica gel flash column chromatography (PE/EA, 10:1 $\rightarrow 1: 1$, v/v) to give 22 as a white solid $(92 \%) . R_{\mathrm{f}}$ $=0.22(\mathrm{PE} / \mathrm{EA}, 3: 1, \mathrm{v} / \mathrm{v}) ; \mathrm{IR}$ (film) 3212, 2916, 2849, 1712, 1463, 1196, 730, 651, 549 $\mathrm{cm}^{-1} ;{ }^{1} \mathrm{H}$ NMR (500 MHz, $\mathrm{CDCl}_{3}$ ) $\delta$ 3.97-3.95 (m, $\left.1 \mathrm{H}, \mathrm{H}-2\right), 2.42-2.40$ (m, $1 \mathrm{H}, \mathrm{H}-3$ ), 1.70-1.68 (m, $1 \mathrm{H}, \mathrm{H}-4 \mathrm{a}), 1.63-1.60$ (m, $1 \mathrm{H}, \mathrm{H}-4 \mathrm{~b}), 1.34-1.25$ (m, $39 \mathrm{H}, \mathrm{H}-5-\mathrm{H}-22$ and $\left.\mathrm{CH}_{3}-1\right), 0.88$ (t, $\left.J=6.3 \mathrm{~Hz}, 3 \mathrm{H}, \mathrm{CH}_{3}-23\right) ;{ }^{13} \mathrm{C} \mathrm{NMR}\left(125 \mathrm{MHz}, \mathrm{CDCl}_{3}\right) \delta 178.6\left(\mathrm{C}-3^{\prime}\right)$, 68.2 (C-2), 52.4 (C-3), 31.9, 29.7, 29.7, 29.7, 29.6, 29.6, 29.5, 29.4, 29.4, 29.3, 27.2 2 22.7, 21.6 (C-1 and C-4-C-22), 14.1 (C-23); HRMS (ESI): calcd. for $\left[\mathrm{C}_{24} \mathrm{H}_{48} \mathrm{O}_{3}-\mathrm{H}\right]^{-}: 383.3531$; found: 383.3562 .

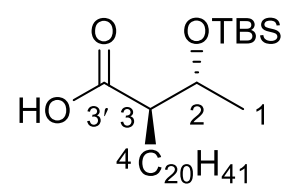

(R)-2-((R)-1-(tert-Butyldimethylsilyloxy)ethyl)docosanoic acid (3a). TBSOTf $(72 \mu \mathrm{L}, 0.322 \mathrm{mmol})$ and 2,6-lutidine $(56 \mu \mathrm{L}, 0.484$ mmol) were added to a solution of $22(12.4 \mathrm{mg}, 0.032 \mathrm{mmol})$ in DCM $(1 \mathrm{~mL})$, and the reaction mixture stirred at r.t. for $54 \mathrm{~h}$. After this time, $\mathrm{H}_{2} \mathrm{O}(0.05 \mathrm{~mL})$ and $\mathrm{K}_{2} \mathrm{CO}_{3} / \mathrm{MeOH}(0.11 \mathrm{~mL}, 10 \mathrm{mg} / \mathrm{mL})$ was added, and the reaction stirred at r.t. for 30 min. The reaction mixture was diluted with $\mathrm{H}_{2} \mathrm{O}(1 \mathrm{~mL})$ and extracted with DCM $(3 \times 3$ $\mathrm{mL})$, and the organic layers washed with $\mathrm{HCl}(2 \times 5 \mathrm{~mL}, 0.1 \mathrm{M}), \mathrm{H}_{2} \mathrm{O}(10 \mathrm{~mL})$ and brine (10 mL), dried over $\mathrm{MgSO}_{4}$, and concentrated in vacuo. Then residue was purified by gradient silica gel flash column chromatography (PE/EA, 50:1 $\rightarrow$ 15:1 v/v) to give 3a eluting in $15: 1$ as a white solid $(67 \%) . R_{\mathrm{f}}=0.83(\mathrm{PE} / \mathrm{EA}, 3: 1, \mathrm{v} / \mathrm{v})$; IR (film) 2922, 2853, 
1708, 1463,1378, 1256, 1099, 832, 740, $666 \mathrm{~cm}^{-1}$; ${ }^{1} \mathrm{H}$ NMR $\left(500 \mathrm{MHz}, \mathrm{CDCl}_{3}\right) \delta 4.01-$ 3.99 ( m, 1H, H-2), 2.39-2.36 (m, 1H, H-3), 1.69-64 (m, 1H, H-4a), 1.53-1.48 (m, 1H, H4b), 1.34-1.25 (m, 39H, H-5-H-22 and $\left.\mathrm{CH}_{3}-1\right), 0.92$ (s, 9H, $\left.\mathrm{SiC}\left(\mathrm{CH}_{3}\right)_{3}\right), 0.88$ (t, 3H, $\mathrm{CH}_{3}-$ 23), 0.14 (1 s, 3H, $\left.\mathrm{Si}\left(\mathrm{CH}_{3}\right)\right), 0.13\left(1 \mathrm{~s}, 3 \mathrm{H}, \mathrm{Si}\left(\mathrm{CH}_{3}\right)\right) ;{ }^{13} \mathrm{C} \mathrm{NMR}\left(125 \mathrm{MHz}, \mathrm{CDCl}_{3}\right) \delta$ 175.0 (C-3'), 69.6 (C-2), 53.3(C-3), 31.9, 29.7, 29.65, 29.61, 29.5, 29.4, 29.4, 29.3, 27.3, 22.1 (C-4-C-22), $\left.25.6\left(\mathrm{SiC}\left(\mathrm{CH}_{3}\right)_{3}\right), 22.7(\mathrm{C}-1), 17.8\left(\mathrm{SiC}_{(\mathrm{CH}}\right)_{3}\right), 14.1(\mathrm{C}-23),-4.3,-5.1$ $\left(\mathrm{Si}\left(\mathrm{CH}_{3}\right)_{2}\right)$; HRMS (ESI): calcd. for $\left[\mathrm{C}_{30} \mathrm{H}_{62} \mathrm{O}_{3} \mathrm{Si}-\mathrm{H}\right]^{-}: 497.4395$; obsd.: 497.4395.
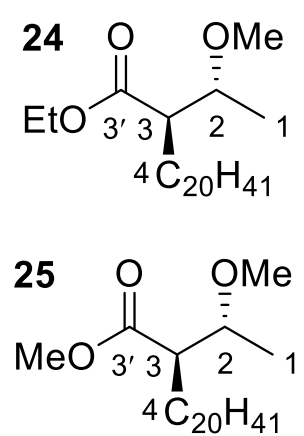

$(R)$-Ethyl 2-((R)-1-methoxyethyl)docosanoate $(24)$ and $(R)$ Methyl 2-((R)-1-methoxyethyl)docosanoate (25). NaH (44.5 mg, $1.363 \mathrm{mmol})$ was added to a solution of $21(34.0 \mathrm{mg}, 0.082 \mathrm{mmol})$ in $\mathrm{MeI}(3.5 \mathrm{~mL})$ and the reaction mixture stirred at r.t. for $24 \mathrm{~h}$. The reaction was quenched with $\mathrm{MeOH}$, concentrated in vacuo, and purified by gradient silica gel flash column chromatography to give the desired methoxy-derivative in a 5:1 mixture of $\mathbf{2 4 / 2 5}$, as a white solid (30.5 mg, $0.072 \mathrm{mmol}, 87 \%) . R_{\mathrm{f}}=0.74(\mathrm{PE} / \mathrm{EA}, 3: 1, \mathrm{v} / \mathrm{v}) ;[\alpha]_{\mathrm{D}}^{21}=+6.0(c=1.0$, $\mathrm{CHCl}_{3}$ ); IR (film) 2921, 2852, 1735, 1465, 1377, 1178, 1030, $721 \mathrm{~cm}^{-1} ;{ }^{1} \mathrm{H}$ NMR (500 $\left.\mathrm{MHz}, \mathrm{CDCl}_{3}\right) \delta$ 4.20-4.13 (m, 2H, 3'- $\mathrm{OCH}_{2} \mathrm{CH}_{3}$ ), 3.49-45 (m, 1H, H-2), 3.29 (s, 3H, 2$\left.\mathrm{OCH}_{3}\right), 2.47-2.39$ (m, 1H, H-3), 1.54-1.51 (m, 1H, H-4a), 1.44-1.40 (m, 1H, H-4b), 1.28$1.25\left(\mathrm{~m}, 39 \mathrm{H}, \mathrm{H}-5-\mathrm{H}-22\right.$ and $\left.3^{\prime}-\mathrm{OCH}_{2} \mathrm{CH}_{3}\right), 1.15\left(\mathrm{~d}, J_{1,2}=6.1 \mathrm{~Hz}, 3 \mathrm{H}, 1-\mathrm{CH}_{3}\right), 0.86(\mathrm{t}, J$ $\left.=7.0 \mathrm{~Hz}, 3 \mathrm{H}, \mathrm{CH}_{3}-23\right) ;{ }^{13} \mathrm{C} \mathrm{NMR}\left(125 \mathrm{MHz}, \mathrm{CDCl}_{3}\right) \delta 174.7\left(\mathrm{C}-3^{\prime}\right), 78.2(\mathrm{C}-2), 60.1$ (3'$\mathrm{OCH}_{2} \mathrm{CH}_{3}$ ), 56.6 (2- $\left.\mathrm{OCH}_{3}\right), 52.3$ (C-3), 31.9, 29.7, 29.6, 29.5, 29.4, 29.4, 28.1, 28.0, 27.5, 22.7 (C-4-C-22), 16.3 (C-1), 14.3 (3'- $\left.\mathrm{OCH}_{2} \mathrm{CH}_{3}\right), 14.1$ (C-23); HRMS (ESI): calcd. for $\left[\mathrm{C}_{27} \mathrm{H}_{54} \mathrm{O}_{3}+\mathrm{H}\right]^{+}$: 427.4146; obsd.: 427.4148; calcd. for $\left[\mathrm{C}_{26} \mathrm{H}_{52} \mathrm{O}_{3}+\mathrm{H}\right]^{+}$: 413.3989; obsd.: 413.3779.

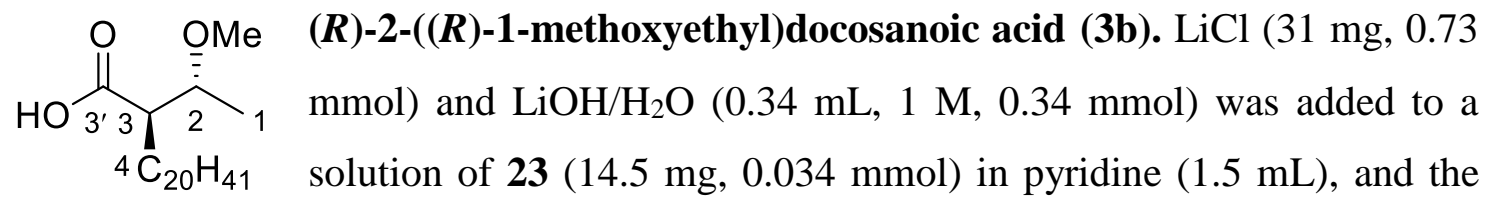
resulting mixture was refluxed for $19 \mathrm{~h}$. After this time, additional $\mathrm{LiOH} / \mathrm{H}_{2} \mathrm{O}(0.34 \mathrm{~mL}$, $1 \mathrm{M}, 0.34 \mathrm{mmol}$ ) was added and the reaction refluxed for a further $8 \mathrm{~h}$, then quenched with $\mathrm{HCl}(1 \mathrm{M})$ and concentrated under reduced pressure. The resultant oil was partitioned between EtOAc $(3 \mathrm{~mL})$ and water $(3 \mathrm{~mL})$, and the organic layer washed with water $(3 \mathrm{~mL})$ and brine $(3 \mathrm{~mL})$. The aqueous layer was extracted with EtOAc twice more 
( $2 \times 3 \mathrm{~mL}$ ) and washed with water and brine. The combined organic layers were dried over $\mathrm{MgSO}_{4}$, and concentrated in vacuo, and the crude product was purified by gradient silica gel flash column chromatography (PE/EA, 30:1 $\rightarrow 5: 1$, v/v) to give $\mathbf{3 b}$ as a white solid (10.8 mg, $0.027 \mathrm{mmol}, 80 \%) ; R_{\mathrm{f}}=0.54(\mathrm{PE} / \mathrm{EA}, 3: 1$, v/v); IR (film) 3212, 2917, 2849, 1708, 1461, 1377, 1226, $730 \mathrm{~cm}^{-1}$; ${ }^{1} \mathrm{H} \mathrm{NMR}\left(500 \mathrm{MHz}, \mathrm{CDCl}_{3}\right.$ ) $\delta 3.52$ (quin, $J=$ $6.2 \mathrm{~Hz}, 1 \mathrm{H}, \mathrm{H}-2$ ), 3.37 (s, 3H, 2- $\mathrm{OCH}_{3}$ ), 2.47 (quin, $J=4.8 \mathrm{~Hz}, 1 \mathrm{H}, \mathrm{H}-3$ ), 1.64-1.60 (m, 1H, H-4a), 153-1.50 (m, 1H, H-4b), 1.31-1.25 (m, 36H, H-5-H-22), 1.21 (d, $J_{1,2}=6.1$ $\left.\mathrm{Hz}, 1-\mathrm{CH}_{3}\right), 0.88$ (t, $\left.J=6.6 \mathrm{~Hz}, 3 \mathrm{H}, \mathrm{CH}_{3}-23\right) ;{ }^{13} \mathrm{C} \mathrm{NMR}\left(125 \mathrm{MHz}, \mathrm{CDCl}_{3}\right) \delta 177\left(\mathrm{C}-3{ }^{\prime}\right)$, 77.5 (C-2), $56.8\left(2-\mathrm{OCH}_{3}\right), 52.1$ (C-3), 31.9, 29.7, 29.6, 29.6, 29.5, 29.4, 29.3, 27.4, 22.7 (C-5-C-22), 28.6, (C-4), 16.6 (C-1), 14.1 (C-23); HRMS (ESI): calcd. for $\left[\mathrm{C}_{25} \mathrm{H}_{50} \mathrm{O}_{3}-\mathrm{H}\right]^{-}$ : 397.3687; obsd.: 397.3688 .<smiles>CCCC(C(=O)O)C1CO1</smiles>

$(\boldsymbol{R})$-2-((S)-oxiran-2-yl)docosanoic acid (3c). To a solution of 5 (25.2 $\mathrm{mg}, 0.061 \mathrm{mmol})$ in $\mathrm{THF} / \mathrm{H}_{2} \mathrm{O} / \mathrm{MeOH}(12: 2: 1,2 \mathrm{~mL})$ was added $\mathrm{LiOH} \cdot \mathrm{H}_{2} \mathrm{O}(12.9 \mathrm{mg}, 0.31 \mathrm{mmol})$. After stirring at r.t. for $7 \mathrm{~h}$, the reaction mixture was quenched with $\mathrm{HCl}(1 \mathrm{M})$, extracted with hot EtOAc $(3 \times 3 \mathrm{~mL})$, and the combined organic layers washed with water, brine, dried over $\mathrm{MgSO}_{4}$, and concentrated in vacuo. The crude product mixture was purified by gradient silica gel flash column chromatography (PE/EA, 30:1 $\rightarrow$ 0:1 v/v) to give $\mathbf{3 c}$ as a white solid $(8.7 \mathrm{mg}$, $0.023 \mathrm{mmol}, 37 \%) . R_{\mathrm{f}}=0.45(\mathrm{PE} / \mathrm{EA}, 2: 1, \mathrm{v} / \mathrm{v})$; IR (film) 2914, 2847, 1729, 1463, 1377 , $1141,719 \mathrm{~cm}^{-1} ;{ }^{1} \mathrm{H}$ NMR $\left(300 \mathrm{MHz}, \mathrm{CDCl}_{3}\right) \delta 3.17$ (ddd, $J_{2,3}=7.8 \mathrm{~Hz}, J_{2,1 \mathrm{a}}=4.1 \mathrm{~Hz}$, $\left.J_{2,1 \mathrm{~b}}=2.7 \mathrm{~Hz}, 1 \mathrm{H}, \mathrm{H}-2\right), 2.87\left(\mathrm{dd}, J_{1 \mathrm{a}, 1 \mathrm{~b}}=4.8 \mathrm{~Hz}, J_{1 \mathrm{a}, 2}=4.1 \mathrm{~Hz}, 1 \mathrm{H}, \mathrm{H}-1 \mathrm{a}\right), 2.60\left(\mathrm{dd}, J_{1 \mathrm{a}, 1 \mathrm{~b}}\right.$ $\left.=4.8 \mathrm{~Hz}, J_{1 \mathrm{~b}, 2}=2.7 \mathrm{~Hz}, 1 \mathrm{H}, \mathrm{H}-1 \mathrm{~b}\right), 2.20\left(\mathrm{dd}, J_{3,4}=14.6 \mathrm{~Hz}, J_{2,3}=7.8 \mathrm{~Hz}, 1 \mathrm{H}, \mathrm{H}-3\right), 1.83-$ 1.73 (m, 1H, H-4a), 1.71-1.62 (m, 1H, H-4b), 1.35-1.22 (m, 36 H, H5-H-22), 0.90 (t, $J=$ $6.8 \mathrm{~Hz}) ;{ }^{13} \mathrm{C}$ NMR $\left(150 \mathrm{MHz}, \mathrm{CDCl}_{3}\right) \delta 52.4(\mathrm{C}-2), 48.5(\mathrm{C}-3), 46.6(\mathrm{C}-1), 31.9,29.7$, 29.7, 29.6, 29.6, 29.5, 29.4, 22.7 (C-6-C22), 29.0 (C-4), 27.2 (C-5), 14.1 (C-23); HRMS (ESI): calcd. for $\left[\mathrm{C}_{24} \mathrm{H}_{46} \mathrm{O}_{3}-\mathrm{H}\right]^{-}: 381.3374$, obsd.: 381.3378 .

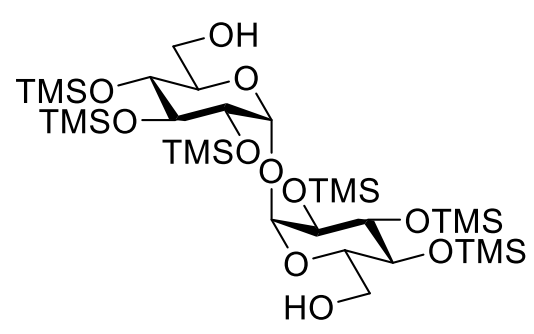

$2,2^{\prime}, 3,3^{\prime}, 4,4^{\prime}$-Hexa- $O$-trimethylsilyl- $\alpha, \alpha^{\prime}$-D-trehalose (4). $\alpha, \alpha$-D-Trehalose dihydrate $6(0.253 \mathrm{~g}, 0.667 \mathrm{mmol})$ was co-evaporated with anhydrous DMF $(2 \times 5 \mathrm{~mL})$ and then dissolved in DMF $(1 \mathrm{~mL}) . \quad N, O-$ bis(trimethylsilyl)acetamide $(1.4 \mathrm{~mL}, 5.74 \mathrm{mmol}, 8.6$ 
equiv.) and TBAF (0.04 mL, $0.04 \mathrm{mmol}, 0.06$ equiv.) were added and the reaction mixture stirred at r.t. for $2.5 \mathrm{~h}$, after which time the reaction mixture was quenched with isopropanol $(0.25 \mathrm{~mL})$, diluted with $\mathrm{MeOH}(15 \mathrm{~mL})$ and cooled to $0{ }^{\circ} \mathrm{C} . \mathrm{K}_{2} \mathrm{CO}_{3}$ solution (20 mL, $0.03 \mathrm{M}, 0.67 \mathrm{mmol}$ ) was added and the reaction stirred at $0{ }^{\circ} \mathrm{C}$ for $2 \mathrm{~h}$ before being neutralised with $\mathrm{AcOH}(0.1 \mathrm{~mL})$, concentrated in vacuo and partitioned between $\mathrm{Et}_{2} \mathrm{O}$ and brine. The aqueous layer was extracted with $\mathrm{Et}_{2} \mathrm{O}(2 \times 30 \mathrm{~mL})$ and the combined organic layers dried over $\mathrm{MgSO}_{4}$ and concentrated in vacuo. The crude product was purified by gradient silica gel flash column chromatography (PE/EA, 5:1 $\rightarrow 3: 1$, v/v) to give 4 as a white solid $(0.412 \mathrm{~g}, 0.531 \mathrm{mmol}, 80 \%) . R_{\mathrm{f}}=0.36(\mathrm{PE} / \mathrm{EA}, 3: 1, \mathrm{v} / \mathrm{v})$; IR (film) 3495, 2957, 1386, 1249, 1108, 1074, 832, $746 \mathrm{~cm}^{-1} ;{ }^{1} \mathrm{H}$ NMR (500 MHz, $\left.\mathrm{CDCl}_{3}\right) \delta 4.90$ $\left(\mathrm{d}, J_{1,2}=2.9 \mathrm{~Hz}, 2 \mathrm{H}, \mathrm{H}-1\right), 3.89$ (t, $\left.J=9.2 \mathrm{~Hz}, 2 \mathrm{H}, \mathrm{H}-3\right), 3.86-3.84$ (m, 2H, H-5), 3.733.67 (m, 4H, H-6a and H-6b), 3.48 (t, $J=9.2 \mathrm{~Hz}, 2 \mathrm{H}, \mathrm{H}-4), 3.42\left(\mathrm{dd}, J_{2,3}=9.2 \mathrm{~Hz}, J_{2,1}=\right.$ $2.9 \mathrm{~Hz}, 2 \mathrm{H}, \mathrm{H}-2), 1.77$ (2H, 6-OH), 0.16, 0.14, 0.12 (3 s, 54H, 6 x Si( $\left.\left(\mathrm{CH}_{3}\right)_{3}\right) ;{ }^{13} \mathrm{C} \mathrm{NMR}$ $\left(125 \mathrm{MHz}, \mathrm{CDCl}_{3}\right) \delta 94.6(\mathrm{C}-1), 73.3(\mathrm{C}-3), 72.9(\mathrm{C}-5), 72.7$ (C-2), $71.4(\mathrm{C}-4), 61.6(\mathrm{C}-$ 6), 1.0, 0.8, $0.1\left(\mathrm{Si}\left(\mathrm{CH}_{3}\right)_{3}\right)$; HRMS (ESI): calcd. for $\left[\mathrm{C}_{30} \mathrm{H}_{70} \mathrm{O}_{11} \mathrm{Si}_{6}+\mathrm{Na}\right]^{+}$: 797.3426; obsd.: 797.3438 .

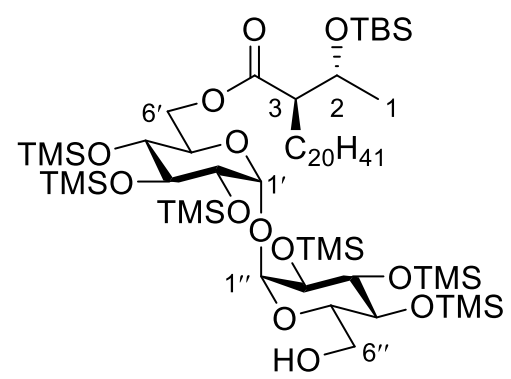

$$
2^{\prime}, 2^{\prime \prime}, 3^{\prime}, 3^{\prime \prime}, 4^{\prime}, 4^{\prime \prime}-\text { hexa- } O \text {-trimethylsilyl-6-O-[(R)-2- }
$$
((R)-1-(tert-Butyldimethylsilyloxy)ethyl)docosanoyl]6"-hydroxy- $\alpha^{\prime}, \alpha^{\prime \prime}$-D-trehalose (27). To a solution of TMS-trehalose 4 (4.2 $\mathrm{mg}, 0.0054 \mathrm{mmol})$ and protected mycolic acid 3a $(10.7 \mathrm{mg}, 0.021 \mathrm{mmol})$ in toluene $(1.5$ $\mathrm{mL})$ was added EDCI (6.7 $\mathrm{mg}, 0.035 \mathrm{mmol})$ and DMAP $(1.3 \mathrm{mg}, 0.011 \mathrm{mmol})$. The reaction mixture was stirred at $55^{\circ} \mathrm{C}$ for $8 \mathrm{~d}$, with additional reagents added after $1 \mathrm{~d}$ (DMAP, $2.6 \mathrm{mg}, 0.021 \mathrm{mmol}$ ), $5 \mathrm{~d}$ (DMAP, $1.3 \mathrm{mg}, 0.011 \mathrm{mmol}$; EDCI, $2.1 \mathrm{mg}, 0.011 \mathrm{mmol}$ ), and $6 \mathrm{~d}$ (DMAP, $3.2 \mathrm{mg}, 0.026 \mathrm{mmol}$ ). The resulting precipitate was filtered and washed with EtOAc $(10 \mathrm{~mL})$ and concentrated in vacuo. The resultant oil was redissolved in EtOAc $(3 \mathrm{~mL})$ and washed with water $(3 \mathrm{~mL})$ and brine $(3 \mathrm{~mL})$. The aqueous layer was extracted with EtOAc $(2 \times 3 \mathrm{~mL})$ and washed with water and brine, and the combined organic layers were dried over $\mathrm{MgSO}_{4}$, and concentrated in vacuo. The crude product was purified by gradient silica gel flash column chromatography (PE/EA, 40:1 $\rightarrow 5: 1$, v/v) followed by size exclusion chromatography on lipophilic sephadex (DCM/MeOH, 1:1) to give 27 as a colourless oil, (2.5 mg, 0.0016 
mmol, 29\%). $R_{\mathrm{f}}=0.69(\mathrm{PE} / \mathrm{EA}, 5: 1, \mathrm{v} / \mathrm{v})$; IR (film) 2955, 2923, 2853, 1740, 1462, 1380, 1250, 1109, 1075, 872, 835, $748 \mathrm{~cm}^{-1} ;{ }^{1} \mathrm{H} \mathrm{NMR}\left(600 \mathrm{MHz}, \mathrm{CDCl}_{3}\right) \delta 4.91\left(\mathrm{~d}, J_{1^{\prime \prime}, 2^{\prime \prime}}=3.1\right.$, $\left.1 \mathrm{H}, \mathrm{H}-1^{\prime \prime}\right), 4.83$ (d, $\left.J_{1^{\prime}, 2^{\prime}}=3.1 \mathrm{~Hz}, 1 \mathrm{H}, \mathrm{H}-1^{\prime}\right), 4.37$ (dd, $J_{6^{\prime} \mathrm{a}, 6^{\prime} \mathrm{b}}=11.8 \mathrm{~Hz}, J_{6 \mathrm{a}^{\prime}, 5^{\prime}}=2.3 \mathrm{~Hz}$, $\left.1 \mathrm{H}, \mathrm{H}-6^{\prime} \mathrm{a}\right), 4.08$ (dd, $\left.J_{6^{\prime} \mathrm{a}, 6^{\prime} \mathrm{b}}=11.8 \mathrm{~Hz}, J_{6 \mathrm{~b}^{\prime}, 5^{\prime}}=4.8 \mathrm{~Hz}, 1 \mathrm{H}, \mathrm{H}-6^{\prime} \mathrm{b}\right), 4.07-4.04$ (m, 1H, H2), 3.99-3.92 (m, 1H, H-5'), 3.90 (t, $J=8.7 \mathrm{~Hz}, 1 \mathrm{H}, \mathrm{H}-3^{\prime}$ or $\left.\mathrm{H}-3^{\prime \prime}\right), 3.89$ (t, $J=8.7 \mathrm{~Hz}$, $1 \mathrm{H}, \mathrm{H}-3^{\prime}$ or H-3"), 3.83 (dt, $\left.J_{5^{\prime \prime} \mathrm{a}, 4^{\prime \prime}}=9.5 \mathrm{~Hz}, J_{5^{\prime \prime}, 6^{\prime \prime} \mathrm{ab}}=3.4 \mathrm{~Hz}, 1 \mathrm{H}, \mathrm{H}-5^{\prime \prime}\right), 3.71-3.64$ (m, 2H, H-6"a and H-6"'b), 3.47 (t, $J=9.0 \mathrm{~Hz}, 1 \mathrm{H}, \mathrm{H}-4^{\prime}$ or H-4"), 3.46 (t, $J=9.0 \mathrm{~Hz}, 1 \mathrm{H}, \mathrm{H}-$ $4^{\prime}$ or $\left.\mathrm{H}-4^{\prime \prime}\right), 3.42\left(\mathrm{dd}, J_{2^{\prime \prime}, 3^{\prime \prime}}=9.3 \mathrm{~Hz}, J_{2^{\prime \prime}, 1^{\prime \prime}}=3.1 \mathrm{~Hz}, 1 \mathrm{H}, \mathrm{H}-2^{\prime \prime}\right), 3.39\left(\mathrm{dd}, J_{2^{\prime}, 3^{\prime}}=9.4 \mathrm{~Hz}\right.$, $\left.J_{2^{\prime}, 1^{\prime}}=3.1 \mathrm{~Hz}, 1 \mathrm{H}, \mathrm{H}-2^{\prime}\right), 2.46-2.23(\mathrm{~m}, 1 \mathrm{H}, \mathrm{H}-3), 1.72-1.66(\mathrm{~m}, 2 \mathrm{H}, \mathrm{H}-4 \mathrm{a}$ and H-4b), 1.34-1.25 (m, $36 \mathrm{H}, \mathrm{H}-5-\mathrm{H}-22), 1.11$ (d, $\left.J_{1,2}=6.1 \mathrm{~Hz}, 3 \mathrm{H}, \mathrm{CH}_{3}-1\right), 0.91$ (s, 9H, TBS$\left.\mathrm{SiC}\left(\mathrm{CH}_{3}\right)_{3}\right), 0.87\left(\mathrm{t}, J=6.0 \mathrm{~Hz}, 3 \mathrm{H}, \mathrm{CH}_{3}-23\right), 0.16-0.03\left(\mathrm{~m}, 60 \mathrm{H}, \mathrm{TBS}-\mathrm{Si}\left(\mathrm{CH}_{3}\right)_{2}\right.$ and $6 \mathrm{x}$ TMS-Si $\left.\left(\mathrm{CH}_{3}\right)_{3}\right) ;{ }^{13} \mathrm{C}$ NMR (150 MHz, $\left.\mathrm{CDCl}_{3}\right) \delta 174.3(\mathrm{C}=\mathrm{O}), 94.4\left(\mathrm{C}-1^{\prime \prime}\right), 94.2\left(\mathrm{C}-1^{\prime}\right)$, $73.4\left(\mathrm{C}-3^{\prime} / 3^{\prime \prime}\right), 73.3\left(\mathrm{C}-3^{\prime} / 3^{\prime \prime}\right), 72.83\left(\mathrm{C}-5^{\prime \prime}\right), 72.76\left(\mathrm{C}-2^{\prime \prime}\right), 72.66\left(\mathrm{C}-2^{\prime}\right), 72.0\left(\mathrm{C}-4^{\prime}\right), 71.4$ (C-4"), 70.8 (C-5'), 69.7 (C-2), 62.5 (C-6'), $61.7\left(\mathrm{C}^{\prime \prime} 6^{\prime \prime}\right), 54.1$ (C-3), 31.9, 29.8, 29.71, 29.68, 29.66, 29.5, 29.47, 29.37, 27.9, 26.9, 25.8, 22.6 (C-4-C-22), 25.8 (TBS$\left.\mathrm{SiC}\left(\mathrm{CH}_{3}\right)_{3}\right), 20.6(\mathrm{C}-1), 18.0\left(\mathrm{TBS}-\mathrm{SiC}\left(\mathrm{CH}_{3}\right)_{3}\right), 14.1$ (C-23), -4.5, -5.0 (TBS-Si $\left.\left(\mathrm{CH}_{3}\right)_{2}\right)$; 1.06, 1.00, 0.96, 0.85, 0.18, 0.05 (TMS-Si(CH$\left.)_{3}\right)$; HRMS (ESI): calcd. for $\left[\mathrm{C}_{60} \mathrm{H}_{130} \mathrm{O}_{13} \mathrm{Si}_{7}+\mathrm{NH}_{4}\right]^{+}:$1272.8235; obsd.:1272.8094.

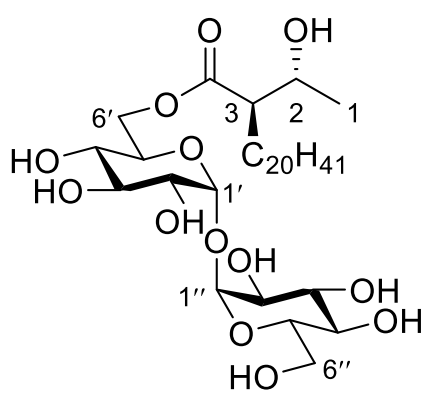

\section{$6^{\prime}-O-[(R)-2-((R)-1-H y d r o x y e t h y l) d o c o s a n o y l]-6^{\prime \prime}-$} hydroxy- $\boldsymbol{\alpha}^{\prime}, \boldsymbol{\alpha}^{\prime \prime}$-D-trehalose (1a). A solution of TME 27 (2.0 $\mathrm{mg}, 0.0016 \mathrm{mmol})$ in pyridine $(17 \mu \mathrm{L})$ was treated with $\mathrm{HF} \cdot$ pyridine $(70 \% \mathrm{HF}$ in pyridine, $5.8 \mu \mathrm{L}, 0.0223 \mathrm{mmol})$.

The reaction was neutralised with aq. $\mathrm{Ca}(\mathrm{OAc})_{2}(1.0 \mathrm{M}, 0.11$ $\mathrm{mL}$ ) after $20 \mathrm{~h}$ and the resulting precipitate filtered, washed with pyridine $(3 \mathrm{~mL})$, and concentrated in vacuo. The crude product was purified by size exclusion chromatography on lipohilic sephadex $(\mathrm{DCM} / \mathrm{MeOH}, 1: 1)$ to give $\mathbf{1 a}$ as a white solid (1.0 mg, $0.0014 \mathrm{mmol}, 88 \%$ ). ${ }^{1} \mathrm{H} \mathrm{NMR}$ (600 MHz, CD $\left.3 \mathrm{OD}\right) \delta$ 5.09-5.08 (m, 2H, H-1' and H-1"'), $4.47\left(\mathrm{dd}, J_{6^{\prime} \mathrm{a}, 6^{\prime} \mathrm{b}}=12.1 \mathrm{~Hz}, J_{6 \mathrm{a}^{\prime}, 5^{\prime}}=2.1 \mathrm{~Hz}, 1 \mathrm{H}, \mathrm{H}-6^{\prime} \mathrm{a}\right), 4.17\left(\mathrm{dd}, J_{6^{\prime} \mathrm{a}, 6^{\prime} \mathrm{b}}=\right.$ $11.8 \mathrm{~Hz}, J_{6 \mathrm{~b}^{\prime}, 5^{\prime}}=5.3 \mathrm{~Hz}, 1 \mathrm{H}, \mathrm{H}-6^{\prime} \mathrm{b}$ ), 4.07-4.04 (m, $1 \mathrm{H}, \mathrm{H}-5^{\prime}$ ), 3.89 (quin, $J_{1,2}=J_{2,3}=6.9$ $\mathrm{Hz}, 1 \mathrm{H}, \mathrm{H}-2), 3.83-3.80$ (m, 1H, H-5"), 3.80-3.76 (m, 2H, H-3' and H-3"), 3.68-3.64 (m, 2H, H-6"a and H-6"b), 3.46 (dd, $J_{2,3}=9.9 \mathrm{~Hz}, J_{1,2}=3.7 \mathrm{~Hz}, 2 \mathrm{H}, \mathrm{H}-2^{\prime}$ and H-2"'), 3.353.32 (m, 2H, H-4' and H-4"), 2.39-2.36 (m, 1H, H-3), 1.61-1.57 (m, 1H, H-4a), 1.49-1.44 (m, 1H, H-4b), 1.39-1.28 (m, 36H, H-5-H-22), 1.19 (d, J1,2 = 6.5 Hz, 3H, $\mathrm{CH}_{3}-1$ ), 0.90 
(t, $\left.J=7.1 \mathrm{~Hz}, 3 \mathrm{H}, \mathrm{CH}_{3}-23\right) ;{ }^{13} \mathrm{C} \mathrm{NMR}\left(150 \mathrm{MHz}, \mathrm{CD}_{3} \mathrm{OD}\right) \delta 174.7(\mathrm{C}=\mathrm{O}), 93.8\left(\mathrm{C}-1^{\prime} / 1^{\prime \prime}\right)$, $93.7\left(\mathrm{C}-1^{\prime} / 1^{\prime \prime}\right), 73.1\left(\mathrm{C}-3^{\prime} / 3^{\prime \prime}\right), 73.0\left(\mathrm{C}-3^{\prime} / 3^{\prime \prime}\right), 72.4\left(\mathrm{C}-5^{\prime \prime}\right), 71.8\left(\mathrm{C}-2^{\prime \prime}\right), 71.7\left(\mathrm{C}-2^{\prime}\right), 70.6$ $\left(\mathrm{C}-4^{\prime} / 4^{\prime \prime}\right), 70.5\left(\mathrm{C}-4^{\prime} / 4^{\prime \prime}\right), 70.0\left(\mathrm{C}-5^{\prime}\right), 68.4$ (C-2), 63.0 (C-6'), 61.2 (C-6"), 54.3 (C-3), 31.7, 29.4, 29.36, 29.33, 29.26, 29.15, 29.06, 28.2, 27.3, 26.4, 22.3, 19.7 (C-1, C-4-C22), 13.0 (C-23); HRMS (ESI): calcd. for $\left[\mathrm{C}_{36} \mathrm{H}_{68} \mathrm{O}_{13}+\mathrm{NH}_{4}\right]^{+}:$726.4998; obsd.: 726.4982.

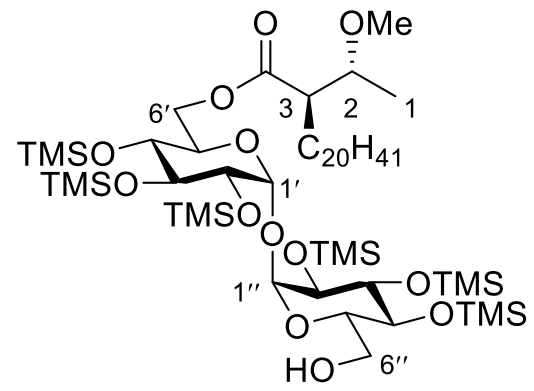

$2^{\prime}, 2^{\prime \prime}, 3^{\prime}, 3^{\prime \prime}, 4^{\prime}, 4^{\prime \prime}-$ Hexa-O-trimethylsilyl-6'-O-[(R)-2((R)-1-(methoxyethyl)docosanoyl]-6"-hydroxy$\boldsymbol{\alpha}^{\prime}, \boldsymbol{\alpha}^{\prime \prime}$-D-trehalose (29). EDCI (9.4 mg, $\left.0.049 \mathrm{mmol}\right)$ and DMAP (1.8 $\mathrm{mg}, 0.015 \mathrm{mmol})$ were added to a solution of TMS-trehalose $4(5.6 \mathrm{mg}, 0.0073 \mathrm{mmol})$ and mycolic acid 3b (11.6 mg, $0.029 \mathrm{mmol})$ in toluene

$(1.5 \mathrm{~mL})$. The reaction was stirred at $55^{\circ} \mathrm{C}$ for $24 \mathrm{~h}$, after which time additional DMAP $(1.8 \mathrm{mg}, 0.015 \mathrm{mmol})$ was added and the reaction stirred for a further $7 \mathrm{~d}$. The resulting precipitate was filtered, washed with EtOAc $(10 \mathrm{~mL})$ and concentrated in vacuo. The resultant oil was redissolved in EtOAc $(3 \mathrm{~mL})$ and washed with water $(3 \mathrm{~mL})$ and brine $(3 \mathrm{~mL})$. The aqueous layer was extracted with EtOAc $(2 \times 3 \mathrm{~mL})$ and washed with water and brine, and the combined organic layers were dried over $\mathrm{MgSO}_{4}$, filtered, and concentrated in vacuo. The crude product was resubmitted to reaction with EDCI (9.3 $\mathrm{mg}, 0.049 \mathrm{mmol})$ and DMAP $(5.0 \mathrm{mg}, 0.041 \mathrm{mmol})$ in toluene $(1.5 \mathrm{~mL})$. After stirring at $58{ }^{\circ} \mathrm{C}$ for a further $6 \mathrm{~d}$, the reaction mixture subjected to the afore mentioned workup procedure, and purified by gradient silica gel flash column chromatography (PE/EA, 40:1 $\rightarrow 5: 1, \mathrm{v} / \mathrm{v})$ to give 29 as a colourless oil $(2.1 \mathrm{mg}, 0.0018 \mathrm{mmol}, 25 \%) . R_{\mathrm{f}}=0.68(\mathrm{PE} / \mathrm{EA}$, 5:1, v/v); IR (film) 2923, 2853, 1739, 1460, 1379, 1250, 1108, 10751007, 840, $748 \mathrm{~cm}^{-}$ 1; ${ }^{1} \mathrm{H}$ NMR (500 MHz, CDCl3) $\delta 4.92$ (broad s, 1H, H-1"'), 4.85 (broad s, 1 H, H-1'), 4.52 (d, $\left.J_{6^{\prime} \mathrm{a}, 6^{\prime} \mathrm{b}}=11.8 \mathrm{~Hz}, 1 \mathrm{H}, \mathrm{H}-6^{\prime} \mathrm{a}\right), 4.04$ (m, 1H, H-6'b), 3.99-3.97 (m, 1H, H-5'), 3.90 (t, $J$ = 9.1 Hz, 1H, H-3'), 3.89 (t, $\left.J=9.2 \mathrm{~Hz}, 1 \mathrm{H}, \mathrm{H}-3^{\prime \prime}\right), 3.83-3.81$ (m, 1H, H-5"), 3.69-3.66 (m, 2H, H-6"a and H-6"'b), 3.54 (t, $J=6.4 \mathrm{~Hz}, 1 \mathrm{H}, \mathrm{H}-2), 3.51-3.44\left(\mathrm{~m}, 2 \mathrm{H}, \mathrm{H}-4^{\prime}\right.$ and H$\left.\left.4^{\prime \prime}\right), 3.43-3.41 \mathrm{~m}, 1 \mathrm{H}, \mathrm{H}-2^{\prime \prime}\right), 3.38-3.37$ (m, 1H, H-2'), 3.29 (s, 3H, 2-OCH 3 ), 2.56-2.51 (m, 1H, H-3), 1.67-1.57 (m, 2H, H-4a and H-4b), 1.31-1.25 (m, 36 H, H-5-H-22), 1.14 (d, $\left.J_{1,2}=5.7 \mathrm{~Hz}, 3 \mathrm{H}, \mathrm{CH}_{3}-1\right), 0.89-0.83\left(\mathrm{~m}, 3 \mathrm{H}, \mathrm{CH}_{3}-23\right), 0.16,0.15,0.15,0.14,011(5$ x s, 54H, 6 x Si( $\left.\mathrm{CH}_{3}\right)_{3}$; HRMS (ESI): calcd. for $\left[\mathrm{C}_{55} \mathrm{H}_{118} \mathrm{O}_{13} \mathrm{Si}_{6}+\mathrm{Na}\right]^{+}$: 1177.7080; obsd.: 1177.7066. 


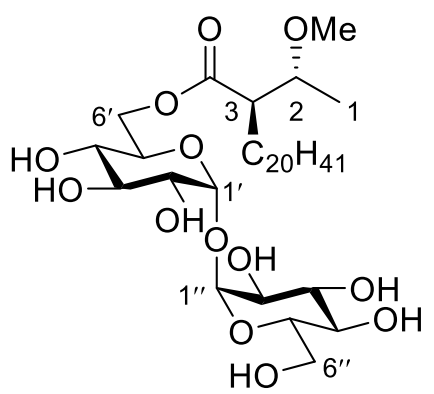

hydroxy- $\boldsymbol{\alpha}^{\prime}, \boldsymbol{\alpha}^{\prime \prime}$-D-trehalose (1b). To a solution of TME 29 $(2.1 \mathrm{mg}, 0.0018 \mathrm{mmol})$ in pyridine $(20 \mu \mathrm{L})$ was added $\mathrm{HF} \cdot$ pyridine (17\% HF in pyridine, $2.24 \mu \mathrm{L}, 0.0216 \mathrm{mmol})$.

After $20 \mathrm{~h}$ the reaction was neutralised with aq. $\mathrm{Ca}(\mathrm{OAc})_{2}$ $(1.0 \mathrm{M})$ and the resulting precipitate filtered, washed with pyridine $(3 \mathrm{~mL})$, and concentrated in vacuo. The crude product was purified by size exclusion chromatography on lipohilic sephadex (DCM/MeOH, 1:1) to give $\mathbf{1 b}$ as a white solid (1.6 mg, $0.0021 \mathrm{mmol}$, quant.). ${ }^{1} \mathrm{H}$ NMR (600 MHz, $\left.\mathrm{CD}_{3} \mathrm{OD}\right) \delta$ 5.08-5.07 (m, 2H, H-1' and H-1" $), 4.40\left(\mathrm{dd}, J_{6^{\prime} \mathrm{a}, 6^{\prime} \mathrm{b}}=12.0 \mathrm{~Hz}, J_{6 \mathrm{a}^{\prime}, 5^{\prime}}=2.1 \mathrm{~Hz}, 1 \mathrm{H}, \mathrm{H}-6^{\prime} \mathrm{a}\right), 4.17\left(\mathrm{dd}, J_{6^{\prime} \mathrm{a}, 6^{\prime} \mathrm{b}}=\right.$ $\left.11.7 \mathrm{~Hz}, J_{6 \mathrm{~b}^{\prime}, 5^{\prime}}=5.0 \mathrm{~Hz}, 1 \mathrm{H}, \mathrm{H}-6^{\prime} \mathrm{b}\right), 4.03-4.00$ (m, 1H, H-5'), 3.81-3.79 (m, 1H, H-5'), 3.79-3.74 (m, 2H, H-3' and H-3"), 3.67-3.62 (m, 2H, H-6"a and H-6"b), 3.52-3.49 (m, $1 \mathrm{H}, \mathrm{H}-2), 3.45\left(\mathrm{dd}, J_{2,3}=9.9 \mathrm{~Hz}, J_{1,2}=3.7 \mathrm{~Hz}, 2 \mathrm{H}, \mathrm{H}-2^{\prime}\right.$ and $\left.\mathrm{H}-2^{\prime \prime}\right), 3.35-3.30(\mathrm{~m}, 6 \mathrm{H}, 2-$ $\mathrm{OCH}_{3}, \mathrm{H}-4^{\prime}$ and $\left.\mathrm{H}-4^{\prime \prime}\right), 2.47-2.44$ (m, 1H, H-3), 1.48-1.41 (m, 2H, H-4a and H-4b), 1.351.27 (m, $36 \mathrm{H}, \mathrm{H}-5-\mathrm{H}-22), 1.12\left(\mathrm{~d}, J_{1,2}=6.1 \mathrm{~Hz}, 3 \mathrm{H}, \mathrm{CH}_{3}-1\right), 0.88$ (t, $J=6.9 \mathrm{~Hz}, 3 \mathrm{H}$, $\left.\mathrm{CH}_{3}-23\right) ;{ }^{13} \mathrm{C}$ NMR $\left(150 \mathrm{MHz}, \mathrm{CD}_{3} \mathrm{OD}\right) \delta 175.9(\mathrm{C}=\mathrm{O}), 95.1\left(\mathrm{C}-1^{\prime} / 1^{\prime \prime}\right), 95.0\left(\mathrm{C}-1^{\prime} / 1^{\prime \prime}\right)$, 79.4 (C-2), $74.6\left(\mathrm{C}-3^{\prime} / 3^{\prime \prime}\right), 74.4\left(\mathrm{C}-3^{\prime} / 3^{\prime \prime}\right), 73.8$ (C-5"), $73.15\left(\mathrm{C}-2^{\prime} / 2^{\prime \prime}\right), 73.13\left(\mathrm{C}-2^{\prime} / 2^{\prime \prime}\right)$, $71.91\left(\mathrm{C}-4^{\prime} / 4^{\prime \prime}\right), 71.86\left(\mathrm{C}-4^{\prime} / 4^{\prime \prime}\right), 71.4\left(\mathrm{C}-5^{\prime}\right), 64.3\left(\mathrm{C}-6^{\prime}\right), 62.6\left(\mathrm{C}-6^{\prime \prime}\right), 56.8\left(2-\mathrm{OCH}_{3}\right)$, 53.5 (C-3), 33.0, 30.74, 30.73, 30.6, 30.5, 30.4, 28.9, 28.5, 23.7, 16.6 (C-4-C-22), 14.4 (C-23); HRMS (ESI): calcd. for $\left[\mathrm{C}_{37} \mathrm{H}_{70} \mathrm{O}_{13}+\mathrm{NH}_{4}\right]^{+}:$740.5160; obsd.: 740.5134 .

\section{$2^{\prime}, 2^{\prime \prime}, 3^{\prime}, 3^{\prime \prime}, 4^{\prime}, 4^{\prime \prime}$-Hexa- $O$-trimethylsilyl-6'- $O$-[(R)-2-((S)-oxiran-2-yl)docosanoyl $]-$} 6"-hydroxy- $\alpha^{\prime}, \alpha^{\prime \prime}$-D-trehalose (32) and $2^{\prime}, 2^{\prime \prime}, 3^{\prime}, 3^{\prime \prime}, 4^{\prime}, 4^{\prime \prime}$-Hexa-O-trimethylsilyl$6^{\prime}, 6^{\prime \prime}-\operatorname{di}-O-[(R)-2-((S)-o x i r a n-2-y l) d o c o s a n o y l]-\alpha^{\prime}, \alpha^{\prime \prime}-$ D-trehalose (33). To a solution

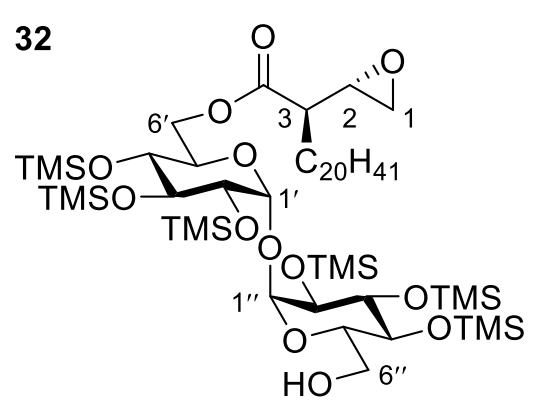
of TMS-trehalose $4(5.5 \mathrm{mg}, 0.0071 \mathrm{mmol})$ and mycolic acid 3c (10.9 mg, $0.029 \mathrm{mmol})$ in toluene $(1.5$ $\mathrm{mL})$ was added EDCI $(8.9 \mathrm{mg}, 0.046 \mathrm{mmol})$ and DMAP (1.7 mg, $0.014 \mathrm{mmol})$. The reaction was stirred at $55{ }^{\circ} \mathrm{C}$ for $5 \mathrm{~d}$, with additional DMAP $(1.5 \mathrm{mg}, 0.012$ mmol) added after $20 \mathrm{~h}$. The resulting precipitate was

filtered, washed with EtOAc $(10 \mathrm{~mL})$ and concentrated in vacuo. The resultant oil was redissolved in EtOAc $(3 \mathrm{~mL})$ and washed with water $(3 \mathrm{~mL})$ and brine $(3 \mathrm{~mL})$. The aqueous layer was extracted with EtOAc $(2 \times 3 \mathrm{~mL})$ and washed with water and brine, and the combined organic layers were dried over $\mathrm{MgSO}_{4}$, and concentrated in vacuo. The 


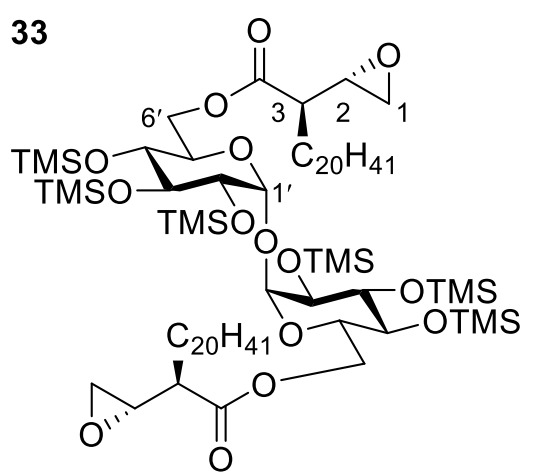

crude product was purified by gradient silica gel flash column chromatography (PE/EA, 30:1 $\rightarrow 0: 1$, v/v) to give 32 (3.4 $\mathrm{mg}, 0.0029 \mathrm{mmol}, 42 \%)$ and $\mathbf{3 3}(1.6 \mathrm{mg}$, $0.0010 \mathrm{mmol}, 15 \%)$ as colourless oils. 32: $R_{\mathrm{f}}=0.58$ (PE/EA, 5:1, v/v), IR (film) 2956, 2924, 2853, 1740, $1458,1377,1251,1166,1076,1007,842,735 \mathrm{~cm}^{-1} ;{ }^{1} \mathrm{H}$ NMR (500 MHz, CDCl3) $\delta 4.92\left(\mathrm{~d}, J_{1^{\prime \prime}, 2^{\prime \prime}}=2.7,1 \mathrm{H}, \mathrm{H}-\right.$ $\left.1^{\prime \prime}\right), 4.88\left(\mathrm{~d}, J_{1^{\prime}, 2^{\prime}}=2.2 \mathrm{~Hz}, 1 \mathrm{H}, \mathrm{H}-1^{\prime}\right), 4.47$ (d, $\left.J_{6^{\prime}, 6^{\prime} \mathrm{b}}=12.0 \mathrm{~Hz}, 1 \mathrm{H}, \mathrm{H}-6^{\prime} \mathrm{a}\right), 4.10$ (dd, $\left.J_{6^{\prime} \mathrm{a}, 6^{\prime} \mathrm{b}}=11.7 \mathrm{~Hz}, J_{6 b^{\prime}, 5^{\prime}}=3.9 \mathrm{~Hz}, 1 \mathrm{H}, \mathrm{H}-6^{\prime} \mathrm{b}\right), 4.01-3.99\left(\mathrm{~m}, 1 \mathrm{H}, \mathrm{H}-5^{\prime}\right), 3.91$ (t, $J=9.2 \mathrm{~Hz}$, $1 \mathrm{H}, \mathrm{H}-3^{\prime}$ ), 3.89 (t, $\left.J=9.5 \mathrm{~Hz}, 1 \mathrm{H}, \mathrm{H}-3^{\prime \prime}\right), 3.84-3.82$ (m, 1H, H-5"), 3.72-3.66 (m, 2H, H6"a and H-6"b), 3.50 (t, $\left.J=9.1 \mathrm{~Hz}, 1 \mathrm{H}, \mathrm{H}-4^{\prime}\right), 3.47$ (t, $\left.J=8.7 \mathrm{~Hz}, 1 \mathrm{H}, \mathrm{H}-\mathrm{H}-4^{\prime \prime}\right), 3.42$ (dd, $J_{2^{\prime} / 2^{\prime \prime}, 3^{\prime} / 3^{\prime \prime}}=9.3 \mathrm{~Hz}, J_{2^{\prime} / 2^{\prime \prime}, 1^{\prime} / 1^{\prime \prime}}=2.8 \mathrm{~Hz}, 2 \mathrm{H}, \mathrm{H}-2^{\prime}$ and H-2"), 3.17-3.15 (m, $\left.1 \mathrm{H}, \mathrm{H}-2\right)$, 2.82-2.80 (m, 1H, H-1a) 2.56-2.55 (m, 1H, H-1b), 2.24 (q, $J=7.0$ Hz, 1H, H-3), $1.74-$ 1.71 (m, 1H, H-4a), 1.62-1.57 (m, 1H, H-4b), 1.34-1.25 (m, 36 H, H-5-H-22),0.89-0.83 (m, 3H, $\left.\mathrm{CH}_{3}-23\right), 0.16,0.15,0.15,0.14,0.14,0.13$ (6 x s, 54H, TMS-CH 3 's); ${ }^{13} \mathrm{C}$ NMR $\left.\left(125 \mathrm{MHz}, \mathrm{CDCl}_{3}\right) \delta 173.3 \mathrm{C}=\mathrm{O}\right), 94.4\left(\mathrm{C}-1^{\prime \prime}\right), 94.3\left(\mathrm{C}-1^{\prime}\right), 73.5\left(\mathrm{C}-3^{\prime}\right), 73.3\left(\mathrm{C}-3^{\prime \prime}\right), 72.9$ (C-5"), 72.8 (C-2"), 72.6 (C-2'), 71.9 (C-4'), 71.4 (C-4"), 70.8 (C-5'), 63.2 (C-6'), 61.7 (C-6"), 52.5 (C-2), 48.7 (C-3), 46.2 (C-1), 31.9, 29.7, 29.7, 29.6, 29.6, 29.4, 29.4, 27.3, 22.7 (C-5-C-22), 29.0 (C-4), 14.1 (C-23), 1.1, .0, 0.9, 0.8, 0.2, 0.1 (TMS-CH3's); HRMS (ESI): calcd. for $\left[\mathrm{C}_{54} \mathrm{H}_{114} \mathrm{O}_{13}+\mathrm{NH}_{4}\right]^{+}:$1156.7213; obsd.: 1156.7195. 33: $R_{\mathrm{f}}=0.53$ (PE/EA, 5:1, v/v); IR (film) 2922, 2852, 1740, 1464, 1377, 1251, 1163, 1110, 1076, 1008, $841,739 \mathrm{~cm}^{-1} ;{ }^{1} \mathrm{H}$ NMR $(300 \mathrm{MHz}, \mathrm{CDCl} 3) \delta 4.90\left(\mathrm{~d}, J_{1^{\prime}, 2^{\prime}}=2.3 \mathrm{~Hz}, 1 \mathrm{H}, \mathrm{H}-1^{\prime}\right), 4.50-$ 4.46 (m, H-6'a), 4.10-405 (m, 1H, H-6'b), 4.02-3.98 (m, 1H, H-5'), 3.91 (t, $J=8.7 \mathrm{~Hz}$, $\left.1 \mathrm{H}, \mathrm{H}-3^{\prime}\right), 3.51\left(\mathrm{t}, J=9.1 \mathrm{~Hz}, 1 \mathrm{H}, \mathrm{H}-4^{\prime}\right), 3.42\left(\mathrm{dd}, J_{2^{\prime}, 3^{\prime}}=12.0 \mathrm{~Hz}, J_{2^{\prime}, 1^{\prime}}=2.9 \mathrm{~Hz}, 1 \mathrm{H}, \mathrm{H}-\right.$ $\left.2^{\prime}\right), 3.18-3.14(\mathrm{~m}, 1 \mathrm{H}, \mathrm{H}-2), 2.81\left(\mathrm{t}, J_{1 \mathrm{a}, 1 \mathrm{~b}}=J_{1 \mathrm{a}, 2}=5.0 \mathrm{~Hz}, 1 \mathrm{H}, \mathrm{H}-1 \mathrm{a}\right), 2.57-2.55(\mathrm{~m}, 1 \mathrm{H}$, $\mathrm{H}-1 \mathrm{~b}$ ), 2.30-2.25 (m, 1H, H-3), 1.77-1.68 (m, 2H, H-4a and H-4b), 1.34-1.20 (m, $36 \mathrm{H}$, $\mathrm{H}-5-\mathrm{H}-22), 0.90-0.84$ (m, 3H, CH 3 -23), 0.16-0.11 (m, 54H, TMS-CH 3 's); HRMS (ESI): calcd. for $\left[\mathrm{C}_{80} \mathrm{H}_{162} \mathrm{O}_{13} \mathrm{Si}_{6}+\mathrm{Na}\right]^{+}$: 1522.0523 ; obsd.: 1522.0587 . 


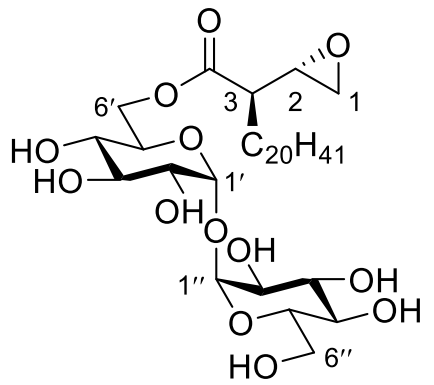

$6^{\prime}-O-[(R)-2-((S)-o x i r a n-2-y l) d o c o s a n o y l]-6^{\prime \prime}-h y d r o x y-$ $\boldsymbol{\alpha}^{\prime}, \boldsymbol{\alpha}^{\prime \prime}$-D-trehalose (1c). To a solution of TME $32(2.4 \mathrm{mg}$, $0.0021 \mathrm{mmol})$ in pyridine $(20 \mu \mathrm{L})$ was added $\mathrm{HF} \cdot$ pyridine (17\% HF in pyridine, $2.29 \mu \mathrm{L}, 0.0211 \mathrm{mmol})$. After $11 \mathrm{~h}$ the reaction was neutralised with aq. $\mathrm{Ca}(\mathrm{OAc})_{2}(1.0 \mathrm{M})$ and the resulting precipitate filtered, washed with pyridine $(3 \mathrm{~mL})$ and $\mathrm{MeOH} / \mathrm{DCM}$ (3 mL, 1:1, v/v), and concentrated in vacuo. The crude product was purified by size exclusion chromatography on lipohilic sephadex (DCM/MeOH, 1:1) to give a mixture of products including 1c. HRMS (ESI): calcd. for $\left[\mathrm{C}_{36} \mathrm{H}_{66} \mathrm{O}_{13}+\mathrm{NH}_{4}\right]^{+}$: 724.4847; obsd.: 724.4837 .

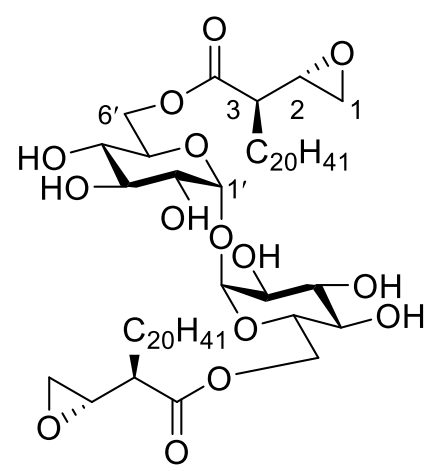

$6^{\prime}, 6^{\prime \prime}$-di- $O$-[(R)-2-((S)-oxiran-2-yl)docosanoyl]- $\alpha^{\prime}, \alpha^{\prime \prime}-\mathrm{D}-$ trehalose (2c). To a solution of TME $33(2.1 \mathrm{mg}, 0.0014$ mmol) in pyridine $(20 \mu \mathrm{L})$ was added $\mathrm{HF} \cdot$ pyridine $(17 \% \mathrm{HF}$ in pyridine, $1.45 \mu \mathrm{L}, 0.0140 \mathrm{mmol})$. After $24 \mathrm{~h}$ the reaction was neutralised with aq. $\mathrm{Ca}(\mathrm{OAc})_{2}(1.0 \mathrm{M})$ and the resulting precipitate filtered, washed with pyridine $(3 \mathrm{~mL})$ and $\mathrm{MeOH} / \mathrm{DCM}(3 \mathrm{~mL}, 1: 1, \mathrm{v} / \mathrm{v})$, and concentrated in vacuo to yield 2c as a mixture of products. HRMS (ESI): calcd. for $\left[\mathrm{C}_{60} \mathrm{H}_{110} \mathrm{O}_{15}+\mathrm{NH}_{4}\right]^{+}$: 1088.8183; obsd.: 1088.8087. 


\section{References}

1. Bansal-Mutalik, R.; Nikaido, H., Quantitative lipid composition of cell envelopes of Corynebacterium glutamicum elucidated through reverse micelle extraction. Proc. Natl. Acad. Sci. U. S. A. 2011, 108 (37), 15360-15365.

2. Al Dulayymi, J. R.; Baird, M. S.; Maza-Iglesias, M.; Vander, B. S.; Grooten, J., The first unique synthetic mycobacterial cord factors. Tetrahedron Lett. 2009, 50, 37023705 .

3. Ravindran, R.; Bhowmick, S.; Das, A.; Ali, N., Comparison of BCG, MPL and cationic liposome adjuvant systems in leishmanial antigen vaccine formulations against murine visceral leishmaniasis. BMC Microbiol. 2010, 10 (181).

4. Sarpe, V. A.; Kulkarni, S. S., Synthesis of maradolipid. J. Org. Chem. 2011, 76, 6866-6870.

5. Khan, A. A.; Stocker, B. L.; Timmer, M. S. M., Trehalose glycolipids-synthesis and biological activities. Carbohydr. Res. 2012, 356, 25-36.

6. Brennan, P. J.; Nikaido, H., The Envelope of Mycobacteria. Annu. Rev. Biochem. 1995, 64 (1), 29-63.

7. Verschoor, J. A.; Baird, M. S.; Grooten, J., Towards understanding the functional diversity of cell wall mycolic acids of Mycobacterium tuberculosis. Prog. Lipid Res. 2012, 51 (4), 325-339.

8. Takayama, K.; Wang, C.; Besra, G. S., Pathway to Synthesis and Processing of Mycolic Acids in Mycobacterium tuberculosis. Clin. Microbiol. Rev. 2005, 18 (1), 81101.

9. Watanabe, M.; Aoyagi, Y.; Ridell, M.; Minnikin, D. E., Separation and characterization of individual mycolic acids in representative mycobacteria. Microbiology 2001, 147 (7), 1825-1837.

10. Chatterjee, D., The mycobacterial cell wall: structure, biosynthesis and sites of drug action. Curr. Opin. Chem. Biol. 1997, 1 (4), 579-588.

11. Barry Iii, C. E.; Lee, R. E.; Mdluli, K.; Sampson, A. E.; Schroeder, B. G.; Slayden, R. A.; Yuan, Y., Mycolic acids: structure, biosynthesis and physiological functions. Prog. Lipid Res. 1998, 37 (2-3), 143-179.

12. Puech, V.; Chami, M.; Lemassu, A.; Lanéelle, M.-A.; Schiffler, B.; Gounon, P.; Bayan, N.; Benz, R.; Daffé, M., Structure of the cell envelope of corynebacteria: importance of the non-covalently bound lipids in the formation of the cell wall permeability barrier and fracture plane. Microbiology 2001, 147 (5), 1365-1382.

13. Collins, M. D.; Goodfellow, M.; Minnikin, D. E., A Survey of the Structures of Mycolic Acids in Corynebacterium and Related Taxa. J. Gen. Microbiol. 1982, 128 (1), 129-149.

14. Goren, M. B.; Brokl, O.; Roller, P.; Fales, H. M.; Das, B. C., Sulfatides of Mycobacterium tuberculosis: the structure of the principal sulfatide (SL-I). Biochemistry 1976, 15 (13), 2728-2735.

15. Werninghaus, K.; Babiak, A.; Gross, O.; Hoelscher, C.; Dietrich, H.; Agger, E. M.; Mages, J.; Mocsai, A.; Schoenen, H.; Finger, K.; Nimmerjahn, F.; Brown, G. D.; 
Kirschning, C.; Heit, A.; Andersen, P.; Wagner, H.; Ruland, J.; Lang, R., Adjuvanticity of a synthetic cord factor analogue for subunit Mycobacterium tuberculosis vaccination requires FcR $\gamma$-Syk-Card9-dependent innate immune activation. J. Exp. Med. 2009, 206 (1), 89-97.

16. Schoenen, H.; Bodendorfer, B.; Hitchens, K.; Manzanero, S.; Werninghaus, K.; Nimmerjahn, F.; Agger, E. M.; Stenger, S.; Andersen, P.; Ruland, J.; Brown, G. D.; Wells, C.; Lang, R., Cutting Edge: Mincle Is Essential for Recognition and Adjuvanticity of the Mycobacterial Cord Factor and its Synthetic Analog Trehalose-Dibehenate. $J$. Immunol. 2010, 184, 2756-2760.

17. Ishikawa, E.; Ishikawa, T.; Morita, Y. S.; Toyonaga, K.; Yamada, H.; Takeuchi, O.; Kinoshita, T.; Akira, S.; Yoshikai, Y.; Yamasaki, S., Direct recognition of the mycobacterial glycolipid, trehalose dimycolate, by C-type lectin Mincle. J. Exp. Med. 2009, 206 (13), 2879-2888.

18. Ottenhoff, T. H. M.; Doherty, T. M.; van Dissel, J. T.; Bang, P.; Lingnau, K.; Kromann, I.; Andersen, P., First in humans: A new molecularly defined vaccine shows excellent safety and strong induction of long-lived <em>Mycobacterium tuberculosis</em>-specific Th1-cell like responses. Hum. Vaccin. 2010, 6 (12), 10071015.

19. Yamamoto, H.; Oda, M.; Nakano, M.; Watanabe, N.; Yabiku, K.; Shibutani, M.; Inoue, M.; Imagawa, H.; Nagahama, M.; Himeno, S.; Setsu, K.; Sakurai, J.; Nishizawa, M., Development of Vizantin, a Safe Immunostimulant, Based on the Structure-Activity Relationship of Trehalose-6,6'-dicorynomycolate. J. Med. Chem. 2013, 56 (1), 381-385. 20. Holten-Andersen, L.; Doherty, T. M.; Korsholm, K. S.; Andersen, P., Combination of the Cationic Surfactant Dimethyl Dioctadecyl Ammonium Bromide and Synthetic Mycobacterial Cord Factor as an Efficient Adjuvant for Tuberculosis Subunit Vaccines. Infect. Immun. 2004, 72 (3), 1608-1617.

21. Lang, R.; Schoenen, H.; Desel, C., Targeting Syk-Card9-activating C-type lectin receptors by vaccine adjuvants: Findings, implications and open questions. Immunobiology 2011, 216 (11), 1184-1191.

22. Agger, E. M.; Rosenkrands, I.; Hansen, J.; Brahimi, K.; Vandahl, B. S.; Aagaard, C.; Werninghaus, K.; Kirschning, C.; Lang, R.; Christensen, D.; Theisen, M.; Follmann, F.; Andersen, P., Cationic Liposomes Formulated with Synthetic Mycobacterial Cordfactor (CAF01): A Versatile Adjuvant for Vaccines with Different Immunological Requirements. PLoS ONE 2008, 3 (9), e3116.

23. Numata, F.; Nishimura, K.; Ishida, H.; Ukei, S.; Tone, Y.; Ishihara, C.; Saiki, I.; Sekikawa, I.; Azuma, I., Lethal and adjuvant activities of cord factor and (trhalose-6,6'dimycolate) and synthetic analogs in mice. Chem. Pharm. Bull. 1985, 33 (10), 4544-4555. 24. Burkovski, A., Cell Envelope of Corynebacteria: Structure and Influence on Pathogenicity. ISRN Microbiol. 2013, 2013, 11.

25. Hovav, A.-H.; Bercovier, H., Pseudo-rationale design of efficient TB vaccines: lesson from the mycobacterial 27-kDa lipoprotein. Tuberculosis 2006, 86, 225-235.

26. Hunter, R. L.; Olsen, M. R.; Jagannath, C.; Actor, J. K., Multiple Roles of Cord Factor in the Pathogenesis of Primary, Secondary, and Cavitary Tuberculosis, Including 
a Revised Description of the Pathology of Secondary Disease. Ann. Clin. Lab. Sci. 2006, 36 (4), 371-386.

27. Harland, C. W.; Botyanszki, Z.; Rabuka, D.; Bertozzi, C. R.; Parthasarathy, R., Synthetic Trehalose Glycolipids Confer Desiccation Resistance to Supported Lipid Monolayers. Langmuir 2009, 25, 5193-5198.

28. Ojha, A. K.; Trivelli, X.; Guerardel, Y.; Kremer, L.; Hatfull, G. F., Enzymatic hydrolysis of trehalose dimycolate releases free mycolic acids during mycobacterial growth in biofilms. J. Biol. Chem. 2010, 285 (23), 17380-17389.

29. Singh, G.; Singh, G.; Jadeja, D.; Kaur, J., Lipid hydrolizing enzymes in virulence: Mycobacterium tuberculosis as a model system. CRC Cr. Rev. Microbiol. 2010, 36 (3), 259-269.

30. Fairn, G. D.; Grinstein, S., How nascent phagosomes mature to become phagolysosomes. Trends Immunol. 2012, 33 (8), 397-405.

31. Dover, L. G.; Cerdeño-Tárraga, A. M.; Pallen, M. J.; Parkhill, J.; Besra, G. S., Comparative cell wall core biosynthesis in the mycolated pathogens, Mycobacterium tuberculosis and Corynebacterium diphtheriae. FEMS Microbiol. Rev. 2004, 28 (2), 225 250 .

32. Retzinger, G. S.; Meredith, S. C.; Takayama, K.; Hunter, R. L.; Kezdy, F. J., The role of surface in the biological activities of trehalose 6,6'-dimycolate. Surface properties and development of a model system. J. Biol. Chem. 1981, 256 (15), 8208-8216.

33. Karakousis, P. C.; Bishai, W. R.; Dorman, S. E., Mycobacterium tuberculosis cell envelope lipids and the host immune response. Cell. Microbiol. 2004, 6 (2), 105-116.

34. Hunter, R. L.; Armitige, L.; Jagannath, C.; Actor, J. K., TB Research at UTHouston - A review of cord factor: new approaches to drugs, vaccines and the pathogenesis of tuberculosis. Tuberculosis 2009, 89, S18-S25.

35. Spargo, B. J.; Crowe, L. M.; Ioneda, T.; Beaman, B. L.; Crowe, J. H., Cord Factor ( $\alpha, \alpha$-Trehalose 6,6'-Dimycolate) Inhibits Fusion Between Phospholipid Vesicles. P. Natl. Acad. Sci. USA. 1991, 88 (3), 737-740.

36. Sydor, T.; von Bargen, K.; Hsu, F.-F.; Huth, G.; Holst, O.; Wohlmann, J.; Becken, U.; Dykstra, T.; Söhl, K.; Lindner, B.; Prescott, J. F.; Schaible, U. E.; Utermöhlen, O.; Haas, A., Diversion of phagosome trafficking by pathogenic Rhodococcus equi depends on mycolic acid chain length. Cell. Microbiol. 2013, 15 (3), 458-473.

37. Indrigo, J.; Hunter Jr, R. L.; Actor, J. K., Influence of trehalose 6,6'-dimycolate (TDM) during mycobacterial infection of bone marrow macrophages. Microbiology 2002, 148, 1991-1998.

38. Indrigo, J.; Hunter, R. L., Jr.; Actor, J. K., Influence of trehalose 6,6'-dimycolate (TDM) during mycobacterial infection of bone marrow macrophages. Microbiology 2002, 148, 1991-1998.

39. Hunter, R. L.; Olsen, M. R.; Jagannath, C.; Actor, J. K., Multiple Roles of Cord Factor in the Pathogenesis of Primary, Secondary, and Cavitary Tuberculosis, Including a Revised Description of the Pathology of Secondary Disease. Ann. Clin. Lab. Sci. 2006, 36 (4), 371-386. 
40. Keshishian, J. M.; Abad, J. M.; Fuchs, M., Lipoid Pneumonia: Review with a Report of a Case of Carcinoma Occurring Within an Area of Lipoid Pneumonia. Ann. Thorac. Surg. 1969, 7 (3), 231-234.

41. Hoption, C. S. A.; van Netten, J. P.; van Netten, C., Dr William Coley and tumour regression: a place in history or in the future. Postgrad. Med. J. 2003, 79, 672-680.

42. Nauts, H. C.; Swift, W. E.; Coley, B. L., The Treatment of Malignant Tumors by Bacterial Toxins as Developed by the Late William B. Coley, M.D., Reviewed in the Light of Modern Research. Cancer Res. 1946, 6 (4), 205-216.

43. Brandau, S.; Suttmann, H., Thirty years of BCG immunotherapy for non-muscle invasive bladder cancer: A success story with room for improvement. Biomed. Pharmacother. 2007, 61, 299-305.

44. Morales, A., Treatment of carcinoma in situ of the bladder with BCG. Cancer Immunol. Immun. 1980, 9 (1), 69-72.

45. Matsunaga, I.; Moody, D. B., Mincle is a long sought receptor for mycobacterial cord factor. J. Exp. Med. 2009, 206 (13), 2865-2868.

46. Perrie, Y.; Mohammed, A. R.; Kirby, D. J.; McNeil, S. E.; Bramwell, V. W., Vaccine adjuvant systems: enhancing the efficacy of sub-unit protein antigens. Int. J. Pharm. 2008, 364 (2), 272-80.

47. Reed, S. G.; Bertholet, S.; Coler, R. N.; Friede, M., New horizons in adjuvants for vaccine development. Trends Immunol. 2009, 30 (1), 23-32.

48. Pitt, J. M.; Blankley, S.; McShane, H.; O'Garra, A., Vaccination against tuberculosis: how can we better BCG? Microb. Pathog. 2013, 58, 2-16.

49. Castillo-Velazquez, U.; Aranday-Cortes, E.; Gutierrez-Pabello, J. A., Alternative activation modifies macrophage resistance to Mycobacterium bovis. Vet. Microbiol. 2011, 151, 51-59.

50. Freund, J.; Casals, J.; Hosmer, E. P., Sensitization and Antibody Formation after Injection of Tubercle Bacilli and Paraffin Oil. Exp. Biol. Med. 1937, 37 (3), 509-513.

51. Rosenkrands, I.; Agger, E. M.; Olsen, A. W.; Korsholm, K. S.; Andersen, C. S.; Jensen, K. T.; Andersen, P., Cationic Liposomes Containing Mycobacterial Lipids: a New Powerful Th1 Adjuvant System. Infect. Immun. 2005, 73 (9), 5817-5826.

52. Ribi, E.; Toubiana, R.; Strain, S. M.; Milner, K. C.; McLaughlin, C.; Cantrell, J.; Azuma, I.; Das, B. C.; Parker, R., Further studies on the structural requirements of agents for immunotherapy of the guinea pig line-10 tumor. Cancer Immunol. Immun. 1978, 3, 171-177.

53. Geisel, R. E.; Sakamoto, K.; Russell, D. G.; Rhoades, E. R., In Vivo Activity of Released Cell Wall Lipids of Mycobacterium bovis Bacillus Calmette-Guerin Is Due Principally to Trehalose Mycolates. J. Immunol. 2005, 174, 5007-5015.

54. Wells, C. A.; Salvage-Jones, J. A.; Li, X.; Hitchens, K.; Butcher, S.; Murray, R. Z.; Beckhouse, A. G.; Lo, Y.-L.-S.; Manzanero, S.; Cobbold, C.; Schroder, K.; Ma, B.; Orr, S.; Stewart, L.; Lebus, D.; Sobieszczuk, P.; Hume, D. A.; Stow, J.; Blanchard, H.; Ashman, R. B., The Macrophage-Inducible C-Type Lectin, Mincle, Is an Essential Component of the Innate Immune Response to Candida albicans. J. Immunol. 2008, 180, 7404-7413. 
55. Yarkoni, E.; Rapp, H. J.; Polonsky, J.; Lederer, E., Immunotherapy with an intralesionally administered synthetic cord factor analogue. Int. J. Cancer 1978, 22 (5), 564-569.

56. Parant, M.; Audibert, F.; Parant, F.; Chedid, L.; Soler, E.; Polonsky, J.; Lederer, E., Nonspecific immunostimulant activities of synthetic trehalose-6,6'-diesters (lower homologs of cord factor). Infect. Immun. 1978, 20 (1), 12-19.

57. Miyake, Y.; Toyonaga, K.; Mori, D.; Kakuta, S.; Hoshino, Y.; Oyamada, A.; Yamada, H.; Ono, K.-i.; Suyama, M.; Iwakura, Y.; Yoshikai, Y.; Yamasaki, S., C-type Lectin MCL Is an FcR $\gamma$-Coupled Receptor that Mediates the Adjuvanticity of Mycobacterial Cord Factor. Immunity 2013, 38 (5), 1050-1062.

58. Furukawa, A.; Kamishikiryo, J.; Mori, D.; Toyonaga, K.; Okabe, Y.; Toji, A.; Kanda, R.; Miyake, Y.; Ose, T.; Yamasaki, S.; Maenaka, K., Structural analysis for glycolipid recognition by the C-type lectins Mincle and MCL. Proc. Natl. Acad. Sci. U. S. A. 2013, 110 (43), 17438-17443.

59. Robinson, M. J.; Sancho, D.; Slack, E. C.; LeibundGut-Landmann, S.; Sousa, C. R., Myeloid C-type lectins in innate immunity. Nat. Immunol. 2006, 7 (12), 1258-1265.

60. Osorio, F.; Reis e Sousa, C., Myeloid C-type Lectin Receptors in Pathogen Recognition and Host Defense. Immunity 2011, 34, 651-664.

61. Kerrigan, A. M.; Brown, G. D., Syk-coupled C-type lectins in immunity. Trends Immunol. 2011, 32 (4), 151-156.

62. Balch, S. G.; Greaves, D. R.; Gordon, S.; McKnight, A. J., Organization of the mouse macrophage C-type lectin ( $\mathrm{Mcl})$ gene and identification of a subgroup of related lectin molecules. Eur. J. Immunogenet. 2002, 29, 61-64.

63. Richardson, M. B.; Williams, S. J., MCL and Mincle: C-Type Lectin Receptors That Sense Damaged Self and Pathogen-Associated Molecular Patterns. Frontiers in immunology 2014, 5, 288.

64. Balch, S. G.; McKnight, A. J.; Seldin, M. F.; Gordon, S., Cloning of a Novel Ctype Lectin Expressed by Murine Macrophages. J. Biol. Chem. 1998, 273 (29), 1865618664.

65. Kerscher, B.; Willment, J. A.; Brown, G. D., The Dectin-2 family of C-type lectin-like receptors: an update. Int. Immunol. 2013, 25 (5), 271-277.

66. Graham, L. M.; Gupta, V.; Schafer, G.; Reid, D. M.; Kimberg, M.; Dennehy, K. M.; Hornsell, W. G.; Guler, R.; Campanero-Rhodes, M. A.; Palma, A. S.; Feizi, T.; Kim, S. K.; Sobieszczuk, P.; Willment, J. A.; Brown, G. D., The C-type Lectin Receptor CLECSF8 (CLEC4D) Is Expressed by Myeloid Cells and Triggers Cellular Activation through Syk Kinase. J. Biol. Chem. 2012, 287 (31), 25964-25974.

67. Arce, I.; Martínez-Muñoz, L.; Roda-Navarro, P.; Fernández-Ruiz, E., The human C-type lectin CLECSF8 is a novel monocyte/macrophage endocytic receptor. Eur. J. Immunol. 2004, 34 (1), 210-220.

68. Lobato-Pascual, A.; Saether, P. C.; Fossum, S.; Dissen, E.; Daws, M. R., Mincle, the receptor for mycobacterial cord factor, forms a functional receptor complex with MCL and FceRI- $\gamma$. Eur. J. Immunol. 2013, 43 (12), 3167-3174.

69. Yamasaki, S., Signaling while eating: MCL is coupled with Mincle. Eur. J. Immunol. 2013, 43 (12), 3156-3158. 
70. Feinberg, H.; Jégouzo, S. A. F.; Rowntree, T. J. W.; Guan, Y.; Brash, M. A.; Taylor, M. E.; Weis, W. I.; Drickamer, K., Mechanism for Recognition of an Unusual Mycobacterial Glycolipid by the Macrophage Receptor Mincle. J. Biol. Chem. 2013, 288 (40), 28457-28465.

71. Yamasaki, S.; Matsumoto, M.; Takeuchi, O.; Matsuzawa, T.; Ishikawa, E.; Sakuma, M.; Tateno, H.; Uno, J.; Hirabayashi, J.; Mikami, Y.; Takeda, K.; Akira, S.; Saito, T., C-type lectin Mincle is an activating receptor for pathogenic fungus, Malassezia. Proc. Natl. Acad. Sci. U. S. A. 2009, 106 (6), 1897-1902.

72. Ishikawa, T.; Itoh, F.; Yoshida, S.; Saijo, S.; Matsuzawa, T.; Gonoi, T.; Saito, T.; Okawa, Y.; Shibata, N.; Miyamoto, T.; Yamasaki, S., Identification of Distinct Ligands for the C-type Lectin Receptors Mincle and Dectin-2 in the Pathogenic Fungus Malassezia. Cell Host Microbe 2013, 13 (4), 477-488.

73. Khan, A. A.; Chee, S. H.; McLaughlin, R. J.; Harper, J. L.; Kamena, F.; Timmer, M. S. M.; Stocker, B. L., Long-Chain Lipids Are Required for the Innate Immune Recognition of Trehalose Diesters by Macrophages. ChemBioChem 2011, 12, 25722576.

74. Stocker, B. L.; Khan, A. A.; Chee, S. H.; Kamena, F.; Timmer, M. S. M., On One Leg: Trehalose Monoesters Activate Macrophages in a Mincle-Dependant Manner. ChemBioChem 2014, 15 (3), 382-388.

75. Khan, A. A.; Kamena, F.; Timmer, M. S. M.; Stocker, B. L., Development of a benzophenone and alkyne functionalised trehalose probe to study trehalose dimycolate binding proteins. Org. Biomol. Chem. 2013, 11 (6), 881-885.

76. Rao, V.; Fujiwara, N.; Porcelli, S. A.; Glickman, M. S., Mycobacterium tuberculosis controls host innate immune activation through cyclopropane modification of a glycolipid effector molecule. J. Exp. Med. 2005, 201 (4), 535-543.

77. Rao, V.; Gao, F.; Chen, B.; Jacobs, W. R., Jr.; Glickman, M. S., Transcyclopropanation of mycolic acids on trehalose dimycolate suppresses Mycobacterium tuberculosis -induced inflammation and virulence. J. Clin. Invest. 2006, 116 (6), 1660-7. 78. Vander Beken, S.; Al Dulayymi, J. a. R.; Naessens, T.; Koza, G.; Maza-Iglesias, M.; Rowles, R.; Theunissen, C.; De Medts, J.; Lanckacker, E.; Baird, M. S.; Grooten, J., Molecular structure of the Mycobacterium tuberculosis virulence factor, mycolic acid, determines the elicited inflammatory pattern. Eur. J. Immunol. 2011, 41 (2), 450-460.

79. Martin-Bertelsen, B.; Korsholm, K. S.; Rose, F.; Nordly, P.; Franzyk, H.; Andersen, P.; Agger, E. M.; Christensen, D.; Yaghmur, A.; Foged, C., The supramolecular structure is decisive for the immunostimulatory properties of synthetic analogues of a mycobacterial lipid in vitro. RSC Adv. 2013, 3 (43), 20673-20683.

80. Jegouzo, S. A.; Harding, E. C.; Acton, O.; Rex, M. J.; Fadden, A. J.; Taylor, M. E.; Drickamer, K., Defining the conformation of human mincle that interacts with mycobacterial trehalose dimycolate. Glycobiology 2014.

81. Reed, S. G.; Orr, M. T.; Fox, C. B., Key roles of adjuvants in modern vaccines. Nat. Med. 2013, 19 (12), 1597-1608.

82. Watanabe, R.; Yoo, Y. C.; Hata, K.; Mitobe, M.; Koike, Y.; Nishizawa, M.; Garcia, D. M.; Nobuchi, Y.; Imagawa, H.; Yamada, H.; Azuma, I., Inhibitory effect of trehalose dimycolate (TDM) and its stereoisometric derivatives, trehalose 
dicorynomycolates (TDCMs), with low toxicity on lung metastasis of tumour cells in mice. Vaccine 1999, 17 (11-12), 1484-1492.

83. Toubiana, R.; Das, B. C.; Defaye, J.; Mompon, B.; Toubiana, M.-J., Étude du cord-factor et de ses analogues. : Partie III. Synthèse du cord-factor (6,6'-di-O-mycoloyl$\alpha, \alpha$-tréhalose) et du 6,6'-di-O-palmitoyl- $\alpha, \alpha$-tréhalose. Carbohydr. Res. 1975, 44 (2), 308-312.

84. Johnson, D. A., Simple procedure for the preparation of trimethylsilyl ethers of carbohydrates and alcohols. Carbohydr. Res. 1992, 237, 313-318.

85. Khan, A. A.; Chee, S. H.; Stocker, B. L.; Timmer, M. S. M., The Synthesis of Long-Chain $\alpha$-Alkyl- $\beta$-Hydroxy Esters Using Allylic Halides in a Fráter-Seebach Alkylation. Eur. J. Org. Chem 2012, 2012 (5), 995-1002.

86. Wipf, P.; Uto, Y.; Yoshimura, S., Total Synthesis of a Stereoisomer of Bistramide $\mathrm{C}$ and Assignment of Configuration of the Natural Product. Chem. Eur. J. 2002, 8 (7), 1670-1681.

87. Saito, S.; Ishikawa, T.; Kuroda, A.; Koga, K.; Moriwake, T., A revised mechanism for chemoselective reduction of esters with borane-dimethyl sulfide complex and catalytic sodium tetrahydroborate directed by adjacent hydroxyl group. Tetrahedron 1992, 48 (20), 4067-4086.

88. Badorrey, R.; Portana, E.; Diaz-de-Villegas, M. D.; Galvez, J. A., Stereocontrolled synthesis of orthogonally protected 2-substituted 4-aminopiperidines. Org. Biomol. Chem. 2009, 7 (14), 2912-2918.

89. Yue, S.; Huang, S. J.; Bradford, J., Anthraquinone based near ir emitting compounds and uses thereof. Google Patents: 2012.

90. Falck, J. R.; Wallukat, G.; Puli, N.; Goli, M.; Arnold, C.; Konkel, A.; Rothe, M.; Fischer, R.; Müller, D. N.; Schunck, W.-H., 17(R),18(S)-Epoxyeicosatetraenoic Acid, a Potent Eicosapentaenoic Acid (EPA) Derived Regulator of Cardiomyocyte Contraction: Structure-Activity Relationships and Stable Analogues. J. Med. Chem. 2011, 54 (12), 4109-4118.

91. Corey, E. J.; Cho, H.; Rücker, C.; Hua, D. H., Studies with trialkylsilyltriflates: new syntheses and applications. Tetrahedron Lett. 1981, 22 (36), 3455-3458.

92. Lee, C. K.; Lindley, M. G., Synthesis of dimethyl ethers of $\alpha$, $\alpha$-trehalose. Carbohyd. Res. 1978, 63 (0), 277-282.

93. Purdie, T.; Irvine, J. C., C.-The alkylation of sugars. J. Chem. Soc. 1903, 83 (0), 1021-1037.

94. Janssen, D. E.; Wilson, T. P., 4-Iodoveratrole. Org. Synth. 1956, 36.

95. Barroso, S.; Castelli, R.; Baggelaar, M. P.; Geerdink, D.; ter Horst, B.; CasasArce, E.; Overkleeft, H. S.; van der Marel, G. A.; Codée, J. D. C.; Minnaard, A. J., Total Synthesis of the Triglycosyl Phenolic Glycolipid PGL-tb1 from Mycobacterium tuberculosis. Angew. Chem. Int. Edit. 2012, 51 (47), 11774-11777.

96. Wuts, G. M.; Green, T. W., Greene's Protecting Groups in Organic Synthesis. John Wiley \& Sons, Inc: New Jersey, 2007; Vol. 4.

97. Elsinger, F.; Schreiber, J.; Eschenmoser, A., Notiz über die Selektivität der Spaltung von Carbonsäuremethylestern mit Lithiumjodid. Helv. Chim. Acta 1960, 43 (1), 113-118. 
98. Salomon, C. J.; Mata, E. G.; Mascaretti, O. A., Bis (tributyltin) oxide. A mild, neutral and selective reagent for cleavage of esters. Scope and limitation of the reaction. Tetrahedron Lett. 1991, 32 (34), 4239-4242.

99. Salomon, C. J.; Mata, E. G.; Mascaretti, O. A., Selective deprotection of phenacyl, benzyl and methyl esters of N-protected amino acids and dipeptides and N-protected amino acids benzyl ester linked to resins with bis(tributyltin) oxide. J. Chem. Soc. Perkin Trans. 1 1996, (10), 995-999.

100. Mata, E. G.; Mascaretti, O. A., Mild and effective cleavage of esters with bis(tributyltin) oxide: A useful application in the deprotection of Pom penicillanate esters. Tetrahedron Lett. 1988, 29 (52), 6893-6896.

101. Davies, A. G., Organotin Chemistry. Wiley-VCH: 2004; Vol. 2.

102. Harrowven, D. C.; Guy, I. L., KF-Silica as a stationary phase for the chromatographic removal of tin residues from organic compounds. Chemical communications (Cambridge, England) 2004, (17), 1968-9.

103. Renaud, P.; Lacôte, E.; Quaranta, L., Alternative and mild procedures for the removal of organotin residues from reaction mixtures. Tetrahedron Lett. 1998, 39 (15), 2123-2126.

104. Neises, B.; Steglich, W., Simple Method for the Esterification of Carboxylic Acids. Angew. Chem. Int. Edit. 1978, 17 (7), 522-524.

105. Lienkamp, K.; Madkour, A. E.; Kumar, K.-N.; Nüsslein, K.; Tew, G. N., Antimicrobial Polymers Prepared by Ring-Opening Metathesis Polymerization: Manipulating Antimicrobial Properties by Organic Counterion and Charge Density Variation. Chem. Eur. J. 2009, 15 (43), 11715-11722.

106. Badorrey, R.; Portana, E.; Diaz-de-Villegas, M. D.; Galvez, J. A., Stereocontrolled synthesis of orthogonally protected 2-substituted 4-aminopiperidines. Org. Biomol. Chem. 2009, 7, 2912-2918.

107. Suzuki, T.; Saimoto, H.; Tomioka, H.; Oshima, K.; Nozaki, H., Regio- and stereoselective ring opening of epoxy alcohols with organoaluminum compounds leading to 1,2-diols. Tetrahedron Lett. 1982, 23, 3597-600.

108. Fujioka, H.; Ohba, Y.; Hirose, H.; Murai, K.; Kita, Y., A double iodoetherification of $\sigma$-symmetric diene acetals for installing four stereogenic centers in a single operation: Short asymmetric total synthesis of rubrenolide. Angew. Chem., Int. Ed. 2005, 44 (5), 734-737.

109. Liu, Y.-H.; Liu, Q.-S.; Zhang, Z.-H., Amberlyst-15 as a new and reusable catalyst for regioselective ring-opening reactions of epoxides to $\beta$-alkoxy alcohols. J. Mol. Catal. A-Chem. 2008, 296 (1-2), 42-46.

110. Izquierdo, J.; Rodriguez, S.; Gonzalez, F. V., Regioselective ring opening and isomerization reactions of 3,4-epoxyesters catalyzed by boron trifluoride. Org. Lett. 2011, 13, 3856-3859. 
7 Appendix - NMR Spectra 
${ }^{1} \mathrm{H}$ NMR $\left(500 \mathrm{MHz}, \mathrm{CDCl}_{3}\right)$

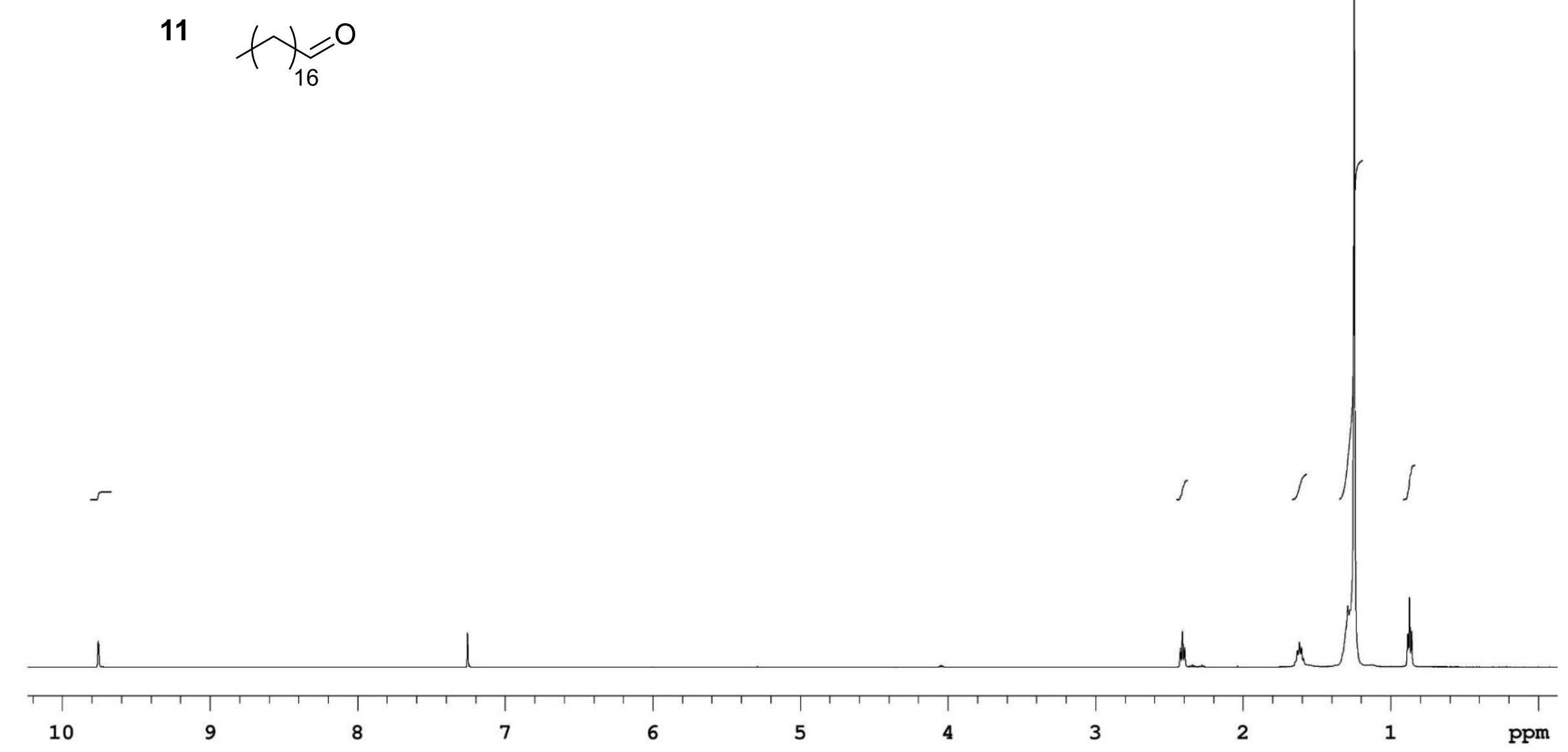


${ }^{13} \mathrm{C} \mathrm{NMR}\left(125 \mathrm{MHz}, \mathrm{CDCl}_{3}\right)$

11<smiles>CC(C)(C)CC(=O)[18O]</smiles>

(1) 
${ }^{1} \mathrm{H}$ NMR (300 MHz, $\mathrm{CDCl}_{3}$ )

$7 \times x_{16}^{2}-1$

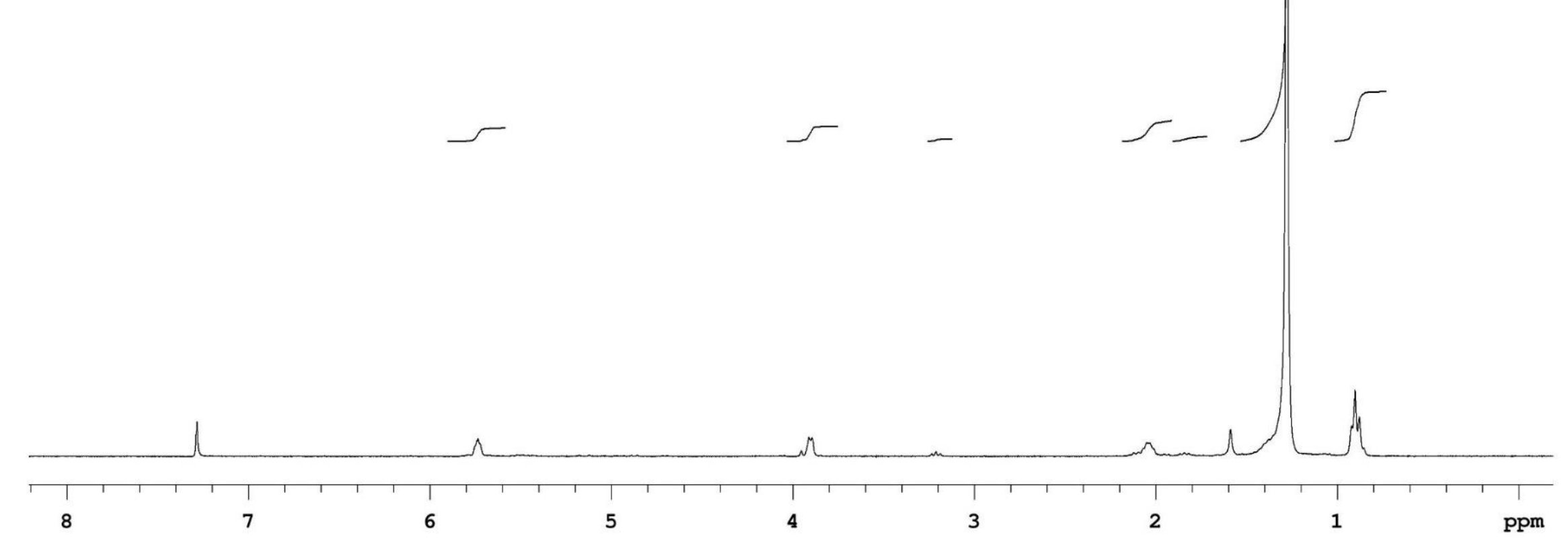


${ }^{13} \mathrm{C}$ NMR (125 MHz, $\left.\mathrm{CDCl}_{3}\right)$

$7+x_{16}^{2 n-1}$
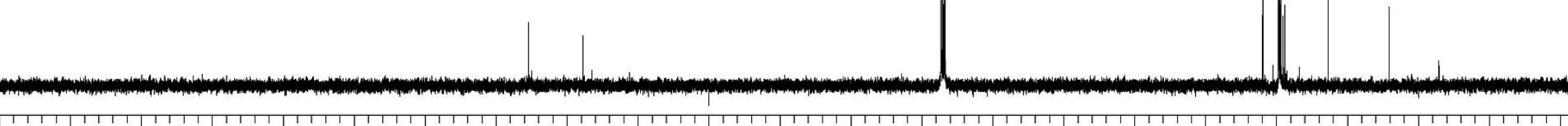
${ }^{1} \mathrm{H}$ NMR (300 MHz, $\mathrm{CDCl}_{3}$ )

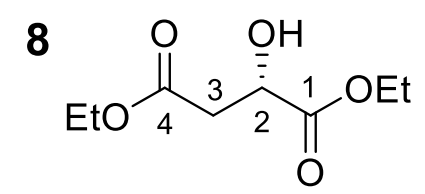

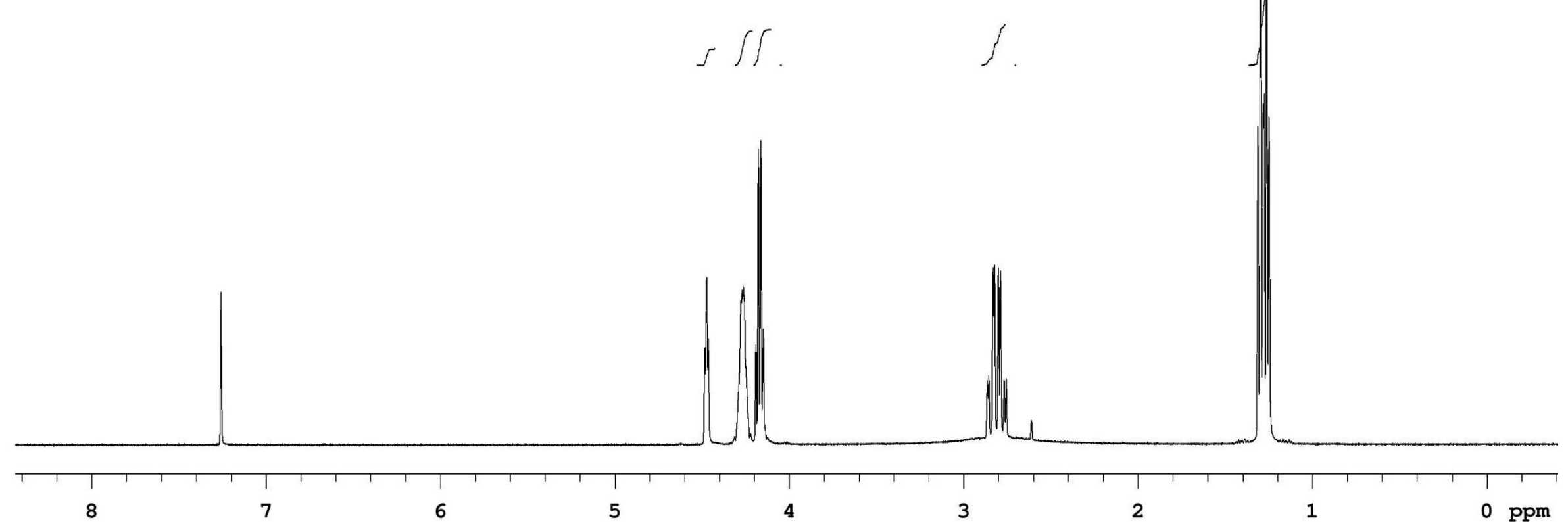


${ }^{13} \mathrm{C}$ NMR (125 MHz, $\left.\mathrm{CDCl}_{3}\right)$

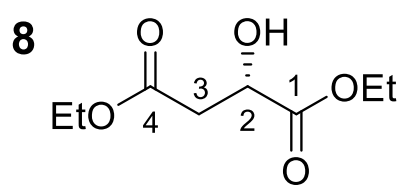
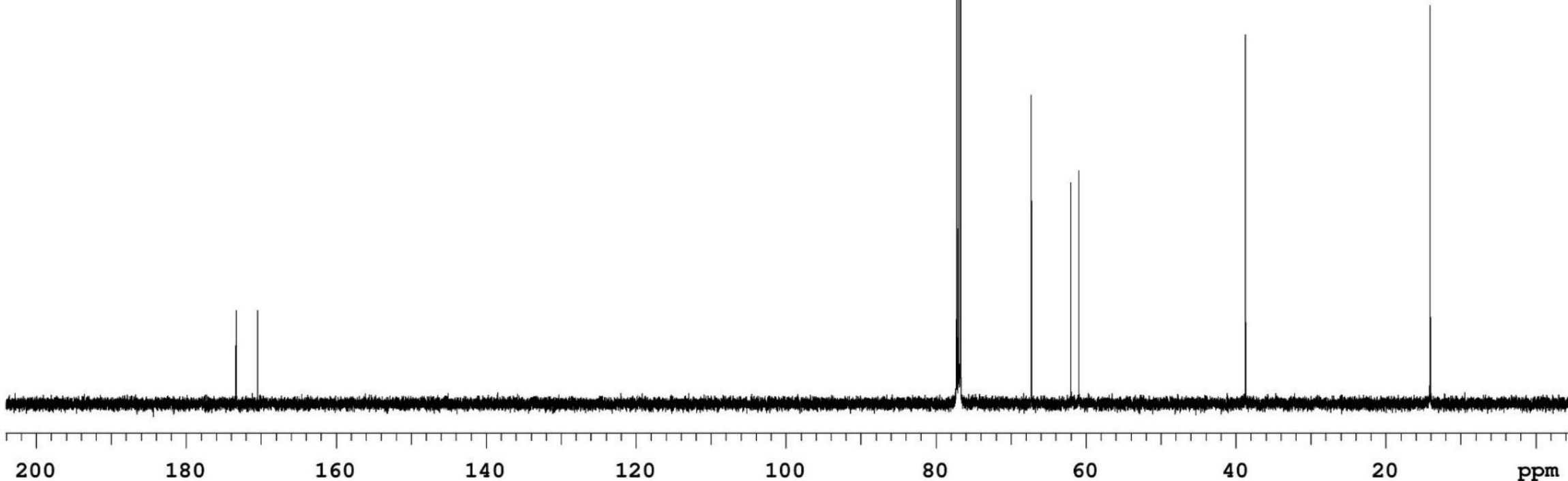
${ }^{1} \mathrm{H}$ NMR (500 MHz, $\mathrm{CDCl}_{3}$ )

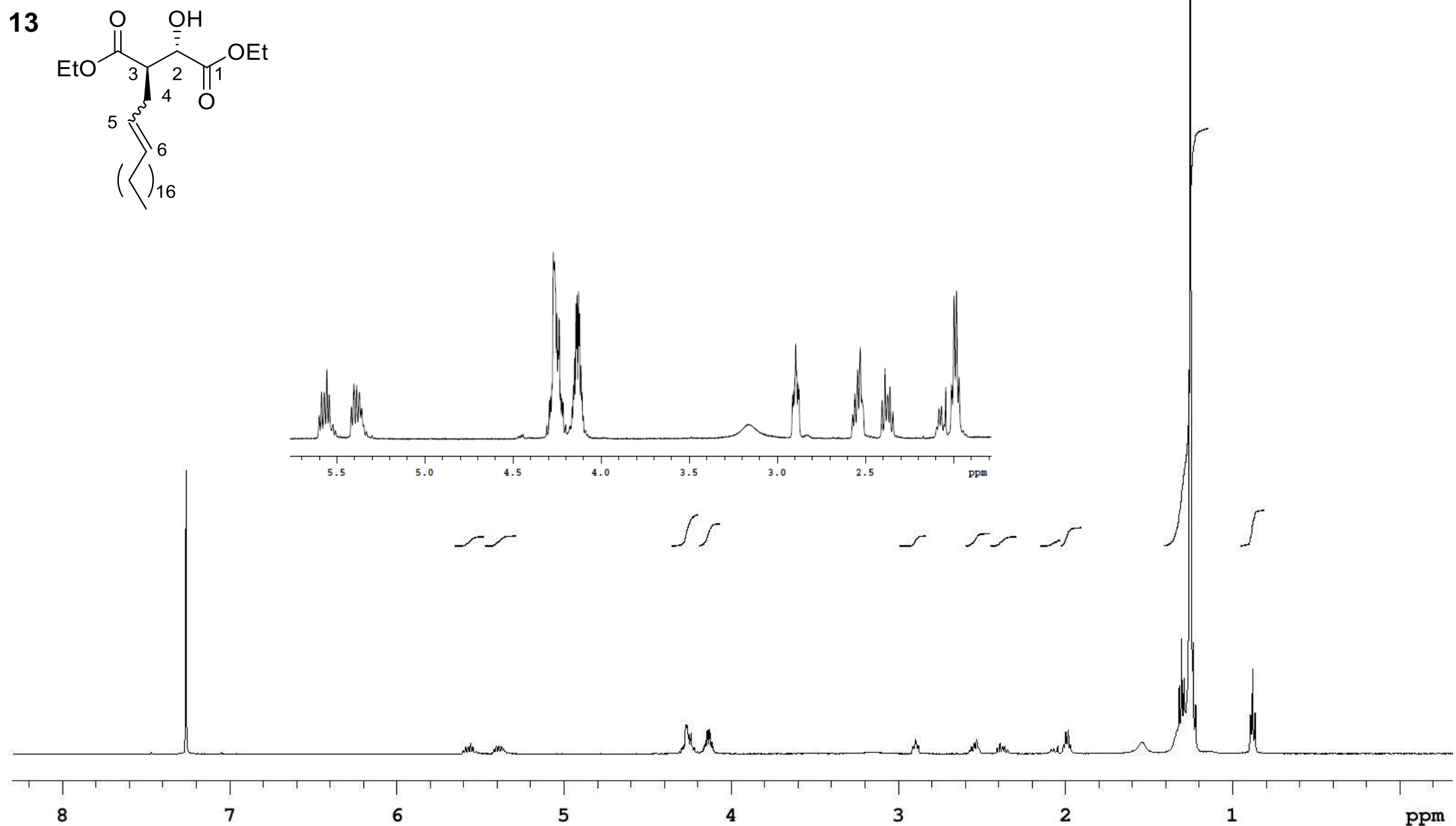


${ }^{13} \mathrm{C}$ NMR (125 MHz, $\left.\mathrm{CDCl}_{3}\right)$

13

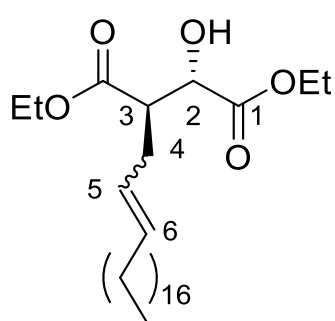


${ }^{1} \mathrm{H}$ NMR $\left(500 \mathrm{MHz}, \mathrm{CDCl}_{3}\right)$

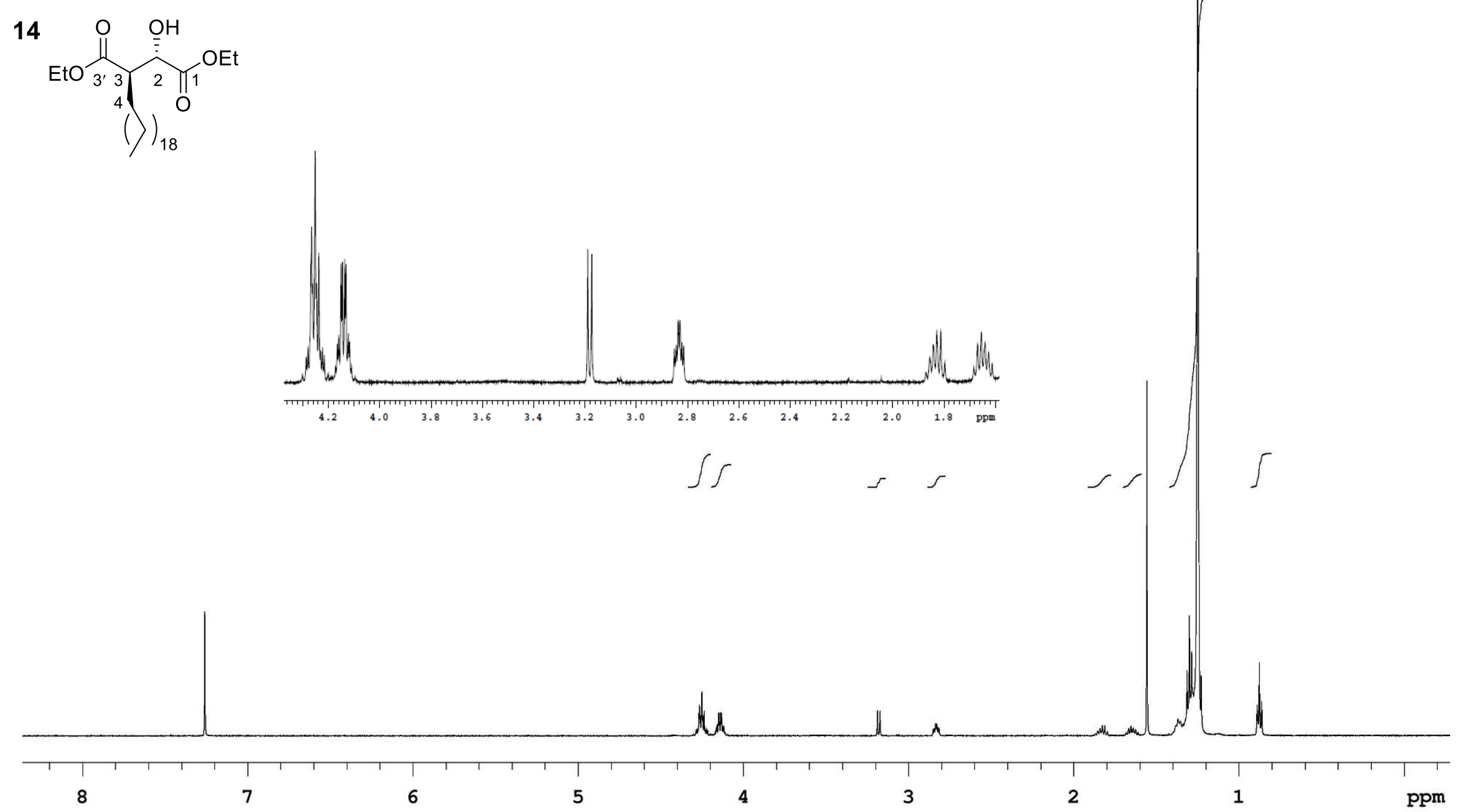




$$
1
$$


${ }^{1} \mathrm{H}$ NMR $\left(500 \mathrm{MHz}, \mathrm{CDCl}_{3}\right)$

$15 \overbrace{(>)_{18}}^{\mathrm{O}} \overbrace{3_{2}^{3}}^{\mathrm{O}} \mathrm{OH}$

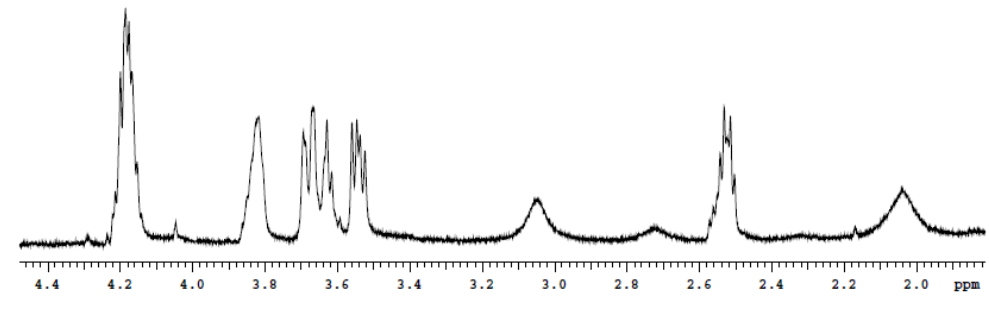

$\alpha \cos$
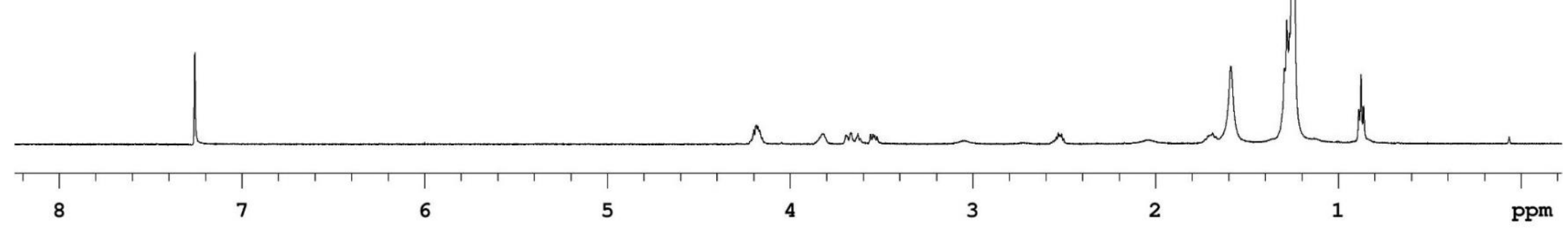
${ }^{13} \mathrm{C}$ NMR $\left(125 \mathrm{MHz}, \mathrm{CDCl}_{3}\right)$

$$
\begin{aligned}
& 15 \quad \mathrm{O} \quad \underline{\mathrm{O}} \\
& \mathrm{EtO}_{33^{\prime}} \overbrace{4}^{3})_{18}
\end{aligned}
$$

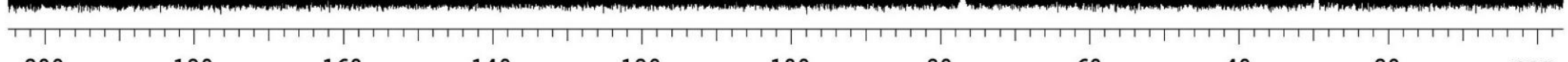


${ }^{1} \mathrm{H}$ NMR $\left(500 \mathrm{MHz}, \mathrm{CDCl}_{3}\right)$

16 (1)

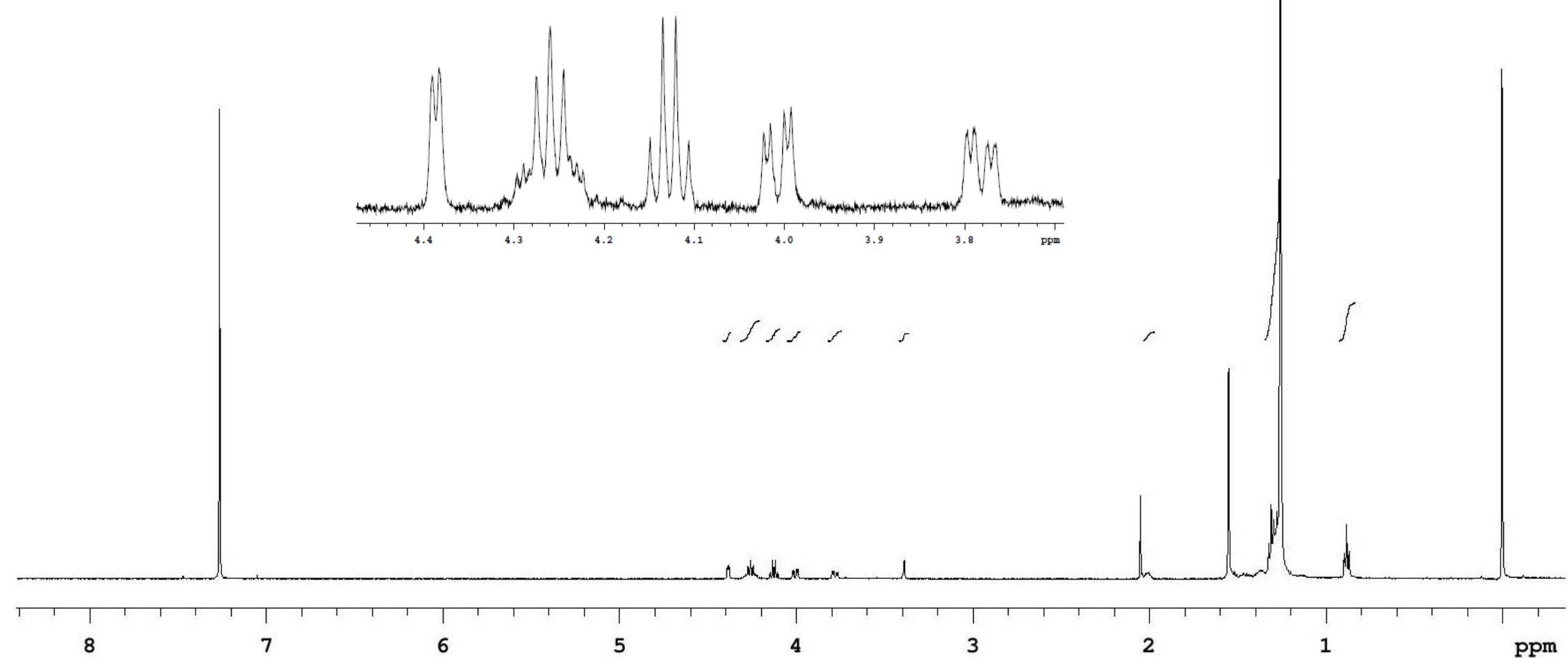


${ }^{13} \mathrm{C}$ NMR $\left(125 \mathrm{MHz}, \mathrm{CDCl}_{3}\right)$

16 (1)

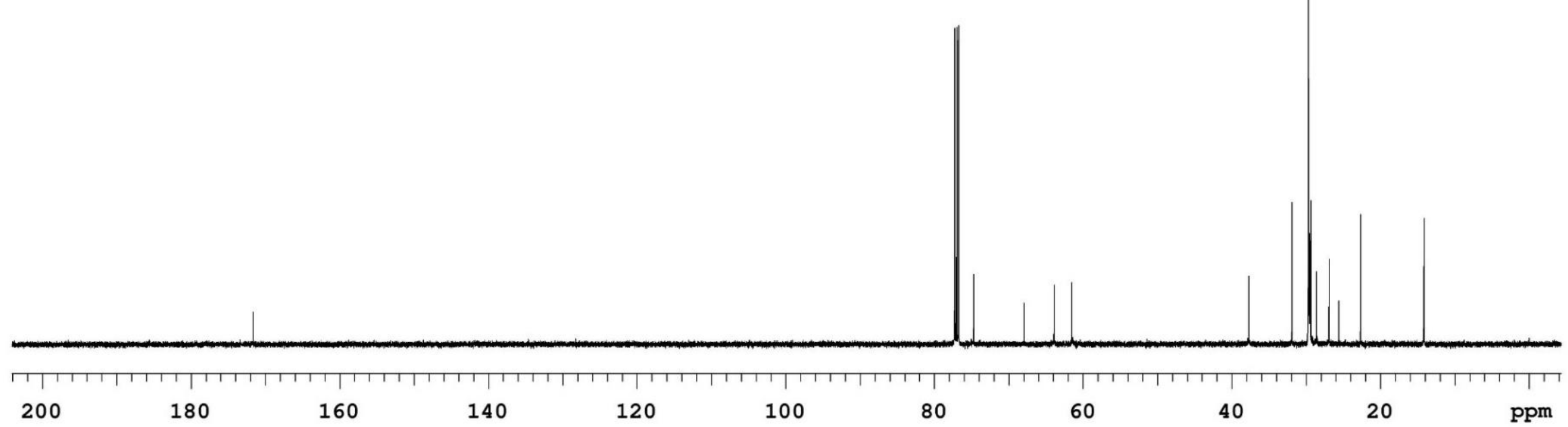


${ }^{1} \mathrm{H}$ NMR $\left(500 \mathrm{MHz}, \mathrm{CDCl}_{3}\right)$
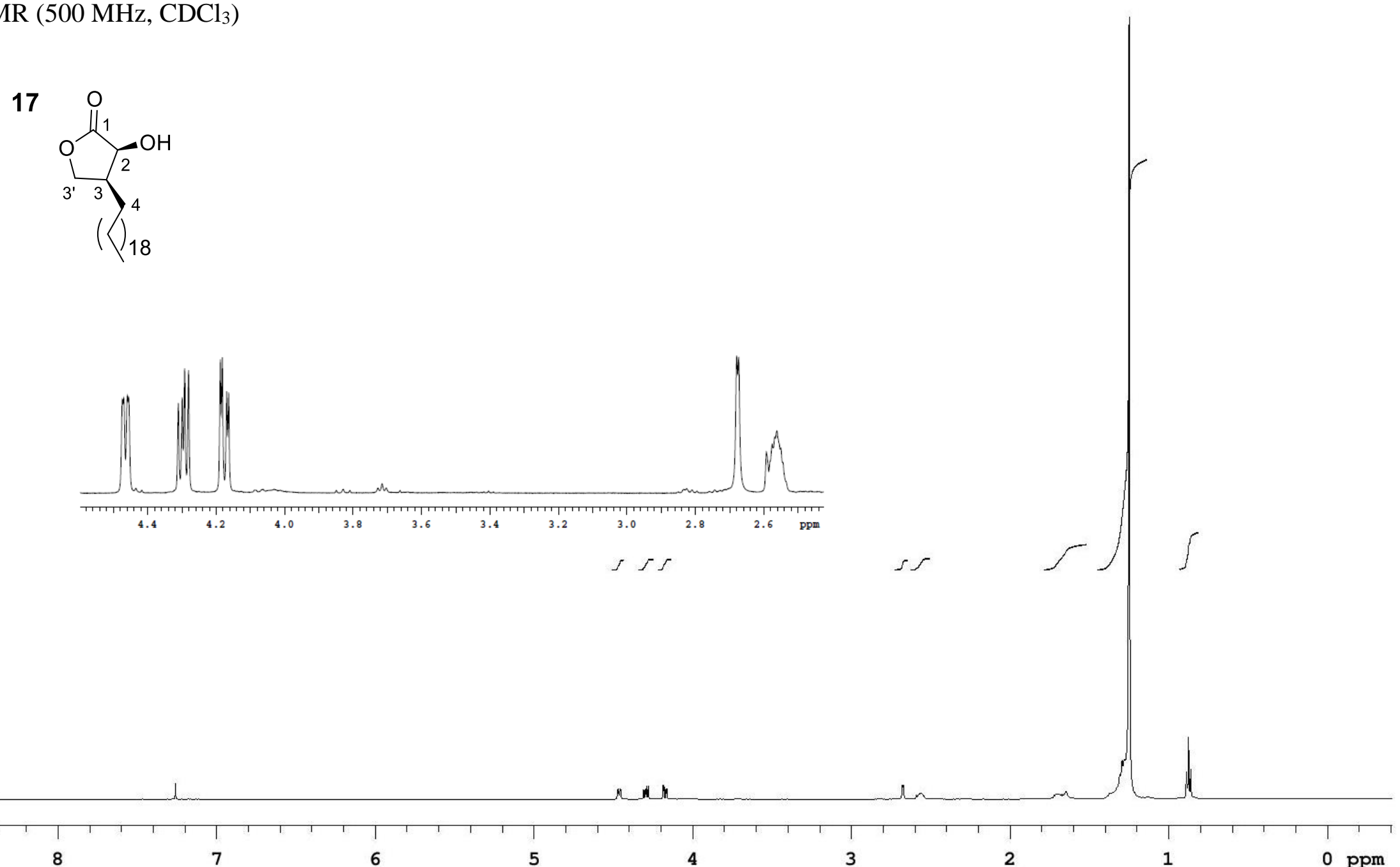
${ }^{13} \mathrm{C} \mathrm{NMR}\left(125 \mathrm{MHz}, \mathrm{CDCl}_{3}\right)$
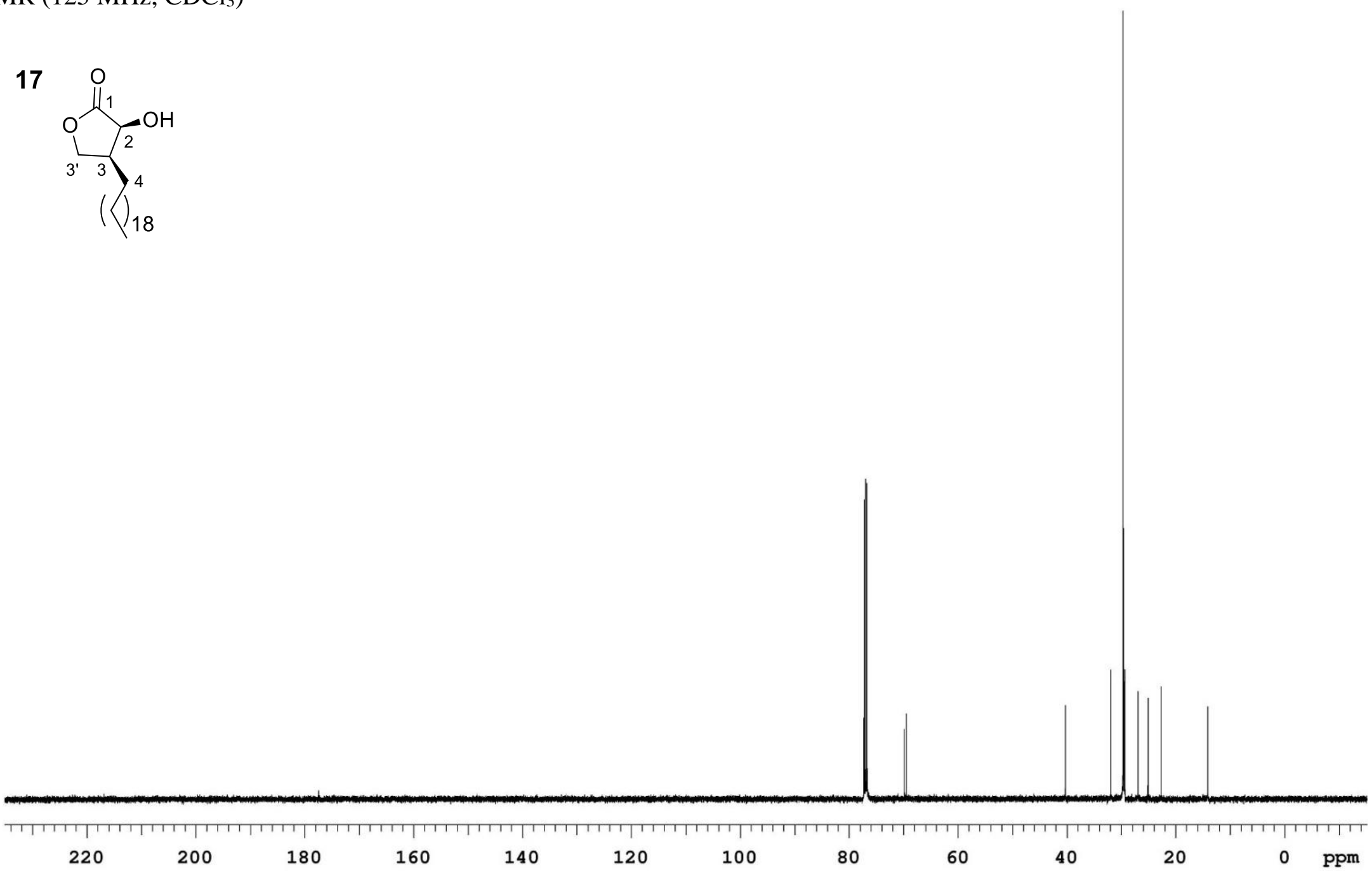
${ }^{1} \mathrm{H}$ NMR (300 MHz, $\mathrm{CDCl}_{3}$ )

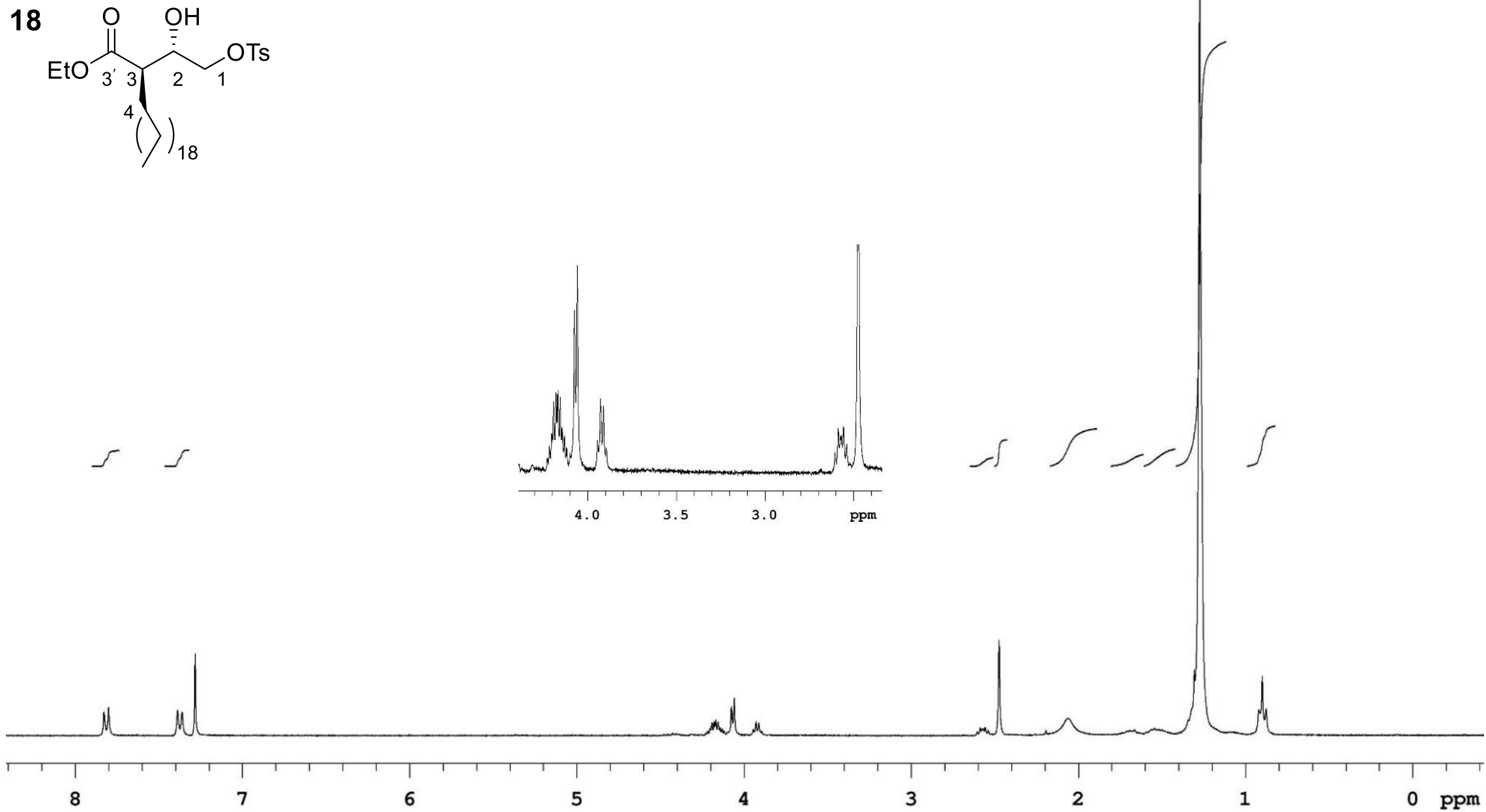


${ }^{13} \mathrm{C}$ NMR (125 MHz, $\left.\mathrm{CDCl}_{3}\right)$

18

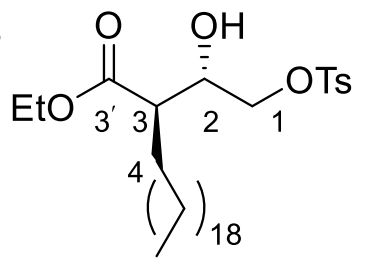

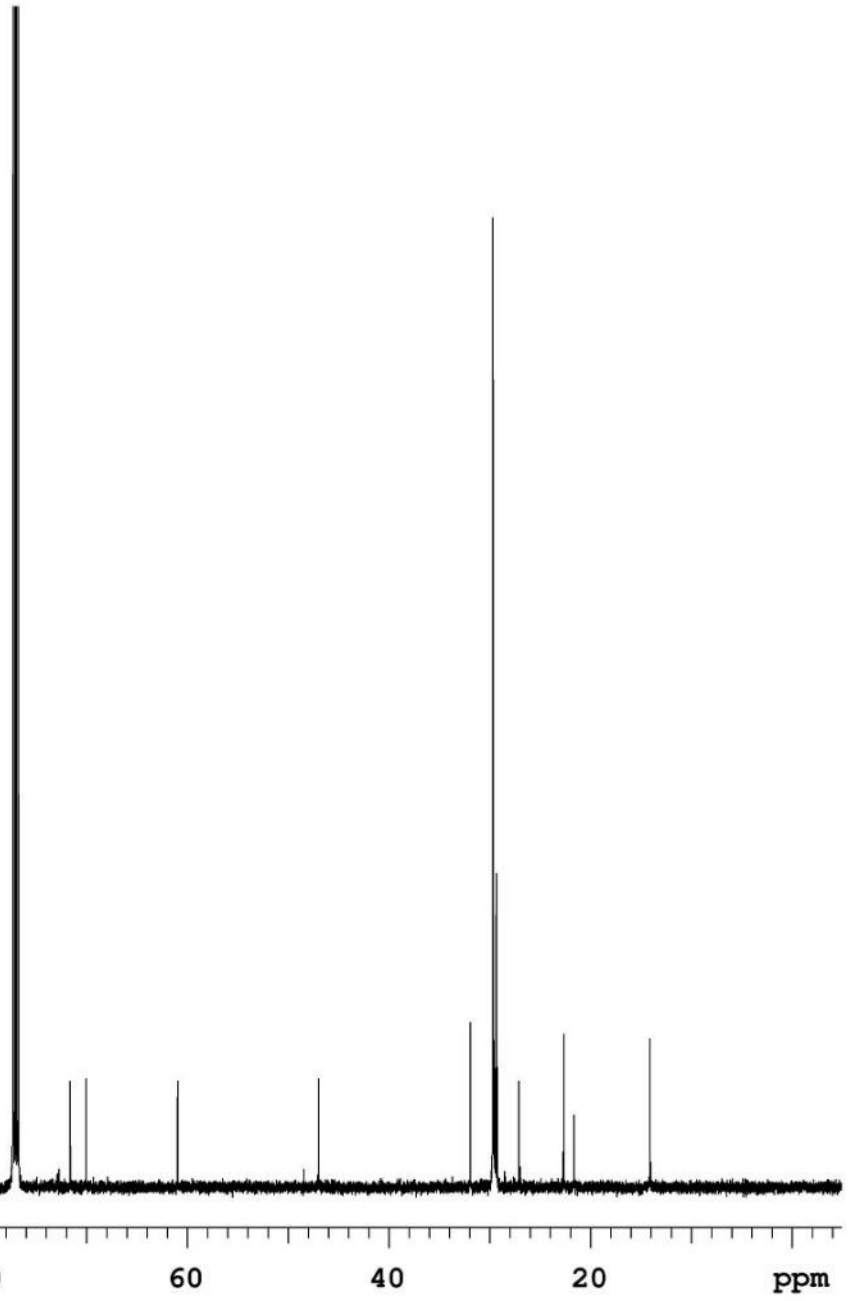

119 
${ }^{1} \mathrm{H} \mathrm{NMR}\left(500 \mathrm{MHz}, \mathrm{CDCl}_{3}\right)$

19

9

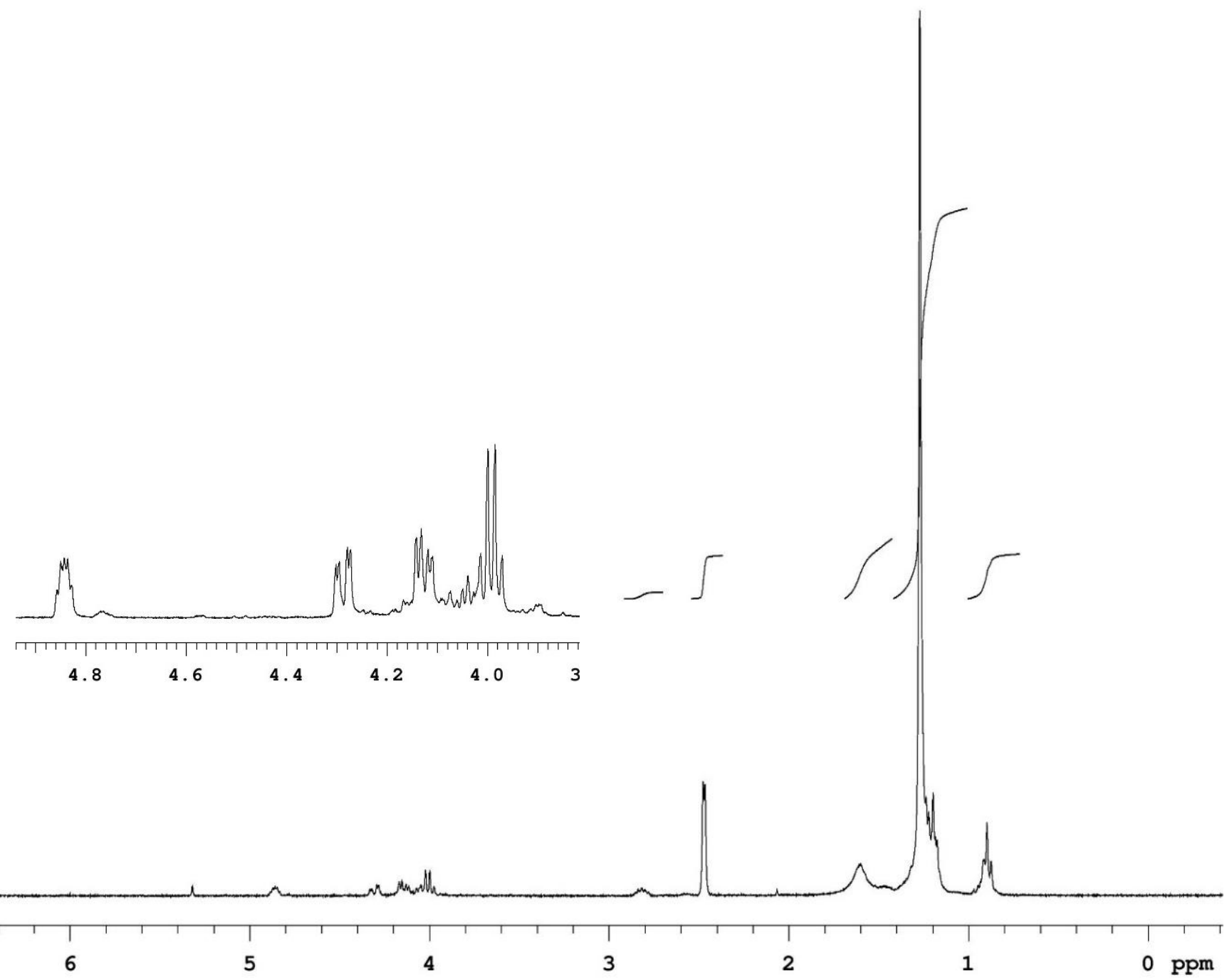


${ }^{13} \mathrm{C}$ NMR $\left(125 \mathrm{MHz}, \mathrm{CDCl}_{3}\right)$

$$
\begin{aligned}
& 19
\end{aligned}
$$

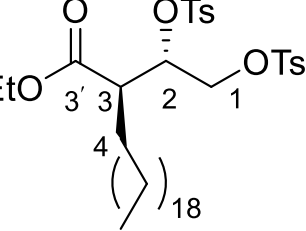

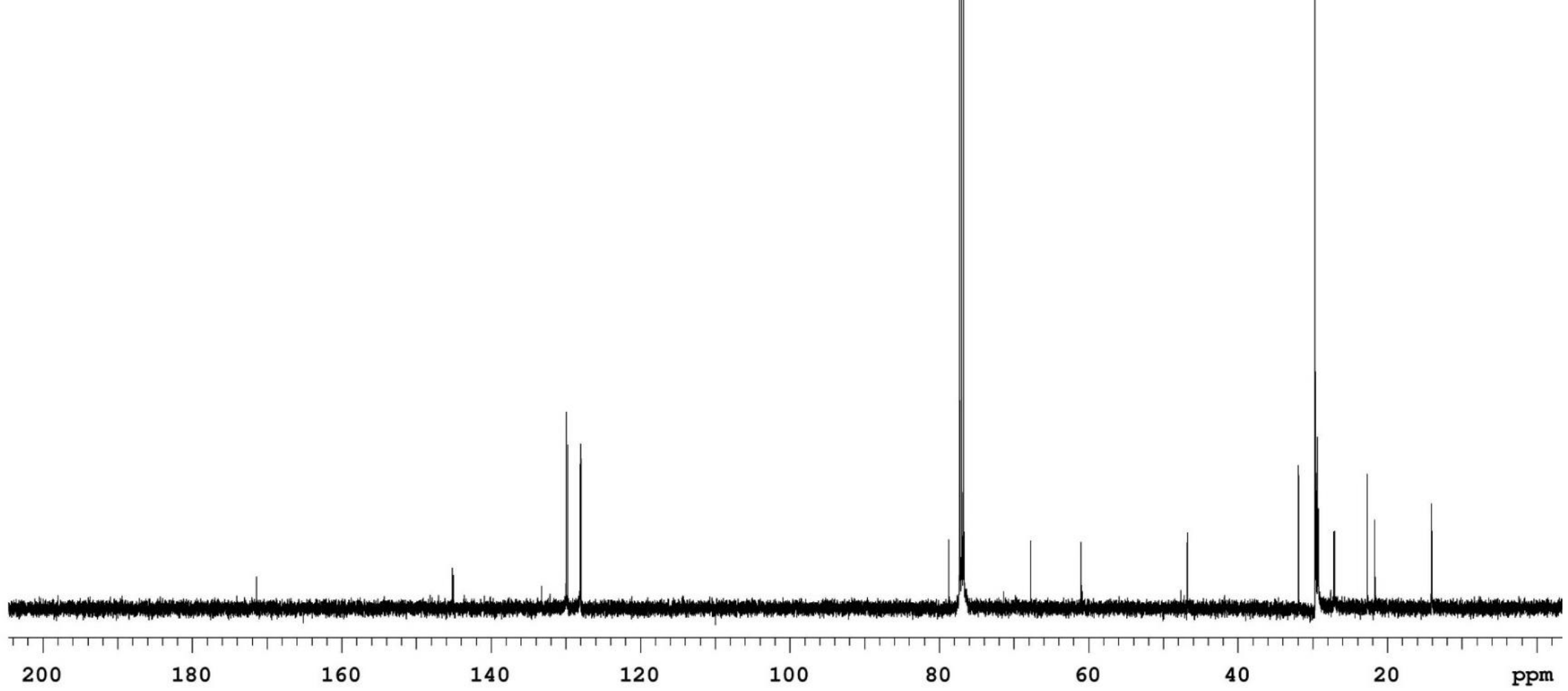


${ }^{1} \mathrm{H}$ NMR $\left(500 \mathrm{MHz}, \mathrm{CDCl}_{3}\right)$

$$
5
$$
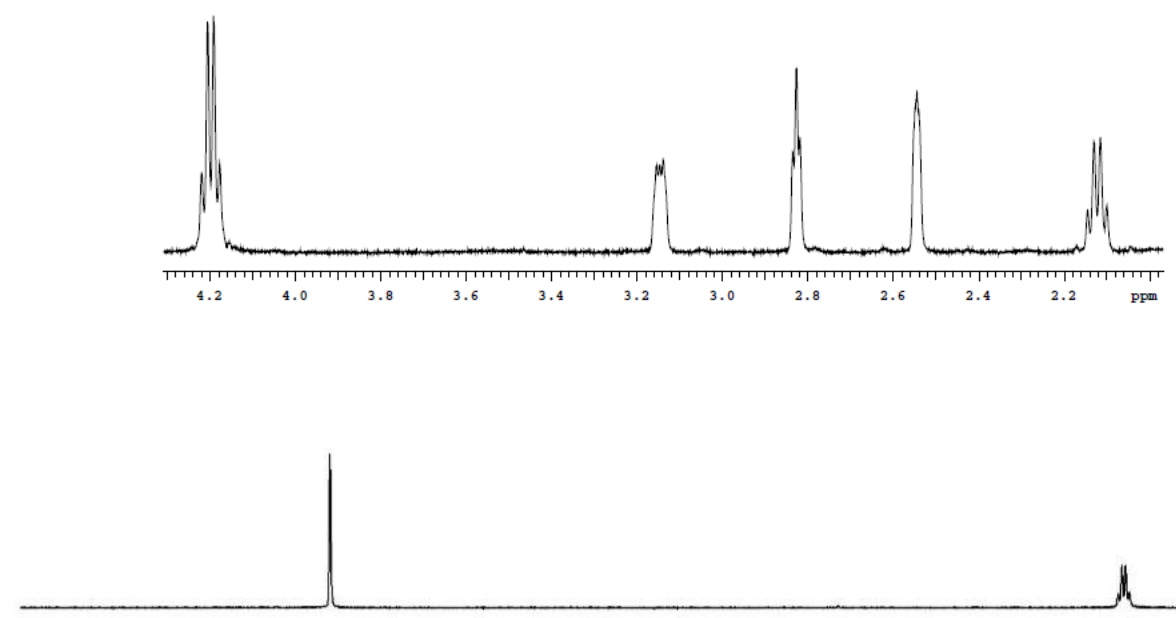
${ }^{13} \mathrm{C}$ NMR $\left(125 \mathrm{MHz}, \mathrm{CDCl}_{3}\right)$

$$
5 \overbrace{3_{3}^{\prime} \mathrm{C}_{20} \mathrm{H}_{41}}^{O}
$$


${ }^{1} \mathrm{H}$ NMR (500 MHz, $\mathrm{CDCl}_{3}$ )

20
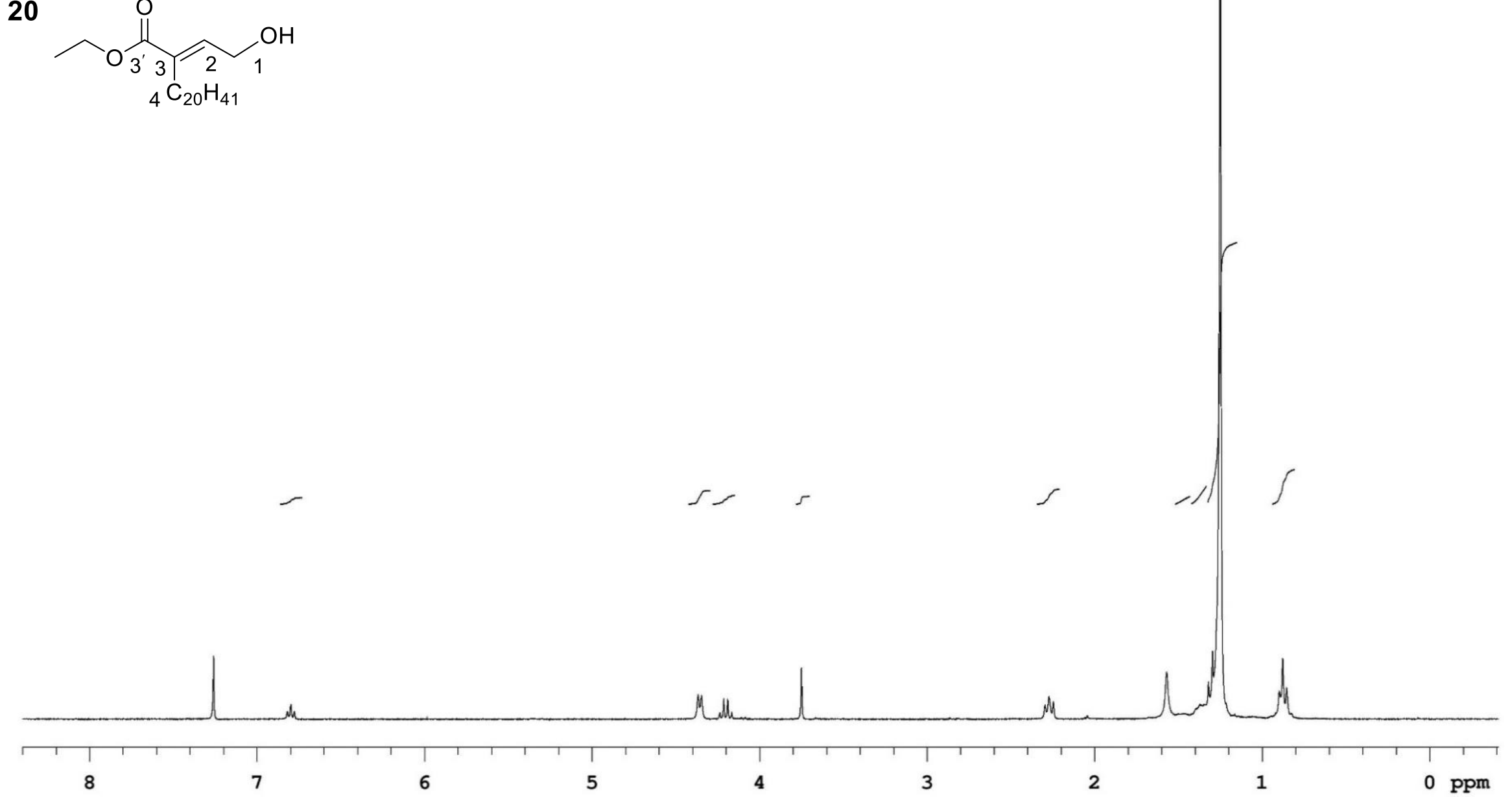
${ }^{13} \mathrm{C}$ NMR (125 MHz, $\left.\mathrm{CDCl}_{3}\right)$

20

$$
\overbrace{3_{4}^{\prime} C_{2} \mathrm{C}_{20} \mathrm{H}_{41}}^{\mathrm{O}}
$$

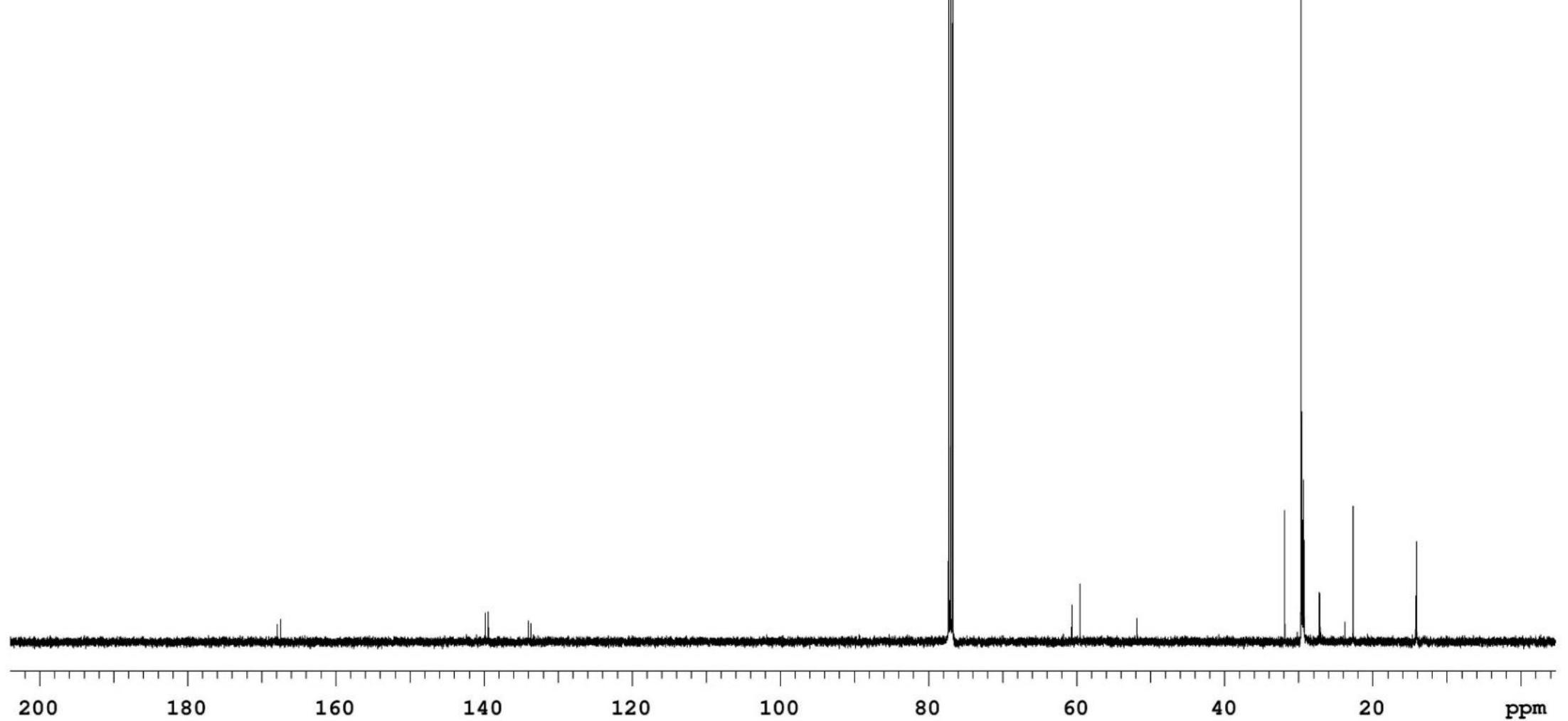


${ }^{1} \mathrm{H}$ NMR (300 MHz, $\left.\mathrm{CDCl}_{3}\right)$

21
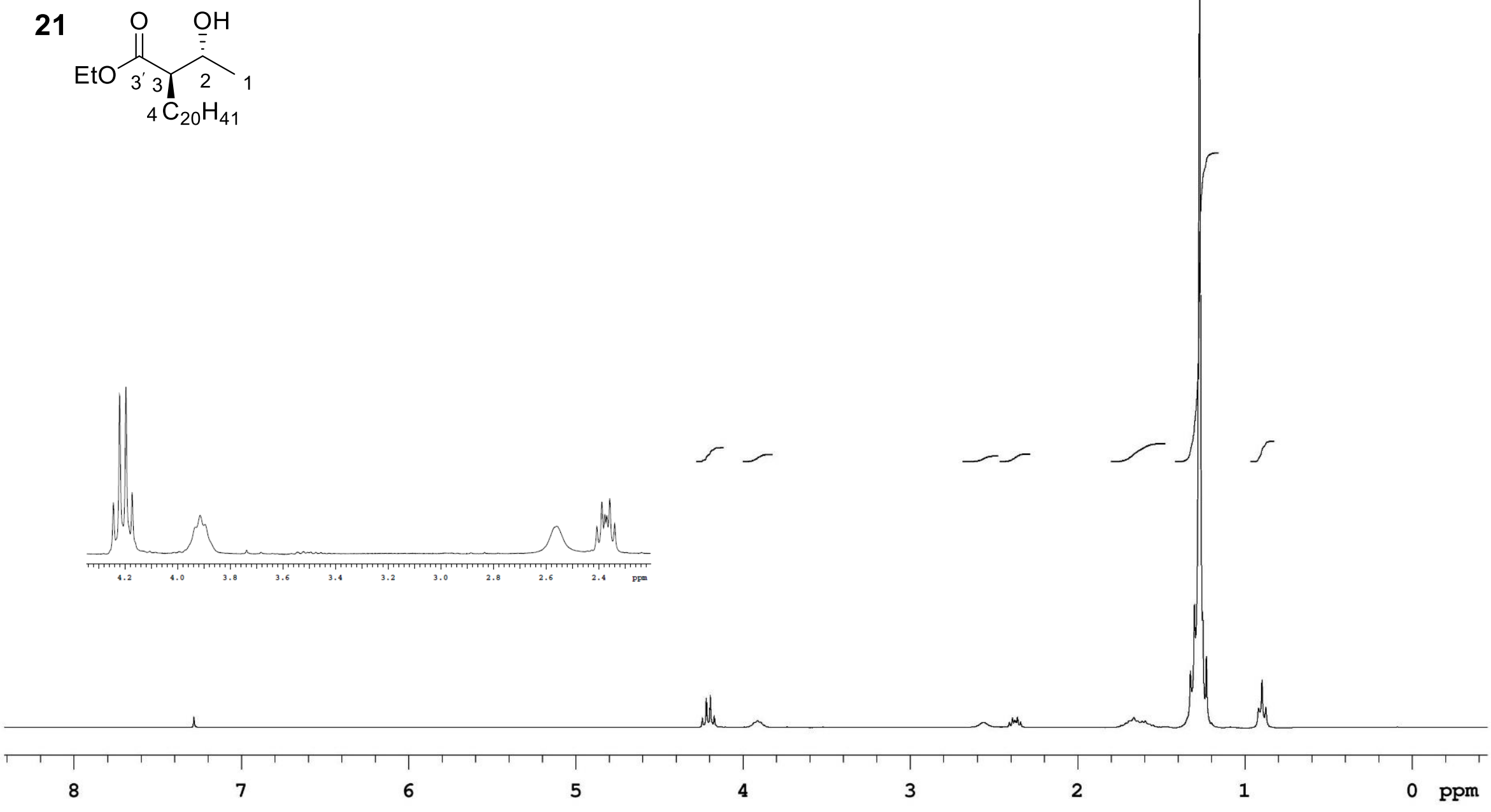
${ }^{13} \mathrm{C}$ NMR $\left(150 \mathrm{MHz}, \mathrm{CDCl}_{3}\right)$

$$
21 \overbrace{\text { EtO }_{3} \mathrm{C}_{20} \mathrm{H}_{41}}^{\mathrm{O}}
$$

\begin{tabular}{|c|c|c|c|c|c|c|c|c|c|}
\hline 200 & 180 & 160 & 140 & 120 & 100 & 80 & 60 & 40 & 20 \\
\hline
\end{tabular}


${ }^{1} \mathrm{H}$ NMR (500 MHz, $\left.\mathrm{CDCl}_{3}\right)$

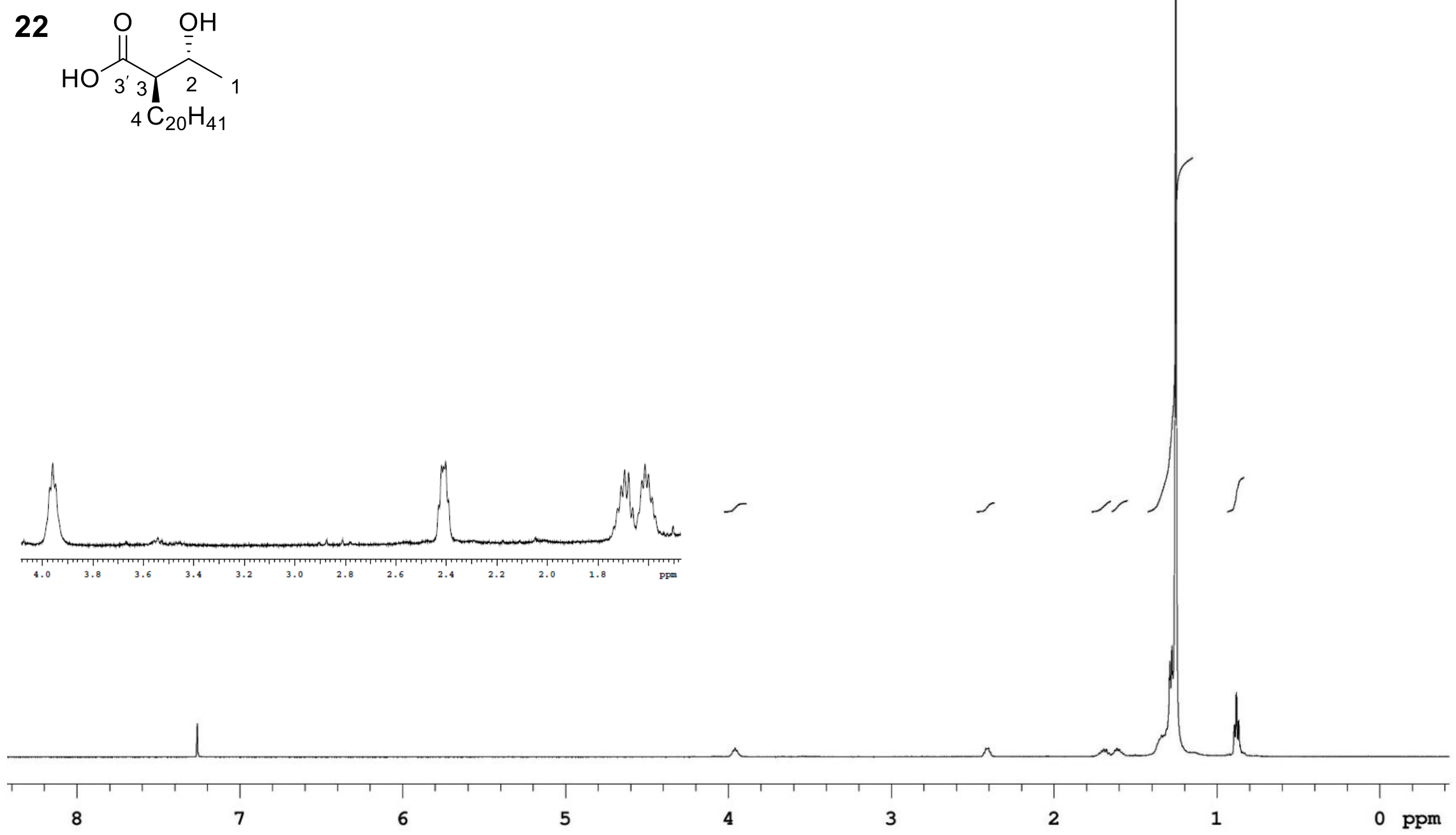


${ }^{13} \mathrm{C}$ NMR (150 MHz, $\mathrm{CDCl}_{3}$ )

$$
22 \overbrace{3_{3}^{\prime} 3 \mathrm{C}_{20} \mathrm{H}_{41}}^{\mathrm{O}}
$$

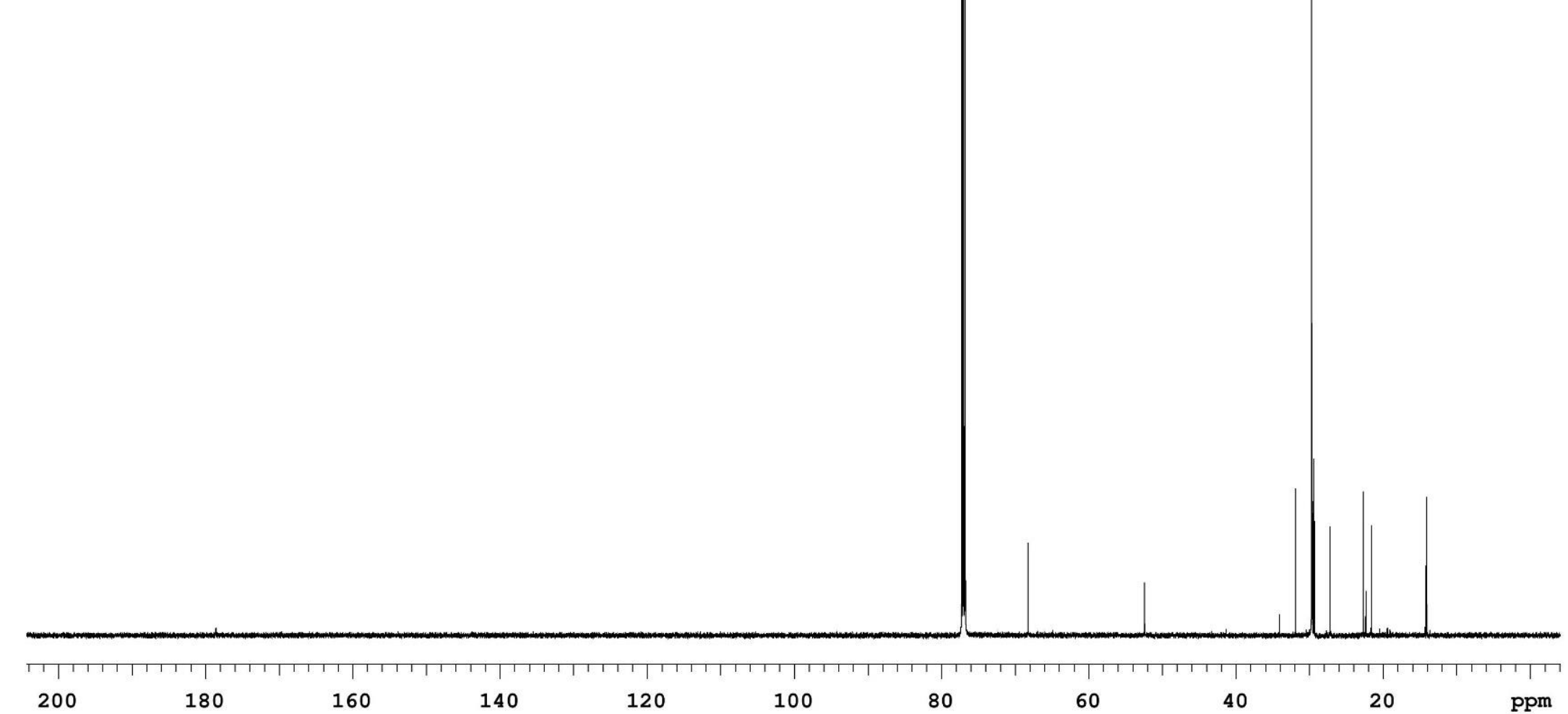


${ }^{1} \mathrm{H}$ NMR $\left(500 \mathrm{MHz}, \mathrm{CDCl}_{3}\right)$

$$
\begin{aligned}
& 3 a \quad \text { OTBS } \\
& \mathrm{HO}_{3} 3 \overbrace{2} \\
& { }_{4} \mathrm{C}_{20} \mathrm{H}_{41}
\end{aligned}
$$

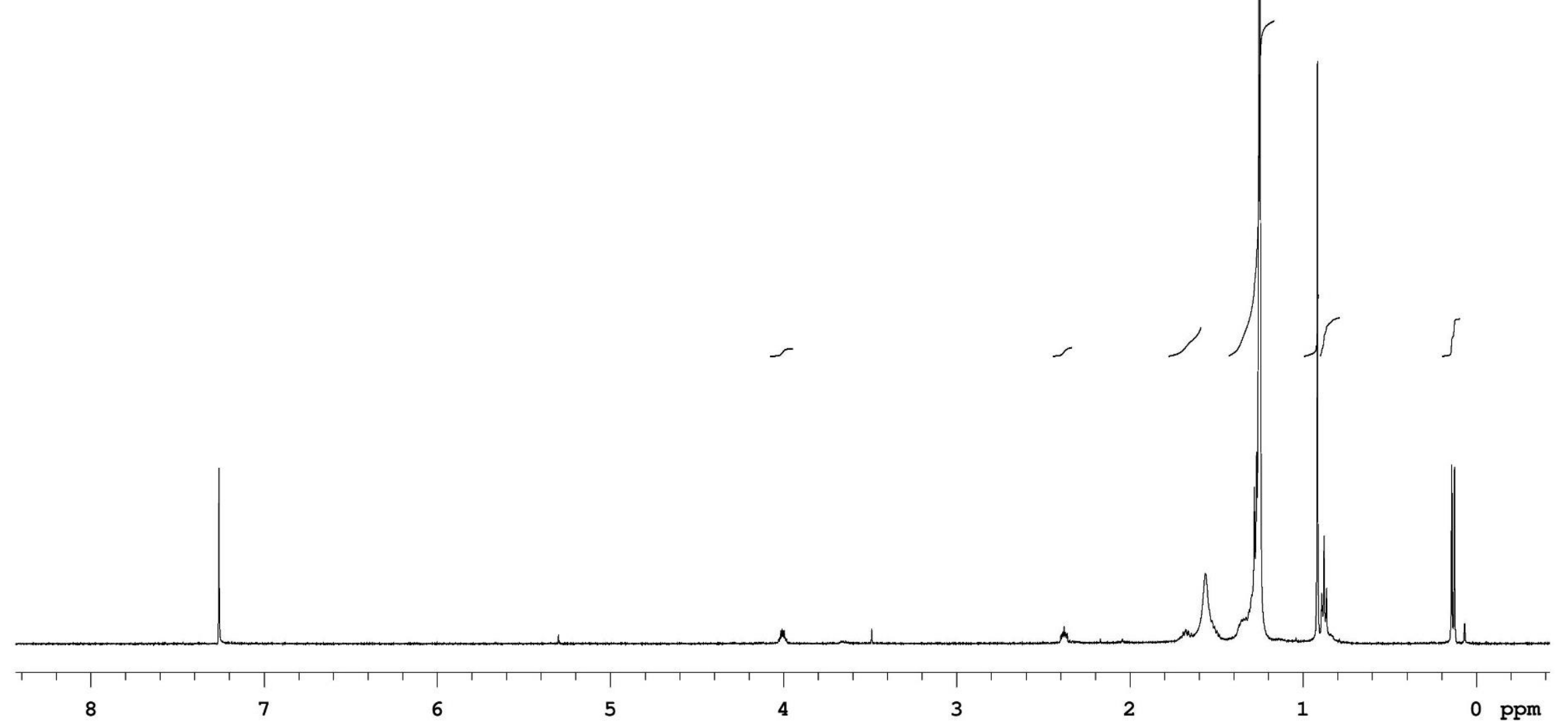


${ }^{13} \mathrm{C}$ NMR $\left(125 \mathrm{MHz}, \mathrm{CDCl}_{3}\right)$
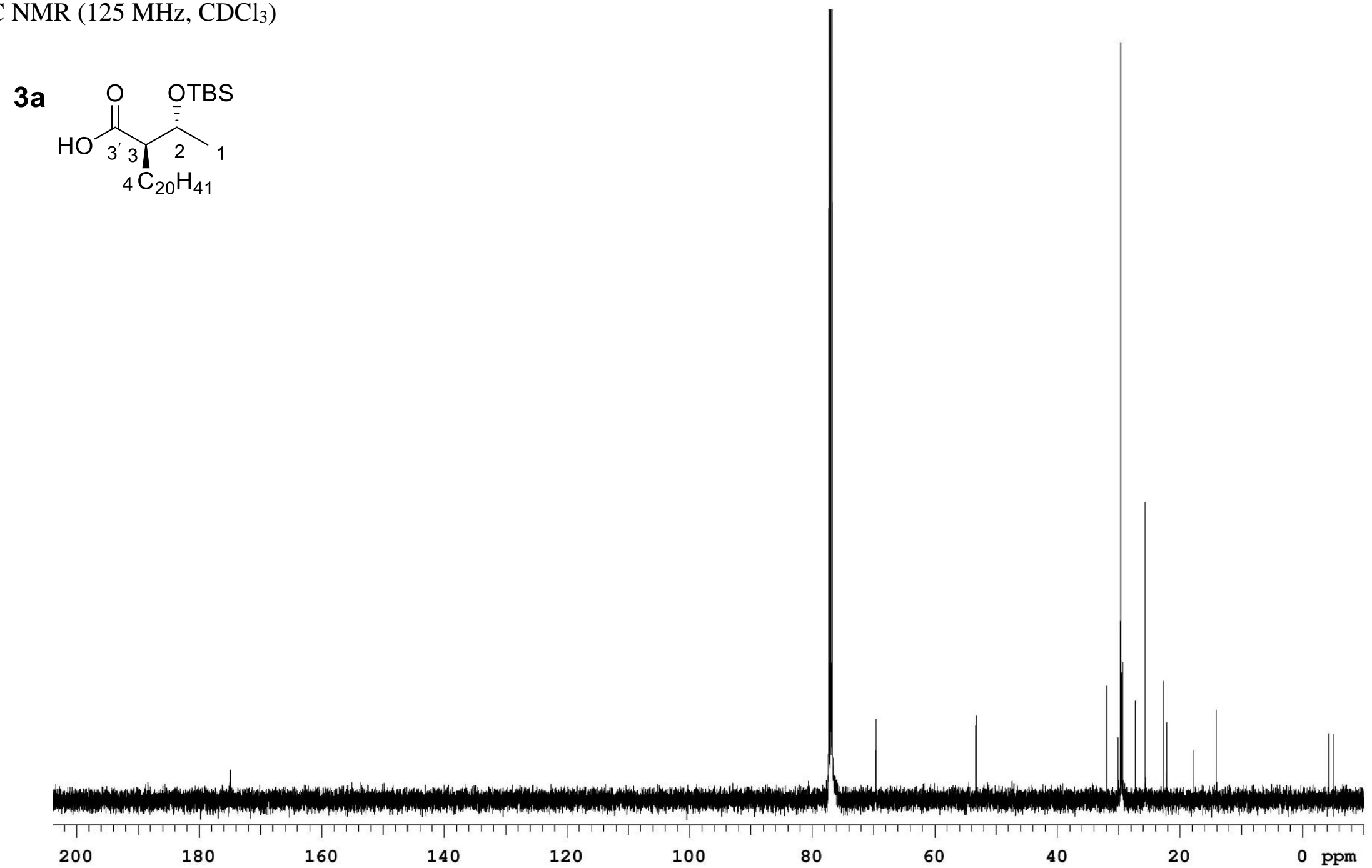
${ }^{1} \mathrm{H}$ NMR (300 MHz, $\mathrm{CDCl}_{3}$ )

$$
24 \overbrace{3^{\prime}}^{3)}{ }_{4 \mathrm{C}_{20} \mathrm{H}_{41}}^{O} \mathrm{HMe}_{1}
$$

25 O OMe

$$
\mathrm{MeO}_{3^{\prime}}{ }_{4}^{4} \mathrm{C}_{20} \mathrm{H}_{41}
$$

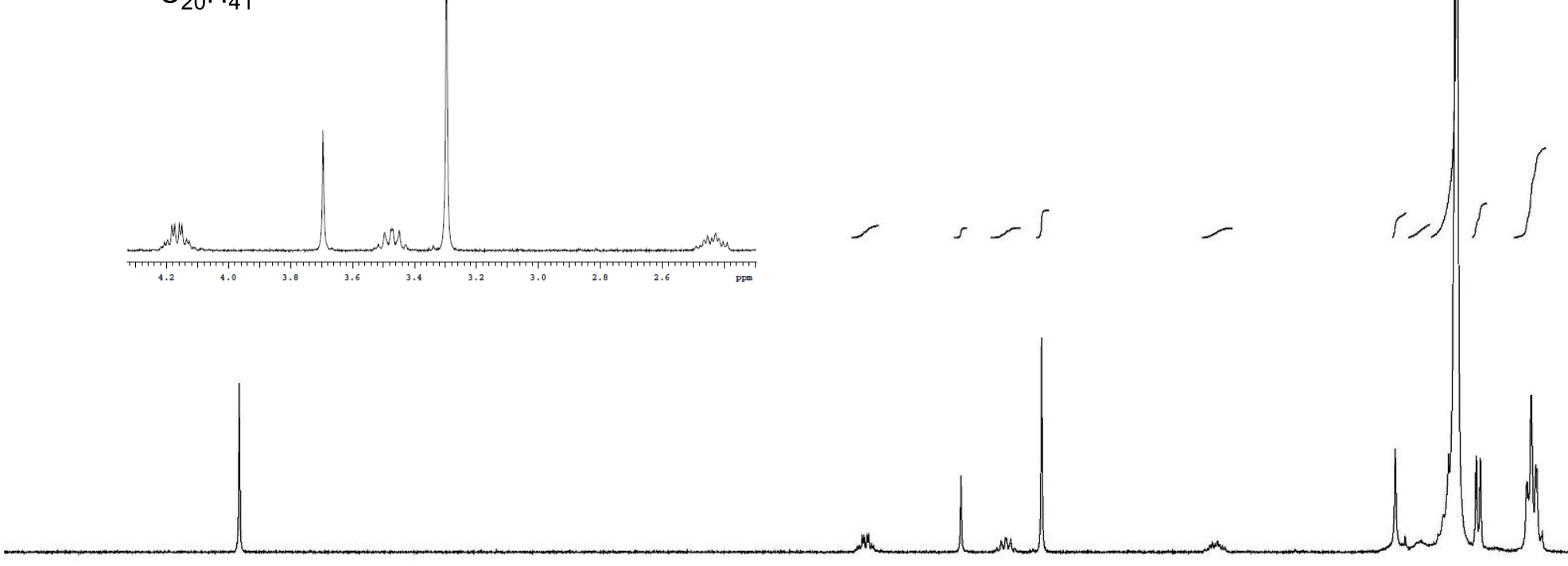


${ }^{13} \mathrm{C}$ NMR $\left(125 \mathrm{MHz}, \mathrm{CDCl}_{3}\right)$

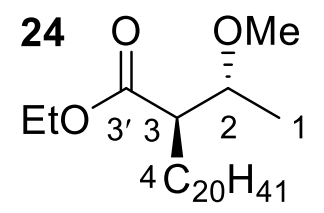

$\mathrm{MeO}_{3}{ }_{4}{ }_{2} 1$

$4 \mathrm{C}_{20} \mathrm{H}_{41}$

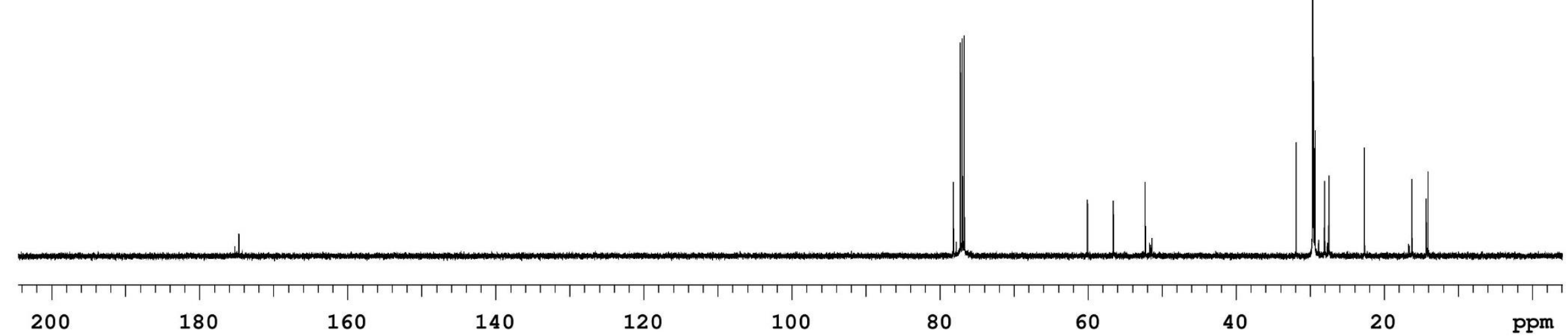


${ }^{1} \mathrm{H}$ NMR (500 MHz, $\mathrm{CDCl}_{3}$ )
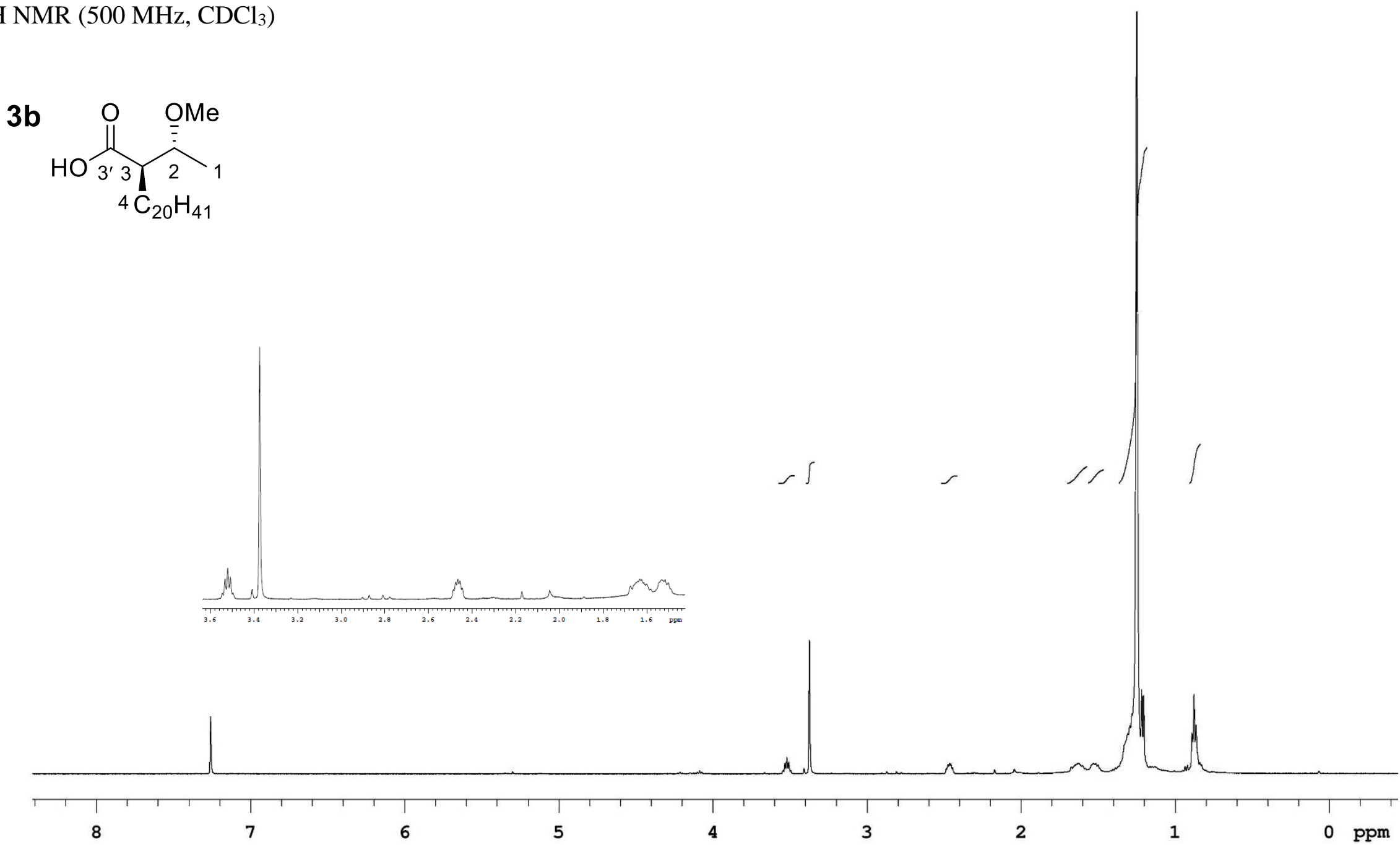
${ }^{13} \mathrm{C}$ NMR $\left(125 \mathrm{MHz}, \mathrm{CDCl}_{3}\right)$

$$
\begin{aligned}
& 3 b \quad O \quad O M e \\
& \mathrm{HO}_{3^{\prime} 3 / 2} \\
& { }_{4}^{4} \mathrm{C}_{20} \mathrm{H}_{41}
\end{aligned}
$$

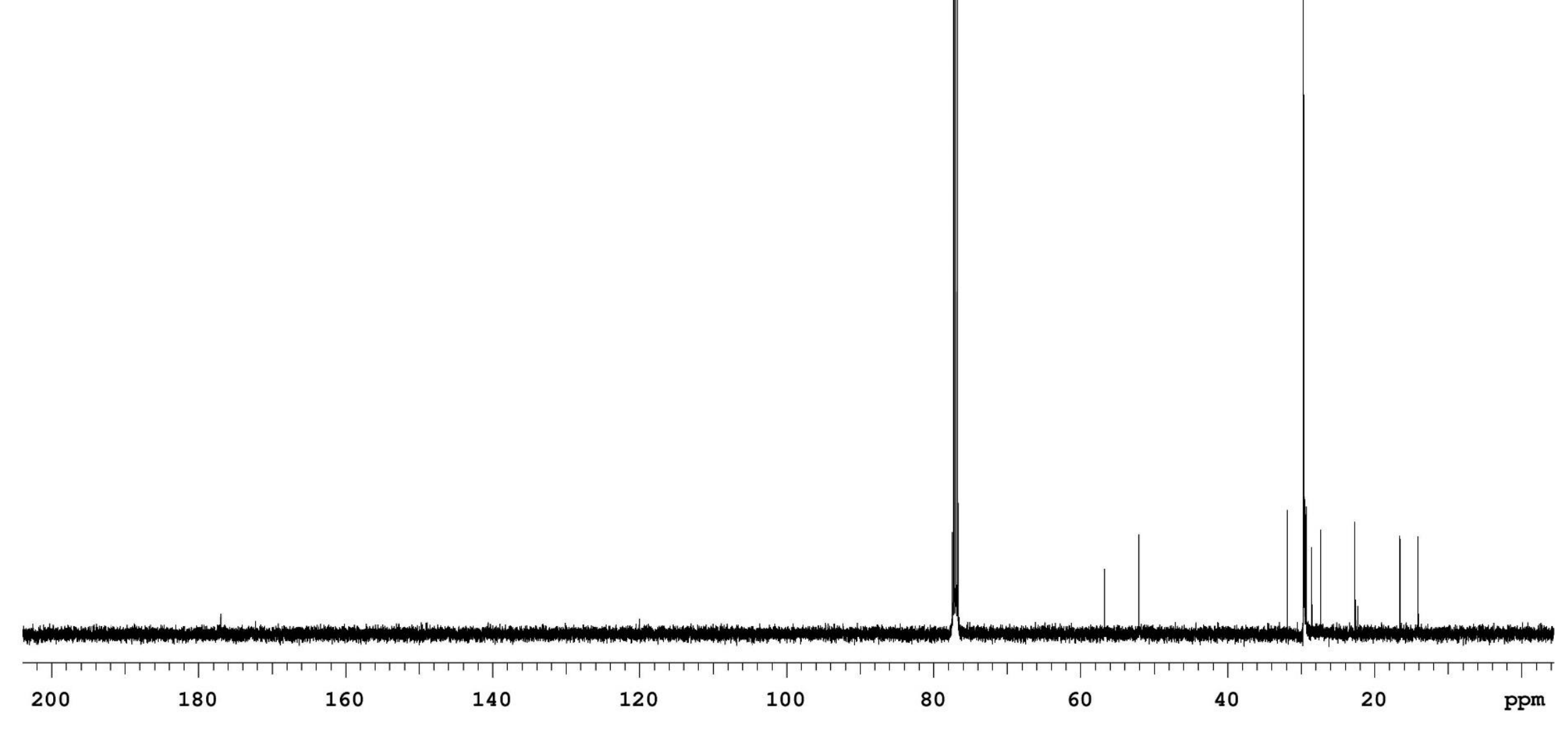


${ }^{1} \mathrm{H}$ NMR (300 MHz, $\mathrm{CDCl}_{3}$ )

$3 c$

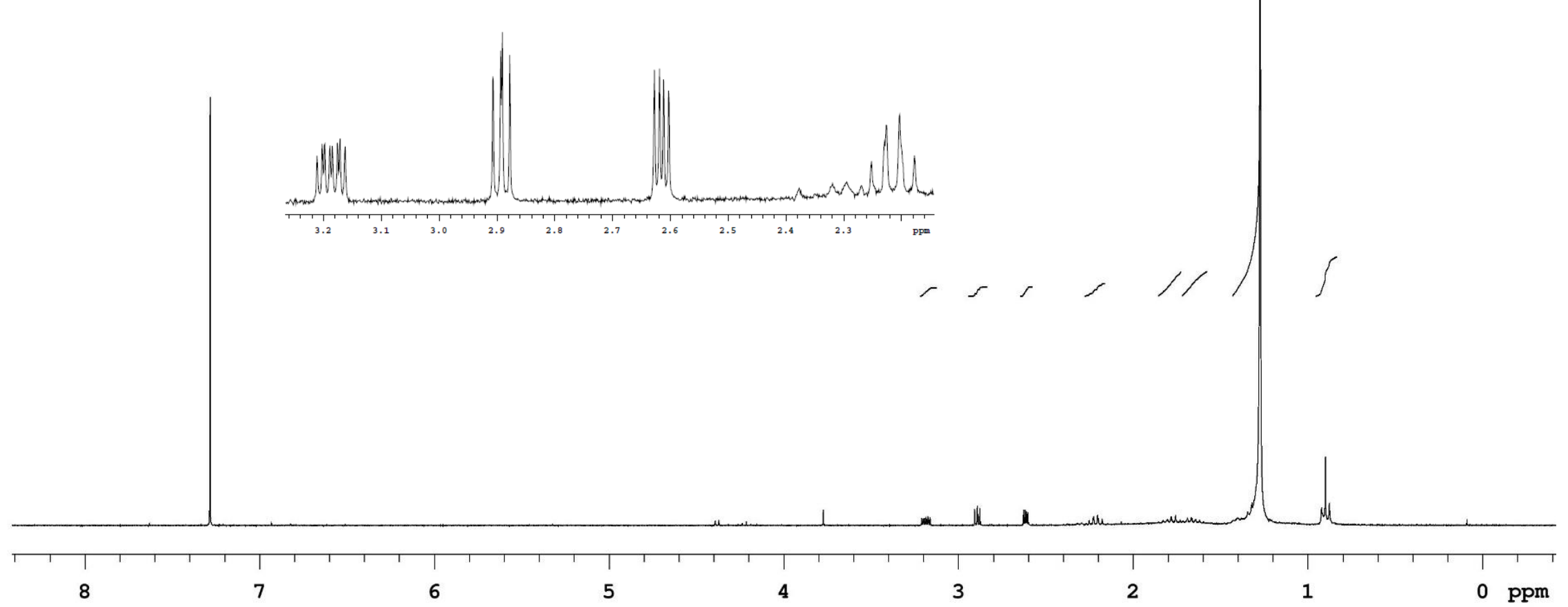


${ }^{13} \mathrm{C}$ NMR $\left(150 \mathrm{MHz}, \mathrm{CDCl}_{3}\right)$
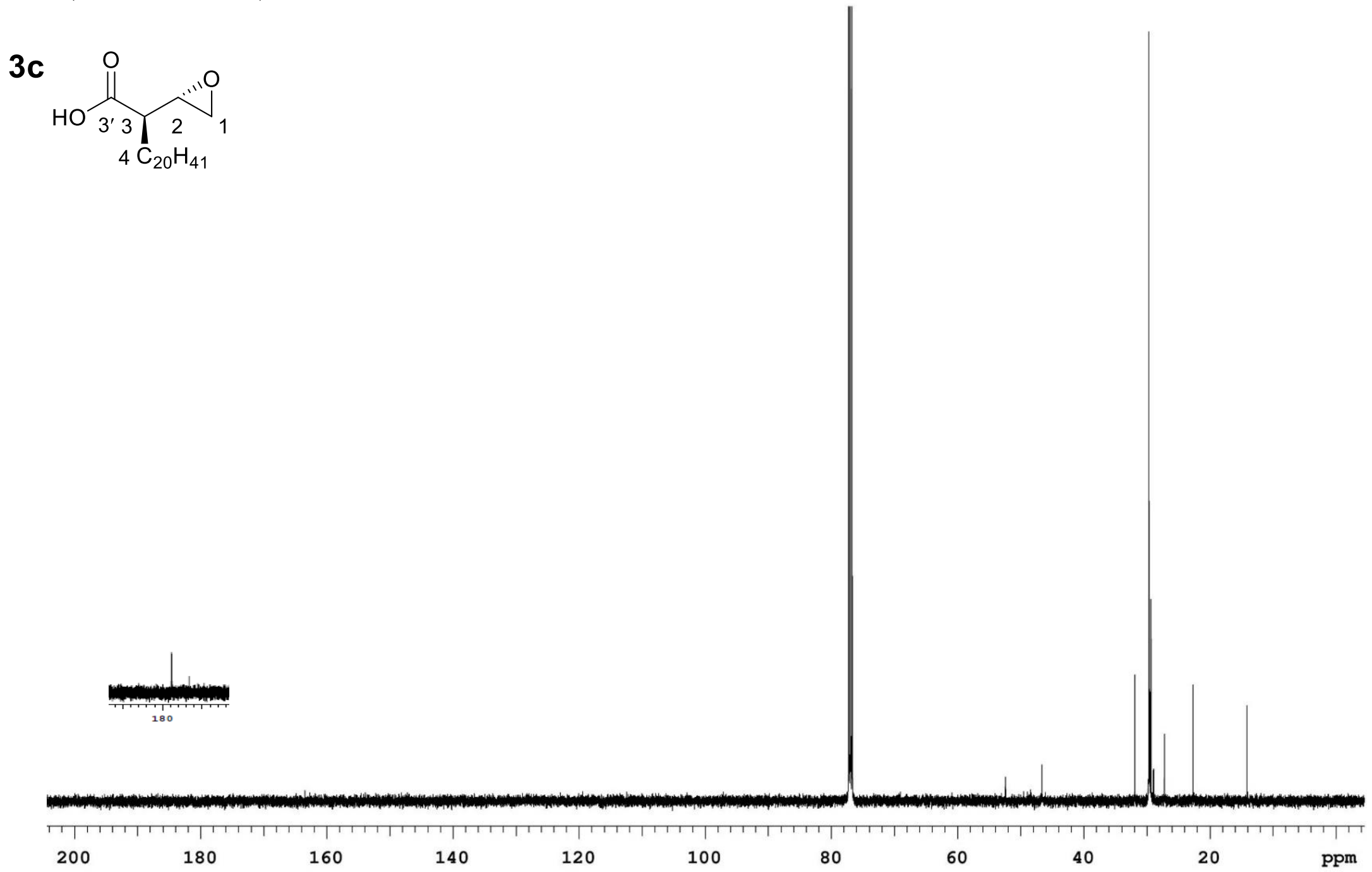
${ }^{1} \mathrm{H}$ NMR (500 MHz, $\mathrm{CDCl}_{3}$ )
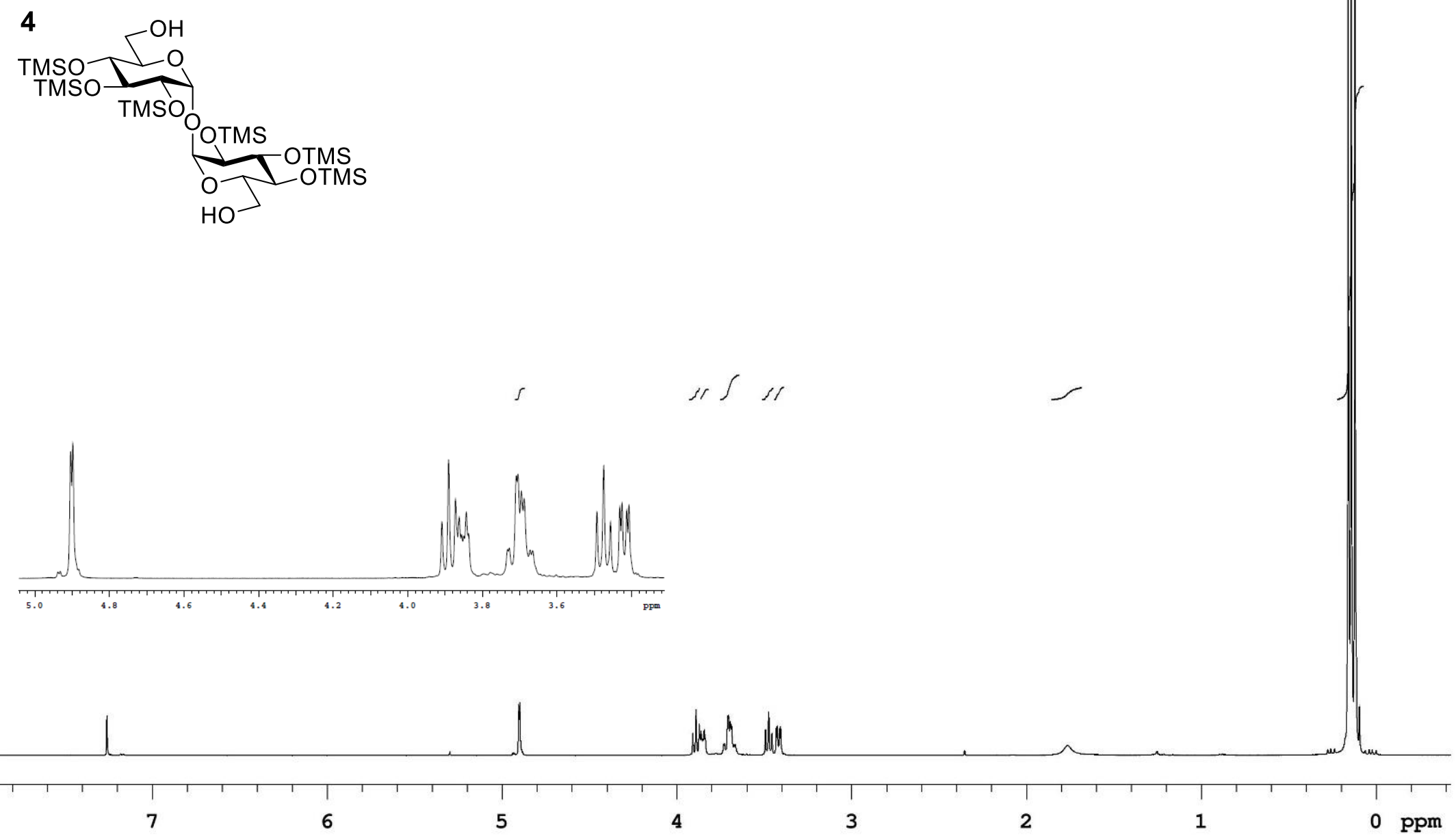
${ }^{13} \mathrm{C}$ NMR (125 MHz, $\left.\mathrm{CDCl}_{3}\right)$

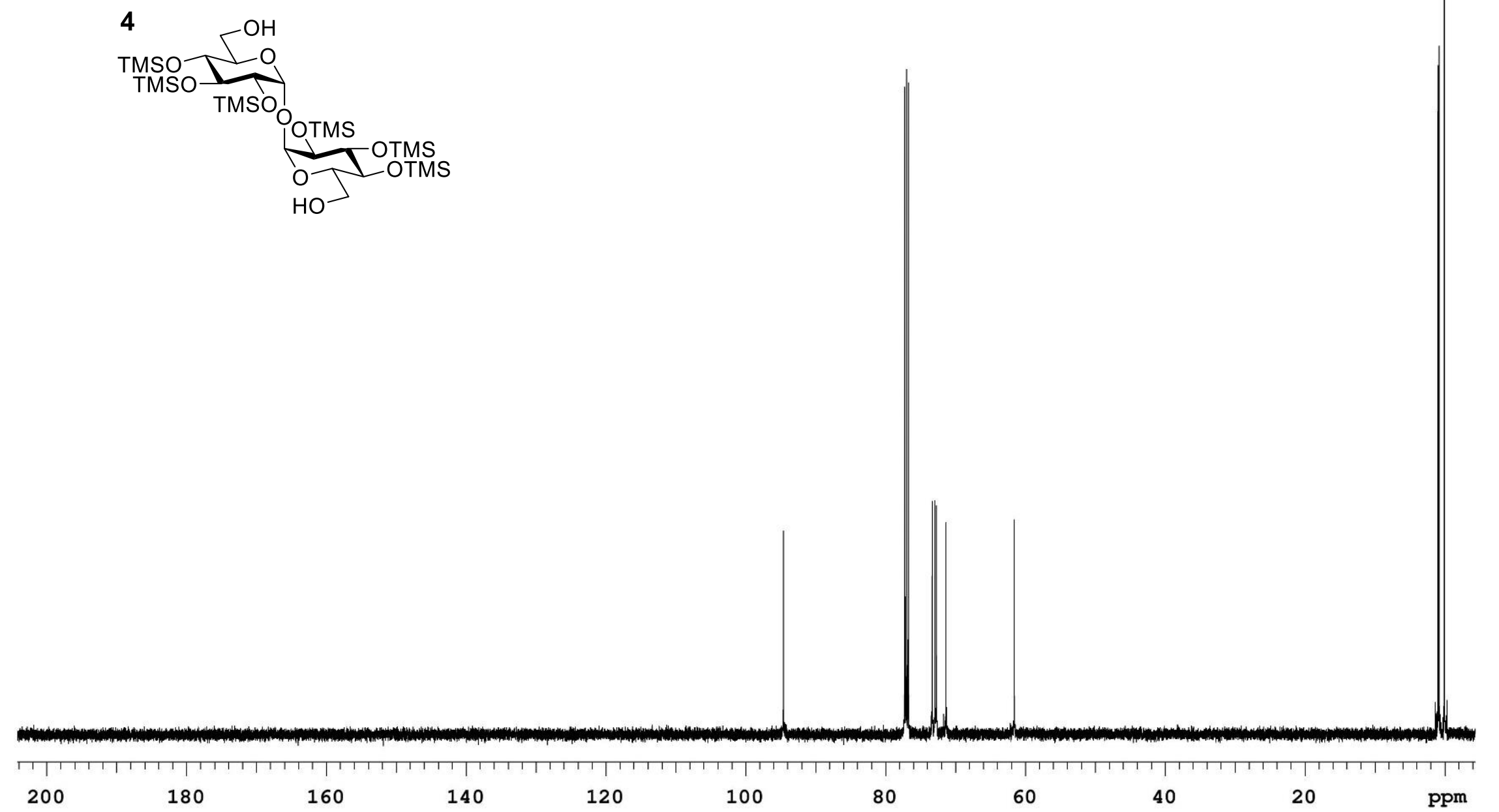


${ }^{1} \mathrm{H}$ NMR (600 MHz, CD $\left.3 \mathrm{OD}\right)$

27

$$
27
$$

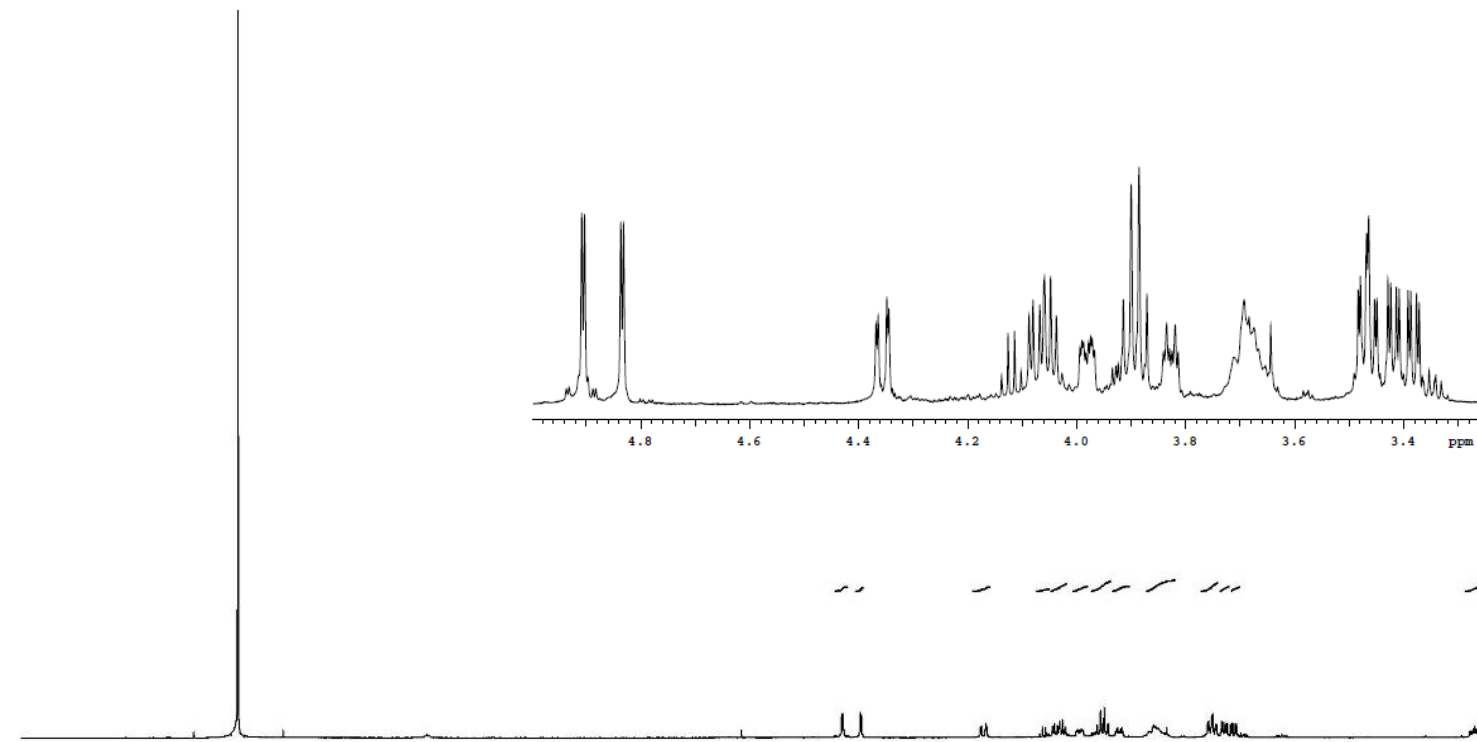


${ }^{13} \mathrm{C} \mathrm{NMR}\left(150 \mathrm{MHz}, \mathrm{CDCl}_{3}\right)$

$$
27
$$

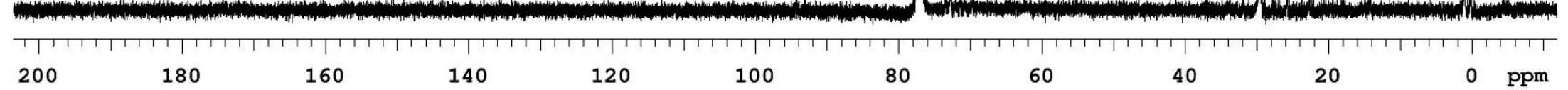




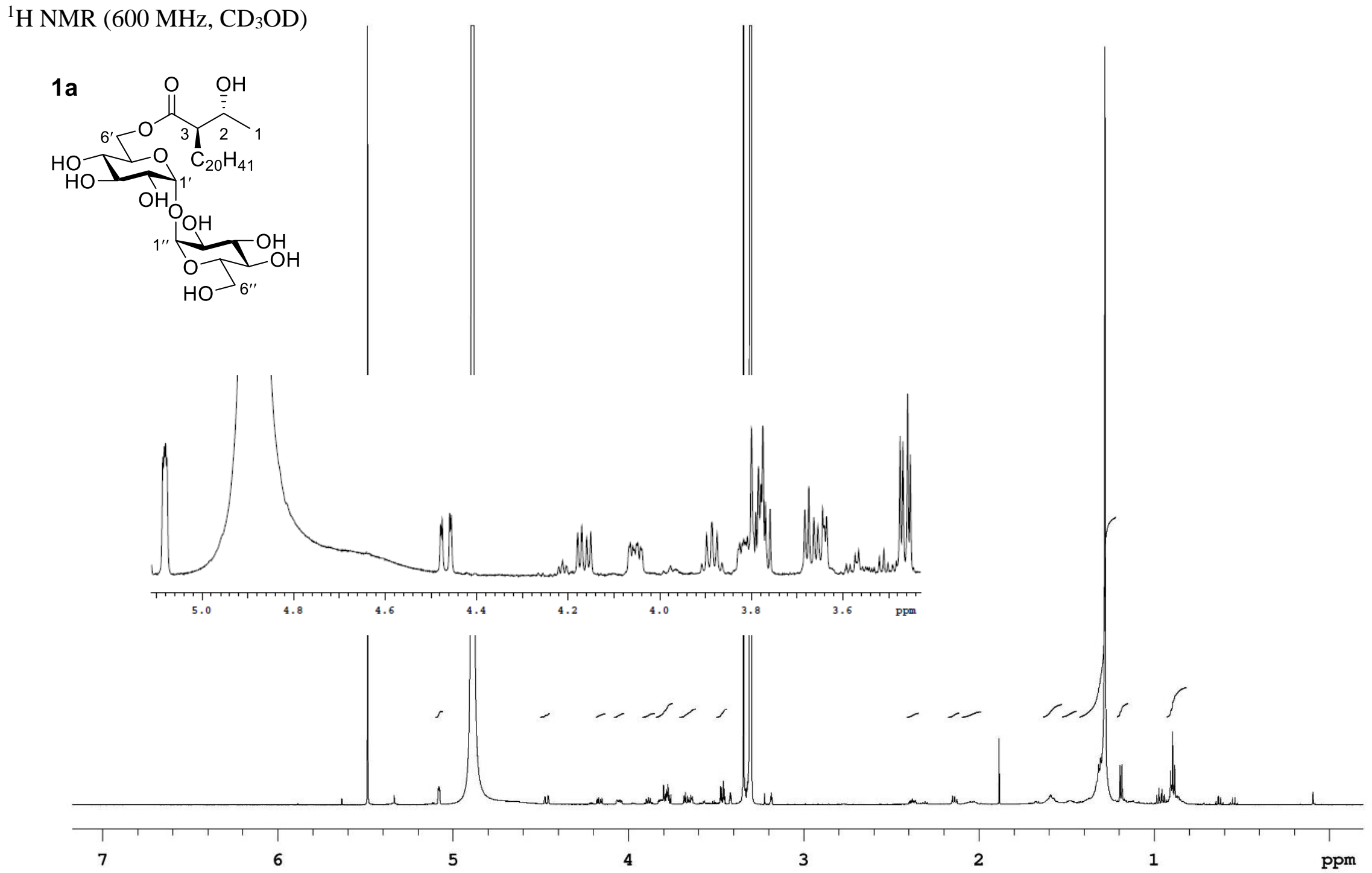


${ }^{13} \mathrm{C}$ NMR $\left(150 \mathrm{MHz}, \mathrm{CD}_{3} \mathrm{OD}\right)$
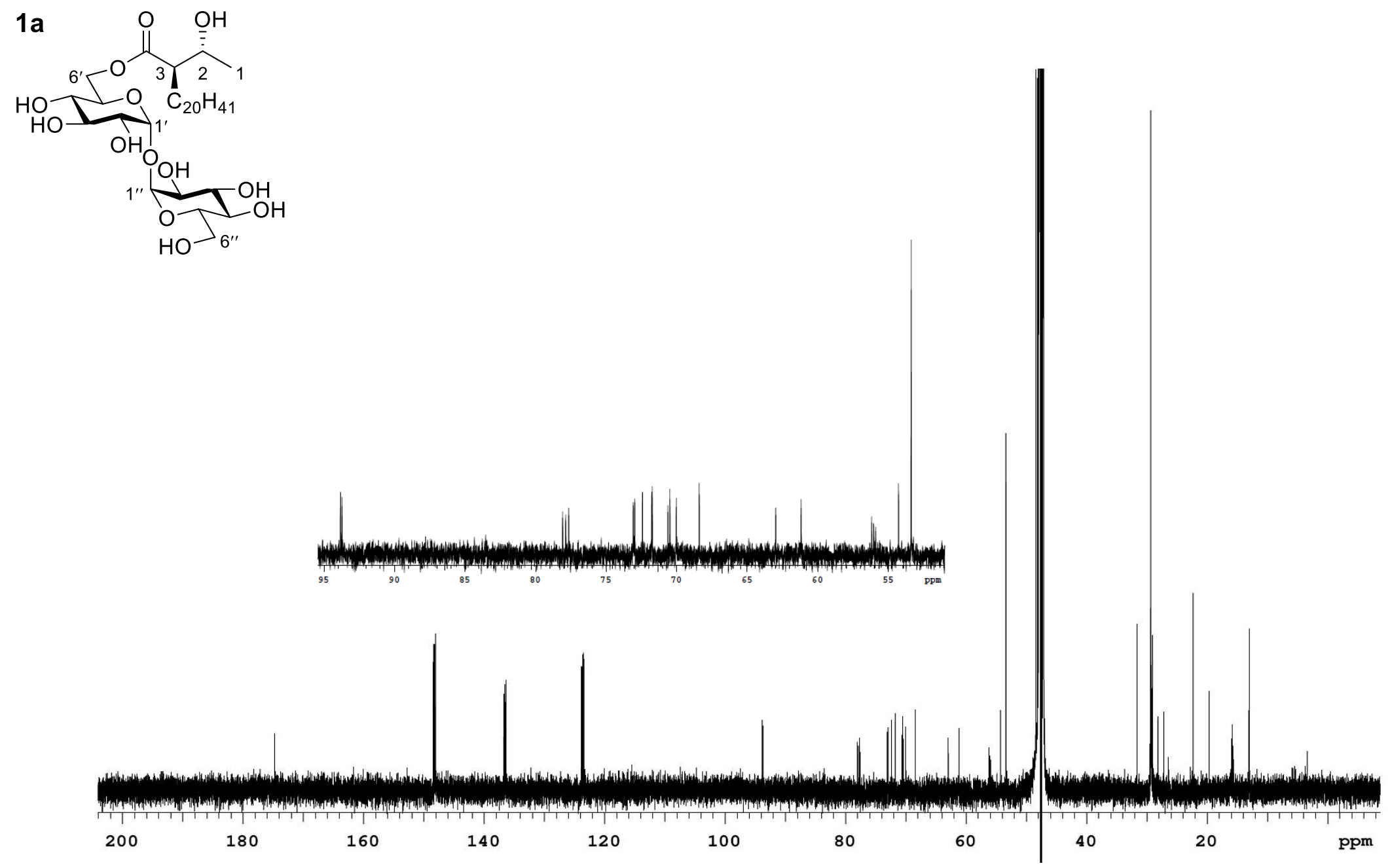
${ }^{1} \mathrm{H}$ NMR (500 MHz, $\mathrm{CDCl}_{3}$ )

$$
29
$$

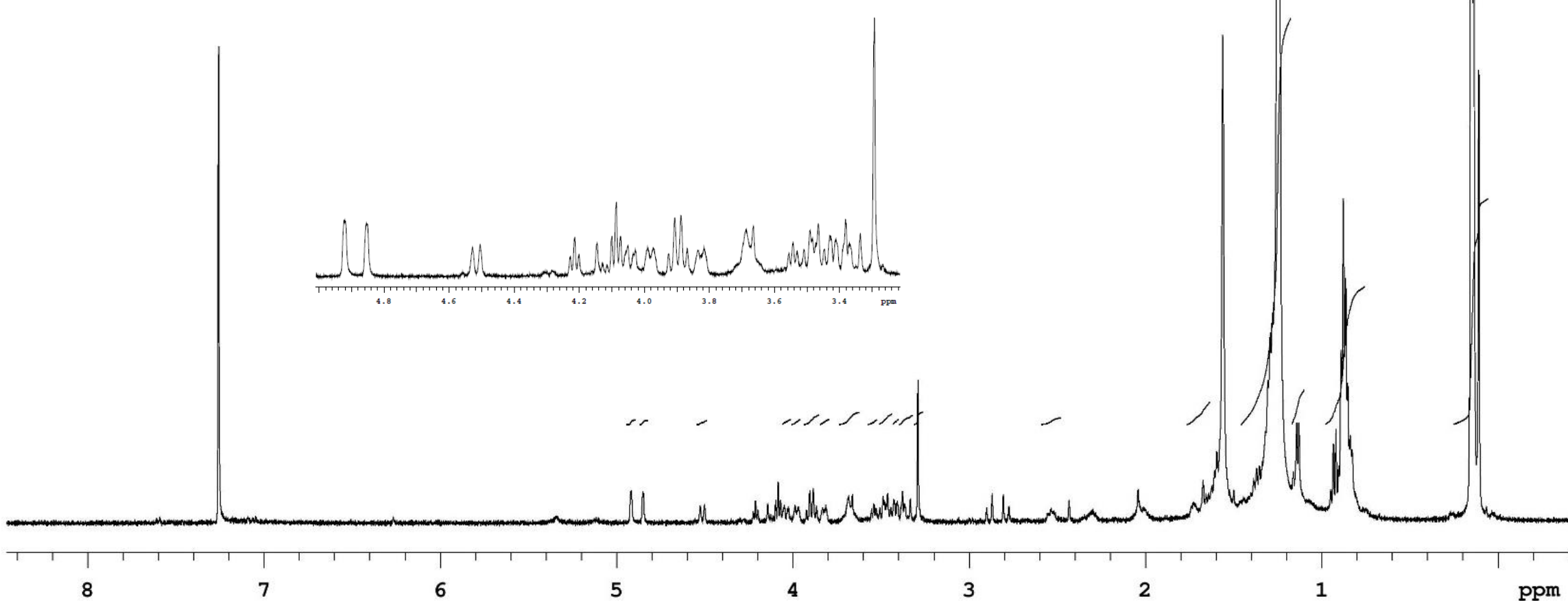


${ }^{1} \mathrm{H}$ NMR (600 MHz, CD ${ }_{3} \mathrm{OD}$ )

$1 b$
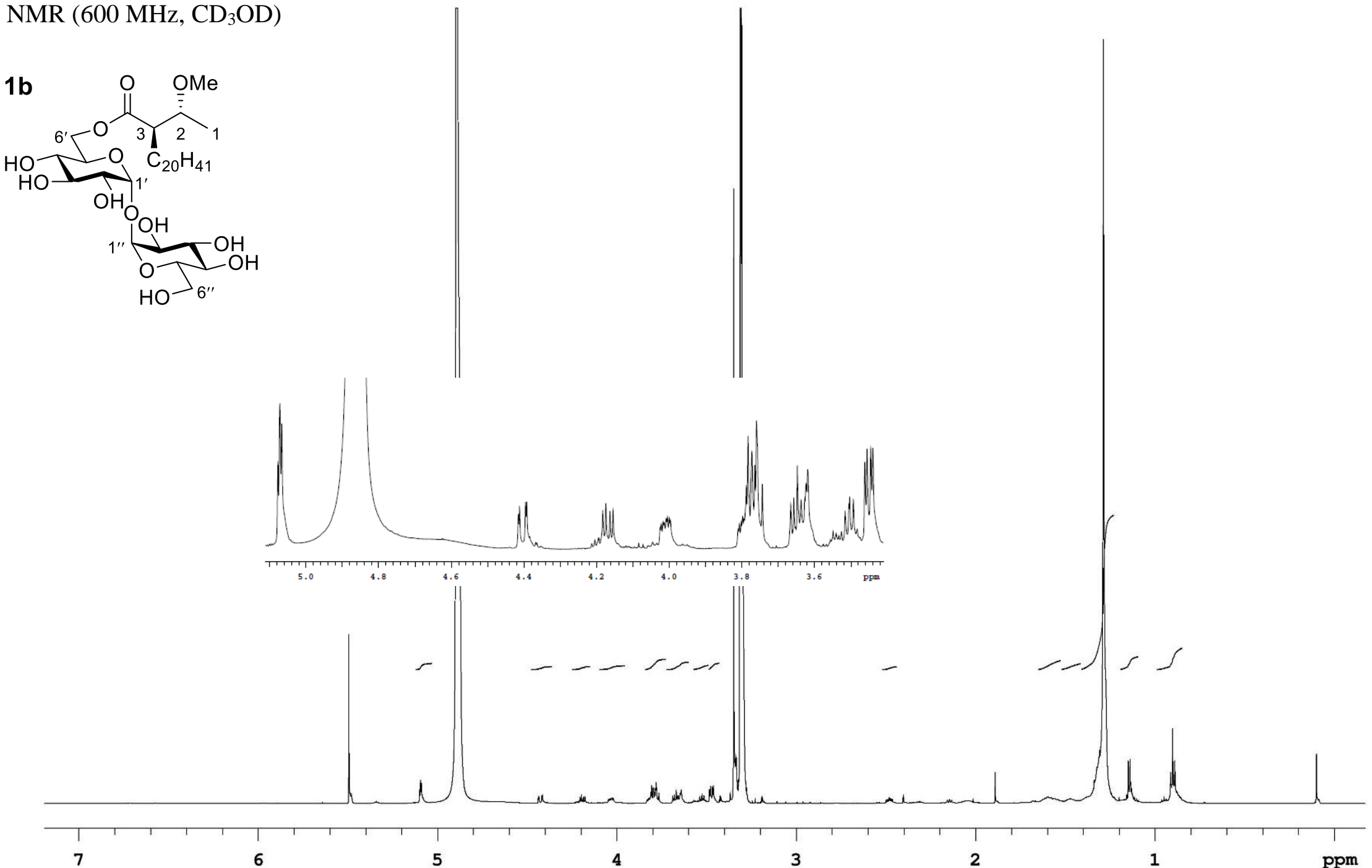
${ }^{13} \mathrm{C}$ NMR (150 MHz, $\left.\mathrm{CD}_{3} \mathrm{OD}\right)$
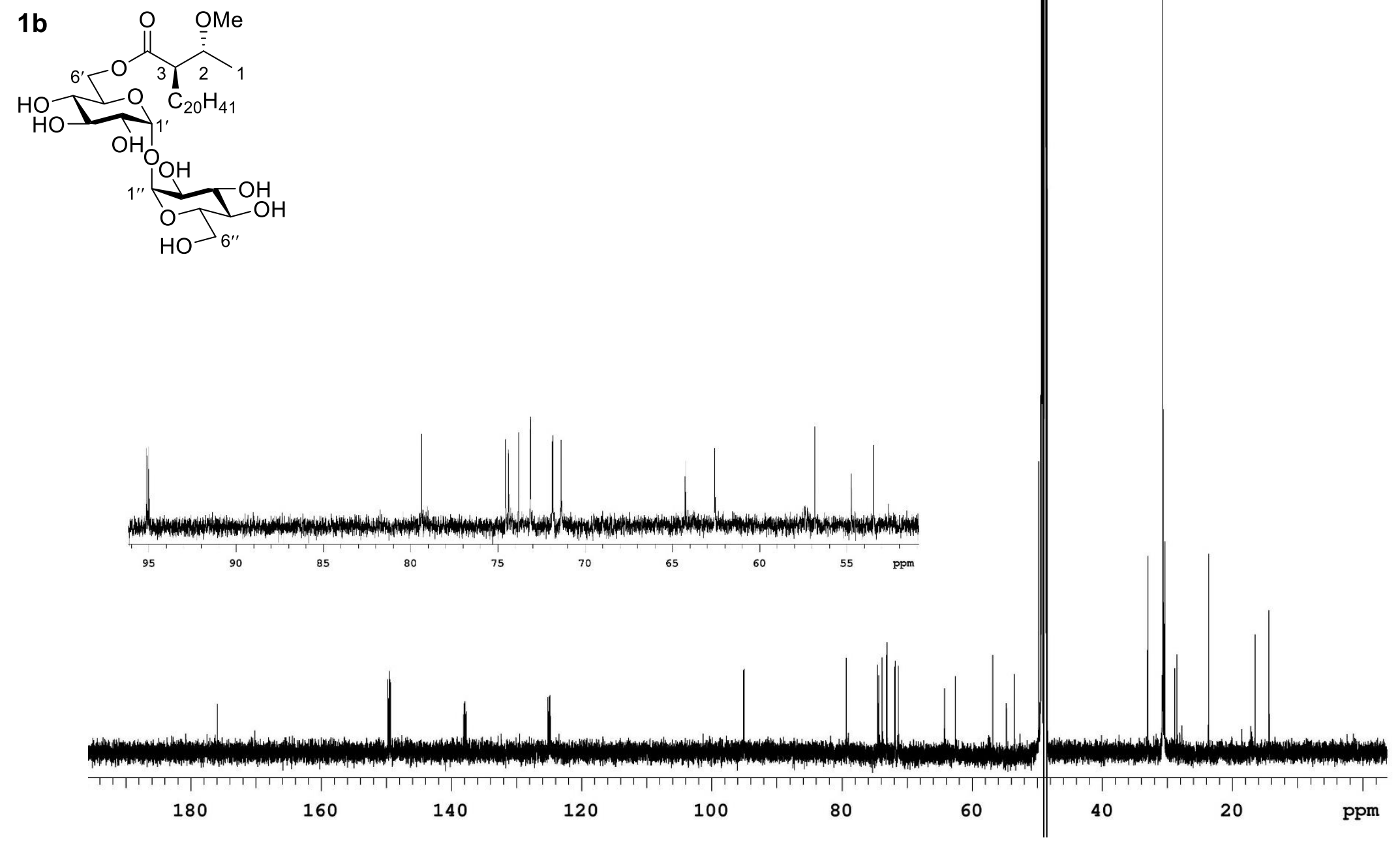
${ }^{1} \mathrm{H}$ NMR $\left(500 \mathrm{MHz}, \mathrm{CDCl}_{3}\right)$

32

$$
32
$$
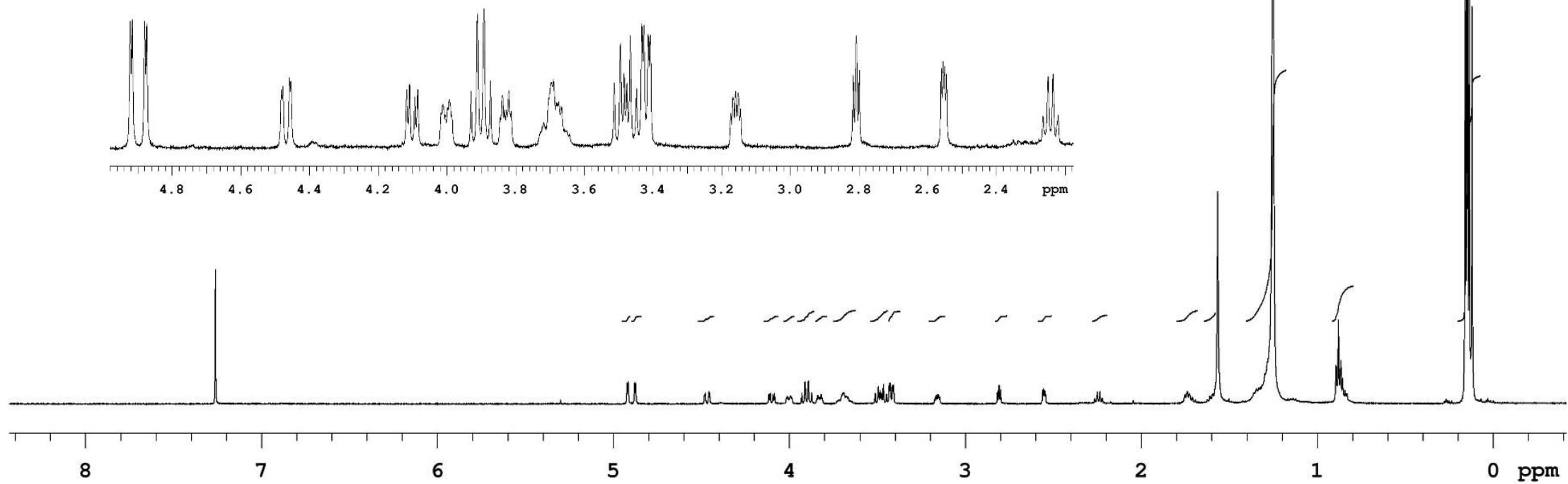
${ }^{13} \mathrm{C}$ NMR (125 MHz, $\left.\mathrm{CDCl}_{3}\right)$

$$
32
$$

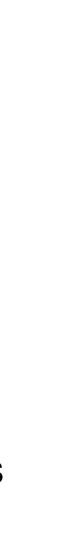

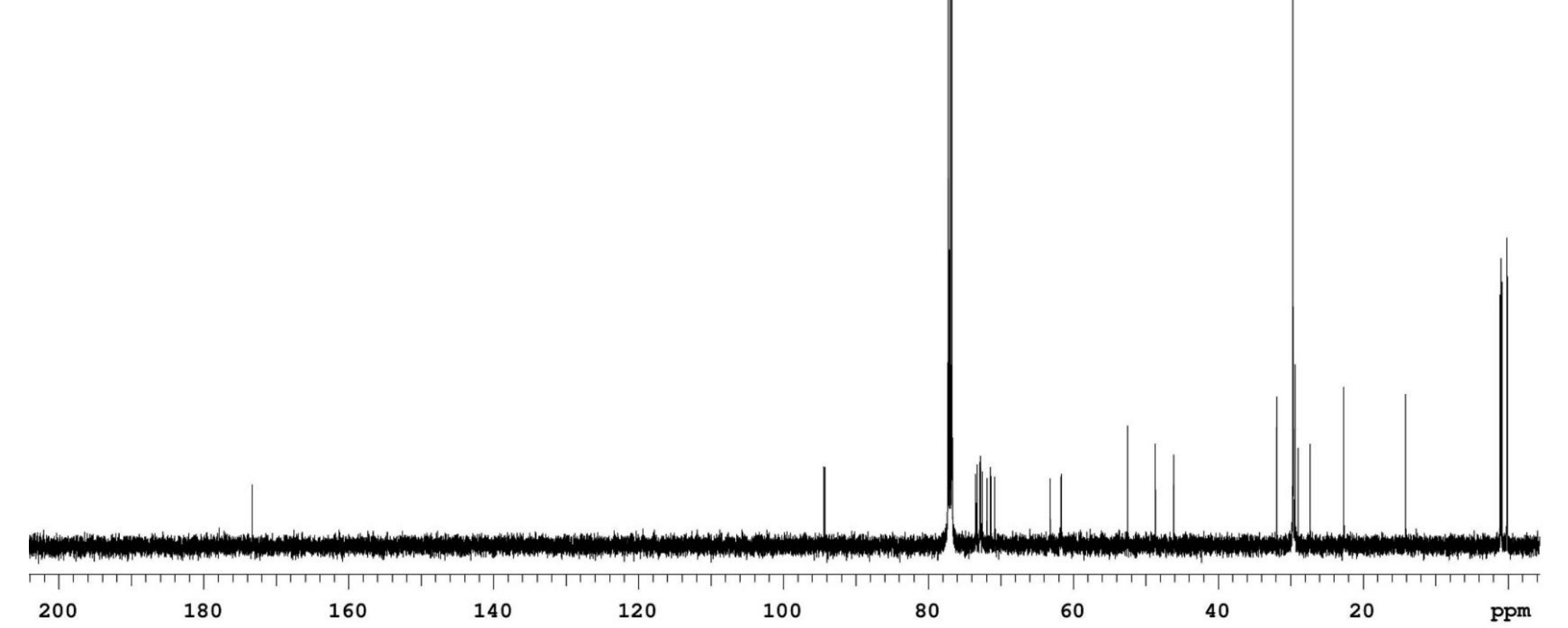


${ }^{1} \mathrm{H}$ NMR (500 MHz, $\mathrm{CDCl}_{3}$ )
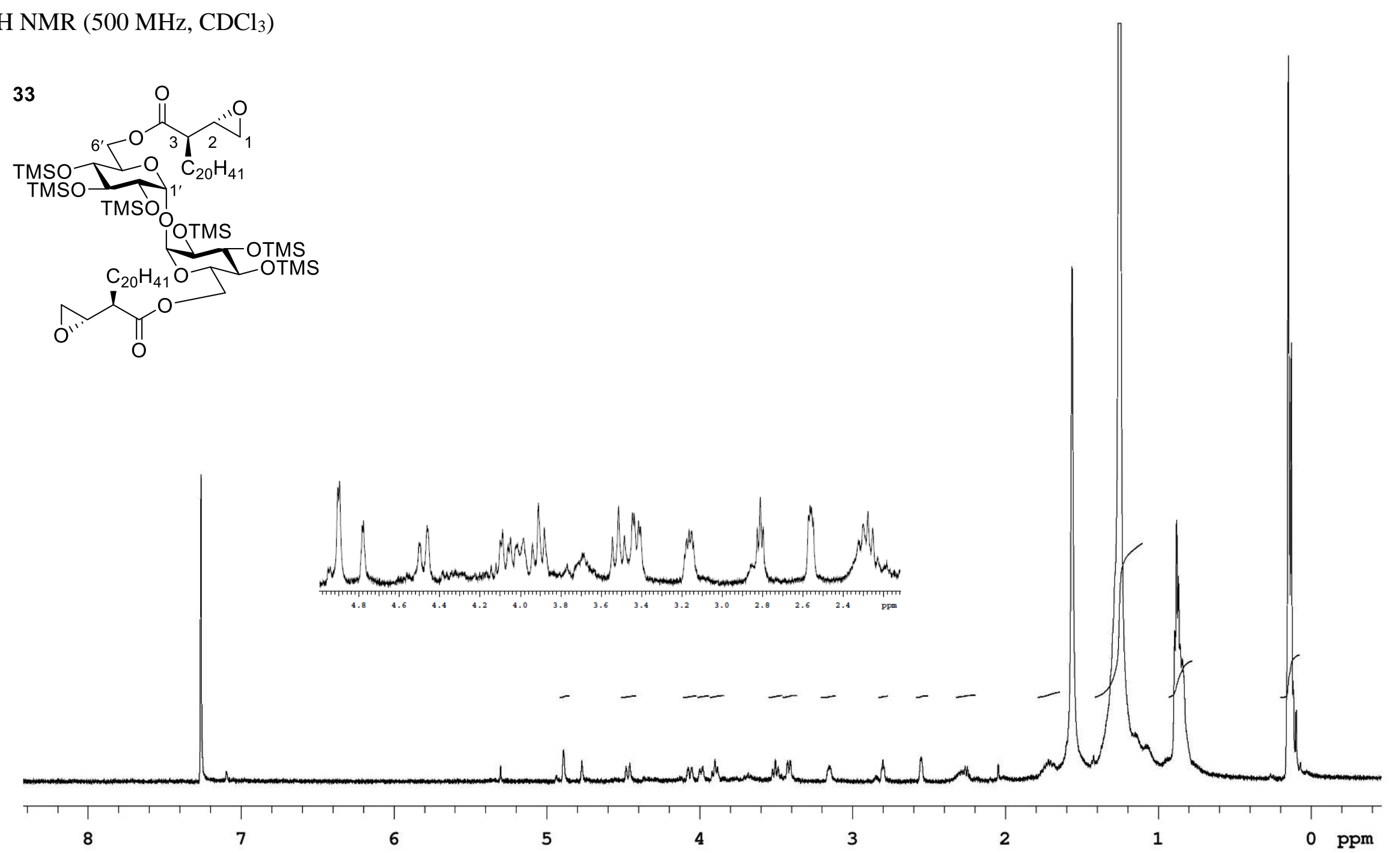